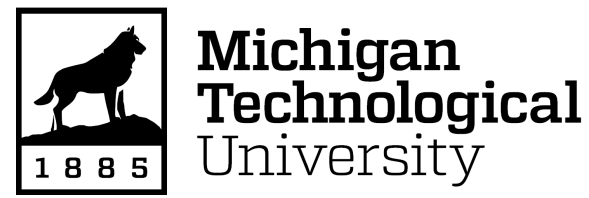

Michigan Technological University Digital Commons @ Michigan Tech

Dissertations, Master's Theses and Master's Reports

2020

DETECTION AND CLASSIFICATION OF EURASIAN WATERMILFOIL WITH MULTISPECTRAL DRONE-ENABLED SENSING

Colin Brooks

Michigan Technological University, cnbrooks@mtu.edu

Copyright 2020 Colin Brooks

Recommended Citation

Brooks, Colin, "DETECTION AND CLASSIFICATION OF EURASIAN WATERMILFOIL WITH MULTISPECTRAL DRONE-ENABLED SENSING", Open Access Dissertation, Michigan Technological University, 2020.

https://doi.org/10.37099/mtu.dc.etdr/1038

Follow this and additional works at: https://digitalcommons.mtu.edu/etdr

Part of the Biology Commons 


\title{
DETECTION AND CLASSIFICATION OF EURASIAN WATERMILFOIL WITH MULTISPECTRAL DRONE-ENABLED SENSING
}

\author{
By \\ Colin N. Brooks \\ A DISSERTATION \\ Submitted in partial fulfillment of the requirements for the degree of \\ DOCTOR OF PHILOSOPHY \\ In Biological Sciences
}

MICHIGAN TECHNOLOGICAL UNIVERSITY

2020

(C) 2020 Colin N. Brooks 
This dissertation has been approved in partial fulfillment of the requirements for the Degree of DOCTOR OF PHILOSOPHY in Biological Sciences.

\title{
Department of Biological Sciences
}

\author{
Dissertation Advisor: $\quad$ Dr. Amy Marcarelli \\ Committee Member: Dr. Casey Huckins \\ Committee Member: Dr. Robert Shuchman \\ Committee Member: Dr. Martin Auer \\ Committee Member: Dr. Evan Kane \\ Department Chair: $\quad$ Dr. Chandrashekhar Joshi
}




\section{Table of Contents}

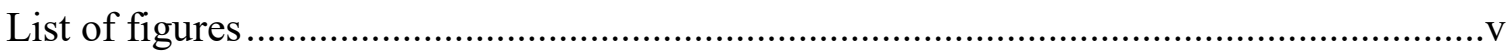

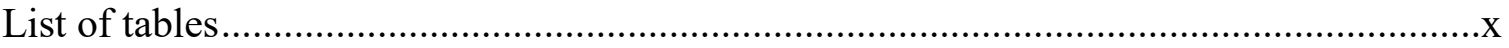

Preface

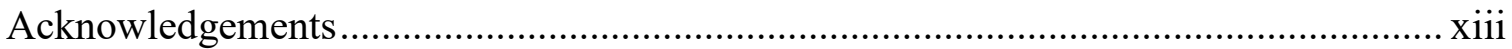

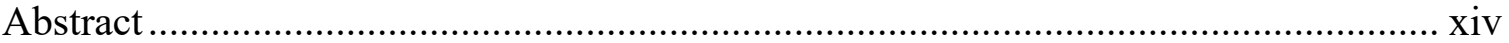

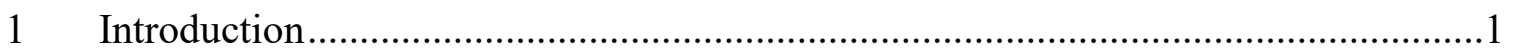

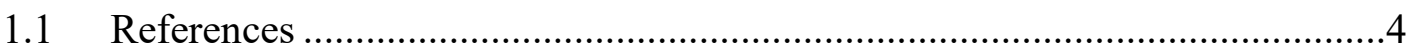

2 Multiscale collection and analysis of submerged aquatic vegetation spectral profiles for Eurasian watermilfoil detection .......................................................................6

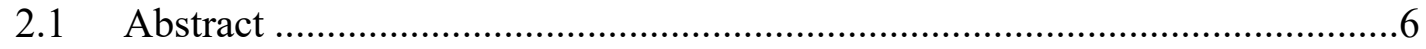

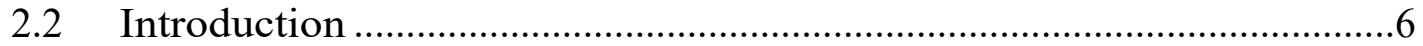

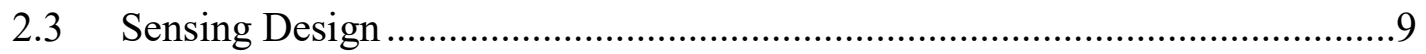

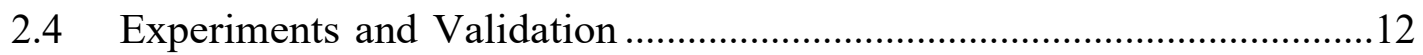

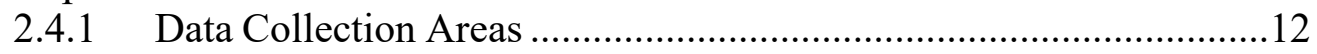

2.4.2 Scales of Spectral Data Collection and Processing Methods.............12

2.4.3 Statistical Analysis Methods...........................................................18

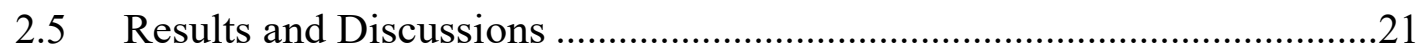

2.5.1 Out-of-Water Spectral Data Results ...........................................21

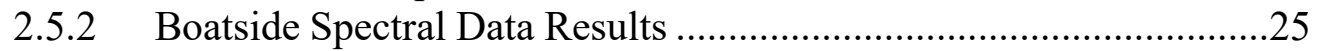

2.5.3 UAS Spectral Data Results ........................................................28

2.5.4 Comparison of Spectral Profile Results across Scale-Based Collection Methods ...................................................................................

2.5.5 Discussion of Spectral Profile Results and Analysis ..........................32

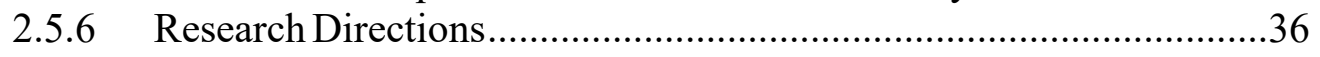

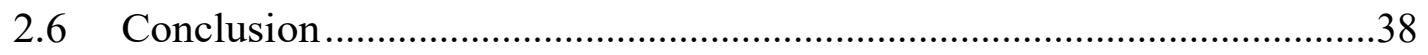

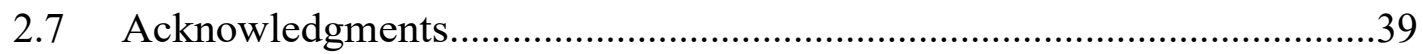

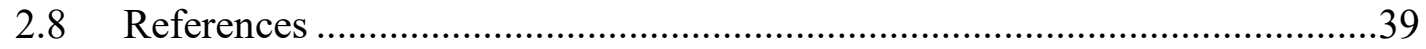

3 Classification of Eurasian Watermilfoil (Myriophyllum spicatum) Using a Drone-

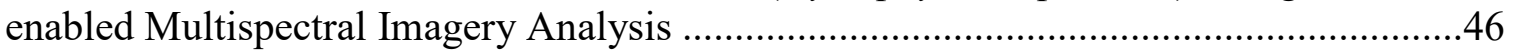

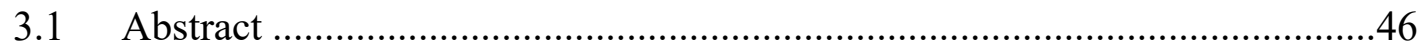

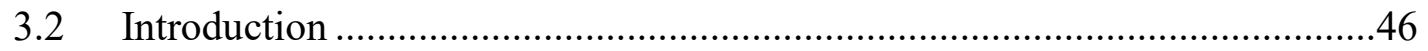




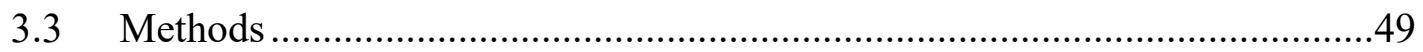

3.3.1 Collection Sites and UAS-based Sensors Deployed for the Project.49

3.3.2 Water Chemistry Data and Analysis Methods ……………………......54

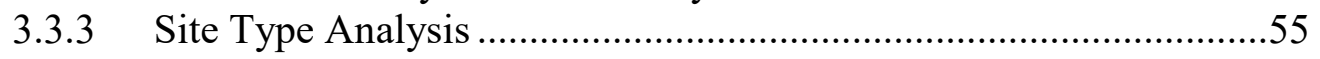

3.3.4 Vegetation Data and Analysis Methods............................................56

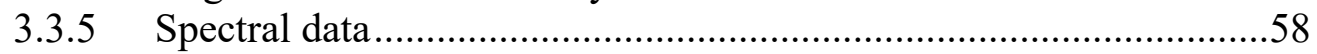

3.3.6 Imagery Analysis and Classification ................................................59

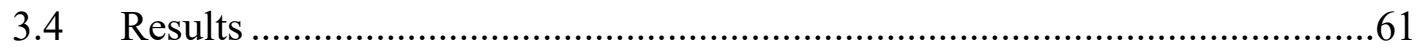

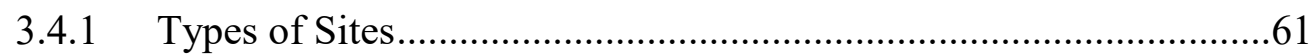

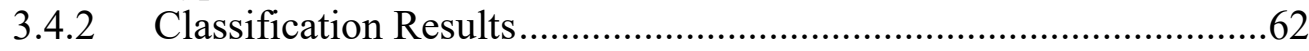

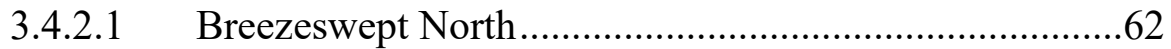

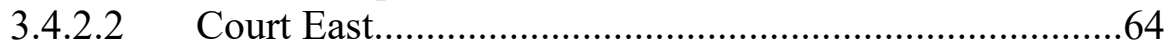

3.4.2.3 Hessel Marina ...............................................................

3.4.2.4 Howells Dock................................................................

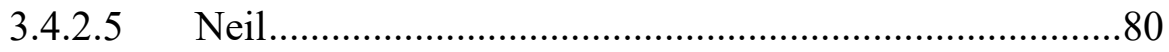

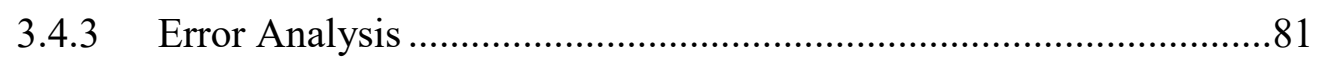

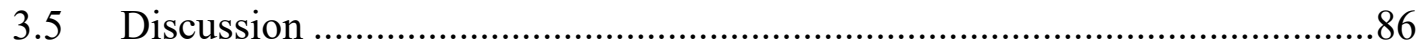

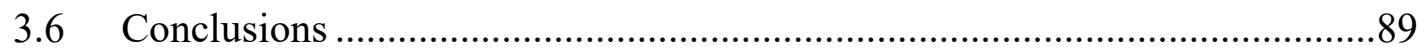

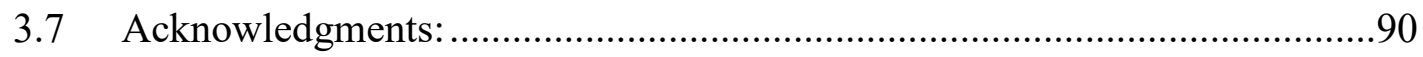

Appendix 3.A: Supplementary Data .....................................................................

4 Measuring Change in EWM Extent Due to Treatment Using Multispectral UAS

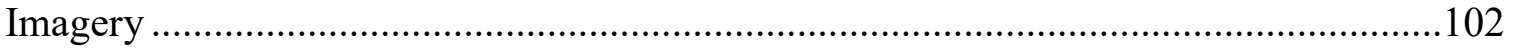

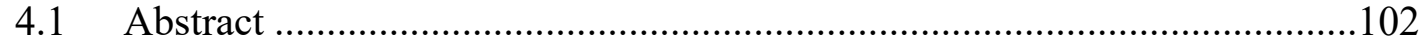

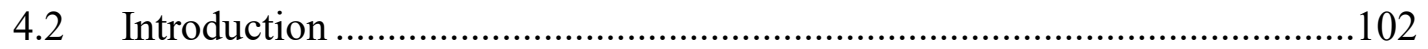

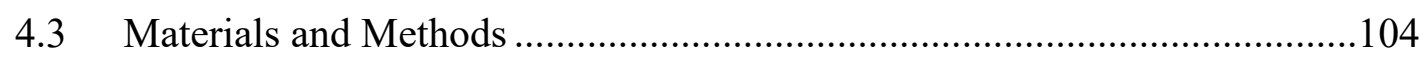

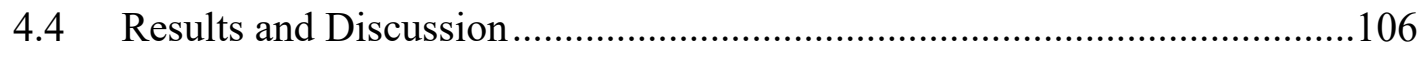

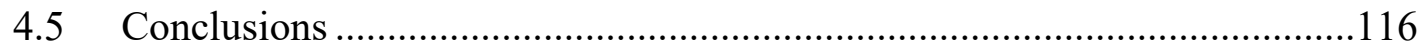

4.6 Acknowledgements ...........................................................................116

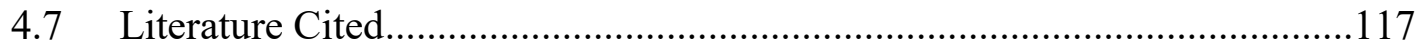




\section{List of figures}

Figure 1.1: Integration of data at intermediate scales enables greater understanding of ecological issues, as shown in Fausch et al., 2002 for discussing fish habitat ecology

Figure 2.1. Location of data collections in the Upper Peninsula of Michigan, including the Keweenaw Waterway in the Keweenaw Peninsula and the Les Cheneaux Islands area in northwest Lake Huron.

Figure 2.2. Detailed locations of data collection sites for spectral and UAS data within the Les Cheneaux Islands and the Keweenaw Waterway.

Figure 2.3. Images demonstrating field data collection methods. (a) Single-species plants on a black tarp about to have their spectral profile recorded for OOW scale data. From left to right: Chara sp. (stonewort), Potamogeton richardsonii (claspingleaf pondweed), and EWM. (b) Collection of OOW scale data using the LPR spectroradiometer during the August 2017 data collection. (c) Collection of spectral profile data at the boatside scale using the LPR spectroradiometer held vertically over an area of predominantly EWM. (d) Aerial photo from 2015 at a site in Keweenaw Waterway showing visible SAV, emergent vegetation, shoreline vegetation, and the Michigan Tech research vessel used for launch and recovery of the DJI Phantom 2 UAS. (e) Aerial photo taken from the Bergen hexacopter with the LPR's five mp camera, with EWM visible near the water's surface at a boat slip in the Hessel Marina site in the Les Cheneaux Islands study area. (f) The LPR mounted underneath the Bergen hexacopter UAS, about to collect spectral data over an area of EWM

Figure 2.4. OOW spectral data: (a) Spectral profiles of eight OOW aquatic plant species from June 2015, showing ultraviolet to near-infrared (350 to $1000 \mathrm{~nm}$ ) wavelengths for all 651 bands. (b) Spectral profiles for nine aquatic plant species, plus a reference tarp, from June 2017, showing all 651 one-nm wide bands.

Figure 2.5. Resampled spectral reflectance values for Tetracam and Becker bands: (a) Resampled to approximate the Tetracam bands for the eight OOW species samples collected in 2015, (b) resampled to the Becker bands for the 2015 OOW data, (c) spectral reflectance values for the Tetracam wavelengths for the nine OOW species collected in June 2017, and (d) spectral reflectance values for the Becker wetland bands for the nine OOW species collected in June 2017

Figure 2.6. Spectral profiles of SAV species and combinations from 2016, collected boatside using the ASD, directly over patches of vegetation in the water.

Figure 2.7. Spectral reflectance values for the UAS data collected over 13 areas with multiple species assemblages, sampled in June 2017. 
Figure 2.8. Comparison of spectral profiles for June 2017 across three methods of sampling: (a) for the six tetracam bands and (b) for the ratio and indices.

Figure 2.9. UAS-collected RGB image of predominantly EWM using an eCognition object-based classification into four class types. Area in red (at bottom) is enlarged in the top two images. Field images at the top left demonstrate that the EWM being mapped is submergent.

Figure 3.1. The Les Cheneaux Islands area in northwest Lake Huron, with data collection sites.

Figure 3.2. The Bergen hexacopter UAS platform being deployed to collect aerial imagery for EWM identification in June 2017 at the Neil site in Hessel, MI. ......50

Figure 3.3. Examples of natural color RGB UAS imagery: a) Hessel Marina from a $12 \mathrm{mp}$ Mavic Pro camera, b) Howells Dock from a 16mp Canon camera (this provided the natural color part of the VISNIR system), and c) Howells Dock from a 36mp Nikon D810 camera.

Figure 3.4. Two Tetracam images (center, shown in color infrared) from July 2017, displayed over a RGB composite Phantom 3A image for the Hessel Marina site taken on the same day; green pentagons indicate field sampling sites.

Figure 3.5. VISNIR imagery for the Court East site in June 2017, with RGB imagery shown at left (A) and near-infrared imagery shown at right (B).

Figure 3.6. Rake toss in action and example results from an area with less dense SAV.57

Figure 3.7. Rake twist sample immediately after retrieval from the water from an area with dense SAV, undergoing visual estimation of density....

Figure 3.8. Dendrogram results for site clustering; sites with a lower extinction coefficient have clustered on the left (in light blue) while darker water sites form multiple clusters but all within the second branch.

Figure 3.9. Tetracam multispectral image of Breezeswept North using color-infrared bands $(\mathrm{A})$ and classification results with scale parameter $=25(\mathrm{~B})$, and with scale parameter $=50(\mathrm{C})$.

Figure 3.10. Field photos helping to document conditions at Breezeswept North on the day of data collection in July 2017, including documentation of EWM and flatstem pondweed near the water's surface (a), flat-stem pondweed as seen underwater (b), an overview RGB image of the site (c), and mostly sunny sky conditions on the day of the data collection (d). 
Figure 3.11. Tetracam multispectral image of Court East from August 2016 using colorinfrared bands (A) and classification results with scale parameter $=25(\mathrm{~B})$ and scale parameter $=50(\mathrm{C})$....

Figure 3.12. Field photographs showing much of the Court East August 2016 classification area on the same day as UAS imagery was collected, including (a) the presence of spatterdock and some loose surface vegetation at the surface near the spatterdock and (b) EWM underwater.

Figure 3.13. VISNIR multispectral image from June 2017 for Court East using colorinfrared bands (A) and classification results with scale parameter $=25(\mathrm{~B})$ and scale parameter $=50(\mathrm{C})$

Figure 3.14. Field photos taken at Court East on the July 2017 survey day, showing a mixture of EWM and Elodea beneath the water surface (A), dense EWM at the water surface (B), detached areas of vegetation to the right of the survey vessel with two sampling buoy locations visible in the background (C), and small pondweed removed from the water (D)....

Figure 3.15. Comparison of June 2017 VISNIR classification results for the northeastern corner of the analyzed image, with scale parameter $=5(\mathrm{~A}), 25(\mathrm{~B})$, and $50(\mathrm{C}) . .68$

Figure 3.16. Tetracam multispectral image from July 2017 for Court East using colorinfrared bands (A) and classification results with scale parameter $=25(\mathrm{~B})$ and scale parameter $=50(\mathrm{C})$

Figure 3.17. Underwater photo taken in the southwest corner of the Court East July 2017 Tetracam image area, showing a matrix of Elodea and EWM.

Figure 3.18. Tetracam multispectral image from July 2017 for Hessel Marina using color-infrared bands (A) and classification results with scale parameter $=25(\mathrm{~B})$ and scale parameter $=50(\mathrm{C})$.

Figure 3.19. Field photo of part of the area covered by the Tetracam image shown in Fig. 3.18, with both EWM and curlyleaf pondweed present.

Figure 3.20. Tetracam multispectral imagery from August 2016 for Howells Dock (A) using color-infrared bands (A) and classification results with scale parameter $=25$ (B) and scale parameter $=50(\mathrm{C})$. .73

Figure 3.21. Tetracam multispectral image number 910 from August 2017 for the northern part of Howells Dock (A) using color-infrared bands (A), classification results with scale parameter $=25(B)$, and with scale parameter $=50(\mathrm{C})$. 
Figure 3.22. Tetracam multispectral image number 916 from August 2017 for the centre part of Howells Dock using color-infrared bands (A), classification results with scale parameter $=25(\mathrm{~B})$, and with scale parameter $=50(\mathrm{C})$.

Figure 3.23. Tetracam multispectral image from August 2018 for Howells Dock using color-infrared bands $(\mathrm{A})$, classification results with scale parameter $=25(\mathrm{~B})$, and with scale parameter $=50(\mathrm{C})$

Figure 3.24. The bright green vegetation is northern watermilfoil that was visible in the August 2016 Tetracam imagery for Howells Dock, while the darker green/brown vegetation is Eurasian watermilfoil.

Figure 3.25. Example of eelgrass peduncles visible at the water's surface near one of the sampling buoys in August 2017 at Howells Dock, with a Trimble GPS unit recording the location in the foreground.

Figure 3.26. Example underwater field photo taken on the same day as the August 2018 Tetracam flight showing EWM.

Figure 3.27. Tetracam multispectral image from August 2018 for Neil using colorinfrared bands (A), classification results with scale parameter $=25(\mathrm{~B})$, and with scale parameter $=50(\mathrm{C})$

Figure 3.28. Example underwater photo of Neil area taken at a transition zone between EWM (top left, taller and darker vegetation) and Chara (bottom right, shorter and lighter colored vegetation).

Figure 3.29. Regression equation for overall accuracy vs. number of SAV classes. .85

Figure 3.30. Regression equation for producer's accuracy vs. number of SAV classes. .86

Figure 4.1. Les Cheneaux Islands and Keweenaw Waterway areas in northern Michigan, USA.

Figure 4.2. Multispectral imagery of the Court East site, A) before mechanical harvesting (June 2017), B) a few days after mechanical harvesting (July 2017), and C) a month after mechanical harvesting.

Figure 4.3. Classification results for the Court East showing imagery before (A) and after (B) mechanical harvesting. Results shown in A and B were previously described in Chapter 3. 108

Figure 4.4. Identical extents for the June 2017 pre-harvesting classification and the August 2017 post-harvesting classification to enable change comparison at the Court East site. 
Figure 4.5. Natural color UAV image of the Court East site, with the harvested "rows" and remaining vegetation also captured in the Tetracam image taken on the same day. Additional harvesting took place towards the docks on the bottom left and further to the top right.

Figure 4.6. Hessel Marina natural color imagery from A) July 2017 at the start of Mt treatment and from B) August 2018 one year after treatment.

Figure 4.7. Hessel Marina classification results from A) July 2017 of the week before Mt treatment and from B) August 2018 one year after treatment.

Figure 4.8. Near-infrared UAV imagery for the same locations at four DASH treatment plots immediately pre- and post-treatment in July, 2017 at the Sloughs site.

Figure 4.9. Classification results for pre- and post-DASH treatment color-infrared imagery

Figure 4.10. Deployment of the Mt fungus from a customized treatment vessel in the Les Cheneaux Islands in 2017 by the Les Cheneaux Watershed Council. .116 


\section{List of tables}

Table 2.1. Collection sites listing types of spectral data collected by time period and data collection scale. The number of averaged spectral profiles collected per site is included in parentheses.

Table 2.2. K-S test of June 2017 OOW spectral data averaged to 6510 -nm-wide bands.

Table 2.3. Results for the mixed model analysis for each tested wavelength, ratio, and index for the complete 2016 to 2017 boatside dataset with 62 spectral profiles. ..27

Table 2.4. K-S test of June 2017 UAS-based spectral data resampled to Tetracam bands plus ratios.

Table 2.5. K-S test of July 2017 UAS-based spectral data resampled to Tetracam bands plus ratios.

Table 2.6. Input data used for analysis of EWM spectral data collected at the OOW, boatside, and UAS scales, with comparison of averages by collection method...34

Table 2.7. Results of the ANOVA, Tukey HSD, and Tukey-Kruskal procedures to test for differences between group means by wavelength, index, and ratio.

Table 3.1. Diagram of hypothesis prediction if $\mathrm{H}_{\mathrm{o}}$ is rejected and the clear and dark water algorithms produce higher accuracies for their own water types.

Table 3.2: Collection sites and sensors deployed by date in the Les Cheneaux Islands from 2016-2018

Table 3.3. Water chemistry and light data summarized by site 56

Table 3.4. Summary of error analysis results for 2016-2018 classifications .82

Table 3.5. Summary of average accuracy results by site (water) type and classification type $($ small scale parameter $=$ light or large scale parameter $=$ dark $)$.

Table 3.6. Results for the mixed model analysis for each tested accuracy (overall, EWM producer's, and EWM user's) using all sites and years.

Table 3.A.1. Water chemistry and light data by site and by collection date.

Table 3.A.2 Error matrices for all classifications, with scale parameter $=25$ and $=50$ results.

Table 4.1. Treatment locations with geospatial analysis of change in EWM extent ......105 
Table 4.2. Change in class areas from June 2017 to August 2017 at the Court East site, before and after mechanical harvesting treatment. .........................................110

Table 4.3. Change in class areas from July 2017 to August 2018 at the Hessel Marina site, from the start of Mt treatment to one year later.

Table 4.4. Change in class areas from July 17, 2017 to July 21, 2017 at the Sloughs site, before and after DASH treatment .114 


\section{Preface}

Chapter 2 has been published as: BROOKS, C.N., GRIMM, A.G., MARCARELLI, A.M. and DOBSON, R.J. 2019. Multiscale collection and analysis of submerged aquatic vegetation spectral profiles for Eurasian watermilfoil detection. Journal of Applied Remote Sensing, 13(3): 037501. https://doi.org/10.1117/1.JRS.13.037501 - Reproduction of this work here requires this statement: (C) The Authors. Published by SPIE under a Creative Commons Attribution 4.0 Unported License. Distribution or reproduction of this work in whole or in part requires full attribution of the original publication, including its DOI. [DOI: 10.1117/1.JRS.13.037501]

Chapter 3 is being prepared for submission in the near future to Remote Sensing of Environment with planned co-authors Colin Brooks, Amanda Grimm, Amy Marcarelli, Nicholas Marion, Michael Sayers, and Robert Shuchman.

Chapter 4 is being prepared for submission in the near future to Lake and Reservoir Management with planned co-authors Colin Brooks, Amy Marcarelli, Nicholas Marion, Casey Huckins, Amanda Grimm, and Richard Dobson. 


\section{Acknowledgements}

This dissertation is the result of support from a large group that has encouraged me in a challenging endeavor that I took on in a part of my career when I had not originally been planning on this. I owe a debt of gratitude too large to ever repay, and I hope that others can be so fortunate. My advisor Dr. Amy Marcarelli provided such incredibly frequent and valuable feedback and support throughout this six-year adventure. My immediate family - Margaret Weiss, Isaac Brooks, and Lillia Brooks - endured many days, weeks, and nights when I was engrossed in dissertation matters. My Mum (Eileen Brooks) and Dad (Tony Brooks) have shown their pride in me so much; I will always be thankful that they encouraged me to watch David Attenborough nature shows when I was growing up. My brother, Dr. Alasdair Brooks, whom I cannot visit right now due to a global pandemic, provided frequent intellectual stimulation growing up. I certainly did not expect the COVID-19 pandemic, with all of its terrible impacts, to give me sufficient time to complete this dissertation in 2020. My primary supervisor for the last 15 years, Dr. Robert Shuchman, has both encouraged and tolerated my long journey in understanding how high-resolution remote sensing can enable ecological insights. The line of teachers and professors who have encouraged me in an educational career that has spanned five decades is also long; I am particularly thankful for Monsieur Charles and Mrs. Beizer in elementary school; my $7^{\text {th }}$ (Mr. Potoschnik), 9th (Mr. Sandy) \& 10th (Mr. Laws) grade science teachers, my undergraduate biology/ecology/botany/humanities professors at Lenoir-Rhyne College (especially Dr. Karen McDougal), Dr. Dan Richter at Duke University; Dr. Steve Francouer at Eastern Michigan University; at Michigan Tech, Dr. Casey Huckins, Dr. Marty Auer, and Dr. Charlie Kerfoot have taught me much about Great Lakes science; at MTRI, Amanda Grimm, Rick Dobson, Nick Marion, Mike Sayers, and Michelle Wienert were major parts of this journey; the Les Cheneaux Islands field crew members (including Ryan Van Goethem, Chris Adams, Kevin Nevorski, Erin Eberhard, Lucy Buller, Mark Clymer, and Bob Smith); my supervisors at The Nature Conservancy in my first internships who taught me how to collect high-quality field data and relate it to geospatial analysis (Dorothy Allard, Cindy Aulbach, Curtis Hutto, Doug Muchoney, Christi Lambert), the GIS crew at the US Forest Service Savannah River Forest Station (Michelle Davalos, Rick Chubb, Harry Park), Dr. Adina Merenlender whom I worked with at the Hopland Research and Extension Center in northern California for nine years, and other friends, colleagues, teachers, mentors, and family members not otherwise mentioned here! The US Environmental Protection Agency under assistance agreements 00E01928 and 00E01291, and the Michigan Department of Natural Resources under project number IS14-2005, provided grant funding that supported this research. 


\section{Abstract}

Littoral zones support growth of submerged aquatic vegetation, creating productive areas that provide food and habitat for fish, amphibians, macroinvertebrates, and other parts of the food web. Understanding macrophyte dynamics requires the identification of submerged aquatic vegetation (SAV) taxa, which can be possible if taxa of interest are spectrally distinct with data collected at appropriate scales. Eurasian watermilfoil, Myriophyllum spicatum or EWM, is a non-native SAV species that forms thick, often monotypic beds that reduce benthic species richness, restrict recreation, reduce property values, clog water intakes, and lower dissolved oxygen concentrations. Remote sensing of SAV species has to address the presence of lake color constituents that reduce lake clarity, making identification of species of interest more challenging. To address this challenge, I first investigated how to collect spectral data of SAV from boatside and drone platforms to determine the number and types of bands needed to identify EWM. Hyperspectral numbers of bands such as $6510-\mathrm{nm}$ wide bands between 350 and 1000nm reliably identified EWM, while use of a modified normalized difference vegetation (NDVI) index provided significant differences among SAV vs. other dominant aquatic vegetation groups. We demonstrated this for classifications at five sites over three years in the littoral areas of the Les Cheneaux Islands in northwestern Lake Huron, Michigan, USA, with $78.7 \%$ average producer's accuracy and 76.7\% average user's accuracy, higher than most previous efforts at remote sensing of SAV. Finally, we applied these mapping capabilities to two areas in the Les Cheneaux Islands and one area in the Keweenaw Peninsula in Michigan's northwestern Upper Peninsula that received treatments to reduce EWM. One site underwent mechanical harvesting, a second had a native fungus applied as a method of biological control, and a third site had diver-assisted suction harvesting completed. Classifications before and after treatment showed that it was possible to quantify the reductions of $63-89 \%$ in EWM extent due to these efforts. These results help demonstrate that UAS-enabled multispectral sensing can produce useful quantitative data on the presence and extent of SAV taxa of interest, providing a tool for monitoring treatment effects and improving understanding of aquatic ecology. 


\section{Introduction}

Remote sensing data can address important ecological and limnological questions regarding the roles of landscape variables affecting nearshore lake dynamics and improve spatial characterization of critical lake littoral zones. Satellite remote sensing covers large areas with relatively high temporal frequency, but most commonly at scales of many tens to hundreds of meters per pixel for readily available imagery. The type of satellite imagery used for whole-lake analysis is particularly poorly matched for examining the extent of invasive aquatic plant species in lake littoral zones. In contrast, traditional field methods provide detailed data, but typically at limited spatial scales with intermittent temporal frequency. Data at intermediate scales have not always been easy to obtain or analyze, yet, ecological understanding must be improved by integrating information at an intermediate scale between the "top down" approach of satellite imagery and the "bottom up" approach of field observations (e.g., Fausch et al. 2002, Figure 1.1). Considering the impacts of analysis at different scales is a foundation of landscape ecology; for example, data necessary for key insights are not accessible when scales too large or small are used for analysis (Turner et al., 1989). A key theme for the research presented in this dissertation is understanding how biological and limnological processes can be further elucidated through appropriate scales of remote sensing analysis to fill key knowledge gaps in how aquatic invasive plants respond to management efforts. I focus here on intermediate scale analyses to provide ecologically-relevant results of aquatic plant identification, extent, and change. To advance this understanding, I describe in the following three chapters how spatially-explicit analysis of unmanned aerial system (UAS, also UAV for "vehicle", or "drone") enabled sensing advanced ecological understanding of the presence and control of Eurasian watermilfoil (Myriophyllum spicatum L., or EWM) at study locations in two littoral zones in the Upper Peninsula (U.P.) of Michigan, USA. 


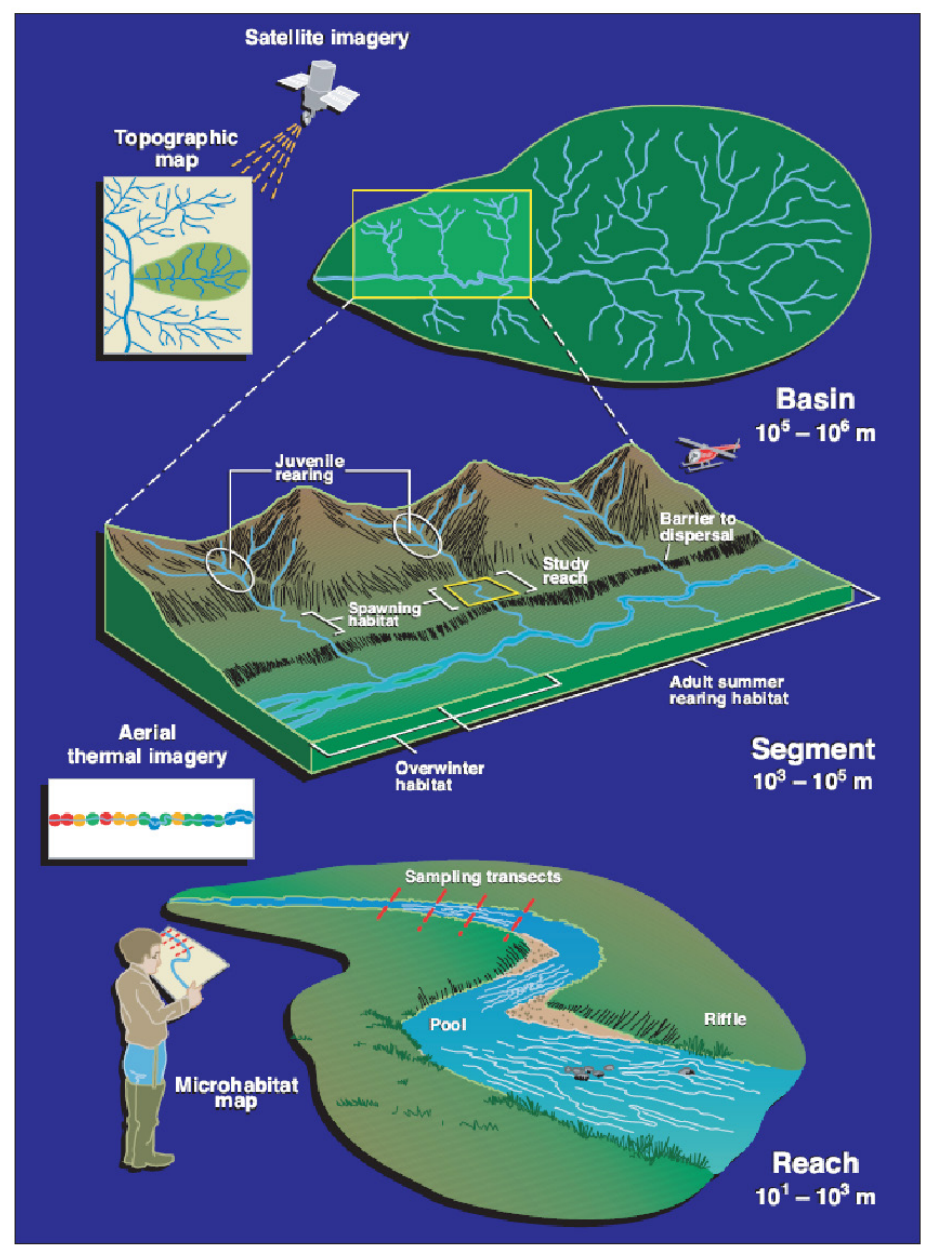

Figure 1.1: Integration of data at intermediate scales enables greater understanding of ecological issues, as shown in Fausch et al., 2002 for discussing fish habitat ecology.

Eurasian watermilfoil is an invasive aquatic plant, first documented in the U.S. in Washington, D.C. in 1942 (Couch \& Nelson, 1985) and in the Great Lakes basin in 1952 (Mills et al., 1994). It can crowd out native plants (Madsen et al., 1991), and interfere with recreational activities such as boating, fishing, and swimming (Madsen, 2005). It can reduce diversity and abundance of native aquatic plants, reduce dissolved oxygen (DO) levels under its canopy, increase nutrient recycling from sediments, reduce macroinvertebrate abundance and density, and change predator/prey equilibria for fish communities (Madsen, 2005). It hybridizes with native milfoil species such as Northern watermilfoil (Myriophyllum sibiricum), impacting the extent of native milfoil and providing a highly plastic growth form (Moody \& Les, 2007; Roley \& Newman, 2006). Recent reports from Michigan's U.P. have indicated that it has become more widespread in the region's coastal embayments (Leguizamon 2017), including nuisance levels in the Portage Lake area of the Keweenaw Peninsula and the Les Cheneaux Islands of the eastern U.P. 
By focusing on high-resolution remote sensing enabled by small UAS platforms and UAS-deployable sensors, the science of developing a scale of analysis between existing satellite and field methods can be advanced. In the research describe here, I develop an ecological perspective on remote sensing data sets (Kennedy et al., 2014), and demonstrate advantages of the increasing usefulness of UAS to ecologists because they can provide greater temporal and spatial resolution than have generally been available, while making a new generation of sensors easier to deploy (Allan et al., 2015; Kennedy et al., 2014). I investigate what spectral information is needed to differentiate EWM from other aquatic taxa and features. Understanding what sensors deployable via small UAS can provide this spectral information formed a logical next step in this research process. I focus on evaluating and demonstrating use of UAS platforms and sensors that would be able to be deployed on a practical basis by ecologists, lake managers, and others interested in where submerged aquatic vegetation (SAV) taxa occur and how they may change over time.

In Chapter 2, I describe how spectral profile data collected at three different spatial scales enabled the evaluation of whether EWM could be differentiated from other SAV. Spectral data were collected for SAV removed from the water, from the side of a boat, and from a UAS. EWM was spectrally different when using 651 1-nm wide and 6510 $\mathrm{nm}$ wide spectral bands, but using only six to eight bands did not result in reliable differentiation. However, a modified normalized difference vegetation index (mNDVI) using a red-edge to red light ratio was significantly different among vegetation groups, providing a potential sensing method to identify EWM from other SAV in the field. Spectral profile data collected via UAS had the lowest reflectance versus the out-of-water and boatside data, but could still be used to understand EWM and other SAV species' spectral differences. A custom-developed lightweight portable radiometer provided a practical platform for collecting spectral profile data that help provide the necessary foundation to understanding if multispectral imaging could be used for identification of an invasive SAV species or taxa of interest.

Using satellite imagery for terrestrial invasive plant identification and mapping has become common (Bradley \& Mustard, 2006; Lass et al., 2009) but less so for submerged aquatic plants, likely due to the unique issues of attenuation of light signals by water that makes image analysis more challenging than for terrestrial plants. Detection of SAV is affected by water column inherent optical properties (IOPs) including dissolved and suspended materials, and apparent optical properties (AOPs) affected by external factors such as weather and sun angle (Bolch et al. 2020).

In Chapter 3, I describe how using object-based image analysis of multispectral UAScollected imagery matched with detailed field data produced an overall mapping accuracy of $76.7 \%$ with EWM producer's accuracy of $78.7 \%$ and user's accuracy $77.6 \%$, higher than previous efforts to map SAV with high-resolution remote sensing. Two sensors were deployed via UAS to collect the imagery needed for classification: a multispectral Tetracam imaging system whose six bands can be tuned to narrow wavelengths of interest, and a low-cost four-band system sensitive to visible light and one wide near 
infrared band. Accounting for differences in water characteristics such as extinction coefficients were investigated, but using different scale parameters based on grouping sites into clearer vs. darker waters did not improve mapping accuracy.

Significant resources are being spent on EWM control in the U.S., often with only shortterm relief (Pimentel 2005 put annual control costs at $\$ 400$ million). In Chapter 4, I describe how I used the methods developed and demonstrated in Chapters 2 and 3 to enable the quantitative documentation of changes in EWM extent with $63 \%$ to $89 \%$ reduction after three different types of treatment intended to reduce EWM presence.

These three chapters followed a theme of understanding if there was a signal of EWM that was detectable using remote sensing data, developing methods to use that signal of EWM presence to map species coverage with multispectral UAS-collected imagery, and then applying that signal to document the effects of EWM treatment. These analysis methods, including enhancements with hyperspectral data, could be applied to other species and communities of aquatic vegetation that possess spectrally-distinct signatures to increase ecological understanding of dynamic littoral zones.

\subsection{References}

ALLAN, B. M., IERODIACONOU, D., NIMMO, D. G., HERBERT, M. \& RITCHIE, E. G. 2015. Free as a drone: ecologists can add UAVs to their toolbox. Frontiers in Ecology and the Environment, 13, 354-355.

BOLCH, E. A., SANTOS, M. J., ADE, C., KHANNA, S., BASINGER, N. T., READER, M. O. \& HESTIR, E. L. 2020. Remote Detection of Invasive Alien Species. In: CAVENDER-BARES, J., GAMON, J. A. \& TOWNSEND, P. (eds.) Remote Sensing of Plant Biodiversity. Cham, Switzerland: Springer Open.

BRADLEY, B. A. \& MUSTARD, J. F. 2006. Characterizing the landscape dynamics of an invasive plant and risk of invasion using remote sensing. Ecological Applications, 16, 1132-1147.

COUCH, R. \& NELSON, E. 1985. Myriophyllum spicatum in North America. Proceedings of the First International Symposium on watermilfoil, Vancouver, B.C. pp. 8-18.

FAUSCH, K. D., TORGERSEN, C. E., BAXTER, C. V. \& LI, H. W. 2002. Landscapes to riverscapes: bridging the gap between research and conservation of stream fishes. BioScience, 52, 483-498.

KENNEDY, R. E., ANDRÉFOUËT, S., COHEN, W. B., GÓMEZ, C., GRIFFITHS, P., HAIS, M., HEALEY, S. P., HELMER, E. H., HOSTERT, P. \& LYONS, M. B. 
2014. Bringing an ecological view of change to Landsat-based remote sensing. Frontiers in Ecology and the Environment, 12, 339-346.

LASS, L. W., PRATHER, T. S., GLENN, N. F., WEBER, K. T., MUNDT, J. T. \& PETTINGILL, J. 2009. A review of remote sensing of invasive weeds and example of the early detection of spotted knapweed (Centaurea maculosa) and babysbreath (Gypsophila paniculata) with a hyperspectral sensor. Weed Science, 53(2), pp.242-251.

LEGUIZAMON, C. 2017. Associations Between Invasive Eurasian Watermilfoil and Littoral Fish and Invertebrate Communities in the Keweenaw Waterway of Lake Superior. Open Access Master's Thesis, Michigan Technological University, 2017. https://digitalcommons.mtu.edu/etdr/519

MADSEN, J. D., SUTHERLAND, J., BLOOMFIELD, J., EICHLER, L. \& BOYLEN, C. 1991. The decline of native vegetation under dense Eurasian watermilfoil canopies. Journal of Aquatic Plant Management, 29, 94-99.

MADSEN, J. D. 2005. Eurasian watermilfoil invasions and management across the United States. Journal of Marine Education, 21, 21-26.

MILLS, E. L., LEACH, J. H., CARLTON, J. T. \& SECOR, C. L. 1994. Exotic species and the integrity of the Great Lakes. BioScience, 666-676.

MOODY, M. \& LES, D. 2007. Geographic distribution and genotypic composition of invasive hybrid watermilfoil (Myriophyllum spicatum $\times$ M. sibiricum) populations in North America. Biological Invasions, 9, 559-570.

PIMENTEL, D. 2005. Aquatic nuisance species in the New York State Canal and Hudson River systems and the Great Lakes Basin: an economic and environmental assessment. Environmental Management, 35, 692-702.

ROLEY, S. S. \& NEWMAN, R. M. 2006. Developmental performance of the milfoil weevil, Euhrychiopsis lecontei (Coleoptera: Curculionidae), on northern watermilfoil, Eurasian watermilfoil, and hybrid (northern $\times$ Eurasian) watermilfoil. Environmental Entomology, 35, 121-126.

TURNER, M. G., O'NEILL, R. V., GARDNER, R. H. \& MILNE, B. T. 1989. Effects of changing spatial scale on the analysis of landscape pattern. Landscape Ecology, 3, $153-162$. 


\section{Multiscale collection and analysis of submerged aquatic vegetation spectral profiles for Eurasian watermilfoil detection}

\subsection{Abstract}

The ability to differentiate a non-native aquatic plant, Myriophyllum spicatum (Eurasian watermilfoil or EWM), from other submerged aquatic vegetation (SAV) using spectral data collected at multiple scales was investigated as a precursor to mapping of EWM. Spectral data were collected using spectroradiometers for SAV taken out of the water, from the side of a boat directly over areas of SAV and from a lightweight portable radiometer system flown from an unmanned aerial system (UAS). EWM was spectrally different from other SAV when using 651 spectral bands collected in ultraviolet to nearinfrared range of 350 to $1000 \mathrm{~nm}$ but does not provide a practical system for EWM mapping because this exceeds the capabilities of available airborne hyperspectral imaging systems. Using only six spectral bands corresponding to an available multispectral camera or eight wetlands-centric bands did not reliably differentiate EWM from other SAV and assemblages. However, a modified version of the normalized difference vegetation index (mNDVI), using a ratio of red-edge to red light, was significantly different among dominant vegetation groups. Also, averaging the full range of spectral to 6510 -nm wide bands, similar to available hyperspectral imaging systems, provided the ability to identify EWM separately from other SAV. The UAS-collected spectral data had the lowest remote sensing reflectance versus the out-of-water and boatside data, emphasizing the need to collect optimized data. The spectral data collected for this study support that with relatively clear and calm water, hyperspectral data, and mNDVI, it is likely that UAS- based imaging can help with mapping and monitoring of EWM.

\subsection{Introduction}

Aquatic vegetation provides a key refuge and growth habitat for a variety of plant and animal species in the shallow littoral regions on the edges of waterbodies (Jeppesen et al. 2012, Rozas and Odum 1988), supporting more species per unit of primary production than open water (limnetic) zones (Vadeboncoeur et al. 2011). In a study of 14 of the world's largest lakes, Vadeboncoeur et al. (2011) found that more than $93 \%$ of fish species were found in the littoral zones and $72 \%$ of species were restricted to this area. Aquatic vegetation is a key factor controlling the structure and function of littoral zones, cycling nutrients, fixing carbon via photosynthesis, providing habitat for periphyton colonization and facilitating carbon and nutrient cycling by other primary producers (Carpenter and Lodge 1986, Marcarelli and Wurstbaugh 2009). Aquatic vegetation is a source of both food and habitat for macroinvertebrates, fishes, and amphibians that are part of the food web (Ziegler et al. 2015). Finally, littoral zones are highly influenced by anthropogenic activity yet are poorly studied compared to limnetic zones. There are many aquatic invasive plant species (Trebitz and Taylor 2007), whose ecological and 
management impacts have resulted in control and treatment efforts in need of monitoring (Ailstock et al. 2001, Kettenring and Adams 2011, Nelson and Shearer 2005, Tucker 2017, Wagner et al. 2007). Invasive aquatic plants can interfere with recreation, affect property values, impact subsistence fisheries harvests, increase nutrient loading, and deplete dissolved oxygen (Lake Superior Work Group 2014). For example, non-native Myriophyllum spicatum (Eurasian watermilfoil or "EWM") forms thick, submerged monotypic beds that typically reduce the richness, diversity, and distributions of benthic invertebrates and fishes in littoral zones (Buchan and Padilla 2000). Challenges to the study of aquatic vegetation include relative difficulty of site access compared to terrestrial systems and attenuation of light in water, especially for freshwater systems.

Aquatic vegetation in littoral zones includes both species that emerge above the water surface (emergent aquatic vegetation) and those submerged below the surface (hereafter submerged aquatic vegetation, or SAV), which presents different opportunities and challenges for remote sensing. Mapping emergent vegetation with satellite imagery is relatively well established, in part because it does not require addressing issues related to light attenuation in water, absorption of infrared light by water, and turbidity (Adam et al. 2010, Ozesmi and Bauer 2002, Silva et al. 2008). Satellite imagery has been used successfully to map wetlands with predominantly emergent vegetation, including coastal tidal marshes, northern peatlands, inland freshwater marshes, and the Prairie Pothole region in the US and Canada (Ozesmi and Bauer 2002, Bourgeau-Chavez et al. 2015).

Previous work has indicated that the mapping of SAV can be possible using satellite imagery under certain conditions. Initial work such as Ackleson and Klemas (1987) showed feasibility for mapping a species of SAV using Landsat satellite imagery, noting the masking impact of optically deep water. Recent work by Brooks et al. (2015) has shown that SAV can be mapped over large areas of the coastal regions of the Laurentian Great Lakes using moderate-resolution satellite imagery such as Landsat, where there is sufficient optical depth due to relatively clear water and where SAV could be summarized in to a single class type dominated by the native alga Cladophora glomerata (Shuchman et al. 2013a). Ozesmi and Bauer (2002) and Silva et al. (2008) have also shown that Landsat-type imagery is useful for large-scale SAV mapping at moderate resolution, particularly for areas of relatively clear water with limited light attenuation and low wind conditions during satellite overpass. Finer spatial resolution commercial satellite imagery such as QuickBird and WorldView data with a 1.0- to 2.4-m multispectral pixel size can also be used to discriminate between submerged and emergent or floating aquatic vegetation with limitations based on water conditions and acquisition costs (Ashraf et al. 2010, Midwood and Chow-Fraser 2010, Dogan et al. 2009, Wolter et al. 2005). Fritz et al. (2017) have shown that 5-m resolution RapidEye imagery can effectively map four different SAV species. Dierssen et al. (2015) showed that airborne hyperspectral imagery can be effective in identifying areas of seagrass and Sargassum macroalgae.

The use of unmanned aerial system (UAS) is a relatively new area of research that can provide a source of mid-to-fine scale data (Flynn and Chapra 2014) that may provide 
better resolution and detection of SAV at appropriate scales for studying lake littoral zones. UAS can be deployed selectively during optimal weather conditions (low winds, more sunlight, optimal sun angles) and collect high resolution imagery that may help with differentiation of species of interest (Hodgson et al. 2013, Zeng et al. 2017). The capabilities of UAS have been increasing in recent years, gaining the attention of ecologists as useful tools for meeting environmental data needs, including mapping (Flynn and Chapra 2014, Anderson and Gaston 2013, Marcaccio et al. 2015).

Understanding ecologically relevant patterns of macrophyte dynamics requires identification of individual SAV species that grow in mixed assemblages, which is possible if SAV species appear spectrally distinct when using scale-appropriate remote sensing. One tool for understanding whether plant species are spectrally distinct is field spectroradiometers, developed for applications such as identifying geological features and vegetation types (Penuelas et al. 1993, Van der Meer et al. 2012). However, they have not been commonly used for spectral profiling of SAV (Williams et al. 2003). Some work has shown the capability to resolve distinct spectral signatures for aquatic plants using spectroradiometers in controlled growth environments, such as tanks of water (Everitt et al. 2011, Cho et al. 2008). Underwood et al. (2006) and Williams et al. (2003) demonstrated capabilities to classify invasive SAV using airborne hyperspectral imagery. Whether similar classification would be possible using multispectral imagery at scales in between the field sampling scale and satellite scale has not yet been answered. Meeting the challenge of this intermediate-scale sensing is likely to require higher spatial resolution data than is available from satellite imagery, further supporting the utility of UAS for studying SAV in lake littoral zones.

EWM provides a test case to evaluate whether UAS-based spectrometry and multispectral imagery can be used to map SAV at scales relevant to management. In this study, we developed methods to rapidly create spectral profiles of aquatic plants of interest due to their invasion and management implications in our study region of the upper Laurentian Great Lakes. These methods would be used to understand how spectral data for an invasive species of interest, EWM, could be reliably collected and analyzed and how they compared between boat-based and UAS-based imaging. We designed the study to address two central study questions:

1. Can spectral profiles of EWM be differentiated from those of other SAV species using spectroradiometer data and multispectral imagery collected in the upper Great Lakes?

2. Do EWM spectral profiles collected at three different sampling scales exhibit similar spectral signatures for our upper Great Lakes study areas?

The three data collection scales were individual SAV samples measured out of the water (sample footprint diameter $\sim 5 \mathrm{~cm}$ ), SAV in the water measured from a boat $(\sim 50 \mathrm{~cm})$, and SAV in the water measured from a UAS platform $(\sim 5 \mathrm{~m})$. If spectral signatures for SAV species appear distinct in one or more of these three levels of spectral profiling [out-of-water (OOW), boat side, and aerial UAS], then UAS-based high-resolution multi- 
spectral and hyperspectral sensing could become a practical tool for monitoring invasive SAV such as EWM.

\subsection{Sensing Design}

To address the study questions, we deployed and developed a set of remote sensing data collection tools that included spectroradiometers, natural color and multispectral cameras, and UAS to collect data at the three scales described above. The goal was to achieve species-level identification using spectroradiometers as a prerequisite for imaging SAV species of interest with multispectral cameras. This would enable mapping and monitoring of EWM versus non-EWM SAV species, with natural color digital cameras helping to identify and describe study areas along with providing a basemap for the multispectral results. We used an ASD Fieldspec 3 (Malvern Panalytical, Malvern, UK) for most OOW and boatside data collections using the software RS3. The ASD FieldSpec series of spectroradiometers have frequently been used for collecting spectral profiles of wetland vegetation species (Adam and Mutanga 2009, Artigas and Yang 2006) including SAV (Yuan and Zhang 2008). For recent aquatic remote sensing research, colleagues at the Michigan Tech Research Institute (MTRI) developed a lightweight portable radiometer (LPR) system to enable spectroscopy at a lower cost and lighter weight than traditional handheld systems, such as the ASD FieldSpec 3 (Sawtell et al. 2019). The LPR is compact and light enough to be flown onboard an UAS able to lift at least $1 \mathrm{~kg}$ and is housed in a plastic box that can be attached to a typical UAS payload platform. Initial field data in 2015 were collected using the first version of the LPR system, which integrated a global positioning system (GPS) receiver, a Raspberry Pi microcomputer for remote WiFi control of the system, a lithium ion battery, a skyward-facing Ocean Optics STS-VIS-RAD model spectrometer (a STS-VIS spectrometer with a range of 350 to 800 $\mathrm{nm}$ and a directly attached cosine corrector) to measure downwelling irradiance, two nadir-facing Ocean Optics spectrometers (one STS-UV/ultraviolet and one STSNIR/near-infrared) with a combined spectral range of 190 to $1100 \mathrm{~nm}$, and a five megapixel (mp) Raspberry Pi camera for identification of the ground footprint captured by the nadir-facing spectrometers. The Ocean Optics STS sensors have been used by other authors for measuring water color (Zeng et al. 2017) and SAV reflectance (Yang et al. 2010). In 2016, field data were collected using LPR version 2, which replaced the UV and NIR nadir-pointing sensors with a single STS-VIS spectrometer with a range of 350 to $800 \mathrm{~nm}$ and a more compact data output format with improved metadata. In 2017, a third version of the LPR was used with similar sensors that covered through $1000 \mathrm{~nm}$. All STS series Ocean Optics spectrometers have a spectral resolution of $\sim 1.5 \mathrm{~nm}$ (FWHM) and a signal-to-noise ratio of greater than 1500:1. The integration time for a single measurement ranges from $10 \mu \mathrm{s}$ to $10 \mathrm{~s}$, making it possible to collect several spectra per UAS flight. The LPR and ASD FieldSpec were used as equivalent devices with calibration, as described in section 2.4, except that the LPR could be mounted on a UAS platform for obtaining airborne spectral data. Recent work has shown that spectra collected with the LPR compared well to ASD data (Becker et al. 2019), with linear relationships with $\mathrm{R}^{2}=0.941$ to 0.992 between ASD and LPR-derived spectra over the 
same locations. To enable the collection of boatside spectra that would be comparable to the UAS-based spectra, these were both collected at nadir to provide a similarly shaped circular footprint. We recognize that there are potential specular reflection issues with these nadir-collected spectra; however, previous studies have collected nadir spectra for shallow-water mapping (Kearney et al. 2009, Legleiter et al. 2009).

We used two multispectral camera systems in this study. We selected the Micro-MCA-6 six-channel multispectral camera manufactured by Tetracam (Chatsworth, California) for its ability to cover the 400 to $1000 \mathrm{~nm}$ (visible to near-infrared) spectral range, availability of different spectral filters within that range, and light weight $(<1 \mathrm{~kg}$ with battery). Each image channel has its own $1.3 \mathrm{mp}$ camera. The system was available for three 1-week data collection periods in 2016 and 2017. Standard Tetracam MCA-6 bands are $490 \mathrm{~nm}$ (blue), $550 \mathrm{~nm}$ (toward the upper range of green), $680 \mathrm{~nm}$ (red), $720 \mathrm{~nm}$ (red edge), $800 \mathrm{~nm}$ (in the near-infrared (NIR) range of $\sim 750$ to $1000 \mathrm{~nm}$ ), and $900 \mathrm{~nm}$ (also in the NIR). However, NIR wavelengths have limited penetration into water due to rapid light attenuation (i.e., strong absorption) (Malthus and George 1997), and maximum penetration into water occurs at around the green wavelength of $530 \mathrm{~nm}$ (Mishra 2005, Allouis et al. 2010). Therefore, for the 2016 and 2017 data collections, the Tetracam manufacturer was able to change the wavelengths for two bands to better meet our study objectives of differentiating and mapping species of SAV. New selected wavelengths were $530 \mathrm{~nm}$ (near maximum light penetration) and $600 \mathrm{~nm}$ (orange) because preliminary 2015 spectral data had shown promising separation of some plant species at around 600 $\mathrm{nm}$. For 2016 and 2017, this made the available wavelengths $490 \mathrm{~nm}$ (blue), $530 \mathrm{~nm}$ (green 1), $550 \mathrm{~nm}$ (green 2), $600 \mathrm{~nm}$ (orange), $680 \mathrm{~nm}$ (red), and $720 \mathrm{~nm}$ (red edge).

As a low-cost multispectral backup, we developed a dual camera system, referred to as the VISNIR system, for the 2017 summer field season that included a Canon point-andshoot $16 \mathrm{mp}$ camera for natural color (RGB) data collection and a second Canon pointand-shoot camera modified to be sensitive only to the near-infrared range of $\sim 830$ to $1100 \mathrm{~nm}$. We deployed this dual system at the same time to collect visible plus nearinfrared images, either on the UAS as described below or pole-mounted for highresolution four-band imaging at a height of $\sim 3 \mathrm{~m}$.

We deployed a variety of UAS for the study, all of which met the US Federal Aviation Administration (FAA) definition of a small UAS (under $25 \mathrm{~kg}$ ) and were flown by experienced UAS pilots. The largest system was a hexacopter (six rotors) system manufactured by Bergen RC Helicopters of Vandalia, Michigan. It had several important parameters, including being controllable remotely, capable of at least $15 \mathrm{~min}$ of flight time, having on-board position data from a GPS, a return to home default capability if the connection is lost, ability to fly a payload of up to $5 \mathrm{~kg}$, a tiltable sensor platform, and a reasonable cost (US \$4,800). It was capable of deploying the LPR as well as digital cameras up to the size of a Nikon full-frame camera and the multispectral cameras described above. The Bergen hexacopter's tiltable sensor platform enabled the LPR to face forward for takeoff but then be pointed nadir for spectral data collection. The Bergen hexacopter has frequently been used by the MTRI study team members as a reliable 
system for deploying a variety of airborne sensor systems (Dobson et al. 2014). Upon initial testing, it was determined that for aquatic applications, the minimum flying height at which the downwash from the Bergen hexacopter does not disturb the water surface to a degree that interferes with spectra and imagery was $10 \mathrm{~m}$. Therefore, the minimum flying altitude of $\sim 10 \mathrm{~m}$ was used for collecting spectral data, and a height of $\sim 25 \mathrm{~m}$ was used for natural color image collection. Smaller DJI Phantom 2 Vision, Phantom 3 Advanced, and Mavic Pro quadcopter UAS were also used to provide rapid, lower resolution imagery of project areas.

Smaller UAS used in this project had their own integrated RGB camera systems with 12 $\mathrm{mp}$. These were intended to provide sufficient detail to identify sites that might have EWM, to potentially map changes in overall SAV density, and most importantly, to provide orthophoto mosaic basemaps of the study areas. The $5 \mathrm{mp}$ camera onboard the LPR during UAS flights fulfilled a similar purpose. For higher resolution RGB imaging of study sites, our previous experience has shown that a Nikon D800 series DSLR camera can provide detailed digital images of ground features at flying heights of 10 to $30 \mathrm{~m}$, (Dobson et al. 2014) so we deployed this system whenever possible to document study sites.

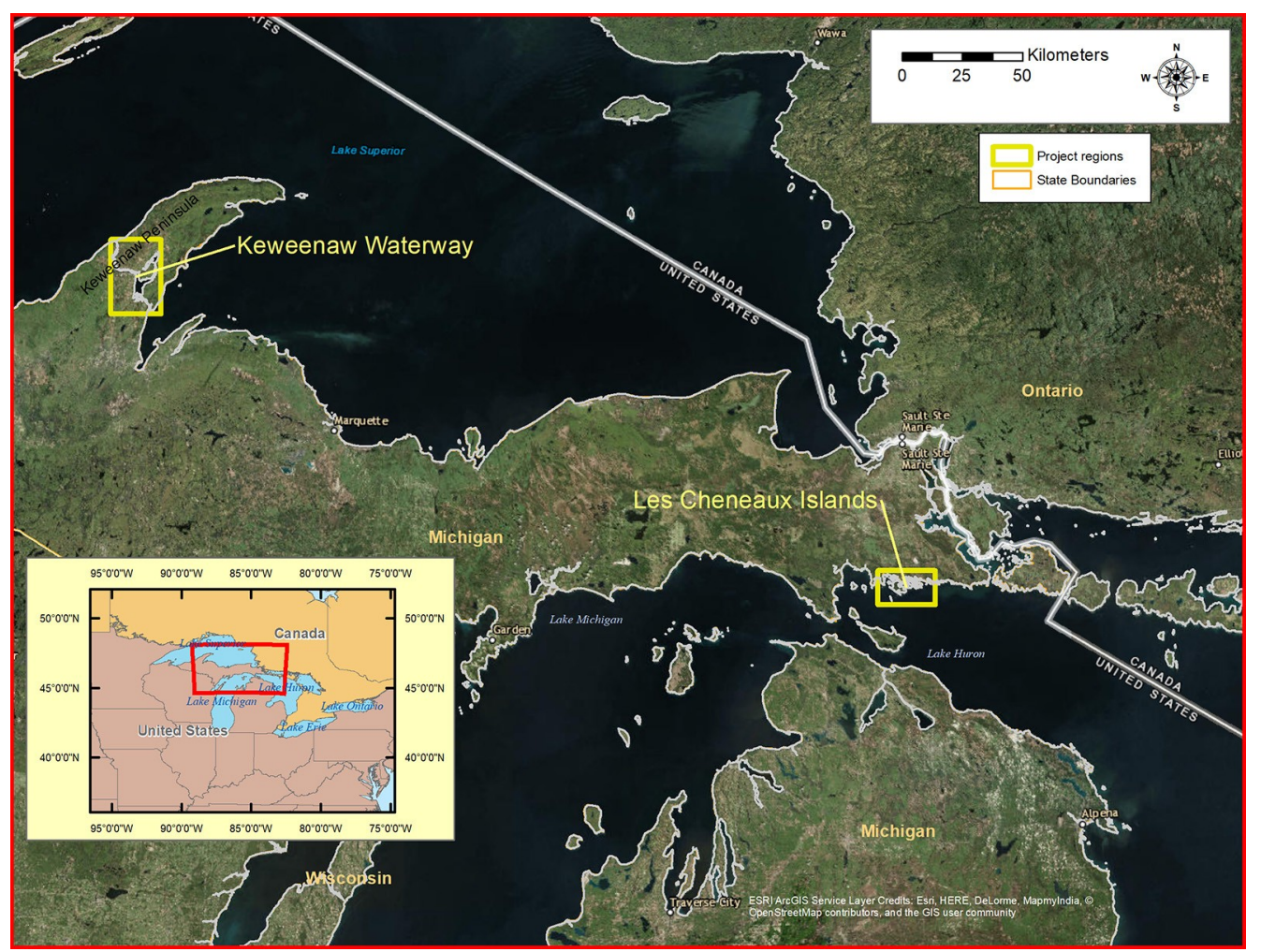

Figure 2.1. Location of data collections in the Upper Peninsula of Michigan, including the Keweenaw Waterway in the Keweenaw Peninsula and the Les Cheneaux Islands area in northwest Lake Huron. 


\subsection{Experiments and Validation}

\subsubsection{Data Collection Areas}

Study data characterizing the spectral profiles of vegetation from individual species to assemblages were collected at multiple sites in the Les Cheneaux Islands region of northwest Lake Huron (Figs. 2.1 and 2.2). EWM in Michigan and in other Midwestern states has been shown to mostly be hybrids of M. spicatum $\times$ Myriophyllum sibiricum (native Northern watermilfoil) and that where the hybrid was found, M. sibiricum was rare (Moody and Les 2007). We anticipated that most EWM in the Les Cheneaux Islands would be the hybrid form based on this and more recent studies (Zallek 2018). In 2015, data were collected at three sites located in the Keweenaw Waterway near Houghton, Michigan (Figs. 2.1 and 2.2), primarily to developed methods, such as the initial OOW data collection.

\subsubsection{Scales of Spectral Data Collection and Processing Methods}

To answer the study questions about EWM detection and spectral profile similarity, a diverse set of field spectra for EWM and other species and bottom types were needed. Table 2.1 lists all the sites, dates, number of averaged spectra by site, and scale of spectral data collections from 2015 to 2017. Species measured at each site on each date varied due to natural seasonal and interannual variability in the SAV assemblages growing at these sites at the time they were sampled, with several species occurring multiple times in the data collections, helping provide comparability among sites and data collection campaigns.

We recorded spectral data at three sampling levels:

1. Plant-level spectra of a single species of aquatic vegetation retrieved out of the water and sensed immediately after removal to prevent spectral decay with either the ASD FieldSpec 3 or the LPR system [Figs. 2.3(a) and 2.3(b)]. The spectrometer optic, with a $25 \mathrm{deg}$ FOV for either system, was held $\sim 10 \mathrm{~cm}$ above the plant surface for a sample footprint diameter of $\sim 5 \mathrm{~cm}$. Plant samples were large enough to occupy the entire footprint of the spectrometer at this distance, and the plant was piled in multiple layers and measured against a matte black tarp to minimize the spectral contribution of the back- ground from any remaining small gaps between leaves. Visser et al. (2013) and Vahtmäe and Kutser (2013) used very similar approaches of piling layers of aquatic vegetation on a black painted canvas and a black plastic bag, respectively, to obtain spectra without water column influences. These data represented the OOW scale and were intended to provide the strongest signal of plant spectra.

2. Spectral measurements were made from the side of the boat, with the sensor head mounted on an extension pole at least $1 \mathrm{~m}$ in length. The pole mount both allowed the operator to hold the sensor away from boat shadows and reflections and safely 
held the sensor at nadir. The spectra were also collected on the sunlit side of the boat to minimize effects of light reflection from the boat or the boat shadow. Either spectrometer was used as available, with the optic held $\sim 1 \mathrm{~m}$ above the water surface immediately above a patch of vegetation for a spectra footprint radius at the water surface of $\sim 45 \mathrm{~cm}$ [Fig. 2.3(c)]. Spectral measurements were taken while keeping the boat stationary and visually confirming minimal disturbance of the water by the boat. Any measurements affected by disturbances such as accidental changes in sensor position or viewing geometry were noted and later removed from the dataset. Measurement locations were selected based on visual observation of the distribution of homogeneous patches of SAV species dominated by one to a few species. These data represented the "boatside" scale and would be similar to the traditional scale of vegetation sampling, such as rake tosses and twists (Johnson and Newman 2011). The spectra footprint radius could also represent a scale similar to aerial imagery collected via UAS.

3. Nadir spectra from the LPR system mounted on a UAS flying directly above a vegetation patch of known composition [Figs. 2.3(d)-2.3(f)]. When mounted on the UAS, the LPR's irradiance sensor was fixed to a rod on top of the system in the zenith direction so that there would be no shadowing. The UAS-based spectra were collected $\sim 10$ to $15 \mathrm{~m}$ above the water surface for a footprint radius at the water surface of 4.5 to $6.5 \mathrm{~m}$. These data represented the "LPR UAS" scale, referred to as just "UAS" in Table 2.1 and hereafter as the LPR that was the only radiometer that could flown in the UAS, and these data covered the largest area for spectral data collection. 

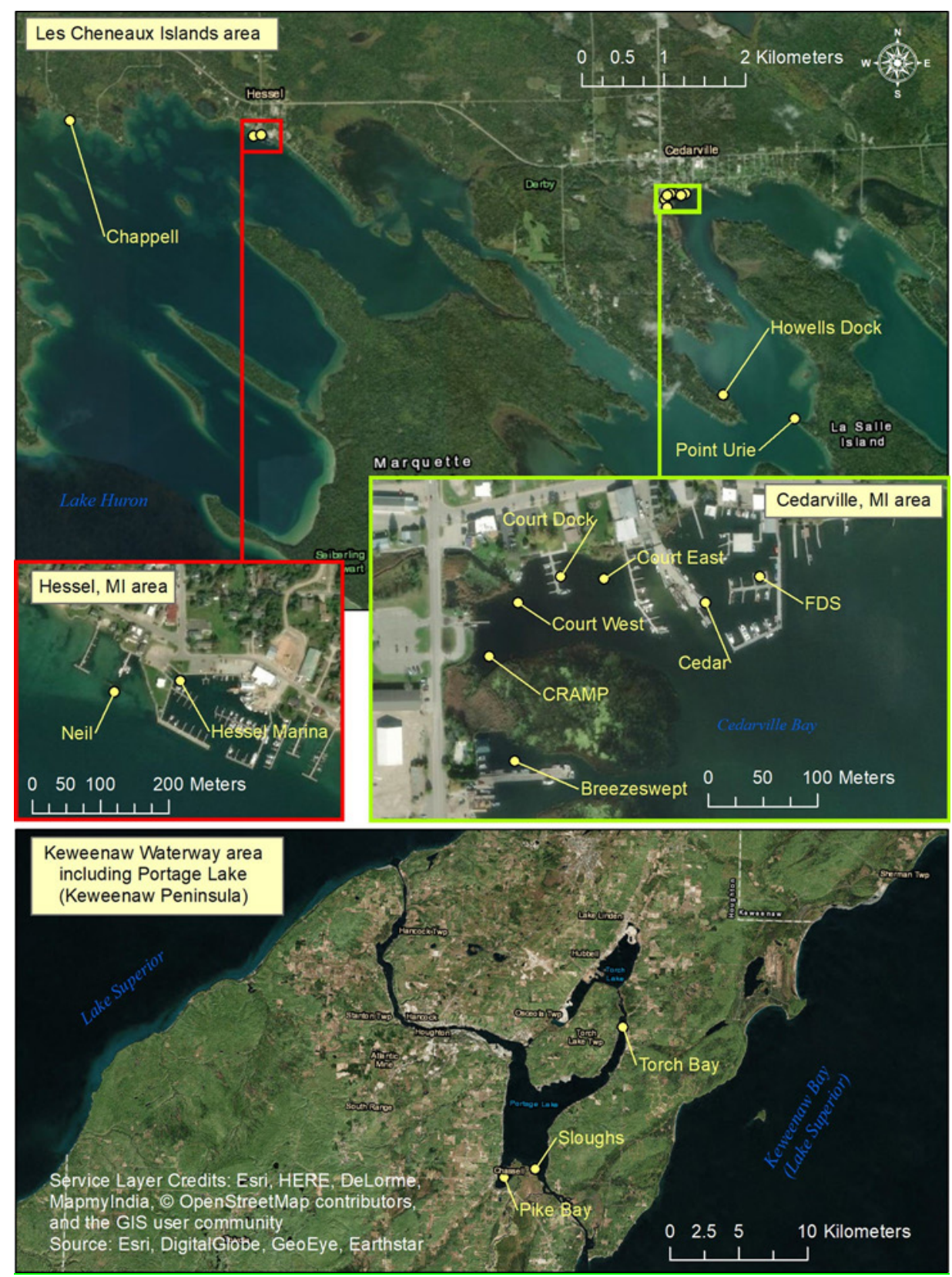

Figure 2.2. Detailed locations of data collection sites for spectral and UAS data within the Les Cheneaux Islands and the Keweenaw Waterway. 
Table 2.1. Collection sites listing types of spectral data collected by time period and data collection scale. The number of averaged

\begin{tabular}{|c|c|c|c|c|c|c|c|}
\hline Collection & Region & June 2015 & July 2016 & August 2016 & June 2017 & July 2017 & August 2017 \\
\hline Pike Bay & Portage Waterway & OOW (4) & & UAS (5) & & & \\
\hline Torch Bay & Portage Waterway & OOW (4) & & & & & \\
\hline Breeze-swept & Les Cheneaux Islands & & & & & $\begin{array}{l}\text { Boatside (3), } \\
\text { UAS (3) }\end{array}$ & $\begin{array}{l}\text { Boatside (3), } \\
\text { OOW (12) }\end{array}$ \\
\hline Cedar & Les Cheneaux Islands & & & & & & OOW (6) \\
\hline Court Dock & Les Cheneaux Islands & & UAS (2) & & & & \\
\hline Court East & Les Cheneaux Islands & & $\begin{array}{l}\text { Boatside (1), } \\
\text { UAS (1) }\end{array}$ & $\begin{array}{l}\text { Boatside (1), } \\
\text { UAS (1) }\end{array}$ & $\begin{array}{l}\text { Boatside (3), } \\
\text { UAS (3) }\end{array}$ & Boatside (2) & $\begin{array}{l}\text { Boatside (3), } \\
\text { OOW (6) }\end{array}$ \\
\hline Court West & Les Cheneaux Islands & & & & & Boatside (1) & OOW (6) \\
\hline Chappell & Les Cheneaux Islands & & & & Boatside (2) & & $\begin{array}{l}\text { Boatside (3), } \\
\text { OOW (6) }\end{array}$ \\
\hline FDS & Les Cheneaux Islands & & $\begin{array}{l}\text { Boatside (5), } \\
\text { UAS (4) }\end{array}$ & Boatside (4), UAS & $\begin{array}{l}\text { Boatside (5), } \\
\text { UAS (4) }\end{array}$ & $\begin{array}{l}\text { Boatside (3), } \\
\text { UAS (2) }\end{array}$ & OOW (6) \\
\hline Hessel Marina & Les Cheneaux Islands & & & & & $\begin{array}{l}\text { Boatside (1), } \\
\text { UAS (1) }\end{array}$ & $\begin{array}{l}\text { Boatside (3), } \\
\text { OOW (6) }\end{array}$ \\
\hline Howells Dock & Les Cheneaux Islands & & & $\begin{array}{l}\text { Boatside (4), } \\
\text { UAS (1) }\end{array}$ & $\begin{array}{l}\text { OOW (10), } \\
\text { Boatside (4), } \\
\text { UAS (3) }\end{array}$ & & $\begin{array}{l}\text { Boatside (3), } \\
\text { OOW (6) }\end{array}$ \\
\hline Neil & Les Cheneaux Islands & & & & $\begin{array}{l}\text { Boatside (4), } \\
\text { UAS (3) }\end{array}$ & $\begin{array}{l}\text { Boatside (2), } \\
\text { UAS (2) }\end{array}$ & $\begin{array}{l}\text { Boatside (2), } \\
\text { OOW (6) }\end{array}$ \\
\hline
\end{tabular}

Note: Scale and method of spectral data collection: OOW, out-of-water; Boatside, from side of boat; UAS, Unmanned aerial system with the lightweight portable radiometer. 


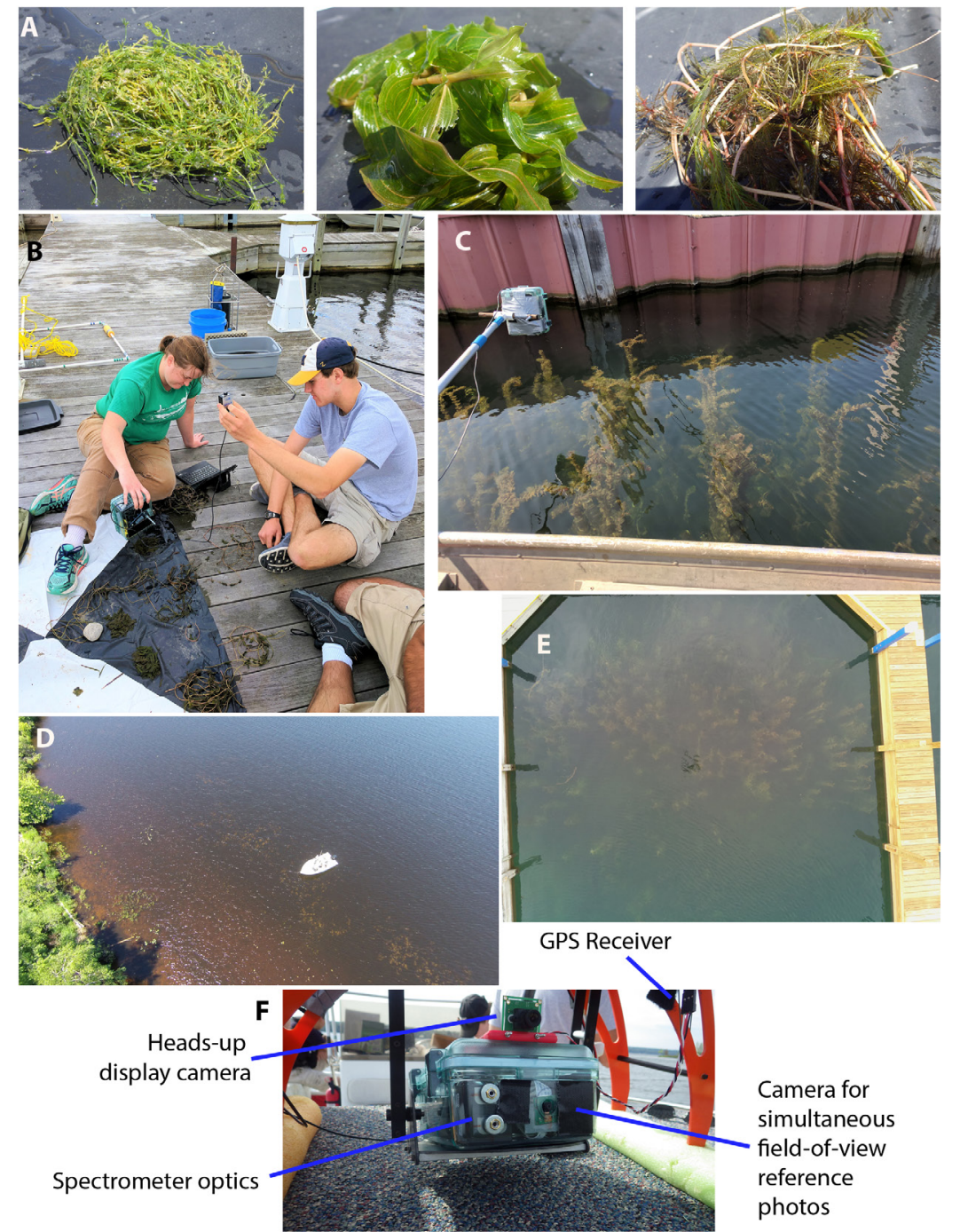

Figure 2.3. Images demonstrating field data collection methods. (a) Single-species plants on a black tarp about to have their spectral profile recorded for OOW scale data. From left to right: Chara sp. (stonewort), Potamogeton richardsonii (clasping-leaf pondweed), and EWM. (b) Collection of OOW scale data using the LPR spectroradiometer during the August 2017 data collection. (c) Collection of spectral profile data at the boatside scale using the LPR spectroradiometer held vertically over an area of predominantly EWM. (d) Aerial photo from 2015 at a site in Keweenaw Waterway showing visible SAV, emergent vegetation, shoreline vegetation, and the Michigan Tech research vessel used for launch and recovery of the DJI Phantom 2 UAS. (e) Aerial photo taken from the Bergen hexacopter with the LPR's five mp camera, with EWM visible near the water's surface at a boat slip in the Hessel Marina site in the Les Cheneaux Islands study area. (f) The LPR mounted underneath the Bergen hexacopter UAS, about to collect spectral data over an area of EWM. 
The boat-based sampling was designed to test and demonstrate the strength of the spectral signature that could be expected to be available for UAS-based spectral profiling and imaging. This is a scale similar to the resolution of UAS-based multispectral imagery. If a strong vegetation spectral signature could be identified directly from the vegetation and from just above the water, then there would be a reasonable chance this could be captured with a UASbased spectrometer and with a multispectral imaging camera that captures relevant spectral wavelengths.

Analysis of the UAS-based spectra was designed to help understand whether vegetation types can be differentiated when a larger area is being assessed than the OOW or boatside scale data. With integration over the larger spectral footprint captured from the UAS platform, plant assemblages tended to include more than one SAV species. To address this issue, the sampling sites were summarized based on the two most dominant species if they made up at least $20 \%$ of the cover based on the visual estimate. For example, a site that had a visual estimate of 50\% EWM and 30\% Elodea was summarized as an "EWM_ELODEA" spectral profile.

Visual estimates of plant species densities by percent were made by an experienced aquatic vegetation expert for areas where spectral data were being recorded, and species identities were confirmed by rake toss after spectral data collection was complete. These estimates were collected to document the dominant vegetation species that would be captured by the boatside and UAS-based spectral data collection. Specifically, for EWM plots, the average area covered by vegetation was $85.2 \%(\sigma=14.3 \%, n=25)$, the average for other SAV (SAV_OTHER) was 84.4\% $(\sigma=15.0 \%, n=14)$, for non-identifiable low vegetation (LOWVEG), the average was $77.8 \%(\sigma=38.5 \%, n=4)$, the deepwater average (DEEPWATER) was $0.0 \%(\sigma=0.0 \%, n=3)$, and the bare average (BARE) was $33.1 \%(\sigma=17.2 \%, n=16)$.

All spectra were calibrated to remote sensing reflectance $\left(R_{\mathrm{rs}}\right)$, a unitless value defined as the ratio of water-leaving radiance to the total downwelling irradiance just above water. The ASD spectra were calibrated using a Spectralon panel of a known reflectance and the LPR spectra using a skyward-facing irradiance sensor (mounted on the UAS for airborne spectral data collections). The field spectra collected with the ASD FieldSpec 3 and the LPR spectroradiometers were examined for data quality. Ten spectra were collected per target when using the ASD. Because it operates less rapidly, five spectra were collected per target when using the LPR to minimize the risk of the sensing platform drifting away from the target location. Outliers among spectra collected for the same target, indicating an effect of glint or other problems, were discarded. A calibration based on the differences between ASD and LPR spectra collected simultaneously for a Spectralon panel illuminated by a highly stable lamp was applied to the radiance and irradiance values from the LPR spectrometers to make them comparable to ASD spectra, as used and described by Sawtell et al. 2019. This calibration was repeated at least once per field season to account for possible instrument drift over time. $R_{\mathrm{rs}}$ was calculated for ASD data using ViewSpec Pro software (Malvern Panalytical) and for LPR data as follows: 


$$
R_{r s}^{0+}=\frac{L_{w}^{0+}\left(\lambda, \theta_{d}\right)}{E_{d}^{0+}(\lambda)}
$$

\section{= Water-leaving radiance just above the water surface / Downwelling Irradiance}

Spectral profiles corresponding to the same sampling run at a particular location and target were averaged.

\subsubsection{Statistical Analysis Methods}

To analyze whether spectral profiles were significantly different from each other for different species or assemblages, the averaged profiles were treated as distributions and analyzed using the nonparametric two-sample Kolmogorov-Smirnov (K-S) test (Sokal and Rohlf 1995) in R (versions 3.4.0 to 3.4.3; R Core Team 2017) with the ks.test command. The two sample K-S test provides the ability to find out if two random variables share an identical distribution or if they come from different distributions (Hassani and Silva 2015, Brooks and Merenlender 2001).

The K-S test analysis focused on the spectral reflectance data for the OOW species-level samples, collected in 2017 and 2015 using the ASD FieldSpec3 spectroradiometer because the differences among species should be strongest in this dataset. A sample of the 2016 boatside data was also analyzed for all bands. To understand whether small variations in spectral responses captured by using all spectral bands were potentially causing the application of the K-S test to not recognize when the profiles were very similar, band averaging was applied to reduce the dataset. These would also simulate the results of using imaging systems with fewer bands that could be practical to deploy, such as hyperspectral and multispectral sensors. Three levels of averaging were analyzed:

1. The same six bands as the Tetracam multispectral camera. These represented averaging of 10 one-nm-wide bands (i.e., $490 \mathrm{~nm}$ is an average of the reflectance values of 485 to $495 \mathrm{~nm}$, etc.). Although such average reflectances may not measure the "true" reflectances that the Tetracam would measure, they provide a good approximation for the reflectance in the Tetracam wave bands, as Tetracam spectral response functions were not available to us. If the Tetracam-like reflectance values for the various SAV species in the spectroradiometer datasets looked significantly different, this would bolster the case that multispectral imaging could reliably differentiate EWM from other aquatic vegetation.

2. The eight spectral bands that contain most of the spectral information needed to map coastal wetlands in the Great Lakes including SAV, according to Becker et al. (Becker et al. 2005, Becker et al. 2007), which were rounded to the nearest nm: $515 \mathrm{~nm}$ (green), $560 \mathrm{~nm}$ (green), $686 \mathrm{~nm}$ (red), and $732 \mathrm{~nm}$ (red edge), plus the near-infrared bands of 812, 824, 836, and $940 \mathrm{~nm}$. The 2015 and 2017 OOW data were averaged to $10-\mathrm{nm}$ bands centered around each of these, which will hereafter be referred to as "Becker bands." These bands were tested to see if they provided 
sufficient spectral information for species differentiation of SAV in our study area.

3. To test the effect of the number of bands on the separability of spectral signatures, the 651 individual spectral bands were averaged into 65 10-nm-wide bands; Everitt et al. (2011) used 10-nm wide bands for their tank-based spectral analysis of SAV. The 10-nm-wide bands covered the individual bands from 350 to 1000 $\mathrm{nm}(350-359 \mathrm{~nm}, 360-369 \mathrm{~nm}$, etc; $1000 \mathrm{~nm}$ was not included to make the 65 bands evenly sized). Testing 65 bands was also more representative of hyperspectral imaging systems that could be deployed than using all 651 bands. The June 2017 OOW dataset was used for this test as it had more SAV vegetation types for evaluating EWM detection versus other species.

To test for the capability of indices and ratios to help differentiate SAV species when combined with reduced datasets, the following indices were calculated as described below:

- Red edge/blue ratio (RE/BLUE, i.e., $720 \mathrm{~nm} / 490 \mathrm{~nm}$ )

- The modified normalized difference vegetation index (mNDVI)

- The modified normalized difference aquatic vegetation index (mNDAVI)

- The modified water-adjusted vegetation index (mWAVI).

NDVI, NDAVI, and WAVI were previously developed for terrestrial (NDVI) or aquatic uses (NDAVI and WAVI) but were included because of the possibility that sufficient light penetration might enable them to be useful for mapping SAV near the water's surface.

The red edge/blue (RE/BLUE) ratio was selected from among several tested ratios [red edge to red $(720: 680 \mathrm{~nm})$, red edge to orange $(720: 600 \mathrm{~nm})$, red edge to green 2 (720:550 $\mathrm{nm})$, and red edge to green $1(720: 530 \mathrm{~nm})]$ based on it having the largest standard deviation for the dominant vegetation types in the June 2017 OOW data and therefore providing the greatest potential for it to differentiate SAV types.

NDVI is a long-used indicator of green biomass, with larger values indicating more green biomass being present (Rouse et al. 1974, Tucker et al. 2005). Here, the 720-nm red edge band was used in place of the NIR band for analysis, as it was the longest wavelength collected with the Tetracam system that was used for SAV mapping. Thus, the modified NDVI has the following formula, where $\rho$ is the wavelength:

$$
m N D V I=\frac{(\rho \operatorname{RedEdge}-\rho \operatorname{Red})}{(\rho \operatorname{RedEdge}+\rho \operatorname{Red})}
$$

Previous work has found red-edge reflectance to be useful for identifying wetland vegetation types due to its sensitivity to biomass (Adam et al. 2010, Ouyang et al. 2013). The nearby red edge wavelength of $715 \mathrm{~nm}$ has also been shown to have a strong relationship with leaf area index (LAI) for SAV (Yang et al. 2010). 
As NDVI was developed as an index for terrestrial biomass analysis, two related aquatic indices reviewed and used by Villa et al. (2014) that might help with SAV mapping were also modified for application here: the NDAVI and WAVI. NDAVI uses a blue band instead of a red band in the NDVI formula. Again, we used the 720-nm red edge band in place of an NIR band, yielding the following formula:

$$
m N D A V I=\frac{\rho_{\text {RedEdge }}-\rho_{B L U E}}{\rho_{\text {RedEdge }}+\rho_{B L U E}}
$$

WAVI also uses a blue band instead of red but also includes a correction factor $(L)$ to adjust for the effect of the background signal. We adopted a value of 0.5 for $L$ based on Villa's description of this as a reasonable value for reducing background influence. The formula for mWAVI is as follows:

$$
m W A V I=(1+L) \frac{\rho_{\text {RedEdge }}-\rho_{B L U E}}{\rho_{\text {RedEdge }}+\rho_{B L U E+L}}
$$

We compared spectral characteristics among plots with differing SAV cover using analysis of variance (ANOVA) using the larger set of boatside data, which totaled 62 spectral data profiles, covering data collections in mid-July 2016, late August 2016, late June 2017, mid-July 2017, and late August 2017. A dominant vegetation type was selected for each of the 62 spectral profiles based on density at each location, resulting in 12 vegetation types. These vegetation types were summarized by dominant vegetation type to help differentiate EWM from other spectral patterns with the month of data collection included. The values of the six Tetracam bands $(490,530,550,600,680$, and $720 \mathrm{~nm}$ ), the RE/BLUE ratio, and the three indices (mNDVI, mNDAVI, and mWAVI) were compared between plots with different dominant plant covers.

To determine whether EWM was generally different from any other sampled SAV type, the other SAV dominant vegetation types were grouped into an "other SAV" class. These dominant vegetation groups were tested with study dates using two-way ANOVA, with plots nested within study areas as a random factor. The classes considered were: DOMVEG_GRP, which included the spectral vegetation profiles grouped in to one representing EWM, the one for all other SAV vegetation types (SAV_OTHER), one for areas of short vegetation at the lake bottom that was not identifiable by species (LOWVEG), areas of deepwater (DEEPWATER), or bare bottom types such as sand or rock (BARE) categories. All two-way ANOVA analyses were conducted using PROC MIXED in SAS version 9.4 (SAS Institute, Inc., Cary, North Carolina), and significance was considered at $p=0.05$. The six Tetracam band wavelengths (averaged from $10-\mathrm{nm}$ wide) were log-transformed to meet assumptions of normal residual distribution and constant variance (Oehlert 2010); all other variables except mWAVI did not require transformation to meet these ANOVA assumptions. mWAVI included negative values and was log-transformed after adding a small value to make them positive. The interaction between DOMVEG_GRP and month (DOMVEG_GRP*MONTH) was included in the ANOVA analysis. 
To evaluate the impact of the three different scales of collecting spectral data, EWM spectral profiles were compared from the June 2017 data collection when OOW, boatside, and LPR UAS data were collected at the same sites on the same day. A singlefactor ANOVA was applied to each band, ratio, and index to evaluate if any of the means were significantly different. Input values were transformed in the same way as the multiyear boatside ANOVA. If the ANOVA indicated that at least one group mean was different at the $p=0.05$ level based on spectral data collection method, then Tukey's honestly significant difference (TukeyHSD) test and the Tukey-Kruskal test were applied to see which group mean pairings were different (UAS versus BOATSIDE, OOW versus BOATSIDE, and OOW versus UAS). The TukeyHSD, also known as the Tukey-Kramer method, is for performing multiple pairwise comparisons between all group means (Whitlock and Schluter 2015). While it can be used when sample sizes are different for groups being tested, this makes it conservative (i.e., harder to reject the null hypothesis of no difference in group means) (Whitlock and Schluter 2015). To account for this, the Tukey-Kruskal procedure was used, which performs a version of TukeyHSD procedure that works for unequal sample sizes (Higgins 2004). These tests were performed in R.

\subsection{Results and Discussions}

\subsubsection{Out-of-Water Spectral Data Results}

To first address the question of whether different SAV species appear spectrally different, we compared OOW spectral profiles. For 2015 to 2017, we collected a total of 78 OOW spectral profiles after averaging. The June 2015 OOW spectral data, collected at the Pike Bay study area, included one sample each of Nymphaea odorata (white water-lily), Vallisneria americana (eel grass), Potamogeton richardsonii (clasping-leaf pondweed), Nuphar advena (spatterdock), Certophyllum demersum (coontail), Sparganium fluctuans (floating bur-reed), Elodea canadensis (common waterweed), and EWM. The OOW spectral reflectance data for June 2017 were collected at the Howells Dock study area in the Les Cheneaux Islands and included profiles for two EWM samples, and one each of Potamogeton robbinsii (fern-leaf pondweed or Robbins' pondweed), Potamogeton richardsonii (clasping-leaf pondweed), Chara spp. (muskgrass), M. sibiricum (northern watermilfoil), Potamogeton praelongus (white-stemmed pondweed), and Potamogeton gramineus (variable-leaf pondweed), plus a matte black background tarp for reference.

Figures 2.4(a) and 2.4(b) show examples of OOW spectral data from 350 to $1000 \mathrm{~nm}$ collected with the ASD Fieldspec 3. Applying the K-S test to these datasets, the EWM OOW sample from 2015 was significantly different than all other vegetation types when using all 651 spectral bands at the $p<0.001$ level. Similarly, both 2017 EWM spectral samples [EWM1 and EWM2 in Fig. 2.4(b)] were also significantly different than all other vegetation types and each other, at the $p<0.001$ level.

For the June 2015 dataset resampled to the Tetracam bands [Fig. 2.5(a)], the EWM sample was significantly different $(p<0.05)$ from the spatterdock and floating bur-reed 
spectral samples but not the white water-lily, eel grass, clasping-leaf pondweed, coontail, or Elodea samples. Using the Becker bands [Fig. 2.5(b)], the EWM sample was not significantly different than any of the other species at the $p<0.05$ level. In Figs. 2.5(a) and 2.5(c), the $720 \mathrm{~nm}$ (red edge) band provides the greatest variation in spectral response. In Figs. 2.5(b) and 2.5(d), all of the Becker NIR bands (732, 812, 824, 836, and $940 \mathrm{~nm}$ ) show relatively clear separation of sampled species. Using the June 2017 OOW spectral data resampled to the Tetracam bands [Fig. 2.5(c)], the two EWM samples only differed significantly from the black reference tarp using the K-S test $(p=0.05)$. They were not significantly different from the curly-leaf pondweed, fern-leaf pondweed, clasping-leaf pondweed, Chara spp., native northern watermilfoil, white-stemmed pondweed, and variable-leaf pondweed spectral samples. There appear to be some groupings at 530 and $550 \mathrm{~nm}$ (the two green bands), with the white-stemmed pondweed, clasping-leaf pond- weed, variable-leaf pondweed, and Chara spectral samples grouping together at higher green values, whereas the two EWM samples (EWM1 and EWM2), curly-leaf pondweed, northern watermilfoil, and fern-leaf pondweed spectral samples group together at lower green reflectance values. Similar to the 2015 data, there is a greater differentiation among species with the $720 \mathrm{~nm}$ (red edge) band [Fig. 2.5(c)]. The same June 2017 OOW dataset resampled to the eight Becker wetlands bands [Fig. 2.5(d)] also did not result in significant differences when comparing the two EWM samples to the other vegetation types using the K-S test. The same groupings occur as in the Tetracam bands, with white-stemmed pondweed, clasping-leaf pondweed, variable-leaf pondweed, and Chara having higher $560 \mathrm{~nm}$ (green) reflectance values, and curly-leaf, both EWM samples, northern watermilfoil, and fern-leaf having lower $560 \mathrm{~nm}$ values. There is a greater separation between values at the Becker red edge bands (centered at $732 \mathrm{~nm}$ rather than the Tetracam's 720-nm red edge wavelength). 


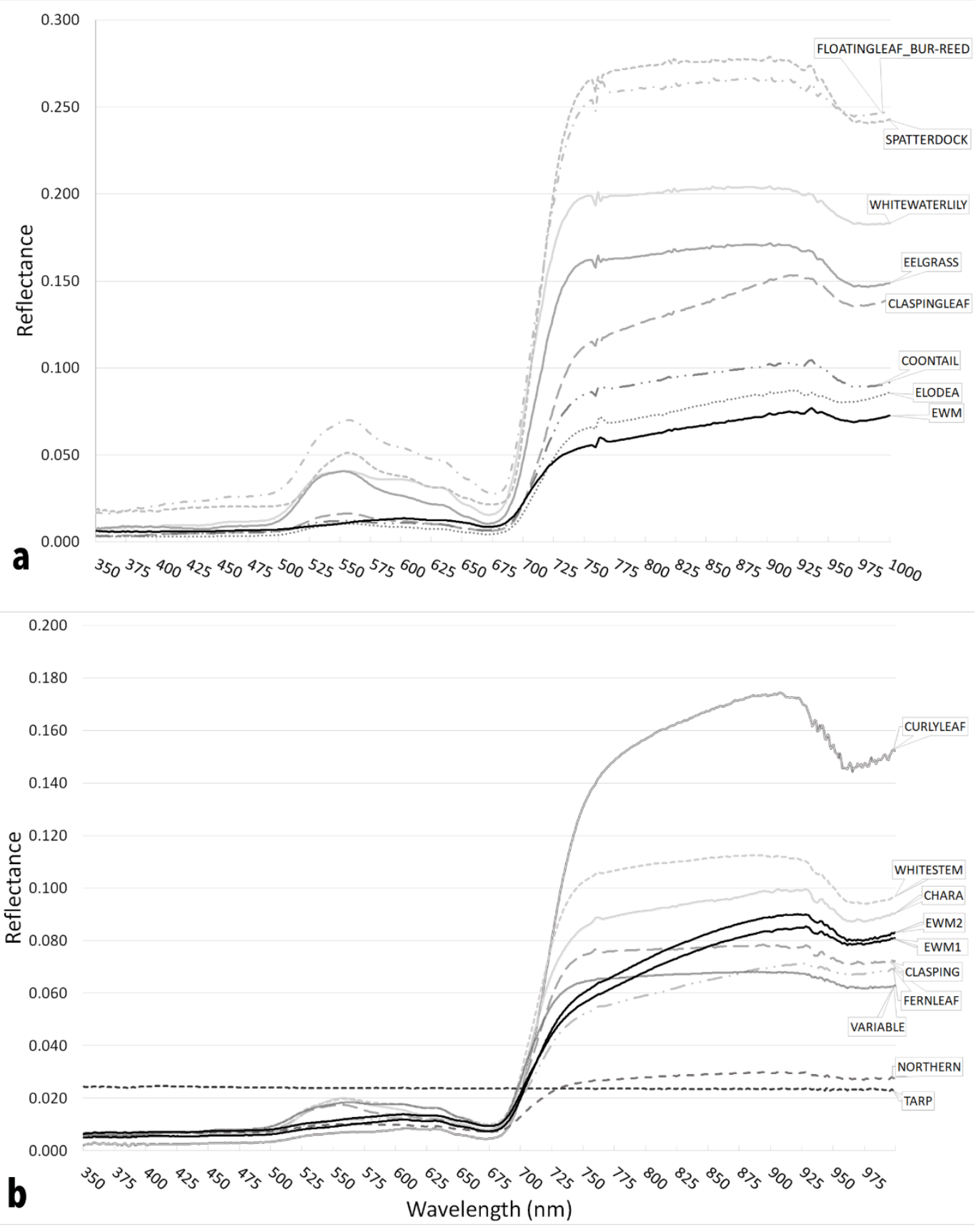

Figure 2.4. OOW spectral data: (a) Spectral profiles of eight OOW aquatic plant species from June 2015, showing ultraviolet to near-infrared (350 to $1000 \mathrm{~nm}$ ) wavelengths for all 651 bands. (b) Spectral profiles for nine aquatic plant species, plus a reference tarp, from June 2017, showing all 651 one-nm wide bands. 


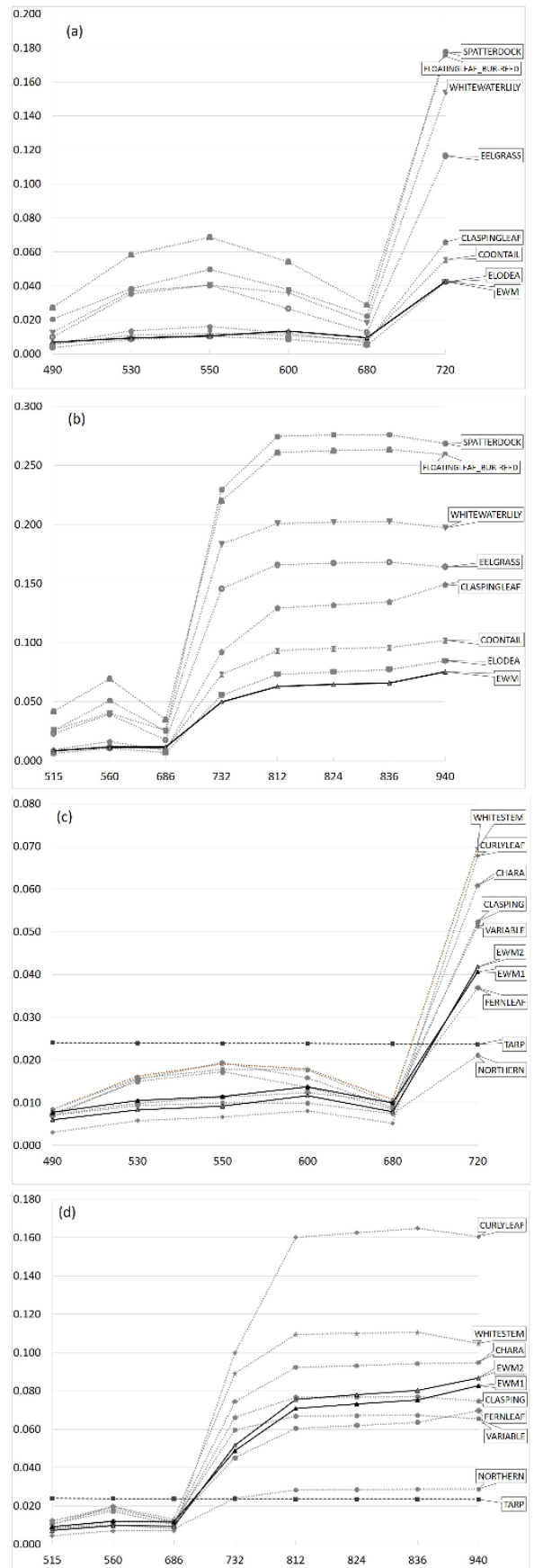

Figure 2.5. Resampled spectral reflectance values for Tetracam and Becker bands: (a) Resampled to approximate the Tetracam bands for the eight OOW species samples collected in 2015, (b) resampled to the Becker bands for the $2015 \mathrm{OOW}$ data, (c) spectral reflectance values for the Tetracam wavelengths for the nine OOW species collected in June 2017, and (d) spectral reflectance values for the Becker wetland bands for the nine OOW species collected in June 2017. 
Using 65 bands and the June 2017 OOW, ASD-collected dataset yielded the K-S results shown in Table 2.2.

This analysis suggested that EWM1 was significantly different from six of the seven other SAV species, the other EWM sample (EWM2), and a black reference tarp, with varying levels of significance. EWM1 was not significantly different from the Claspingleaf pondweed. EWM2 was different from all seven vegetation species and the reference tarp. With both EWM samples being different than nearly all other vegetation samples, this supports the idea that hyperspectral sensing with a number of bands of similar to the 65 average bands tested here may be a reliable way of identifying SAV to species, including invasive aquatic plants such as EWM.

Table 2.2. K-S test of June 2017 OOW spectral data averaged to 6510 -nm-wide bands.

\begin{tabular}{|c|c|c|c|c|c|c|c|c|}
\hline $\begin{array}{l}\text { Tested } \\
\text { profile }\end{array}$ & Species profile & $p$-Value & $D$ & & $\begin{array}{l}\text { Tested } \\
\text { profile }\end{array}$ & Species profile & $p$-Value & $D$ \\
\hline \multirow{9}{*}{$\sum_{-1}^{\infty}$} & CURLYLEAF & 0.0000209 & 0.4 & $* * *$ & \multirow{9}{*}{$\sum_{-1}^{\infty}$} & CURLYLEAF & 0.0000209 & $0.4 * * *$ \\
\hline & FERNLEAF & 0.00746 & 0.3 & $* *$ & & FERNLEAF & 0.00211 & $0.3 * *$ \\
\hline & EWM2 & 0.03858 & 0.2 & $*$ & & EWM1 & 0.03858 & $0.2 *$ \\
\hline & CLASPING & 0.0625 & 0.20 & & & CLASPING & 0.0133 & $0.3 *$ \\
\hline & CHARA & 0.0001122 & 0.45 & $* * *$ & & CHARA & 0.0133 & $0.3 *$ \\
\hline & NORTHERN & 0.00000336 & 0.4 & $*$ & & NORTHERN & 0.00000336 & $0.4 * * *$ \\
\hline & WHITESTEM & 0.0000209 & 0.4 & $* * *$ & & WHITESTEM & 0.0000209 & $0.4 * * *$ \\
\hline & VARIABLE & 0.004037 & 0.3 & $* *$ & & VARIABLE & 0.00107 & $0.3 * *$ \\
\hline & TARP & $<0.0000001$ & 0.5 & $* * *$ & & TARP & $<0.0000001$ & $0.5 * * *$ \\
\hline
\end{tabular}

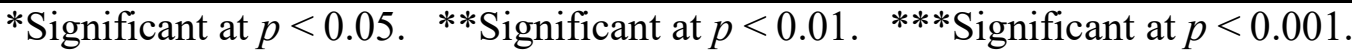

\subsubsection{Boatside Spectral Data Results}

Figure 2.6 represents boatside spectral data collected at three locations in the Les Cheneaux Islands study location in August 2016, a part of the 62 total spectral profiles collected in 2016 to 2017. The site with mostly bare rock beneath the ASD had higher reflectance than the vegetated areas, as would be expected. Vegetation types were either mostly EWM (EWM1, EWM2, EWM3, EWM4, and EWM5), a mixture of EWM and eel grass (EWMEELGRASS), or mostly sheathed pondweed (SHEATHEDPONDWEED1 and SHEATHEDPONDWEED2). In all cases, the August 2016 boatside spectral profiles were different from all other spectral profiles at $p<0.001$ when using all collected bands. 


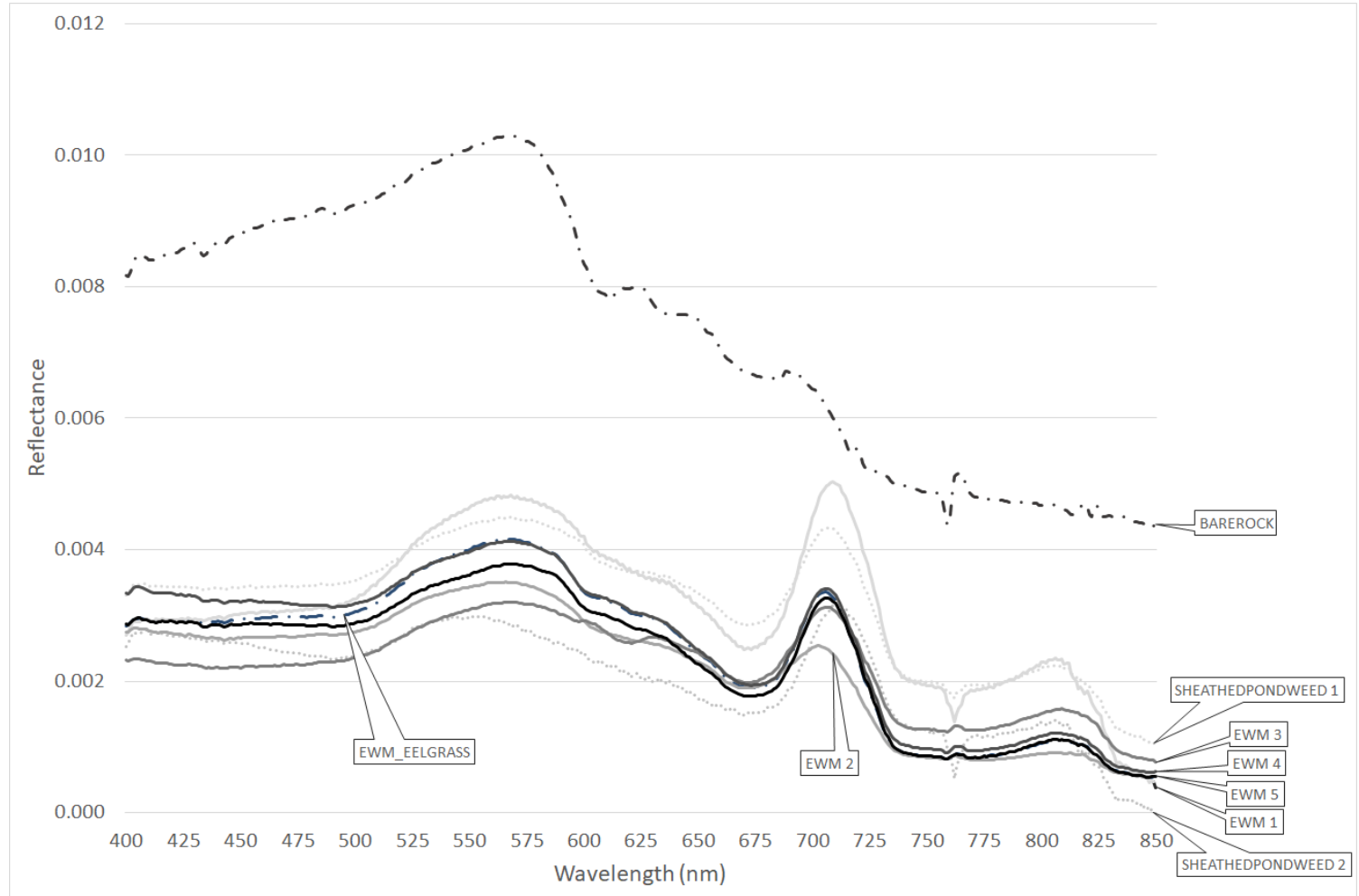

Figure 2.6. Spectral profiles of SAV species and combinations from 2016, collected boatside using the ASD, directly over patches of vegetation in the water.

The results of the two-way ANOVA mixed model analysis of the combined 2016 to 2017 boatside spectral dataset are shown in Table 2.3. 
Table 2.3. Results for the mixed model analysis for each tested wavelength, ratio, and index for the complete 2016 to 2017 boatside dataset with 62 spectral profiles.

\begin{tabular}{|c|c|c|c|c|c|c|}
\hline & \multicolumn{4}{|c|}{$\begin{array}{c}\text { Dependent } \\
\text { variable }\end{array}$} & \multirow[b]{2}{*}{$\operatorname{Pr}>\mathbf{F}$} & \\
\hline & Effect & Num DF & Den DF & F value & & \\
\hline \multirow[t]{3}{*}{$490 \mathrm{~nm}$} & DOMVEG_GRP & 4 & 15.7 & 1.26 & 0.3285 & \\
\hline & MONTH & 2 & 10.6 & 5.53 & 0.0227 & * \\
\hline & DOMVEG_GRP*MONTH & 4 & 9.52 & 1.91 & 0.1888 & \\
\hline \multirow[t]{3}{*}{$530 \mathrm{~nm}$} & DOMVEG_GRP & 4 & 15.3 & 1.22 & 0.3422 & \\
\hline & MONTH & 2 & 10.5 & 6.68 & 0.0135 & * \\
\hline & DOMVEG_GRP*MONTH & 4 & 9.32 & 1.58 & 0.2576 & \\
\hline \multirow[t]{3}{*}{$550 \mathrm{~nm}$} & DOMVEG_GRP & 4 & 15.2 & 1.17 & 0.3637 & \\
\hline & MONTH & 2 & 10.3 & 7.63 & 0.0093 & * \\
\hline & DOMVEG_GRP*MONTH & 4 & 9.09 & 1.47 & 0.2873 & \\
\hline \multirow[t]{3}{*}{$600 \mathrm{~nm}$} & DOMVEG_GRP & 4 & 15.5 & 0.83 & 0.5235 & \\
\hline & MONTH & 2 & 10.1 & 6.8 & 0.0135 & $*$ \\
\hline & DOMVEG_GRP*MONTH & 4 & 8.61 & 1.78 & 0.2198 & \\
\hline \multirow[t]{3}{*}{$680 \mathrm{~nm}$} & DOMVEG_GRP & 4 & 15.9 & 0.64 & 0.6406 & \\
\hline & MONTH & 2 & 9.87 & 4.33 & 0.0446 & * \\
\hline & DOMVEG_GRP*MONTH & 4 & 8.65 & 2.31 & 0.1396 & \\
\hline \multirow[t]{3}{*}{$720 \mathrm{~nm}$} & DOMVEG_GRP & 4 & 15.9 & 0.54 & 0.7055 & \\
\hline & MONTH & 2 & 8.44 & 2.99 & 0.1044 & \\
\hline & DOMVEG_GRP*MONTH & 4 & 6.96 & 2.86 & 0.1072 & \\
\hline \multirow[t]{3}{*}{ RE/BLUE } & DOMVEG_GRP & 4 & 18.6 & 1.22 & 0.3344 & \\
\hline & MONTH & 2 & 18.2 & 0.07 & 0.9348 & \\
\hline & DOMVEG_GRP*MONTH & 4 & 18.0 & 0.90 & 0.4839 & \\
\hline \multirow[t]{3}{*}{ mNDVI } & DOMVEG_GRP & 4 & 17.5 & 3.16 & 0.0402 & $*$ \\
\hline & MONTH & 2 & 17.1 & 1.54 & 0.0135 & \\
\hline & DOMVEG_GRP*MONTH & 4 & 17.0 & 2.00 & 0.2198 & \\
\hline \multirow[t]{3}{*}{ mNDAVI } & DOMVEG_GRP & 4 & 14.9 & 1.35 & 0.2961 & \\
\hline & MONTH & 2 & 15.1 & 0.47 & 0.6358 & \\
\hline & DOMVEG_GRP*MONTH & 4 & 14.9 & 0.77 & 0.5586 & \\
\hline \multirow[t]{3}{*}{ mWAVI } & DOMVEG_GRP & 4 & 23.2 & 0.97 & 0.4415 & \\
\hline & MONTH & 2 & 22.7 & 0.42 & 0.6623 & \\
\hline & DOMVEG_GRP*MONTH & 4 & 22.7 & 0.21 & 0.9319 & \\
\hline
\end{tabular}

*Significant at the $\mathrm{p} 1 / 40.05$ level.

mNDVI was significantly different among dominant vegetation groups (F4;17.5 $=3.16, p$ $=0.04$ ), with no difference among months and no significant interaction between month and dominant vegetation group. The RE/BLUE ratio, mNDAVI, and $\mathrm{mWAVI}$ did not have significant differences among dominant vegetation groups or months and had no significant interactions between month and dominant vegetation group. The logtransformed 490-, 530-, 550-, 600-, and 680-nm variables varied significantly among months, but $720 \mathrm{~nm}$ did not, showing that there is an effect on spectral reflectance depending on whether data were collected in June, July, or August.

To help verify a significant contribution of vegetation to these boatside spectra, we calculated the difference between red edge reflectance $(709 \mathrm{~nm})$ in our spectra and a baseline between 681 and $754 \mathrm{~nm}$, analogous to the MERIS maximum chlorophyll index (MCI) product developed by Gower et al (Gower et al. 2008). Since our original 
classification considered all plots with up to $50 \%$ vegetation cover to belong to the "BARE" class, we also added an additional class of sparse vegetation, "SPARSEVEG," with vegetation percent cover of $25 \%$ to $50 \%$. With this "mixed" class added, we found a distinct difference in MCI values between the EWM and SAV_OTHER classes versus the lower MCI values of the BARE, LOWVEG, and DEEPWATTER classes. The mean values, with standard deviations in parentheses, are SAV OTHER $=0.0012901(\sigma=$ $0.0014205), \mathrm{EWM}=0.0012412(\sigma=0.0017040), \mathrm{BARE}=-0.0000027(\sigma=0.0000932)$, SPARSE VEG $=0.0003125(\sigma=0.0003066)$, LOW VEG $=-0.0000606(\sigma=$ $0.0001971)$, and DEEP WATER $=-0.0001423(\sigma=0.0001133)$.

\subsubsection{UAS Spectral Data Results}

Figure 2.7 shows the complete spectral profiles for the June 2017 UAS data, a part of the 41 total UAS-based spectral profiles collected in 2016 to 2017. The six Tetracam bands were again approximated from the profile data, and the four ratios were added for analysis with the K-S test.

The June 2017 UAS-based data (Fig. 2.7 and Table 2.4) showed that the six samples including significant EWM cover (five with EWM being the most dominant and one dominated by Chara with EWM as a secondary dominant) did appear statistically different than some other vegetation types. For example, the "EWM_SMALL1" (EWM and small-leaf pondweed) sample is significantly different than one of the two Charadominated spectral profiles, and the EWM_CHARA and LOWVEG2 to LOWVEG4 profiles as well. The EWM_SMALL2, EWM_ELODEA, and CURLY_EWM profiles had similar results - they looked different than the two CHARA profiles, the EWM_CHARA, and LOWVEG2 to LOWVEG4 profiles. The EWM spectral profile without a secondary dominant species (EWM) was only different than the second (CHARA2) profile, however. All the "top" spectral data in Figure 2.7 (EWM_ELODEA to LOWVEG1) had to be collected on 2 days when it was $100 \%$ overcast. The "bottom" spectral data in Fig. 2.7 (CHARA2, LOWVEG2, CHARA1, LOWVEG3, and LOWVEG4) were from days when it was $40 \%$ to $60 \%$ cloud cover. There does appear to be an influence of sky conditions here, but with replication already a challenge, we preferred to maintain data whenever possible. 


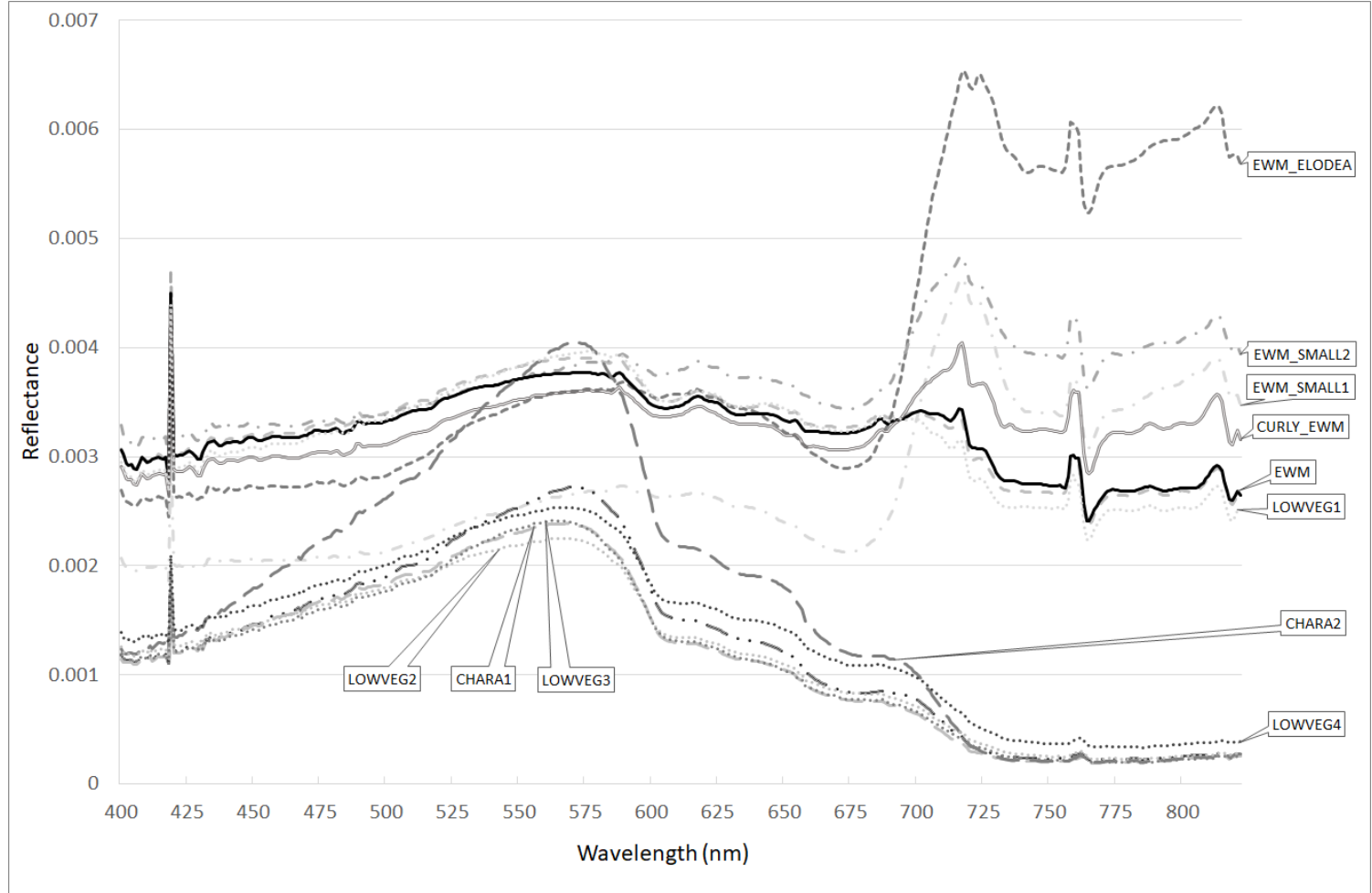

Figure 2.7. Spectral reflectance values for the UAS data collected over 13 areas with multiple species assemblages, sampled in June 2017. 
Table 2.4. K-S test of June 2017 UAS-based spectral data resampled to Tetracam bands plus ratios.

\begin{tabular}{|c|c|c|c|c|c|c|c|}
\hline $\begin{array}{l}\text { Tested } \\
\text { profile }\end{array}$ & Species profile & $p$-Value & $D$ & $\begin{array}{l}\text { Tested } \\
\text { profile }\end{array}$ & Species profile & $p$-Value & $D$ \\
\hline \multirow{13}{*}{$\begin{array}{l}\sum_{2}^{\infty} \\
\exists \\
\sum_{i=1}^{3} \\
\sum_{i=1}^{\prime}\end{array}$} & EWM_SMALL1 & NA & NA & \multirow{13}{*}{ 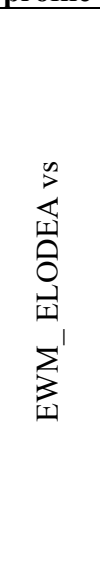 } & EWM_SMALL1 & 0.1678 & 0.5 \\
\hline & EWM_ELODEA & 0.1678 & 0.5 & & EWM_ELODEA & NA & NA \\
\hline & EWM_SMALL2 & 0.1678 & 0.5 & & EWM_SMALL2 & 0.7869 & 0.3 \\
\hline & ELODEA_MIXED & 0.4175 & 0.4 & & ELODEA_MIXED & 0.4175 & 0.4 \\
\hline & LOWVEG1 & 0.4175 & 0.4 & & LOWVEG1 & 0.4175 & 0.4 \\
\hline & CURLY_EWM & 0.4175 & 0.4 & & CURLY_EWM & 0.9945 & 0.2 \\
\hline & EWM & 0.4175 & 0.4 & & EWM & 0.4175 & 0.4 \\
\hline & CHARA1 & 0.01234 & $0.7 *$ & & CHARA1 & 0.0002165 & $0.9 * *$ \\
\hline & CHARA2 & 0.1678 & 0.5 & & CHARA2 & 0.01234 & $0.7 *$ \\
\hline & EWM_CHARA & 0.01234 & $0.7 *$ & & EWM_CHARA & 0.0002165 & $0.9 * *$ \\
\hline & LOWVEEG2 & 0.002017 & $0.8 * * *$ & & LOWVEEG2 & 0.0002165 & $0.9 * *$ \\
\hline & LOWVEG3 & 0.01234 & $0.7^{*}$ & & LOWVEG3 & 0.0002165 & $0.9 * *$ \\
\hline & LOWVEG4 & 0.01234 & $0.7 *$ & & LOWVEG4 & 0.0002165 & $0.9 * *$ \\
\hline \multirow{13}{*}{ 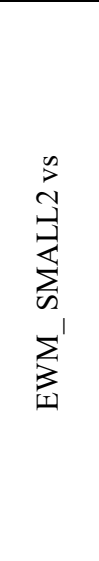 } & EWM_SMALL1 & 0.1678 & 0.5 & \multirow{13}{*}{ 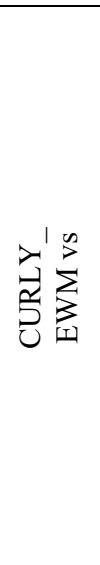 } & EWM_SMALL1 & 0.4175 & 0.4 \\
\hline & EWM_ELODEA & 0.7869 & 0.3 & & EWM_ELODEA & 0.9945 & 0.2 \\
\hline & EWM_SMALL2 & & NA & & EWM_SMALL2 & 0.4175 & 0.4 \\
\hline & ELODEA_MIXED & 0.05245 & 0.6 & & ELODEA_MIXED & 0.7869 & 0.3 \\
\hline & LOWVEG1 & 0.05245 & 0.6 & & LOWVEG1 & 0.7869 & 0.3 \\
\hline & CURLY_EWM & 0.4175 & 0.4 & & CURLY_EWM & & NA \\
\hline & EWM & 0.05245 & 0.6 & & EWM & 0.7869 & 0.3 \\
\hline & CHARA1 & 0.0002165 & $* *$ & & CHARA1 & 0.002057 & $0.8 * * *$ \\
\hline & CHARA2 & 0.002057 & $0.8 * * *$ & & CHARA2 & 0.002057 & $0.8 * * *$ \\
\hline & EWM_CHARA & 0.0002165 & $0.9 * *$ & & EWM_CHARA & 0.002057 & $0.8 * * *$ \\
\hline & LOWVEG2 & 0.0002165 & $0.9 * *$ & & LOWVEG2 & 0.002057 & $0.8 * * *$ \\
\hline & LOWVEG3 & 0.0002165 & $0.9 * *$ & & LOWVEG3 & 0.002057 & $0.8 * * *$ \\
\hline & LOWVEG4 & 0.0002165 & $0.9 * *$ & & LOWVEG4 & 0.002057 & $0.8 * * *$ \\
\hline \multirow{13}{*}{$\sum_{i=1}^{\infty}$} & EWM_SMALL1 & 0.4175 & 0.4 & \multirow{13}{*}{ 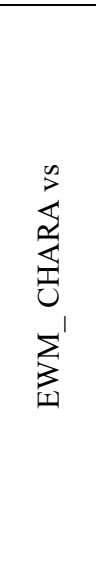 } & EWM_SMALL1 & 0.01234 & $0.7 *$ \\
\hline & EWM_ELODEA & 0.4175 & 0.4 & & EWM_ELODEA & 0.0002165 & $0.9 * *$ \\
\hline & EWM_SMALL2 & 0.05245 & 0.6 & & EWM_SMALL2 & 0.0002165 & $0.9 * *$ \\
\hline & ELODEA_MIXED & 0.9945 & 0.2 & & ELODEA_MIXED & 0.05245 & 0.6 \\
\hline & LOWVEG1 & 0.9945 & 0.2 & & LOWVEG1 & 0.05245 & 0.6 \\
\hline & CURLY_EWM & 0.7869 & 0.3 & & CURLY_EWM & 0.002057 & $0.8 * * *$ \\
\hline & EWM & & NA & & EWM & 0.05245 & 0.6 \\
\hline & CHARA1 & 0.05245 & 0.6 & & CHARA1 & 0.9945 & 0.2 \\
\hline & CHARA2 & 0.002057 & $0.8 * * *$ & & CHARA2 & 0.7869 & 0.3 \\
\hline & EWM_CHARA & 0.05245 & 0.6 & & EWM_CHARA & NA & NA \\
\hline & LOWVEG2 & 0.05245 & 0.6 & & LOWVEG2 & 0.9945 & 0.2 \\
\hline & LOWVEG3 & 0.05245 & 0.6 & & LOWVEG3 & 0.9945 & 0.2 \\
\hline & LOWVEG4 & 0.05245 & 0.6 & & LOWVEG4 & 0.9945 & 0.2 \\
\hline
\end{tabular}

Note: NA, not applicable (same profile).

*Significant at $p<0.05$. ${ }^{* *}$ Significant at $p<0.01$. ${ }^{* * *}$ Significant at $p<0.001$.

We hypothesized that the July 2017 spectral data might show a more distinct pattern for EWM, because the vegetation would be more fully developed (taller, denser) a month later than the relatively early in the growing season June 2017 data. Also, the June 
samples were collected during overcast days, whereas most of the July samples were collected on sunny days. However, as shown in Table 2.5, areas with significant amounts of EWM only looked different than one of the OPEN areas, and then only for three of the four EWM-dominated areas.

\subsubsection{Comparison of Spectral Profile Results across Scale-Based Collection Methods}

In the June 2017 data collection, all three methods of spectral data collection were deployed. This enabled comparison of the EWM spectral data (shown in Table 2.6) at three different scales, using the single-factor ANOVA, TukeyHSD, and Tukey-Kramer methods, as previously described. Figure 2.8 shows the spectral profiles for the six tetracam bands, and the ratios/indices used across analyses.

In Fig. 2.8(a), there is a clear difference between the relatively low reflectance values for EWM seen in the OOW spectra and the higher values for the boatside and UAS spectra. Table 2.6 shows the UAS reflectance for the six Tetracam bands average $13.3 \%$ of the boatside reflectance and $27.4 \%$ of the OOW values. For the ratio and indices, UAS values average $38.6 \%$ of the boatside values and $12.0 \%$ of the OOW values. The boatside reflectance values are generally greater than the OOW values (an average of $202.2 \%$ for the six Tetracam bands) but are lower (32.7\% average) for the ratio and indices.

Table 2.7 shows the results of comparing EWM spectral reflectance values for the three spectral data collection methods. For all of the Tetracam wavelengths and the RE/BLUE ratio, the means of the groups were not equal (see ANOVA results for $p$-values in bold). Since the null hypothesis of equal group means could not be rejected for the mNDVI, mNDAVI, and mWAVI indices, it was not appropriate to apply the post-hoc TukeyHSD or Tukey-Kruskal procedures to these data. Using the TukeyHSD procedure, the UAS versus boatside group means were consistently different for the 490- to 720-nm Tetracam wavelengths but not for the RE/BLUE ratio. OOW versus UAS group means were sometimes different for the 530-, 550-, 600-, and 720-nm wave- lengths, and the RE/BLUE ratio but not for 490- or 680-nm wavelengths. OOW versus boatside group means were only different for the RE/BLUE ratio in the TukeyHSD results. The UAS versus boatside results were similar for the Tukey-Kruskal results with 490- to 680-nm group means being different but not for $720 \mathrm{~nm}$. None of the OOW versus boatside and OOW versus UAS group means were different using Tukey-Kruskal. 
Table 2.5. K-S test of July 2017 UAS-based spectral data resampled to Tetracam bands plus ratios.

\begin{tabular}{|c|c|c|c|c|c|c|c|}
\hline $\begin{array}{l}\text { Tested } \\
\text { profile }\end{array}$ & Species profile & $p$-Value & $D$ & $\begin{array}{l}\text { Tested } \\
\text { profile }\end{array}$ & Species profile & $p$-Value & $D$ \\
\hline & OPEN EWM1 & NA & NA & & OPEN EWM1 & 0.4175 & 0.4 \\
\hline & EWM & 0.4175 & 0.4 & & EWM & NA & NA \\
\hline $1>^{\infty}$ & CHARA & 0.4175 & 0.4 & $\infty$ & CHARA & 0.4175 & 0.4 \\
\hline$z_{1} \bar{\Sigma}$ & ELODEA_EWM & 0.9945 & 0.2 & $\sum$ & ELODEA_EWM & 0.4175 & 0.4 \\
\hline 03 & ELODEA_FLATSTEM & 0.9945 & 0.2 & 3 & ELODEA_FLATSTEM & 0.4175 & 0.4 \\
\hline & OPEN1 & 0.05245 & 0.6 & & OPEN1 & 0.1678 & 0.5 \\
\hline & OPEN EWM2 & 0.4175 & 0.4 & & OPEN EWM2 & 0.4175 & 0.4 \\
\hline & OPEN2 & 0.4175 & 0.4 & & OPEN2 & 0.002017 & $0.8 * *$ \\
\hline & OPEN_EWM1 & 0.9945 & 0.2 & & OPEN_EWM1 & 0.4175 & 0.4 \\
\hline & EWM & 0.4175 & 0.4 & & EWM & 0.4175 & 0.4 \\
\hline$\ll$ & CHARA & 0.4175 & 0.4 & $7^{1} i^{\infty}$ & CHARA & 0.1678 & 0.5 \\
\hline$\Sigma$ & ELODEA_EWM & NA & NA & $\mathrm{Z}_{1} \mathrm{I}$ & ELODEA_EWM & 0.1678 & 0.5 \\
\hline 03 & ELODEA_FLATSTEM & 0.4175 & 0.3 & 皮 & ELODEA_FLATSTEM & 0.1678 & 0.5 \\
\hline & OPEN1 & 0.05245 & 0.6 & & OPEN1 & 0.05245 & 0.6 \\
\hline & OPEN_EWM2 & 0.1678 & 0.5 & & OPEN_EWM2 & NA & NA \\
\hline & OPEN2 & 0.002057 & $0.8 * *$ & & OPEN2 & 0.002057 & $0.8 * *$ \\
\hline
\end{tabular}

Note: NA, not applicable (same profile). ${ }^{*}$ Significant at $\mathrm{p}<0.05 . \quad * *$ Significant at $\mathrm{p}<$ 0.01 . $* * *$ Significant at $\mathrm{p}<0.001$.

\subsubsection{Discussion of Spectral Profile Results and Analysis}

For all tested datasets, using all available 1-nm bands resulted in spectral profiles being different (for example, for the OOW data in Fig. 2.4 and boatside data in Fig. 2.6).

However, deploying an imaging system for mapping in the field that would use over 600 bands is not yet practical. By contrast, using only the Tetracam or Becker bands rarely resulted in EWM being distinguished reliably from other vegetation (Fig. 2.5). One of the UAS datasets, from June 2017, did show that using the Tetracam bands plus the RE/BLUE, mNDVI, mNDAVI, and mWAVI indices could differentiate EWM in 6 of 12 vegetation type comparisons (Table 2.4 ).

This could not be repeated in a similar dataset from a month later (Table 2.5). An analysis of 65 bands (the 651 bands from a June 2017 OOW dataset averaged to 10-nm wide) did show reliable separability of EWM from eight other vegetation spectral profiles including seven different species (Table 2.2). With hyperspectral imaging systems capable of 40 to 80 bands reaching costs of US $\$ 25,000$ to $\$ 40,000$, this level of band imaging may be more practical for deployment in EWM mapping and monitoring efforts.

For distinguishing EWM from other vegetation, the ANOVA mixed model analysis showed that the mNDVI ratio is important (Table 2.3) but that individual Tetracam bands or the RE/BLUE ratio and aquatic-specific mNDAVI and $\mathrm{mWAVI}$ indices were not 
helpful. As noted, NDVI was originally developed as a method of identifying areas of relatively lower or higher green biomass for terrestrial systems in satellite imagery using NIR and red bands. It appears that the spectral profiling is picking up different amounts of biomass even for submerged aquatic vegetation, where light penetration in the rededge to NIR range is limited relative to visible light bands. With mNDVI proving important to EWM detection, we compared the values of the available 720-nm red-edge band to the infrared band of $780 \mathrm{~nm}$ for all the boatside data collections. The relationships between 720 and $780 \mathrm{~nm}$ are nearly linear, with all showing a strong $R^{2}$ value, especially for August $2016\left(R^{2}=0.8681\right)$, June $2017\left(R^{2}=0.9979\right)$, July $2017\left(R^{2}=\right.$ $0.9548)$, and August $2017\left(R^{2}=0.9832\right)$. Only July 2016 falls below 0.85 , which a value of $R^{2}=0.7450$. Based on these results, $720 \mathrm{~nm}$ appears to be a reasonable substitute for $780 \mathrm{~nm}$ for NDVI-type calculations.

A comparison of EWM spectral profiles across the OOW, boatside, and UAS scales of data collection showed significantly lower $R_{\mathrm{rs}}$ values for the UAS method versus the OOW and boatside methods (Table 2.6). The lower values for the UAS are probably caused by the greater distance to the spectroradiometer sensor (10 to $15 \mathrm{~m}$ from the UAS) compared to the OOW and boatside data, where the sensor is very close (one $\mathrm{m}$ or less) to the vegetation being sampled. This could mean that it is harder to identify species when 10 to $15 \mathrm{~m}$ in the air versus sensing from boatside scales. Maximizing the amount of information reaching an UAS-based imaging sensor by collecting on sunny days, near solar noon, and with relatively calm waters should help minimize the impact of this more distant method of vegetation profiling. These methods can help take advantage of the ability of UAS to cover larger areas than boat-based sampling in a relatively short amount of time.

The comparison of EWM spectra across the three data collection methods indicated that the spectral results are different for the Tetracam bands and the RE/BLUE ratio but not for the mNDVI, mNDAVI, and mWAVI indices (Table 2.7). For the Tetracam wavelengths, the average values are different for most wavelengths versus the OOW and boatside scale. The OOW and boatside data appear to be similar for EWM samples across scales. With the mNDVI, mNDAVI, and mWAVI indices not being significantly different, this suggests that these values may be scale independent and more appropriate for EWM identification than relying on spectral bands alone. Tying these results together with the boatside ANOVA mixed model results, mNDVI again appears important for reliable EWM identification. 
Table 2.6. Input data used for analysis of EWM spectral data collected at the OOW, boatside, and UAS scales, with comparison of averages by collection method.

\begin{tabular}{|c|c|c|c|c|c|c|c|c|c|c|c|c|c|c|}
\hline Species & \multicolumn{3}{|c|}{ Scale and site } & & 490 & 530 & $\mathbf{5 5 0}$ & 600 & 680 & 720 & RE_BLUE & NDVI & NDAVI & WAVI \\
\hline EWM SMALL1 & \multicolumn{3}{|c|}{ UAS - COURTEAST (1) } & & 0.00210 & 0.00241 & 0.00254 & 0.00265 & 0.00218 & 0.00448 & 2.1322 & 0.34510 & 0.36147 & 0.00705 \\
\hline EWM_ELODEA & \multicolumn{3}{|c|}{ UAS - COURTEAST (2) } & & 0.00279 & 0.00327 & 0.00348 & 0.00356 & 0.00296 & 0.00645 & 2.3123 & 0.37060 & 0.39619 & 0.01078 \\
\hline EWM_SMALL2 & \multicolumn{3}{|c|}{ UAS - COURTEAST (3) } & & 0.00336 & 0.00361 & 0.00372 & 0.00378 & 0.00349 & 0.00467 & 1.3903 & 0.14552 & 0.16327 & 0.00387 \\
\hline EWM & \multicolumn{3}{|c|}{ UAS - FDS } & & 0.00329 & 0.00360 & 0.00371 & 0.00350 & 0.00326 & 0.00321 & 0.9762 & -0.00715 & -0.01204 & -0.00023 \\
\hline EWM_CHARA & \multicolumn{3}{|c|}{ UAS - NEIL } & & 0.00182 & 0.00231 & 0.00254 & 0.00179 & 0.00084 & 0.00037 & 0.2048 & -0.38486 & -0.65999 & -0.00432 \\
\hline & \multicolumn{3}{|c|}{ Average } & & 0.00267 & 0.00304 & 0.00320 & 0.00306 & 0.00254 & 0.00384 & 1.4032 & 0.09384 & 0.04978 & 0.00343 \\
\hline EWM & \multicolumn{3}{|c|}{ BOATSIDE - COURTEAST } & & 0.03561 & 0.04086 & 0.04295 & 0.04780 & 0.03887 & 0.09122 & 2.5614 & 0.40239 & 0.43842 & 0.13306 \\
\hline EWM & \multicolumn{3}{|c|}{ BOATSIDE - COURTEAST } & & 0.01053 & 0.01173 & 0.01233 & 0.01349 & 0.01132 & 0.02148 & 2.0397 & 0.30993 & 0.34205 & 0.03087 \\
\hline EWM & \multicolumn{3}{|c|}{ BOATSIDE - COURTEAST } & & 0.00672 & 0.00784 & 0.00830 & 0.00899 & 0.00731 & 0.01817 & 2.7053 & 0.42591 & 0.46024 & 0.03273 \\
\hline EWM & \multicolumn{3}{|c|}{ BOATSIDE - FDS } & & 0.01586 & 0.01714 & 0.01773 & 0.01662 & 0.01482 & 0.01376 & 0.8673 & -0.03710 & -0.07104 & -0.00596 \\
\hline EWM & \multicolumn{3}{|c|}{ BOATSIDE - NEIL } & & 0.02843 & 0.03009 & 0.03096 & 0.02862 & 0.02548 & 0.02384 & 0.8385 & -0.03327 & -0.08783 & -0.01247 \\
\hline & \multicolumn{3}{|c|}{ Average } & & 0.01943 & 0.02153 & 0.02245 & 0.02310 & 0.01956 & 0.03369 & 1.8025 & 0.21357 & 0.21637 & 0.03565 \\
\hline$\overline{\text { EWM1 }}$ & \multirow{2}{*}{\multicolumn{3}{|c|}{$\begin{array}{l}\text { OOW - COURTEAST } \\
\text { OOW - HOWELLSDOCK }\end{array}$}} & & 0.00774 & 0.01048 & 0.01144 & 0.01368 & 0.00994 & 0.04062 & 5.2456 & 0.60682 & 0.67978 & 0.08992 \\
\hline EWM2 & & & & & 0.00597 & 0.00833 & 0.00918 & 0.01166 & 0.00790 & 0.04181 & 7.0015 & 0.68229 & 0.75005 & 0.09814 \\
\hline & \multicolumn{3}{|c|}{ Average } & & 0.00686 & 0.00941 & 0.01031 & 0.01267 & 0.00892 & 0.04121 & 6.1236 & 0.64456 & 0.71491 & 0.09403 \\
\hline $\begin{array}{l}\text { Comparison } \\
\text { (average) }\end{array}$ & 490 & 530 & 550 & 600 & 680 & 720 & RE BLUE & mNDVI & mNDAVI & mWAVI & $\begin{array}{l}\text { Average } \\
\text { all }\end{array}$ & $\begin{array}{c}\text { Average } \\
6 \\
\text { Tetracam }\end{array}$ & \multicolumn{2}{|c|}{$\begin{array}{c}\text { Average RE_BLUE, } \\
\text { mNDVI, mNDAVI, } \\
\text { mWAVI }\end{array}$} \\
\hline $\begin{array}{l}\text { UAS average } \\
\text { versus }\end{array}$ & $13.7 \%$ & $14.1 \%$ & $14.2 \%$ & $13.2 \%$ & $13.0 \%$ & $11.4 \%$ & $77.8 \%$ & $43.9 \%$ & $23.0 \%$ & $9.6 \%$ & $23.4 \%$ & $13.3 \%$ & \multicolumn{2}{|c|}{$38.6 \%$} \\
\hline $\begin{array}{l}\text { UAS average } \\
\text { versus OOW }\end{array}$ & $39.0 \%$ & $32.3 \%$ & $31.0 \%$ & $24.1 \%$ & $28.5 \%$ & $9.3 \%$ & $22.9 \%$ & $14.6 \%$ & $7.0 \%$ & $3.6 \%$ & $21.2 \%$ & $27.4 \%$ & \multicolumn{2}{|c|}{$12.0 \%$} \\
\hline $\begin{array}{l}\text { BOATSIDE } \\
\text { versus OOW }\end{array}$ & $283.4 \%$ & $228.9 \%$ & $217.8 \%$ & $182.3 \%$ & $219.4 \%$ & $81.8 \%$ & $29.4 \%$ & $33.1 \%$ & $30.3 \%$ & $37.9 \%$ & $134.4 \%$ & $02.2 \%$ & \multicolumn{2}{|c|}{$32.7 \%$} \\
\hline
\end{tabular}


Table 2.7. Results of the ANOVA, Tukey HSD, and Tukey-Kruskal procedures to test for differences between group means by wavelength, index, and ratio.

\begin{tabular}{|c|c|c|c|c|c|c|c|c|c|c|}
\hline \multicolumn{11}{|c|}{ ANOVA results } \\
\hline Band & $490 \mathrm{~nm}$ & $530 \mathrm{~nm}$ & $550 \mathrm{~nm}$ & $600 \mathrm{~nm}$ & $680 \mathrm{~nm}$ & $720 \mathrm{~nm}$ & RE_BLUE & NDVI & NDAVI & WAVI \\
\hline $\mathrm{p}$-value & 0.0009 & 0.0007 & 0.0006 & 0.0005 & 0.0016 & 0.0050 & 0.0005 & 0.0847 & 0.1180 & 0.1130 \\
\hline F statistic & $\begin{array}{l}\mathrm{F}_{2,9}=16.98 \\
* * *\end{array}$ & $\begin{array}{l}\mathrm{F}_{2,9}=18.22 \\
* * *\end{array}$ & $\begin{array}{l}\mathrm{F}_{2,9}=18.72 \\
* * *\end{array}$ & $\begin{array}{l}\mathrm{F}_{2,9}=19.82 \\
* * *\end{array}$ & $\begin{array}{l}\mathrm{F}_{2,9}=14.33 \\
* *\end{array}$ & $\begin{array}{l}\mathrm{F}_{2,9}=10.12 \\
* *\end{array}$ & $\begin{array}{l}\mathrm{F}_{2,9}=19.96 \\
* * *\end{array}$ & $\mathrm{~F}_{2,9}=3.289$ & $\mathrm{~F}_{2,9}=2.742$ & $\mathrm{~F}_{2,9}=2.805$ \\
\hline \multicolumn{11}{|c|}{ Tukey HSD results } \\
\hline Comparison & p-adjusted & & & & & & & & & \\
\hline LPR UAV vs. & & & & & & & & & & \\
\hline $\begin{array}{l}\text { BOATSIDE } \\
\text { OOW vs. }\end{array}$ & 0.0007 & 0.0005 & 0.0005 & 0.0004 & 0.0013 & 0.0092 & 0.7808 & NA & NA & NA \\
\hline BOATSIDE & 0.1464 & 0.2707 & 0.3076 & 0.5607 & 0.4531 & 0.8180 & 0.0009 & NA & NA & NA \\
\hline OOW vs. LPR UAS & 0.1051 & 0.0440 & 0.0350 & 0.0146 & 0.0538 & 0.0153 & 0.0005 & NA & NA & NA \\
\hline \multicolumn{11}{|c|}{ Tukey-Kruskal method results } \\
\hline Comparison & Reject Ho? & & & & & & & & & \\
\hline $\begin{array}{l}\text { LPR UAV vs. } \\
\text { BOATSIDE } \\
\text { OOW vs. }\end{array}$ & Yes & Yes & Yes & Yes & Yes & No & No & NA & NA & NA \\
\hline BOATSIDE & No & No & No & No & No & No & No & NA & NA & NA \\
\hline OOW vs. LPR UAS & No & No & No & No & No & No & No & NA & NA & NA \\
\hline
\end{tabular}

Note: Bold $=$ significant at adjusted $p$-value $=0.05 . \mathrm{NA}=$ Not applicable since ANOVA Ho not rejected

$*$ significant at $\mathrm{p}=0.05$

$* *$ significant at $\mathrm{p}=0.01$

$* * *=$ significant at $\mathrm{p}=0.00$ 


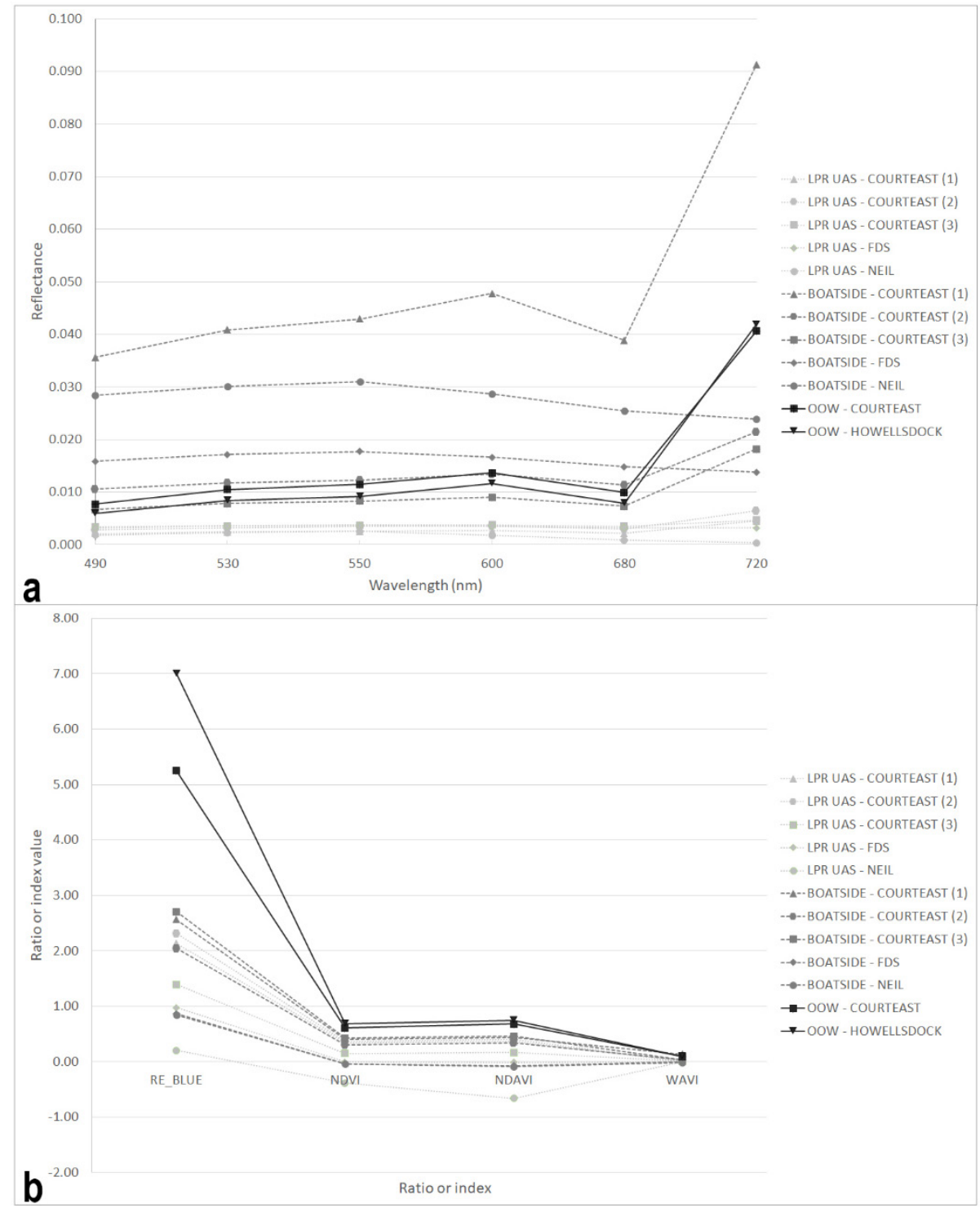

Figure 2.8. Comparison of spectral profiles for June 2017 across three methods of sampling: (a) for the six tetracam bands and (b) for the ratio and indices.

\subsubsection{Research Directions}

Related research is underway to use the methods and results described here to develop an EWM mapping algorithm and apply it for mapping EWM extent for nearshore locations in the Laurentian Great Lakes region. The EWM algorithm combined with the UASbased platform is intended to provide a monitoring tool for evaluating the effectiveness of EWM treatment methods (such as herbicide spraying, mechanical harvesting, and biocontrol) and for investigating areas at risk of invasion or reoccurrence. 
To move this research direction forward, a preliminary proof-of-concept example of mapping EWM from a UAS-collected image was completed, pending development of the spectrally-based EWM-specific algorithm. As noted above, with the UAS flights, $5 \mathrm{mp}$ images were taken over the area, where the OceanOptics spectral data were being recorded to help record the footprint of the LPR sensor. Figure 2.9 shows one of those images analyzed using Trimble eCognition object- based image classification software (Trimble Inc., Sunnyvale, California), where EWM formed the dominant visible SAV. Images were location tagged using global position system data with height recorded, and based on the known sensor size, we could, therefore, appropriately scale the images in ESRI Desktop ArcGIS software, version 10.5.1. Using the visible RGB imagery data from the LPR system's digital photos, it was possible to differentiate the image into water, shallower submerged EWM (dark green), deeper areas of SAV that were most likely EWM (grey) and water (blue), with some small surface floating non-EWM vegetation also identified. These results show promise for extending them to a larger mapping effort covering the Les Cheneaux Islands and similar areas, at least for where EWM is spectrally different than surrounding cover types.

Another research direction is accounting for the impact of water characteristics on the identification of EWM versus other SAV species. As part of the larger project study, data on light conditions and water characteristics have been collected on the same days as the spectral profile data, generally within $2 \mathrm{~h}$ of the spectral collections. For mapping SAV, it is likely to be important to consider the impacts of the attenuating and backscattering features of water that reduce the strength of the plant species' spectral signature versus standard terrestrial spectrometry. Nearshore "case 2" waters can be complex, with chlorophyll, color dissolved organic matter, and suspended minerals dominating the water color constituents (Morel and Prieur 1977, Shuchman et al. 2013b). These can cause significant attenuation of the remote sensing signal from underwater features. Understanding how water chemistry and light characteristics are affecting the vegetation signal reaching the remote sensors is an important consideration for SAV mapping research and will be addressed in the related research. 


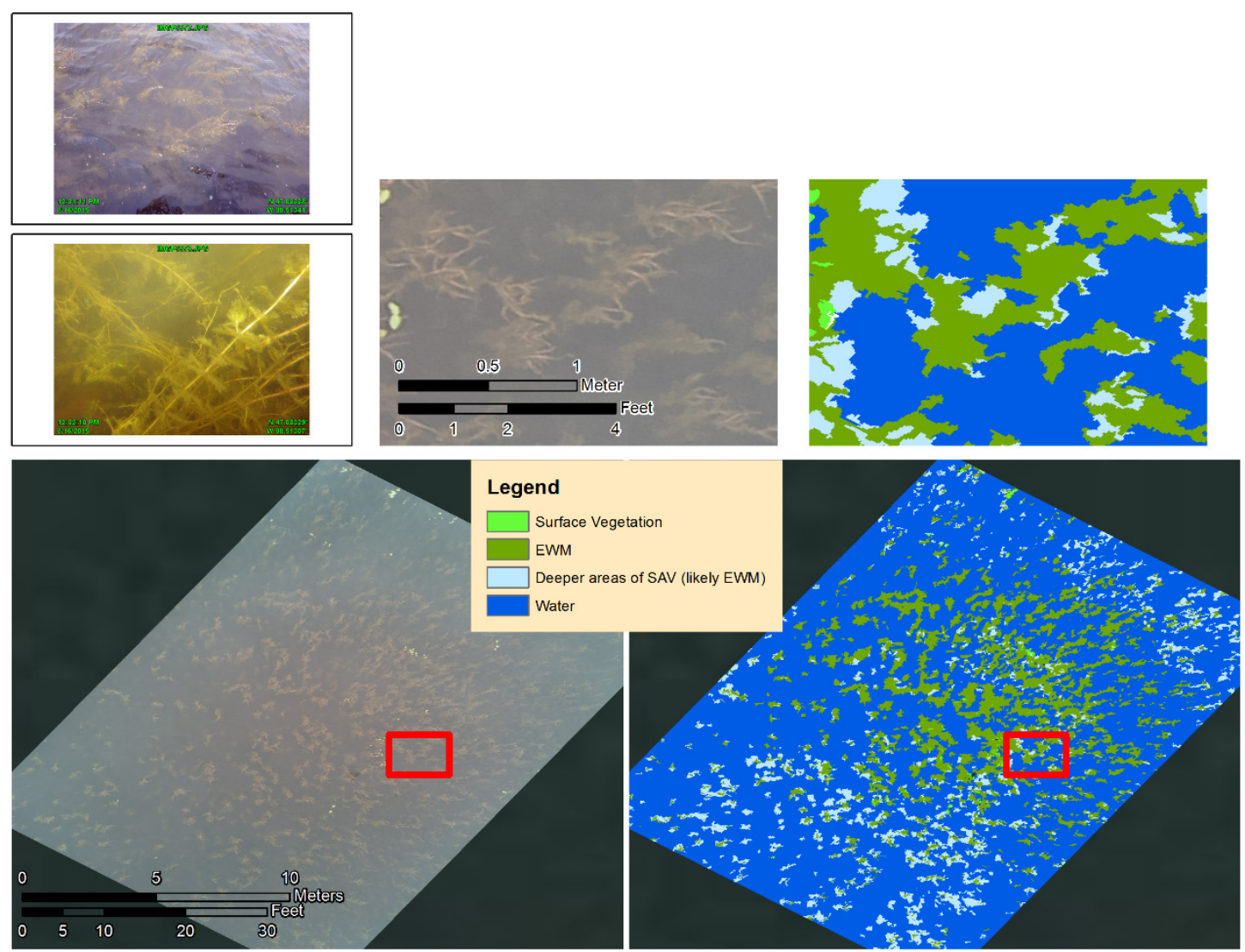

Figure 2.9. UAS-collected RGB image of predominantly EWM using an eCognition object-based classification into four class types. Area in red (at bottom) is enlarged in the top two images. Field images at the top left demonstrate that the EWM being mapped is submergent.

\subsection{Conclusion}

Detailed, multiscale spectral data provided the ability to understand whether and how EWM can be spectrally distinguished from other species. Spectral differences exist between EWM and other SAV species in certain datasets, but the number of bands and types of indices used is important. It appears likely that sky conditions are having impacts on at least some spectral profiles, but data were preserved for analysis to understand if EWM could be detected under a variety of conditions. Hyperspectral-level data, such as the 65 resampled 10-nm bands used here, showed that EWM can be separated from other species when using detailed spectral information. An analysis of six multispectral bands corresponding to those of a UAS-mountable multispectral camera plus ratio and vegetation indices showed that mNDVI was critical in being able to differentiate EWM from other SAV and bottom types. It is likely that mNDVI is sensitive to the denser biomass of EWM that can grow near the water's surface, forming a canopy over-topping other vegetation types near the water's surface (i.e., within $\sim 1 \mathrm{~m}$ ). Because red-edge and 
red light have limited but sufficient penetration in these shallow depths, mNDVI is able to discriminate EWM from non-EWM. mNDVI was part of the group of ratios, whose reflectance values did not differ significantly for EWM across the three data collection methods, indicating that it should be a useful scale-independent metric for identifying EWM. mNDVI and other metrics that include red and infrared wavelengths are likely to be key elements of a mapping algorithm used for monitoring the extent of EWM and changes in response to treatment efforts. Analyzing EWM spectral data at the OOW, boatside, and UAS scales showed a reduced strength of signal for the UAS results versus other methods, with OOW and boatside methods producing similar results. Using boatside sampling appears to provide the same value as removing the vegetation from the water and then creating spectral profiles. The mNDVI, mNDAVI, and mWAVI EWM spectral data were similar across data collection methods, meaning these may provide a scale-independent method of EWM spectral profiling and mapping that can be applied to UAS-based mapping and monitoring of invasive SAV.

Data collected at the UAS scale can cover larger areas than boatside methods or taking vegetation out of the water to identify it for mapping. With sufficient spectral bands and use of mNDVI, UAS-based imagery data are likely to provide the needed mapping information for monitoring EWM over areas larger than individual treatment locations. For imaging of EWM sites, this can mean either flying relatively low $(10 \mathrm{~m})$ to provide single-species, high-resolution mapping capability. However, the weaker signal of the UAS-collected data means that if identifying the spectral profile of underwater vegetation is the most critical element, then the boatside scale is likely to be the most useful since it provides higher-resolution information with a reduced chance for multiple species forming a part of the spectral profile and image, particularly if only small areas need to be monitored.

\subsection{Acknowledgments}

This project has been funded by the United States Environmental Protection Agency under assistance agreements 00E01928 and 00E01291 to Michigan Technological University. The contents of this document do not necessarily reflect the views and policies of the Environmental Protection Agency nor does the EPA endorse trade names or recommend the use of commercial products mentioned in this document. Support was provided by the Michigan Tech Research Institute and the Biological Sciences Department of Michigan Technological University.

\subsection{References}

ACKLESON, S. \& KLEMAS, V. 1987. Remote sensing of submerged aquatic vegetation in lower Chesapeake Bay: A comparison of Landsat MSS to TM imagery. Remote Sensing of Environment, 22, 235-248. 
ADAM, E. \& MUTANGA, O. 2009. Spectral discrimination of papyrus vegetation (Cyperus papyrus L.) in swamp wetlands using field spectrometry. ISPRS Journal of Photogrammetry and Remote Sensing, 64, 612-620.

ADAM, E., MUTANGA, O. \& RUGEGE, D. 2010. Multispectral and hyperspectral remote sensing for identification and mapping of wetland vegetation: a review. Wetlands Ecology and Management, 18, 281-296.

AILSTOCK, M. S., NORMAN, C. M. \& BUSHMANN, P. J. 2001. Common reed Phragmites australis: control and effects upon biodiversity in freshwater nontidal wetlands. Restoration Ecology, 9, 49-59.

ALLOUIS, T., BAILLY, J. S., PASTOL, Y. \& LE ROUX, C. 2010. Comparison of LiDAR waveform processing methods for very shallow water bathymetry using Raman, near-infrared and green signals. Earth Surface Processes and Landforms: The Journal of the British Geomorphological Research Group, 35, 640-650.

ANDERSON, K. \& GASTON, K. J. 2013. Lightweight unmanned aerial vehicles will revolutionize spatial ecology. Frontiers in Ecology and the Environment, 11, 138146.

ARTIGAS, F. J. \& YANG, J. 2006. Spectral discrimination of marsh vegetation types in the New Jersey Meadowlands, USA. Wetlands, 26, 271-277.

ASHRAF, S., BRABYN, L., HICKS, B. J. \& COLLIER, K. 2010. Satellite remote sensing for mapping vegetation in New Zealand freshwater environments: a review. New Zealand Geographer, 66, 33-43.

BECKER, B. L., LUSCH, D. P. \& QI, J. 2005. Identifying optimal spectral bands from in situ measurements of Great Lakes coastal wetlands using second-derivative analysis. Remote Sensing of Environment, 97, 238-248.

BECKER, B. L., LUSCH, D. P. \& QI, J. 2007. A classification-based assessment of the optimal spectral and spatial resolutions for Great Lakes coastal wetland imagery. Remote Sensing of Environment, 108, 111-120.

BECKER, R. H., SAYERS, M., DEHM, D., SHUCHMAN, R., QUINTERO, K., BOSSE, K. \& SAWTELL, R. 2019. Unmanned aerial system based spectroradiometer for monitoring harmful algal blooms: A new paradigm in water quality monitoring. Journal of Great Lakes Research, In press.

BOURGEAU-CHAVEZ, L., ENDRES, S., BATTAGLIA, M., MILLER, M. E., BANDA, E., LAUBACH, Z., HIGMAN, P., CHOW-FRASER, P. \& MARCACCIO, J. 2015. Development of a bi-national Great Lakes coastal wetland and land use map using three-season PALSAR and Landsat imagery. Remote Sensing, 7, 8655-8682. 
BROOKS, C., GRIMM, A., SHUCHMAN, R., SAYERS, M. \& JESSEE, N. 2015. A satellite-based multi-temporal assessment of the extent of nuisance Cladophora and related submerged aquatic vegetation for the Laurentian Great Lakes. Remote Sensing of Environment, 157, 58-71.

BROOKS, C. \& MERENLENDER, A. M. 2001. Determining the pattern of oak woodland regeneration for a cleared watershed in northwest California: A necessary first step for restoration. Restoration Ecology, 9, 1-12.

BUCHAN, L. A. \& PADILLA, D. K. 2000. Predicting the likelihood of Eurasian watermilfoil presence in lakes, a macrophyte monitoring tool. Ecological Applications, 10, 1442-1455.

CARPENTER, S. R. \& LODGE, D. M. 1986. Effects of submersed macrophytes on ecosystem processes. Aquatic botany, 26, 341-370.

CHO, H. J., KIRUI, P. \& NATARAJAN, H. 2008. Test of multi-spectral vegetation index for floating and canopy-forming submerged vegetation. International journal of environmental research and public health, 5, 477-483.

DIERSSEN, H., CHLUS, A. \& RUSSELL, B. 2015. Hyperspectral discrimination of floating mats of seagrass wrack and the macroalgae Sargassum in coastal waters of Greater Florida Bay using airborne remote sensing. Remote Sensing of Environment, 167, 247-258.

DOBSON, R., COLLING, T., BROOKS, C., ROUSSI, C., WATKINS, M. \& DEAN, D. 2014. Collecting Decision Support System Data Through Remote Sensing of Unpaved Roads. Transportation Research Record: Journal of the Transportation Research Board, 108-115.

DOGAN, O. K., AKYUREK, Z. \& BEKLIOGLU, M. 2009. Identification and mapping of submerged plants in a shallow lake using quickbird satellite data. Journal of environmental management, 90, 2138-2143.

EVERITT, J. H., YANG, C., SUMMY, K. R., GLOMSKI, L. M. \& OWENS, C. S. 2011. Evaluation of hyperspectral reflectance data for discriminating six aquatic weeds. Journal of Aquatic Plant Management, 49, 94-100.

FLYNN, K. F. \& CHAPRA, S. C. 2014. Remote sensing of submerged aquatic vegetation in a shallow non-turbid river using an unmanned aerial vehicle. Remote Sensing, 6, $12815-12836$.

FRITZ, C., DÖRNHÖFER, K., SCHNEIDER, T., GEIST, J. \& OPPELT, N. 2017. Mapping submerged aquatic vegetation using RapidEye satellite data: the example of Lake Kummerow (Germany). Water, 9, 510. 
HASSANI, H. \& SILVA, E. S. 2015. A Kolmogorov-Smirnov based test for comparing the predictive accuracy of two sets of forecasts. Econometrics, 3, 590-609.

HIGGINS, J. J. 2004. Introduction to modern nonparametric statistics, Pacific Grove, CA, Cengage Learning.

HODGSON, A., KELLY, N. \& PEEL, D. 2013. Unmanned aerial vehicles (UAVs) for surveying marine fauna: a dugong case study. PloS one, 8, e79556.

JEPPESEN, E., SONDERGAARD, M., SONDERGAARD, M. \& CHRISTOFFERSON, K. 2012. The structuring role of submerged macrophytes in lakes, Springer Science \& Business Media.

JOHNSON, J. A. \& NEWMAN, R. 2011. A comparison of two methods for sampling biomass of aquatic plants. Journal of Aquatic Plant Management, 49, 1-8.

KEARNEY, M. S., STUTZER, D., TURPIE, K. \& STEVENSON, J. C. 2009. The effects of tidal inundation on the reflectance characteristics of coastal marsh vegetation. Journal of Coastal Research, 1177-1186.

KETTENRING, K. M. \& ADAMS, C. R. 2011. Lessons learned from invasive plant control experiments: a systematic review and meta-analysis. Journal of applied ecology, 48, 970-979.

LAKE SUPERIOR WORK GROUP. 2014. Lake Superior Aquatic Invasive Species Complete Prevention Plan. Lake Superior Binational Program. 61 pgs.

LEGLEITER, C. J., ROBERTS, D. A. \& LAWRENCE, R. L. 2009. Spectrally based remote sensing of river bathymetry. Earth Surface Processes and Landforms, 34, 1039-1059.

MALTHUS, T. \& GEORGE, D. 1997. Airborne remote sensing of macrophytes in Cefni Reservoir, Anglesey, UK. Aquatic Botany, 58, 317-332.

MARCACCIO, J. V., MARKLE, C. E. \& CHOW-FRASER, P. 2015. Unmanned aerial vehicles produce high-resolution, seasonally-relevant imagery for classifying wetland vegetation. ISPRS-International Archives of the Photogrammetry, Remote Sensing and Spatial Information Sciences, XL-1/W4, 249-256.

MARCARELLI, A. M. \& WURTSBAUGH, W. A. 2009. Nitrogen fixation varies spatially and seasonally in linked stream-lake ecosystems. Biogeochemistry, 94, 95-110.

MIDWOOD, J. D. \& CHOW-FRASER, P. 2010. Mapping floating and emergent aquatic vegetation in coastal wetlands of Eastern Georgian Bay, Lake Huron, Canada. Wetlands, 30, 1141-1152. 
MISHRA, D. R., NARUMALANI, S., RUNDQUIST, D. \& LAWSON, M. 2005. Characterizing the vertical diffuse attenuation coefficient for downwelling irradiance in coastal waters: Implications for water penetration by high resolution satellite data. ISPRS Journal of photogrammetry and remote sensing, 60, 48-64.

MOODY, M. \& LES, D. 2007. Geographic distribution and genotypic composition of invasive hybrid watermilfoil (Myriophyllum spicatum $\times$ M. sibiricum) populations in North America. Biological Invasions, 9, 559-570.

MOREL, A. \& PRIEUR, L. 1977. Analysis of variations in ocean color. Limnology and oceanography, 22, 709-722.

NELSON, L. S. \& SHEARER, J. 2005. 2, 4-D and Mycoleptodiscus terrestris for control of Eurasian watermilfoil. Journal of Aquatic Plant Management, 43, 29-34.

OEHLERT, G. W. 2010. A first course in design and analysis of experiments. University of Minnesota, 679 pgs.

OUYANG, Z.-T., GAO, Y., XIE, X., GUO, H.-Q., ZHANG, T.-T. \& ZHAO, B. 2013. Spectral discrimination of the invasive plant Spartina alterniflora at multiple phenological stages in a saltmarsh wetland. PloS one, 8, e67315.

OZESMI, S. L. \& BAUER, M. E. 2002. Satellite remote sensing of wetlands. Wetlands ecology and management, 10, 381-402.

PENUELAS, J., GAMON, J. A., GRIFFIN, K. L. \& FIELD, C. B. 1993. Assessing community type, plant biomass, pigment composition, and photosynthetic efficiency of aquatic vegetation from spectral reflectance. Remote Sensing of Environment, 46, 110-118.

ROUSE JR, J. W., HAAS, R., SCHELL, J. \& DEERING, D. 1974. Monitoring vegetation systems in the Great Plains with ERTS. In: Proceedings of the Third Earth Resources Technology Satellite-1 Symposium; NASA SP-351 (pp. 309-317).

ROZAS, L. P. \& ODUM, W. E. 1988. Occupation of submerged aquatic vegetation by fishes: testing the roles of food and refuge. Oecologia, 77, 101-106.

SAWTELL, R. W., ANDERSON, R., TOKARS, R., LEKKI, J. D., SHUCHMAN, R., BOSSE, K. R. \& SAYERS, M. 2019.. Real Time HABs Mapping using NASA Glenn Hyperspectral Imager. Journal of Great Lakes Research, 45(3), 596-608.

SAWTELL, R. W., ANDERSON, R., TOKARS, R., LEKKI, J. D., SHUCHMAN, R. A., BOSSE, K. R. \& SAYERS, M. J. 2019. Real time HABs mapping using NASA Glenn hyperspectral imager. Journal of Great Lakes Research. 
SHUCHMAN, R. A., LESHKEVICH, G., SAYERS, M. J., JOHENGEN, T. H., BROOKS, C. N. \& POZDNYAKOV, D. 2013a. An algorithm to retrieve chlorophyll, dissolved organic carbon, and suspended minerals from Great Lakes satellite data. Journal of Great Lakes Research, 39, 14-33.

SHUCHMAN, R. A., SAYERS, M. J. \& BROOKS, C. N. 2013b. Mapping and monitoring the extent of submerged aquatic vegetation in the Laurentian Great Lakes with multi-scale satellite remote sensing. Journal of Great Lakes Research, 39, 78-89.

SILVA, T. S., COSTA, M. P., MELACK, J. M. \& NOVO, E. M. 2008. Remote sensing of aquatic vegetation: theory and applications. Environmental monitoring and assessment, 140, 131-145.

TREBITZ, A. S. \& TAYLOR, D. L. 2007. Exotic and invasive aquatic plants in Great Lakes coastal wetlands: distribution and relation to watershed land use and plant richness and cover. Journal of Great Lakes Research, 33, 705-721.

TUCKER, C. 2017. Efficiency of Diver-Assisted Suction Harvesting (DASH) of Invasive Milfoil in New Hampshire Waterbodies. Undergraduate Dissertation, Carthage College. 25 pgs.

TUCKER, C. J., PINZON, J. E., BROWN, M. E., SLAYBACK, D. A., PAK, E. W., MAHONEY, R., VERMOTE, E. F. \& EL SALEOUS, N. 2005. An extended AVHRR 8-km NDVI dataset compatible with MODIS and SPOT vegetation NDVI data. International Journal of Remote Sensing, 26, 4485-4498.

UNDERWOOD, E., MULITSCH, M., GREENBERG, J., WHITING, M., USTIN, S. \& KEFAUVER, S. 2006. Mapping invasive aquatic vegetation in the Sacramento-San Joaquin Delta using hyperspectral imagery. Environmental Monitoring and Assessment, 121, 47-64.

VADEBONCOEUR, Y., MCINTYRE, P. B. \& VANDER ZANDEN, M. J. 2011. Borders of biodiversity: life at the edge of the world's large lakes. BioScience, 61, 526-537.

VAHTMÄE, E. \& KUTSER, T. 2013. Classifying the Baltic Sea shallow water habitats using image-based and spectral library methods. Remote Sensing, 5, 2451-2474.

VAN DER MEER, F. D., VAN DER WERFF, H. M., VAN RUITENBEEK, F. J., HECKER, C. A., BAKKER, W. H., NOOMEN, M. F., VAN DER MEIJDE, M., CARRANZA, E. J. M., DE SMETH, J. B. \& WOLDAI, T. 2012. Multi-and hyperspectral geologic remote sensing: A review. International Journal of Applied Earth Observation and Geoinformation, 14, 112-128.

VILlA, P., BRESCIANI, M., BRAGA, F. \& BOLPAGNI, R. 2014. Comparative assessment of broadband vegetation indices over aquatic vegetation. IEEE Journal 
of Selected Topics in Applied Earth Observations and Remote Sensing, 7, 31173127.

VISSER, F., WALLIS, C. \& SINNOTT, A. M. 2013. Optical remote sensing of submerged aquatic vegetation: Opportunities for shallow clearwater streams. LimnologicaEcology and Management of Inland Waters, 43, 388-398.

WAGNER, K. I., HAUXWELL, J., RASMUSSEN, P., KOSHERE, F., TOSHNER, P., ARON, K., HELSEL, D., TOSHNER, S., PROVOST, S. \& GANSBERG, M. 2007. Whole-lake herbicide treatments for Eurasian watermilfoil in four Wisconsin lakes: effects on vegetation and water clarity. Lake and Reservoir Management, 23, 8394.

WHITLOCK, M. C. \& SCHLUTER, D. 2015. The Analysis of Biological Data, Second Edition, Greenwood Village, Colorado, Roberts and Company Publishers.

WILLIAMS, D. J., RYBICKI, N. B., LOMBANA, A. V., O'BRIEN, T. M. \& GOMEZ, R. B. 2003. Preliminary investigation of submerged aquatic vegetation mapping using hyperspectral remote sensing. Environmental Monitoring and Assessment, 81, 383392.

WOLTER, P. T., JOHNSTON, C. A. \& NIEMI, G. J. 2005. Mapping submergent aquatic vegetation in the US Great Lakes using Quickbird satellite data. International Journal of Remote Sensing, 26, 5255-5274.

YANG, C., YANG, D., CAO, W., ZHAO, J., WANG, G., SUN, Z., XU, Z. \& RAVI KUMAR, M. 2010. Analysis of seagrass reflectivity by using a water column correction algorithm. International Journal of Remote Sensing, 31, 4595-4608.

YUAN, L. \& ZHANG, L.-Q. 2008. Mapping large-scale distribution of submerged aquatic vegetation coverage using remote sensing. Ecological Informatics, 3, 245-251.

ZALLEK, T. 2018. Intraspecific genetic variation, population structure, and performance of the invasive aquatic macrophyte Eurasian watermilfoil (Myriophyllum spicatum) in waterbodies with and without histories of chemical herbicide treatment across Michigan. Master of Science, Michigan Technological University.

ZENG, C., RICHARDSON, M. \& KING, D. J. 2017. The impacts of environmental variables on water reflectance measured using a lightweight unmanned aerial vehicle (UAV)-based spectrometer system. ISPRS Journal of Photogrammetry and Remote Sensing, 130, 217-230.

ZIEGLER, J. P., SOLOMON, C. T., FINNEY, B. P. \& GREGORY-EAVES, I. 2015. Macrophyte biomass predicts food chain length in shallow lakes. Ecosphere, 6, 116. 


\section{Classification of Eurasian Watermilfoil (Myriophyllum spicatum) Using a Drone-enabled Multispectral Imagery Analysis}

\subsection{Abstract}

Remote sensing approaches that could identify species of submerged aquatic vegetation (SAV) and measure their extent in lake littoral zones would greatly enhance their study and management, especially if they can provide faster or more accurate results than traditional field methods. Remote sensing with multispectral sensors can provide this capability, but SAV identification with this technology must address the challenges of light extinction in aquatic environments where chlorophyll, dissolved organic carbon, and suspended minerals can affect water clarity and the strength of the sensed light signal. Here, we present an unmanned aerial system (UAS)-enabled methodology to identify the extent of the invasive SAV species Myriophyllum spicatum (Eurasian watermilfoil, or EWM), primarily using a six-band Tetracam multispectral camera, flown over sites in the Les Cheneaux Islands area of northwestern Lake Huron, Michigan, USA. We analyzed water chemistry and light data, and found our sites clustered into darker and clearer water sites. Two different scale parameters in object-based image analysis were compared to understand if creating different sized segmentation polygons for these two types of sites could improve classification accuracy. Smaller and larger scale parameter classification were applied to imagery from 10 sites collected over three years, for 20 classifications total. The overall average accuracy achieved was $76.7 \%$, with $78.7 \%$ producer's and $77.6 \%$ user's accuracy for EWM. These accuracies were higher than previously reported from other studies that used remote sensing to map SAV. Our study found that the two tested scale parameters did not make a significant difference to accuracies based on water clarity. The EWM classification methodology described here should be applicable to other SAV species, especially if they have growth patterns that lead to high amounts of biomass relative to other species in the upper water column, which can be detected with the type of red-edge and infrared sensors deployed for this study.

\subsection{Introduction}

The amount of light penetration into a lake's water column is a controlling factor for the species that exist in particular areas and helps to define the littoral zone where submerged aquatic vegetation (SAV) can grow. Some invasive species of SAV have an advantageous ability to grow in littoral zones with lower light penetration than many native species (Valley and Newman 1998). Therefore, being able to reliably identify SAV to species or taxon in areas with higher extinction coefficients could help with understanding the extent of non-native invaders. The extinction coefficient of light in water is impacted by three main color-producing agents (CPAs): chlorophyll (CHL), suspended minerals (SM), and the colored dissolved organic matter (CDOM) component of dissolved organic carbon (DOC) (Shuchman et al. 2013). Because of these CPAs, 
inland waters can be highly optically complex (Palmer et al. 2015), and CPA concentrations can change significantly over relatively short time intervals (Brezonik et al. 2015).

Being able to remotely identify individual species or taxa of non-native aquatic plants and map their extent would be useful to their management. Identifying to vegetation class or dominant vegetation group may also be useful. Management of SAV is common because of verified and perceived negative impacts. For example, invasive plants that grow as SAV can have significant impacts in aquatic systems, such as reduced dissolved oxygen levels, greater presence of non-native fishes, reduced plant species richness, reduced forage value for waterfowl and macroinvertebrates, reduced human use of littoral zones, and negative influence on zooplankton abundance (Kuehne et al. 2016, Gallardo et al. 2016, Aloo et al. 2013, Trebitz and Taylor 2007). However, in some cases, total species diversity may not be lower in invaded aquatic plant communities (Gallardo et al. 2016), the overall productivity can be the same (Van Goethem et al. 2020), and invasive aquatic plants may provide their own level of beneficial ecosystem services (Hershner and Havens 2008). Therefore, understanding the identity and distribution of species of SAV in lake littoral zones is an important challenge that could be addressed using remote sensing, but addressing this challenge will depend on our ability to remotely identify SAV in the optically complex waters characteristic of lake littoral zones. We expect that SAV will be harder to identify in areas affected by one or more CPAs, reducing light transmission, than in areas that have relatively clearer water. For example, in areas with a local tributary contribution of DOC, it may be more difficult to identify where SAV is located than in areas without sources contributing this CPA component.

To address this possibility, we have continued work initially documented in Brooks et al. 2019 to identify the extent of the invasive non-native submerged aquatic plant Myriophyllum spicatum (Eurasian watermilfoil or EWM) in a part of the Laurentian Great Lakes. EWM has been shown to reduce native species abundance (Boylen et al. 1999, Madsen et al. 1991) and suppress native plants (Madsen 2005), lower lakeshore property values through interference with boating recreation (Zhang and Boyle 2010), impact swimming recreation (Madsen 2005), and it can increase P loads during decomposing after herbicide application (Nichols and Keeney 1973). EWM was known to be present in the Laurentian Great Lakes by the early 1950s (Mills 1994), and it grows most abundantly in one to four meters of water (Smith and Barko 1990).

Based on fieldwork observations, we expected that at least two types of sites might exist in our study area: sites with relatively clear waters and lower levels of CPAs that reduce light penetration, and sites with relatively darker (more turbid) waters and higher levels of CPAs that lead to greater light absorption and scattering. We hypothesized that an EWM identification methodology developed for areas with a higher light extinction coefficient will work better (be more accurate) in darker waters than in clearer waters, and that an EWM identification methodology developed for areas with a lower light extinction coefficient will work better (be more accurate) in clearer waters than in darker 
waters. In this paper, we explored whether different image analysis parameters might lead to higher classification accuracy depending on site type.

This led to the development of a testable hypothesis for this research:

- $\mathrm{H}_{\mathrm{O}}$ : The clear water classification methodology produces the same accuracy result for clear water as it does for dark water; the dark water classification

methodology produces the same accuracy for dark water as it does for clear water

- $\mathrm{H}_{\mathrm{A}}$ : These methodologies do not produce the same accuracy results.

This hypothesis can be diagrammed as follows (Table 3.1) if $\mathrm{H}_{\mathrm{O}}$ can be rejected and accuracies are higher when classification and water type match.

Table 3.1. Diagram of hypothesis prediction if $\mathrm{H}_{\mathrm{o}}$ is rejected and the clear and dark water algorithms produce higher accuracies for their own water types.

\begin{tabular}{|c|c|c|c|}
\hline & & \multicolumn{2}{|c|}{ Classification type } \\
\hline & & Clear & Dark \\
\hline \multirow[t]{2}{*}{ Water type } & Clear & $\overline{\text { Higher }}$ & $\overline{\text { Lower }}$ \\
\hline & $\overline{\text { Dark }}$ & Lower & Higher \\
\hline & & \multicolumn{2}{|c|}{ (Accuracy results) } \\
\hline
\end{tabular}

Also potentially important to EWM identification is how well mixed it is with other SAV species. The presence vs. absence of EWM, such as EWM vs. open water, is likely to be relatively simple to differentiate. However, when EWM is mixed in with several other species that may appear similar to the naked eye in visible light, it is likely to be more difficult to separate using readily available natural color (red/green/blue or RGB) cameras or those with a relatively small number of multispectral bands. In Brooks et al. (2019), we demonstrated that spectral profiles of submerged aquatic vegetation (SAV) can be used to identify EWM when using certain indices and bands. A modified Normalized Difference Vegetation Index (mNDVI, which used a ratio of red edge wavelength light to near-infrared light) was significantly different for EWM vs. other submerged aquatic vegetation, providing a potential means of identifying EWM with high-resolution remote sensing data. Averaging spectral data to $6510-\mathrm{nm}$ wide bands, similar to available hyperspectral systems, provided an ability to differentiate EWM from other species of SAV, whereas using only six to eight bands only worked occasionally. Moving from analyzing spectral profiles to imaging EWM and other SAV in the field is the next step in a process for using remote sensing as a practical tool in invasive SAV management.

This paper focuses on deployment of multispectral cameras from an unmanned aerial system (UAS or "drone") platform to enable rapid, timely imaging of EWM to identify its extent in littoral zones. We sought to understand the accuracy of our EWM mapping using multispectral UAS imagery methodology. The paper includes analysis of whether accounting for water clarity can improve the mapping of SAV, with a focus on EWM extent. 


\subsection{Methods}

\subsubsection{Collection Sites and UAS-based Sensors Deployed for the Project}

We collected data on water color and vegetation characteristics at several sites in the Les Cheneaux Islands area of northwest Lake Huron (Michigan, USA) (Figure 3.1).

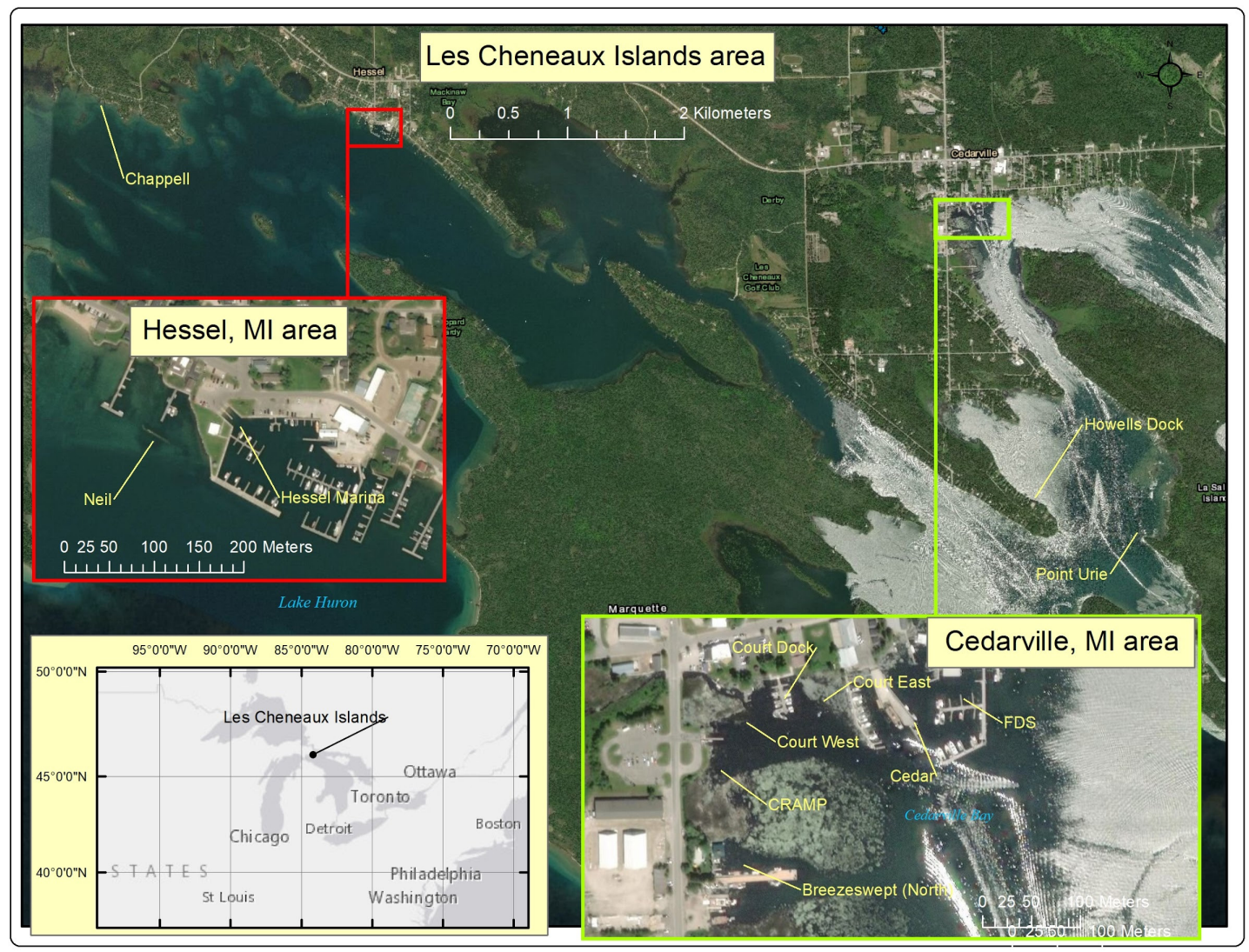

Figure 3.1. The Les Cheneaux Islands area in northwest Lake Huron, with data collection sites.

We sampled 11 sites in the Les Cheneaux Islands over six trips in 2016-2018; the sampling months and the sensor we were able to deploy on each sampling occasion are shown in Table 3.2. Three RGB-only camera systems were deployed via UAS, primarily to provide basemaps of the sites; these cameras were a Nikon D810 36mp camera flown onboard a Bergen hexacopter, the $12 \mathrm{mp}$ camera of a Phantom 3 Advanced (3A) UAS, and the $12 \mathrm{mp}$ camera of a Mavic Pro UAS. The U.S.-made Bergen hexacopter is a larger system that can carry payloads up to $5 \mathrm{~kg}$ for up to 15 minutes of flight (Figure 3.2). The Phantom 3 Advanced and Mavic Pro UAS are made by DJI and are designed to easily obtain RGB aerial photos, but not are not intended to carry additional payloads. 


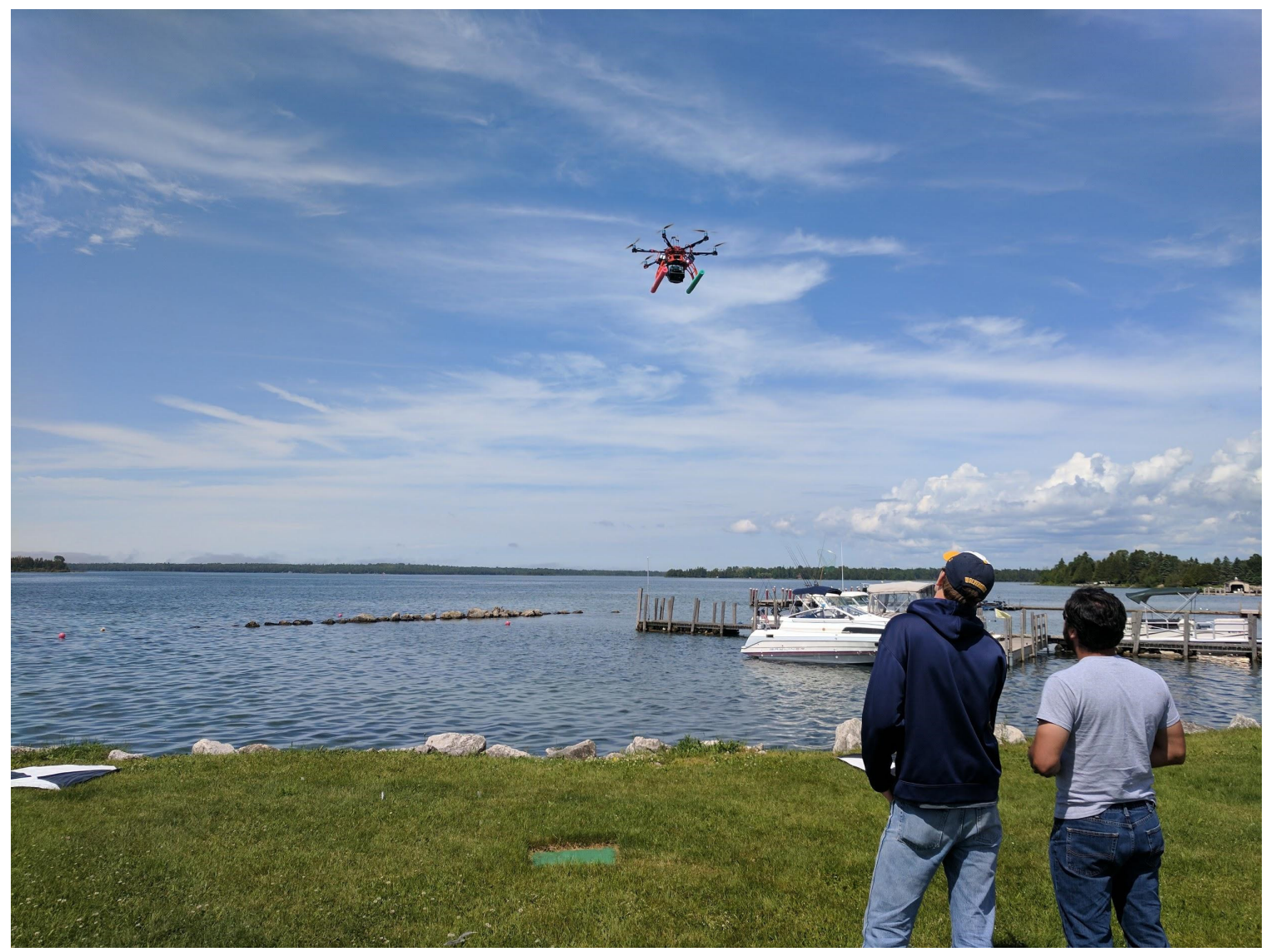

Figure 3.2. The Bergen hexacopter UAS platform being deployed to collect aerial imagery for EWM identification in June 2017 at the Neil site in Hessel, MI.

The six-band Tetracam Micro-MCA (Tetracam Inc.) described in Brooks et al. 2019 was deployed onboard the Bergen hexacopter when available to evaluate whether its multispectral capabilities could help distinguish EWM from other aquatic cover types. The VISNIR system that used a 16mp RGB Canon camera and a near-infrared-sensitive Canon camera was deployed on occasion using the Bergen hexacopter as a less costly potential alternative to the Tetracam for EWM identification purposes. The Bergen hexacopter was used to deploy the Nikon RGB, Tetracam multispectral, or VISNIR system one at a time. The RGB basemaps were also used to provide georeferencing of the Tetracam images, as that sensor did not have a built-in global navigation satellite system (GNSS). For multispectral imagery in 2016, we mostly flew at heights of around 10-15 $\mathrm{m}$, which produced images covering approximately a $3 \times 3 \mathrm{~m}$ area, whereas we flew at heights of about 25-30 m to cover larger areas in each image for 2017 and 2018. After our first year of data collection, we decided that being able to cover larger areas was worth the trade-off of producing lower-resolution imagery when flying higher. 
Table 3.2: Collection sites and sensors deployed by date in the Les Cheneaux Islands from 2016-2018.

\begin{tabular}{|c|c|c|c|c|c|c|}
\hline $\begin{array}{l}\text { Collection } \\
\text { Sites }\end{array}$ & $\begin{array}{l}\text { July } \\
2016\end{array}$ & $\begin{array}{l}\text { August } \\
2016\end{array}$ & $\begin{array}{l}\text { June } \\
2017\end{array}$ & $\begin{array}{l}\text { July } \\
2017\end{array}$ & $\begin{array}{l}\text { August } \\
2017\end{array}$ & $\begin{array}{l}\text { August } \\
2018\end{array}$ \\
\hline Breezeswept & & & & $\begin{array}{l}\text { D810/P3A/ } \\
\text { TCAM/ }\end{array}$ & & \\
\hline North & & D810/ & $\begin{array}{l}\text { P3A } \\
\text { P3A/ }\end{array}$ & $\begin{array}{l}\text { VISNIR } \\
\text { D810/P3A/ }\end{array}$ & P3A/TCAM & Mavic \\
\hline Court Dock & D810/P3A & TCAM & VISNIR & $\begin{array}{l}\text { VISNIR } \\
\text { D810/P3A/ }\end{array}$ & P3A & Mavic \\
\hline Court East & D810/P3A & $\begin{array}{l}\text { D810/ } \\
\text { TCAM }\end{array}$ & $\begin{array}{l}\text { D810/P3A/ } \\
\text { VISNIR }\end{array}$ & $\begin{array}{l}\text { TCAM/ } \\
\text { VISNIR } \\
\text { D810/P3A/ }\end{array}$ & P3A/TCAM & $\begin{array}{l}\text { Mavic/ } \\
\text { VISNIR }\end{array}$ \\
\hline Court West & P3A & & & VISNIR & P3A & $\begin{array}{l}\text { Mavic } \\
\text { Mavic/ }\end{array}$ \\
\hline CRAMP & P3A & & $\begin{array}{l}\text { P3A } \\
\text { D810/Mavic/ }\end{array}$ & $\begin{array}{l}\text { P3A/ } \\
\text { VISNIR } \\
\text { P3A }\end{array}$ & P3A & $\begin{array}{l}\text { TCAM/ } \\
\text { VISNIR }\end{array}$ \\
\hline FDS & $\mathrm{D} 810 / \mathrm{P} 3 \mathrm{~A}$ & $\begin{array}{l}\text { D810/ } \\
\text { TCAM }\end{array}$ & $\begin{array}{l}\text { P3A/VISNI } \\
\text { R } \\
\text { D810/P3A/ }\end{array}$ & $\begin{array}{l}\text { /TCAM/ } \\
\text { VISNIR }\end{array}$ & P3A/TCAM & Mavic \\
\hline Chappell & & & VISNIR & $\mathrm{D} 810 / \mathrm{P} 3 \mathrm{~A} /$ & P3A & \\
\hline $\begin{array}{l}\text { Hessel } \\
\text { Marina }\end{array}$ & & & $\begin{array}{l}\text { P3A/ } \\
\text { VISNIR }\end{array}$ & $\begin{array}{l}\text { TCAM/ } \\
\text { VISNIR } \\
\text { D810/P3A/ }\end{array}$ & $\begin{array}{l}\mathrm{D} 810 / \mathrm{P} 3 \mathrm{~A} / \\
\text { TCAM }\end{array}$ & Mavic \\
\hline Neil & & & $\begin{array}{l}\text { D810/P3A/ } \\
\text { VISNIR }\end{array}$ & $\begin{array}{l}\text { TCAM/ } \\
\text { VISNIR }\end{array}$ & $\begin{array}{l}\text { D810/P3A/ } \\
\text { TCAM }\end{array}$ & $\begin{array}{l}\text { Mavic } \\
\text { Mavic/ }\end{array}$ \\
\hline $\begin{array}{l}\text { Howells } \\
\text { Dock } \\
\text { Urie Point }\end{array}$ & & $\begin{array}{l}\mathrm{D} 810 / \mathrm{P} 3 \mathrm{~A} / \\
\text { TCAM }\end{array}$ & $\begin{array}{l}\text { D810/P3A/ } \\
\text { VISNIR }\end{array}$ & & $\begin{array}{l}\text { D810/P3A/ } \\
\text { TCAM }\end{array}$ & $\begin{array}{l}\text { TCAM/ } \\
\text { VISNIR } \\
\text { Mavic/ } \\
\text { VISNIR }\end{array}$ \\
\hline
\end{tabular}

Sensors: D810 = Nikon D810 RGB, P3A = Phantom 3 Advanced RGB, TCAM =

Tetracam, VISNIR $=$ Visible + Near-Infrared dual Canon, Mavic $=$ Mavic Pro RGB

Figure 3.3 shows an example of three sources of RGB imagery, from the Mavic Pro at Hessel Marina (a), the Canon RGB camera at Howells Dock (b) and the Nikon D810 36mp RGB camera, also for Howells Dock. 

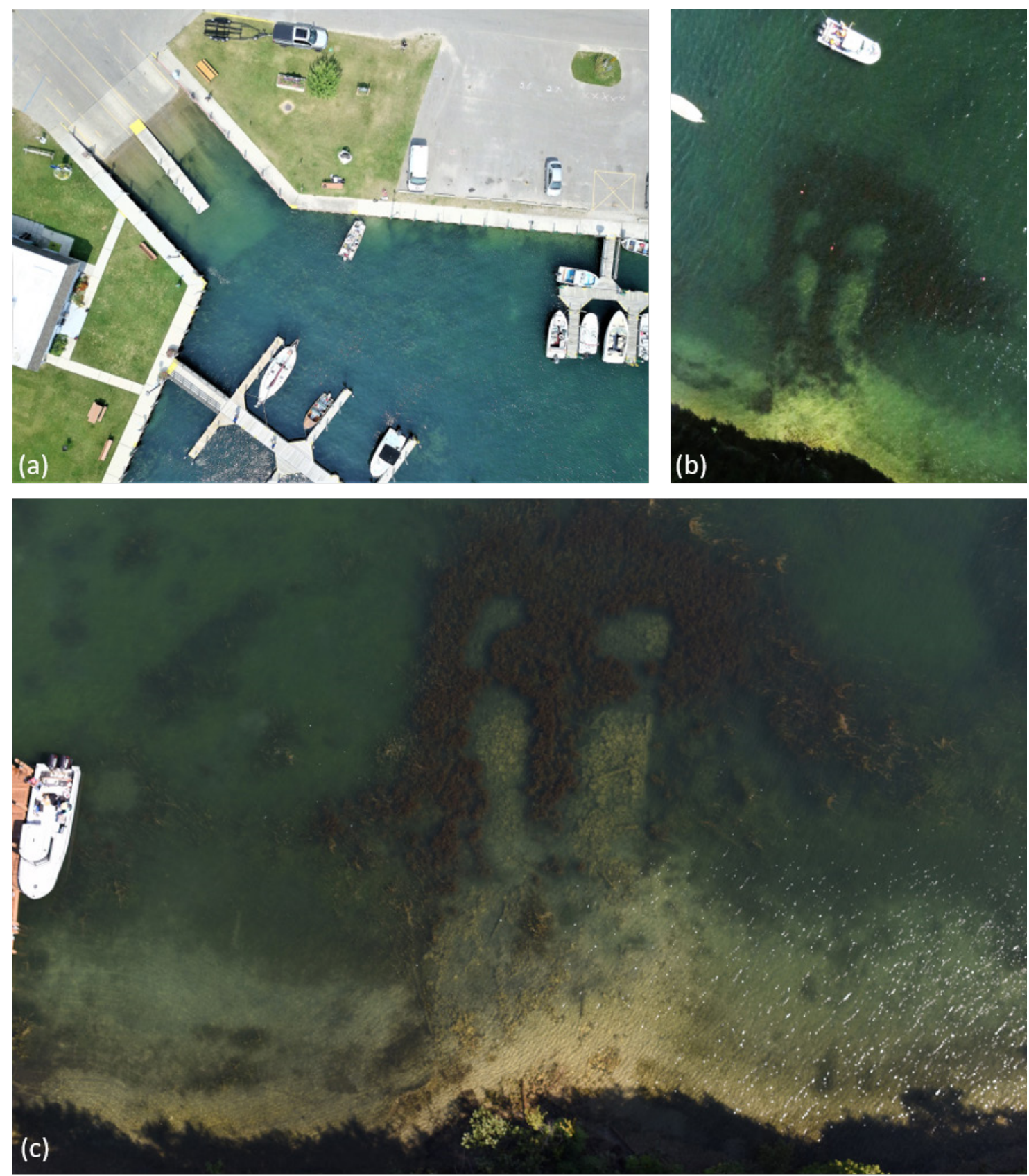

Figure 3.3. Examples of natural color RGB UAS imagery: a) Hessel Marina from a $12 \mathrm{mp}$ Mavic Pro camera, b) Howells Dock from a 16mp Canon camera (this provided the natural color part of the VISNIR system), and c) Howells Dock from a 36mp Nikon D810 camera.

Tetracam imagery consisted of six spectral bands collected at 490 (blue), 530 (green), 550 (upper range of green), 600 (orange), 680 (red), and $720 \mathrm{~nm}$ (red edge), with the modified mNDVI calculated from the red-edge and red bands as described in Brooks et al. 2019. An example of the Tetracam data collected at the Hessel Marina site in July, 
2017 is shown below in Figure 3.4, overlaid on a RGB image taken the same day with a Phantom 3A. The Tetracam imagery is shown in color infrared (CIR), with bands 6 $(720 \mathrm{~nm}), 5(680 \mathrm{~nm})$, and $2(530 \mathrm{~nm})$ displayed in the red, green, and blue channels, respectively. Two different views of the VISNIR data are shown in Figure 3.5, with the left figure (a) showing RGB imagery and the right figure (b) showing the near-infrared image, with vegetation showing as shades of the more prominent pink color.

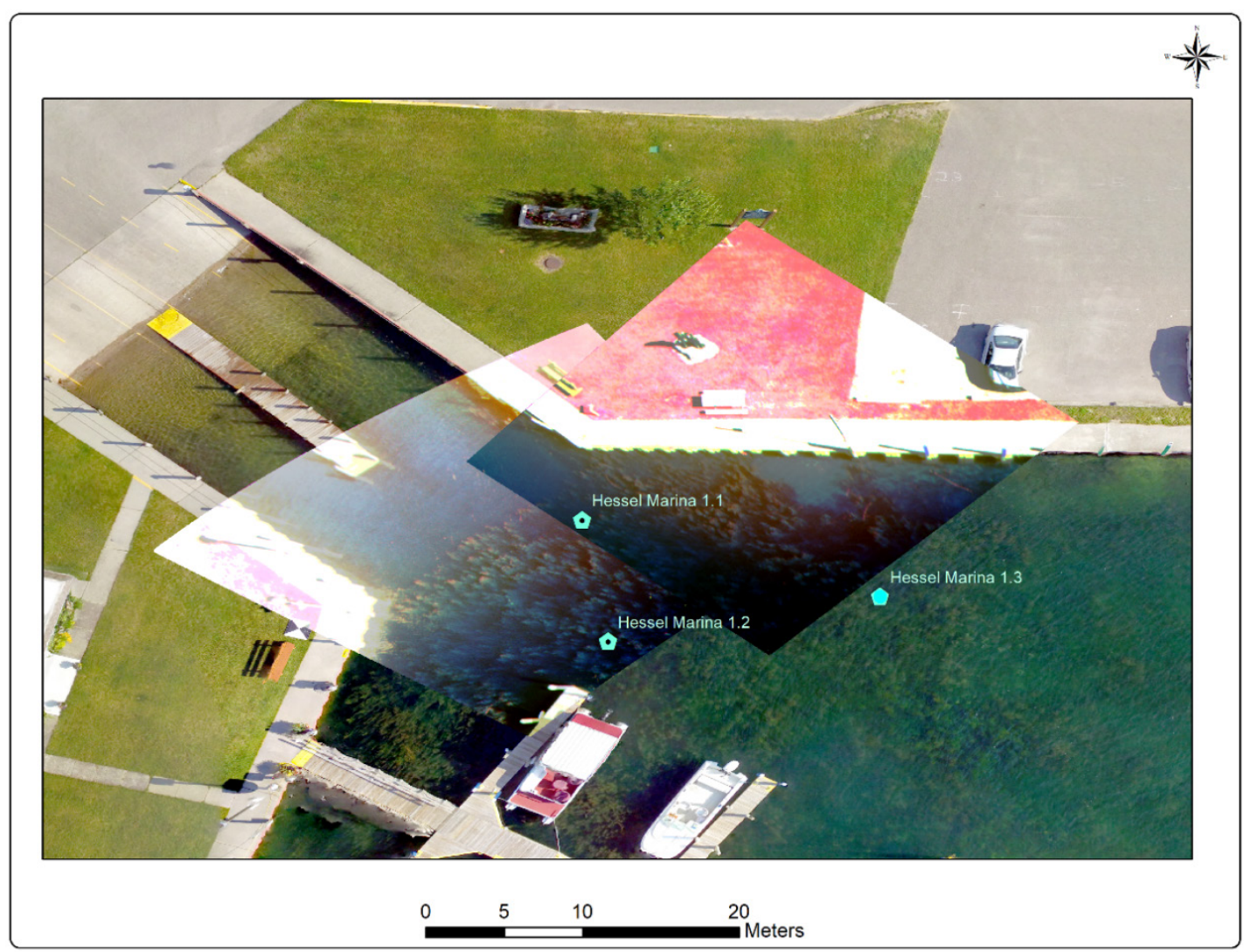

Figure 3.4. Two Tetracam images (center, shown in color infrared) from July 2017, displayed over a RGB composite Phantom 3A image for the Hessel Marina site taken on the same day; green pentagons indicate field sampling sites. 


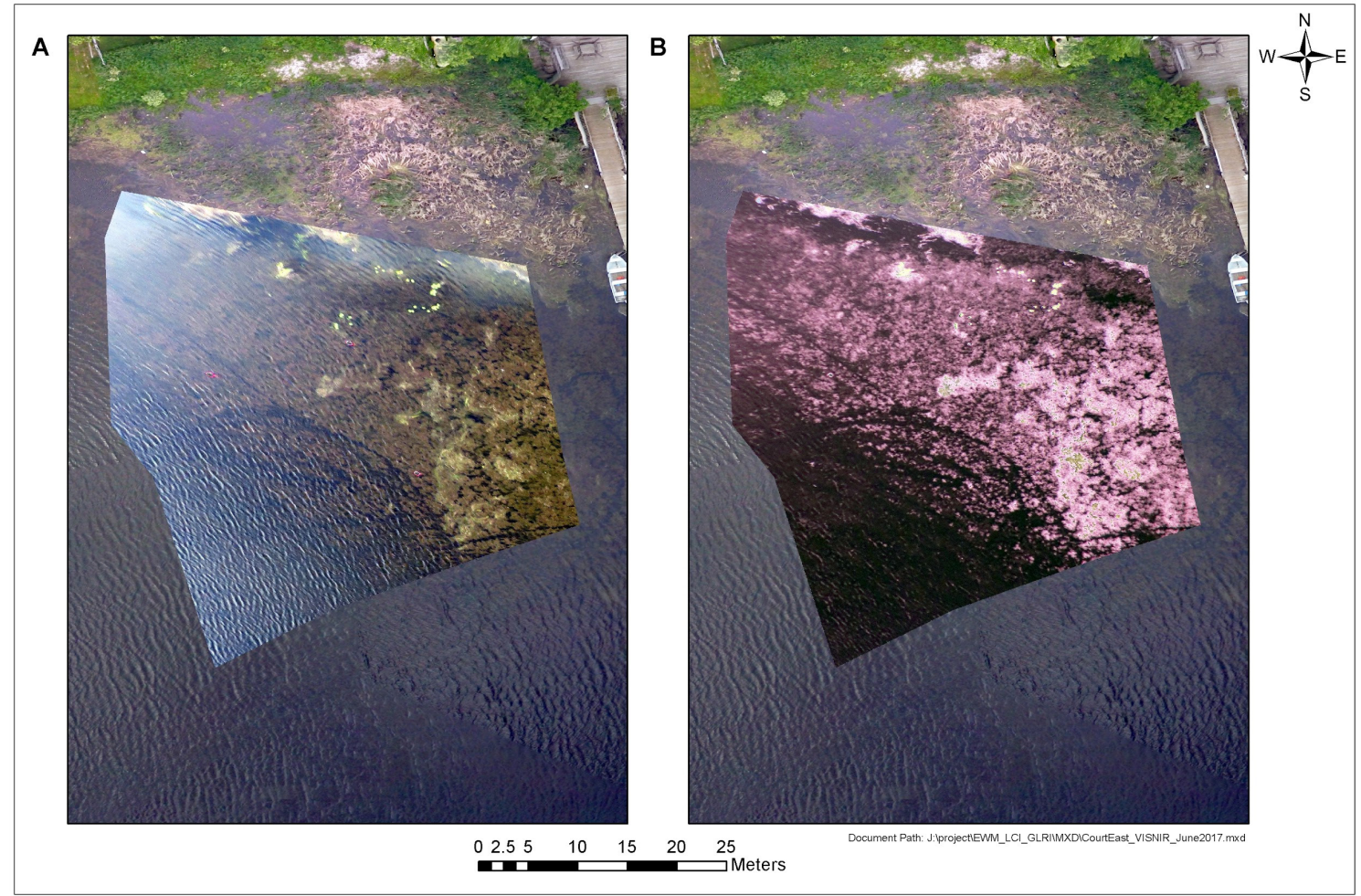

Figure 3.5. VISNIR imagery for the Court East site in June 2017, with RGB imagery shown at left (A) and near-infrared imagery shown at right (B).

\subsubsection{Water Chemistry Data and Analysis Methods}

At each site during each visit, we collected a set of standard water chemistry and light data to help quantify the CPA values at each site and characterize the sites as having darker or clearer waters. Primary data collected included the following:

- Chlorophyll-a concentrations, in $\mathrm{mg} / \mathrm{m} 3$

- Light intensity, used to calculate extinction coefficient $\mathrm{Kd}(\mathrm{PAR})$ (or $\mathrm{k}$ for short)

- Secchi disk transparency, in meters (along with depth to bottom)

- Total suspended solids (TSS), in $\mathrm{mg} / \mathrm{L}$

- Dissolved organic carbon (DOC) concentration, in $\mathrm{mg} / \mathrm{L}$

The method we used for calculating chlorophyll data was based on standard methods (APHA 2005), including collecting water into 1-L plastic bottles and storing samples on ice until returning to the lab within eight hours. Water was filtered through 47-mmdiameter $0.7-\mu \mathrm{m}$ glass fiber filters, with filters wrapped in aluminum foil and frozen at $20^{\circ} \mathrm{C}$ until analysis within a month. Chl-a filters were extracted in $95 \%$ ethanol and analyzed spectrophotometrically following APHA method 10200H.2.b/EPA method 446.0, with calculations following Nusch 1980. 
To calculate the extinction coefficient of photosynthetically active radiation Kd(PAR), we used a Li-Cor LI-193 SA spherical underwater quantum sensor with a LI-1400 datalogger (LI-COR, Inc., Lincoln, NE, USA), with light intensity values recorded above the surface, immediately below the surface, and every $0.5 \mathrm{~m}$ until the bottom was reached, with the bottom depth also being recorded (Wetzel and Likens 2013). The logtransformed light intensity values were then fit to a regression line, with the negative slope of the line being the extinction coefficient. We also recorded Secchi disk transparency depth at each site.

For TSS, we used APHA method 2540B (APHA 2005) to calculate the mass of total suspended solids (TSS) in $\mathrm{mg} / \mathrm{L}$. Water was collected into 1-L plastic bottles and stored on ice until returning to the lab within eight hours. A well-mixed, measured volume of a water sample, typically $750-1000 \mathrm{~mL}$, was filtered through a pre-weighed $47-\mathrm{mm}$ diameter $0.7-\mu \mathrm{m}$ glass fiber filter. The filter was heated to constant mass at $104 \pm 1^{\circ} \mathrm{C}$ and then weighed. The mass of material captured on the filter divided by the water volume filtered is equal to the TSS.

For DOC, we collected water samples in 60-mL Nalgene bottles. Samples were filtered through $0.45-\mu \mathrm{m}$ membrane filters and frozen at $-20^{\circ} \mathrm{C}$ until analysis. DOC samples were acidified with hydrochloric acid and quantified using a Shimadzu TOC-VCSN (Shimadzu Scientific Instruments, Columbia, Maryland).

\subsubsection{Site Type Analysis}

We organized data by site and by date, and then averaged values by site to help understand whether the sites could be clustered into types based on their color producing agents (represented by TSS, Chl-a, and DOC), with water clarity estimated by the extinction coefficient Kd(PAR). Table 3.3 shows the average data, and the data for each individual site by date are included in the supplementary appendix materials. We used the $\mathrm{R}$ cluster package for computing hierarchical clustering (Maechler et al. 2019) and the factoextra package for visualizing the results (Kassambara and Mundt 2007), all in R version 3.6.0 (R Core Team 2019). To investigate the optimal number of clusters, we performed k-means clustering on the site-averaged data initially using $2,3,4$, and 5 clusters to help understand potential site clusters present in the data. We used the gap statistic method to estimate the optimal number of clusters using the fviz_nbclust function available in the factoextra package. We used the ward.D2 method to compute hierarchical clustering using a Euclidean dissimilarity matrix. The fviz_dend function was used to create a dendrogram to visualize the results of the cluster analysis. 
Table 3.3. Water chemistry and light data summarized by site

\begin{tabular}{|c|c|c|c|c|c|c|c|c|c|}
\hline $\begin{array}{l}\text { Collection } \\
\text { Sites }\end{array}$ & Region & $\begin{array}{l}\text { TSS } \\
(\mathrm{g} / \mathrm{L})\end{array}$ & $\begin{array}{l}\text { TSS } \\
\text { S.D. }\end{array}$ & $\begin{array}{l}\text { Chl-a } \\
\left(\mathrm{mg} / \mathrm{m}^{\wedge} 3\right)\end{array}$ & $\begin{array}{l}\text { Chl-a } \\
\text { S.D. }\end{array}$ & $\begin{array}{l}\text { DOC } \\
\text { mgC/ } \\
\text { L }\end{array}$ & $\begin{array}{l}\text { DOC } \\
\text { S.D. }\end{array}$ & $\begin{array}{l}\text { k ext. } \\
\text { coeff. } \\
(\mathrm{m}-1)\end{array}$ & k S.D. \\
\hline Breezeswept & Les Cheneaux & & & & & & & & \\
\hline South & Islands & 0.0056 & 0.0036 & 2.516 & 0.628 & 6.996 & 1.258 & 1.5587 & 0.1533 \\
\hline Breezeswept & Les Cheneaux & & & & & & & & \\
\hline North & $\begin{array}{l}\text { Islands } \\
\text { Les Cheneaux }\end{array}$ & 0.0024 & 0.0000 & 1.332 & 0.209 & 8.017 & 0.928 & 0.9221 & 0.1507 \\
\hline Court Dock & $\begin{array}{l}\text { Islands } \\
\text { Les Cheneaux }\end{array}$ & 0.0183 & & 0.888 & & 5.359 & 1.483 & 2.1960 & 0.4806 \\
\hline Court East & $\begin{array}{l}\text { Islands } \\
\text { Les Cheneaux }\end{array}$ & 0.0036 & 0.0034 & 1.110 & 1.064 & 10.249 & 4.239 & 1.6186 & 0.5407 \\
\hline Court West & $\begin{array}{l}\text { Islands } \\
\text { Les Cheneaux }\end{array}$ & 0.0015 & 0.0013 & 0.740 & 0.209 & 12.730 & 3.917 & 1.8877 & 0.4759 \\
\hline CRAMP & $\begin{array}{l}\text { Islands } \\
\text { Les Cheneaux }\end{array}$ & 0.0072 & & 4.973 & & 5.059 & & 1.2256 & \\
\hline FDS & Islands & 0.0011 & 0.0027 & 1.480 & 1.356 & 5.174 & 2.059 & 1.3115 & 0.5561 \\
\hline Chappell & $\begin{array}{l}\text { Les Cheneaux } \\
\text { Islands }\end{array}$ & 0.0075 & 0.0098 & 0.148 & 0.209 & 2.906 & 1.032 & 0.5010 & 0.0778 \\
\hline Hessel & Les Cheneaux & & & & & & & & \\
\hline Marina & $\begin{array}{l}\text { Islands } \\
\text { Les Cheneaux }\end{array}$ & 0.0005 & 0.0014 & 0.863 & & 2.875 & 0.569 & 0.6194 & 0.5867 \\
\hline Neil & Islands & 0.0012 & 0.0010 & 0.656 & 0.438 & 2.568 & 0.362 & 0.5277 & 0.0878 \\
\hline Howells & Les Cheneaux & & & & & & & & \\
\hline Dock & $\begin{array}{l}\text { Islands } \\
\text { Les Cheneaux }\end{array}$ & 0.0032 & 0.0036 & 1.235 & 1.113 & 3.015 & 0.460 & 0.7424 & 0.0470 \\
\hline Urie Point & Islands & 0.0011 & & 1.733 & & 2.710 & & 0.4396 & \\
\hline
\end{tabular}

\subsubsection{Vegetation Data and Analysis Methods}

Field sampling of vegetation type and density was completed through visual estimates, rake tosses, and rake twists, with results recorded on standardized field sheets. Visual estimate methods and percent vegetation by sampling location were described in Brooks et al. 2019 and based on the Michigan Department of Environmental Quality guidance of 2005 (MDEQ 2005). Visual estimates were made by an experienced aquatic vegetation expert at the same locations used to create the spectral profiles analyzed for Brooks et al. 2019 , representing an approximately 3 -m radius. In 2016, visual estimates were made in approximately the center of each sampling site and recorded on a field data sheet, and location coordinates were recorded with a Trimble GeoExplorer GPS with sub-meter accuracy. In 2017 and 2018, three marker buoys were placed in the water around each site and three visual estimates were made per buoy in different directions, with locations recorded with the same Trimble GPS and visual estimate data recorded on field sheets. These field sheets were later transferred into a project spreadsheet that documented all three years of field survey vegetation and water sampling data. These data formed the primary source of information for classifying the multispectral UAS-collected images and in assessing accuracy of the classification results.

Rake twists provided a more benthic-oriented sampling of vegetation types than rake tosses. For rake tosses, a rake end was tied to a rope, thrown approximately $10 \mathrm{~m}$ and dragged back towards the boat, as shown in Figs. 3.6(a) and 3.6(b). Rake fullness was 
scored on a four-point scale $(1,2,3$, or 4 = found, sparse, common, dense) based on a visual estimation, and vegetation types were recorded by approximate predominance. With rake twists, a rake end mounted on a two-meter pole was thrust downwards into the water immediately off the side of the research vessel (Figure 3.7) (Johnson and Newman 2011). Vegetation caught in the rake was deposited in buckets for sorting and identification, including predominance on a five-point scale. The macrophytes from each twist rake sample were separated and identified to species using Fasset et al. 2006 and Skawinski 2014. Species of Chara and Elodea were identified to genus. EWM and hybrid EWM (M. spicatum $x$ sibiricum) were grouped together, as they are not distinguishable in the field and are difficult to separate (Parkinson et al. 2011). The samples were dried for $48 \mathrm{~h}$ at $60^{\circ} \mathrm{C}$ to determine dry weight (see Van Goethem et al. 2020 for additional detail).

Photographs of sampling sites were taken with a rugged, waterproof GPS-enabled camera. Photos were generally taken both above and below water to help capture the appearance of SAV and provide supplementary information on species identification.
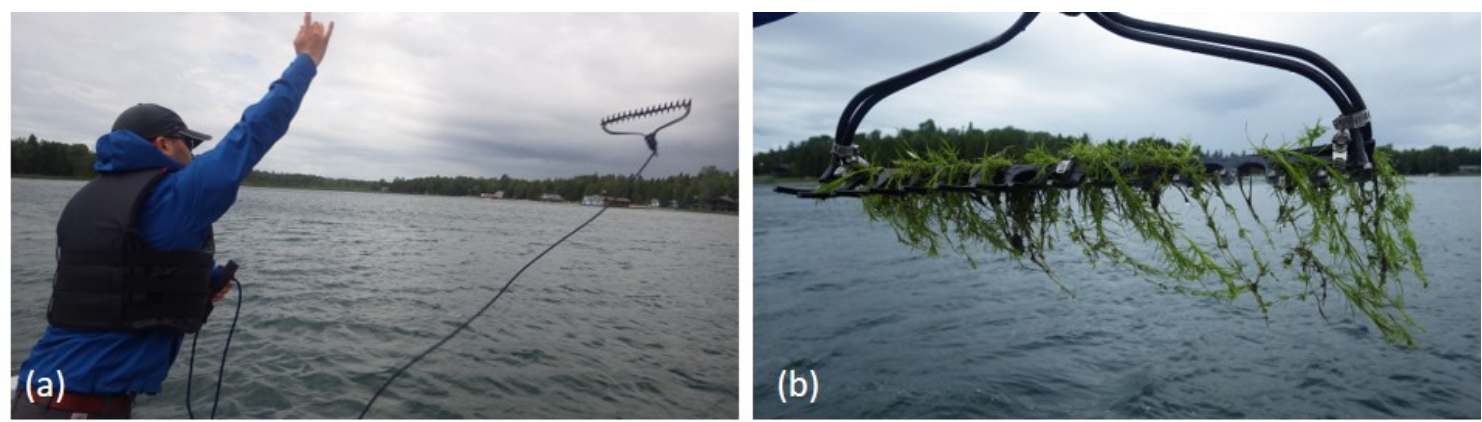

Figure 3.6. Rake toss in action and example results from an area with less dense SAV 


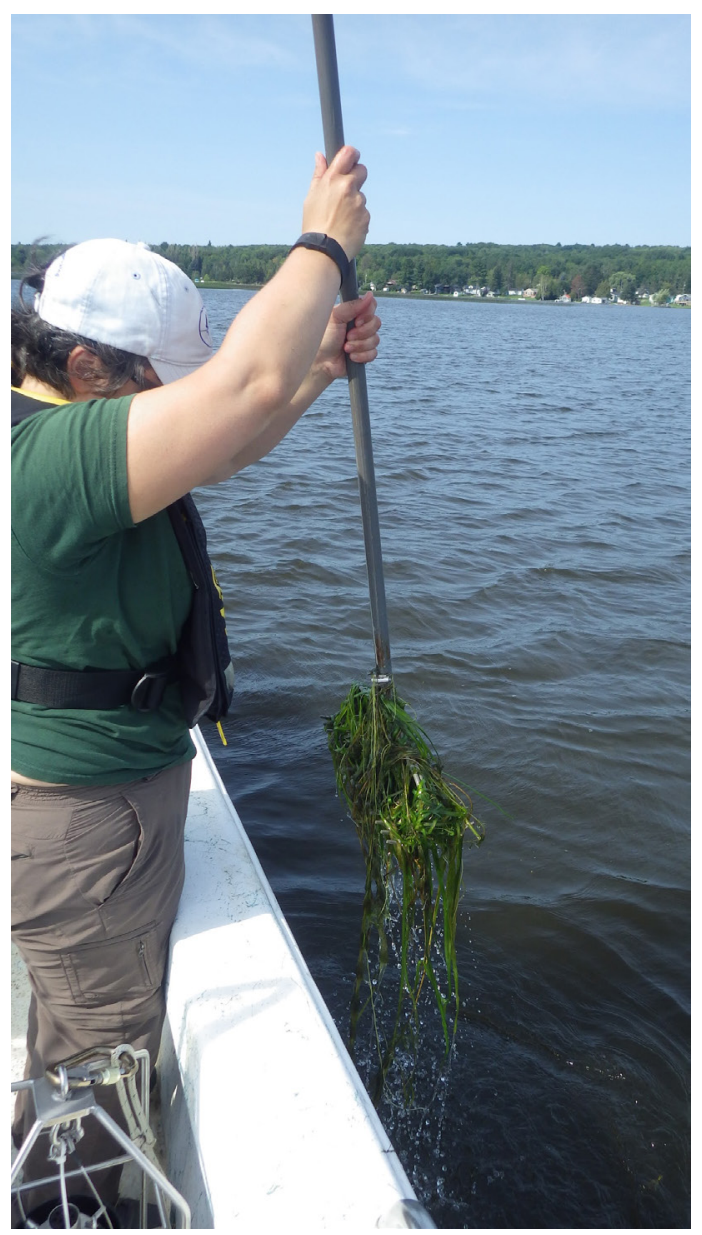

Figure 3.7. Rake twist sample immediately after retrieval from the water from an area with dense SAV, undergoing visual estimation of density.

\subsubsection{Spectral data}

Collection and analysis of spectral data at the project sites is described in Brooks et al. 2019. That study found that a modified Normalized Difference Vegetation Index (mNDVI) using red-edge and red bands was significantly different among dominant vegetation groups using our 2016 and 2017 spectral data, with no difference among months of data collection and no significant interaction between collection month and dominant vegetation group. It appeared that mNDVI was detecting different amounts of SAV biomass, even given the limited water penetration of the red-edge $(720 \mathrm{~nm})$ band. mNDVI also appeared to be scale-independent and more appropriate for identifying EWM than other species of SAV. Using the six spectral bands alone rarely resulted in EWM being identified separately from other vegetation. However, using field spectrometer data averaged to $6510-\mathrm{nm}$ bands, representative of hyperspectral data, did show reliable separability of EWM from the spectral profiles of eight other vegetation types. As noted in the sensor descriptions, the available multispectral systems included either six bands for Tetracam that could be used to calculate mNDVI or four bands for 
VISNIR that could be used to calculate standard NDVI. All of these bands were included for image classification in case some bands in addition to mNDVI or NDVI could help provide differentiation for individual sites, if not consistently.

\subsubsection{Imagery Analysis and Classification}

To create geospatial output layers of EWM location and extent, we used the object-based image analysis (OBIA) software eCognition Developer, version 9 (Trimble Germany 2017). Recent work, particularly by Visser et al. (2013, 2018), has shown promise in applying eCognition's OBIA capabilities to mapping submerged aquatic vegetation, including EWM, in at least a riverine environment. These studies note how impacts of the water column appear to limit SAV species discrimination, but that the shape and texture variables calculated by eCognition show greater ability in helping differentiate species.

We used eCognition Developer's multiresolution segmentation classification routine, with mean brightness, means of each band, and mean max difference as the classification features. Based on initial visual assessment of image segmentation, we modified the scale parameter to develop segmentation objects (polygons) that appeared to capture the extent of submerged aquatic vegetation patches without the polygons being mixed with dissimilar appearing areas. Scale parameter is a user-specified threshold in eCognition where a higher value results in a smaller number of larger segments; smaller values result in smaller, more fine-scale segments. We primarily focused on two scale parameters, one larger and one smaller, to test whether the scale parameter could be optimized for accuracy based on water characteristics. Based on these investigations, a scale parameter of 25 appeared to capture the extent of SAV well for clear water sites, while a larger scale parameter of 50 appeared best at this for representing SAV extent for dark water sites.

We explored whether different segmentation parameters might lead to higher classification accuracy depending on site type. After developing classification schemes that appeared more appropriate for clear and dark water sites, we then also applied the classification scheme to the opposite water type. Visual interpretation of classification results was used, informed by field data including estimation of vegetation species present and their extent, with rake toss and rake twist data also helping to verify visual estimate results. We followed the accuracy assessment methods of Congalton and Green (2019), including selecting their recommended number of assessment points per classification type and randomly locating those points within each class (such as EWM, open water, etc.) using ESRI ArcMap. Any segmentation polygons used for classification training were not used for accuracy assessment.

For each randomly located point in the accuracy assessment, the classifier's identification for the point was compared to what the field team identified the point as in the vegetation surveys, primarily using the visual estimate data since that represented the uppermost layer of vegetation, which was similar to what the UAS imagery was capturing. UAS RGB orthoimagery, the multispectral imagery used for classification, and location-tagged photos were also used to determine classification accuracy. 
The number of sampling points for the accuracy assessment of classification results was determined using the multinomial distribution in the equation shown below (Toratora, 1978). In the equation, $\mathrm{n}$ is equivalent to the number of recommended samples.

$$
n=\mathrm{B} \Pi \mathrm{i}(1-\Pi \mathrm{i}) / \mathrm{bi} 2
$$

For our assessment, we had a desired confidence level of $85 \%$ and a desired precision of $15 \%$ (represented as $b$ in above equation). The Chi-squared $(\chi 2)$ inverse of right tailed probability represented as $\mathrm{B}$, is calculated with $(\boldsymbol{\alpha} / \mathrm{k})=$ probability, assuming 1 degree of freedom. In this case, $\boldsymbol{\alpha}$ is equivalent to desired precision, $\mathrm{k}$ is equivalent to the number of classes at each site and $\Pi \mathrm{i}$ is equivalent to the percent cover of each class (Toratora, 1978; Congalton and Green, 2019). This tends to lead to more common classes (larger total area within an image classification) getting more sampling points, and less common classes getting fewer sampling points.

After determining the values of $\mathrm{n}$ for all classes within a study site, the largest of those values was then chosen as the required number of samples for that site. From there, the total recommended number of samples was next distributed among all classes by multiplying the recommended number of samples by the percent cover of each class. Sample counts were then rounded to the nearest whole number. Based on the sample counts, the specified number of sample points was then generated within each class.

Once points are selected and all classifications have been standardized, the error assessment of each site is begun and an error matrix is created. Each matrix contains reference data along the horizontal axis and classified data along the vertical axis (Congalton and Green, 2019). Once complete, an overall accuracy is computed by summing the diagonal elements of the matrix and then dividing that sum by the totals for each row. In addition to overall accuracy, the producer's and user's accuracy were calculated for EWM. This determines accuracy on a class by class basis. We report the overall accuracy, and the user's and producer's accuracy for EWM. The producer's accuracy is a measure of omission error, calculated by dividing the number of correct pixels (or points) divided by the total number of pixels (or points) derived from groundtruth reference data (Congalton 1991). It helps tell the creator (producer) of the map how well a class has been mapped. The user's accuracy helps describe the probability that a point on the map is classified correctly, and is calculated by dividing the total number of pixels (or points) for a class by the total number of pixels or points that were mapped in that class. It represents how well the classification results for each class represent what is actually present in the mapping area (Banko 1998).

To help understand whether the accuracy of EWM discrimination was dependent on the area of EWM present at a site, the total numbers of classification points used for accuracy assessment (as recommended by the Congalton and Green method) are included in our results. Error matrices were calculated for all classifications following Congalton 1991. 
Applying the two sets of classification parameters (developed for the clear and dark water sites) yielded two accuracy assessments per classification mapping result. To test the hypothesis that classification accuracy was affected by scale parameter, we applied a two-way ANOVA mixed model in JMP version 14.0.0 (SAS Institute Inc., Cary, North Carolina, USA), with fixed model effects, Scale and Site type and the interaction Scale*Site type, as well as a random factor for sampling site and date. Significance for all fixed factors was considered at $p=0.05$. Scale represented whether the accuracy result was based on using the smaller or larger eCognition scale parameter parameter (i.e., 25 or 50 as described above). Site type was determined from the cluster analysis based on CPA at each site as described above. The two-way ANOVA was run for three different response variables: overall accuracy, EWM producer's accuracy, and EWM user's accuracy using all classification accuracy results, to evaluate whether scale or site type might differ for one or more of these accuracy calculations.

\subsection{Results}

\subsubsection{Types of Sites}

The TSS values were very low at all sampling sites (see Table 3.3), with values in the range of 0.0011 to $0.0183 \mathrm{~g} / \mathrm{L}(1.1$ to $18.3 \mathrm{mg} / \mathrm{L})$. Chl-a values were characteristic of oligotrophic conditions (defined as $<2.5 \mathrm{mg} / \mathrm{m} 3$, see Istvánovics 2010), with only single samples at Breezeswept South, Court East, CRAMP, and Howells Dock above 2.5 $\mathrm{mg} / \mathrm{m} 3$. DOC values were relatively high, with the highest values occurring at the sites near Cedarville (averaging 5.06 to $12.73 \mathrm{mg} \mathrm{C} / \mathrm{L}$ ) where a stream (Pearson Creek) empties into Cedarville Bay. Other sites, which do not have a stream near them, had values in the range of 2.57 to $3.02 \mathrm{mg} \mathrm{C} / \mathrm{L}$. Reflecting these inputs, the extinction coefficient values were highest, indicating the lowest water clarity, for the Cedarville area sites of Breezeswept North, Court Dock, Court East, Court West, CRAMP, and FDS $(0.92$ to $2.20 / \mathrm{m})$ but lower for the other sites of Chappell, Hessel Marina, Neil, Howells Dock, and Urie Point (0.50 to $0.74 / \mathrm{m})$.

Figure 3.8 shows the results of the five-group dendrogram analysis. The five sites in the first dendrogram branch (Chappell, Hessel Marina, Neil, Howells Dock, and Urie Point) are the same ones that are not near a stream source and that we labeled as our "clear water" sites; the remaining sites in the second branch (Court Dock, CRAMP, Court East, Court West, Breezeswept South, Breezeswept North, and FDS) are all close to Pearson Creek with its relatively high DOC waters and were labeled as our "dark water" sites. The dendrogram analysis shows that the sites with higher average DOC (higher light extinction coefficient) can be differentiated into different clusters, but all within the same branch. All sites in the clearer water cluster had k values of below $0.8 \mathrm{~m}^{-1}$ while all sites in the darker water cluster had $\mathrm{k}$ values of above $0.9 \mathrm{~m}^{-1}$. 


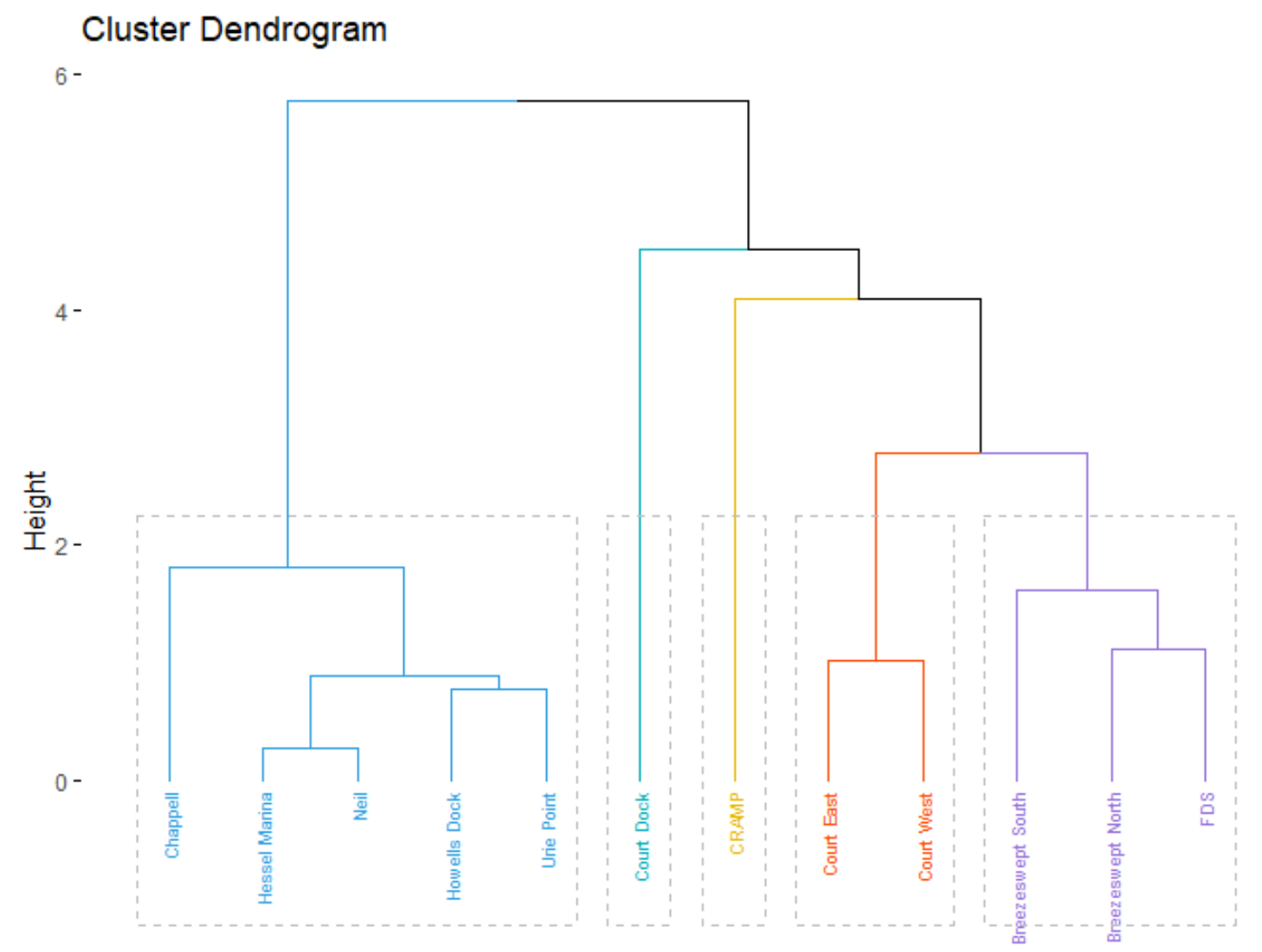

Figure 3.8. Dendrogram results for site clustering; sites with a lower extinction coefficient have clustered on the left (in light blue) while darker water sites form multiple clusters but all within the second branch.

\subsubsection{Classification Results}

We had sufficient project resources and usable multispectral imagery to create classification mapping results for five sites with varying numbers of dates: Breezeswept North (for one date, July 2017), Court East (three dates: August 2016, June 2017, and July 2017), Hessel Marina (one date: July 2017), Howells Dock (three dates: August 2016, August 2017, and August 2018), and Neil (one date: July 2017). The August 2017 Howells Dock classification work was completed using two images that were classified separately to try and produce more accurate results. When they were initially analyzed together, spectral differences for the same species between images made accurate classification difficult. As noted, every site was classified using both the "dark water" and "clear water" eCognition scale parameters (clear $=25$ and dark $=50)$, resulting in at least two results per analyzed site (summarized in Table 3.4).

\subsubsection{Breezeswept North}

Figure 3.9 shows the analyzed Tetracam imagery for Breezeswept North with a CIR band combination in July 2017 (9A) and the classification results with scale parameter $=25$ 
(9B), and with scale parameter $=50(9 \mathrm{C})$; a Nikon D800 RGB image collected via Bergen Hexacopter forms the background. Breezeswept North has relatively higher DOC and $\mathrm{K}_{\mathrm{d}}(\mathrm{PAR})$ extinction values and therefore is in the darker water cluster grouping.

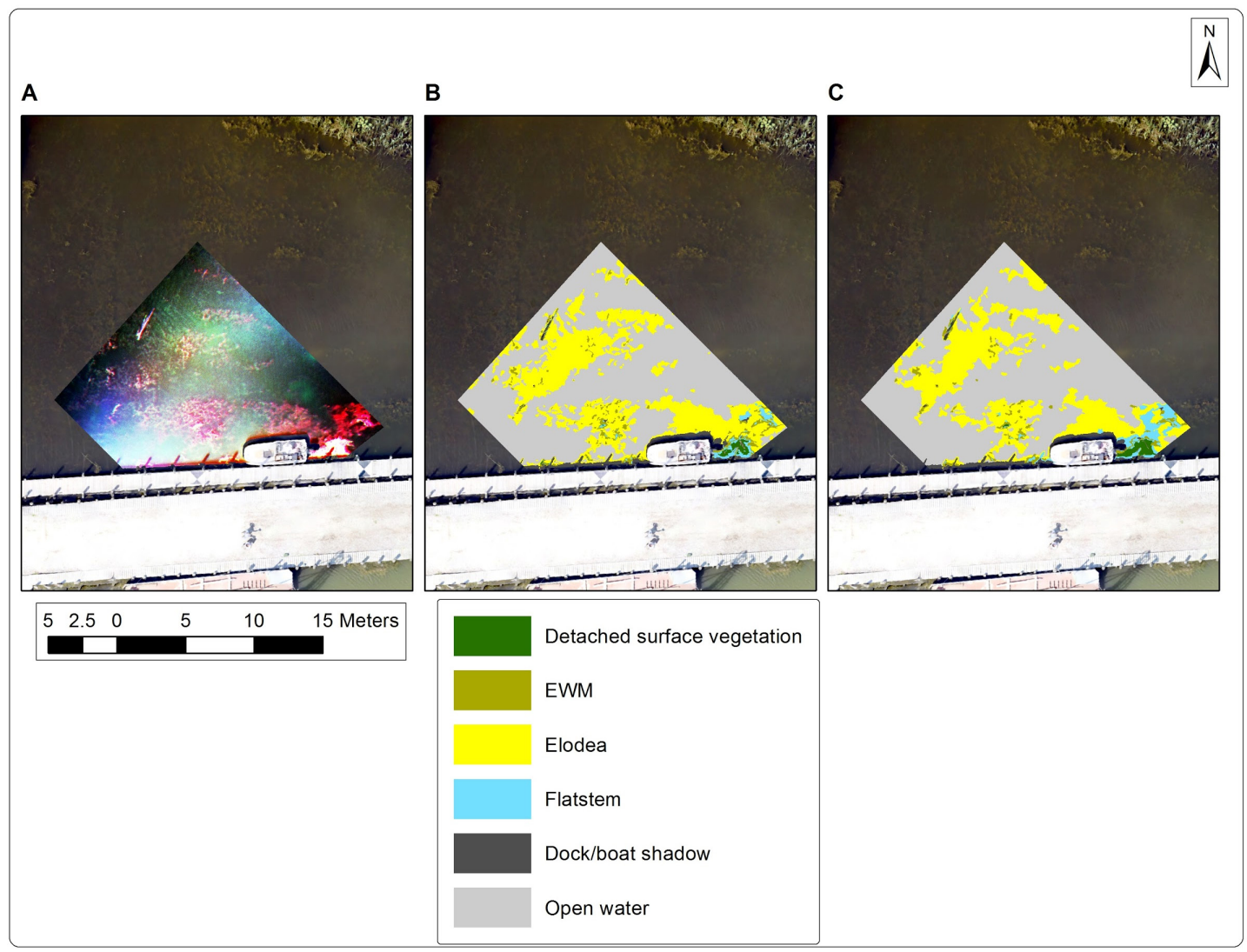

Figure 3.9. Tetracam multispectral image of Breezeswept North using color-infrared bands (A) and classification results with scale parameter $=25(\mathrm{~B})$, and with scale parameter $=50(\mathrm{C})$.

Visual estimates indicated that three SAV species were prominent at Breezeswept North based on four survey points in or near the Tetracam image area: EWM, Elodea canadensis (Canadian waterweed), and Potamogeton zosteriformis (flat-stem pondweed). The canopies of EWM and flat-stem pondweed were $0.5 \mathrm{~m}$ or less from the water surface, while the tallest Elodea was 0.5 to $0.75 \mathrm{~m}$ below the surface. Figure $3.10 \mathrm{~A}$ shows EWM and flat-stem pondweed close to the water's surface at the site, and 3.10B shows mostly flat-stem pondweed beneath the water's surface. 3.10C shows an overview RGB image of the site (taken with the RGB VISNIR camera), and 3.10D shows the mostly sunny conditions on the day of the data collection, which supported greater water penetration by the available sunlight. The densest areas of SAV appear as the brightest red color in Figure 3.9A, just north and northeast of the boat; these areas were mostly Elodea just north of the boat but flat-stem pondweed northeast of the boat. EWM was sparser than either of these species and mostly occurred in the northern part of the image, but was a smaller component than Elodea, which is reflected in the classification results. 
The major visible difference in the classification results using the two scales was that flatstem pondweed formed a larger part of the result with the larger scale parameter. The extent of EWM appears similar with both scale results.
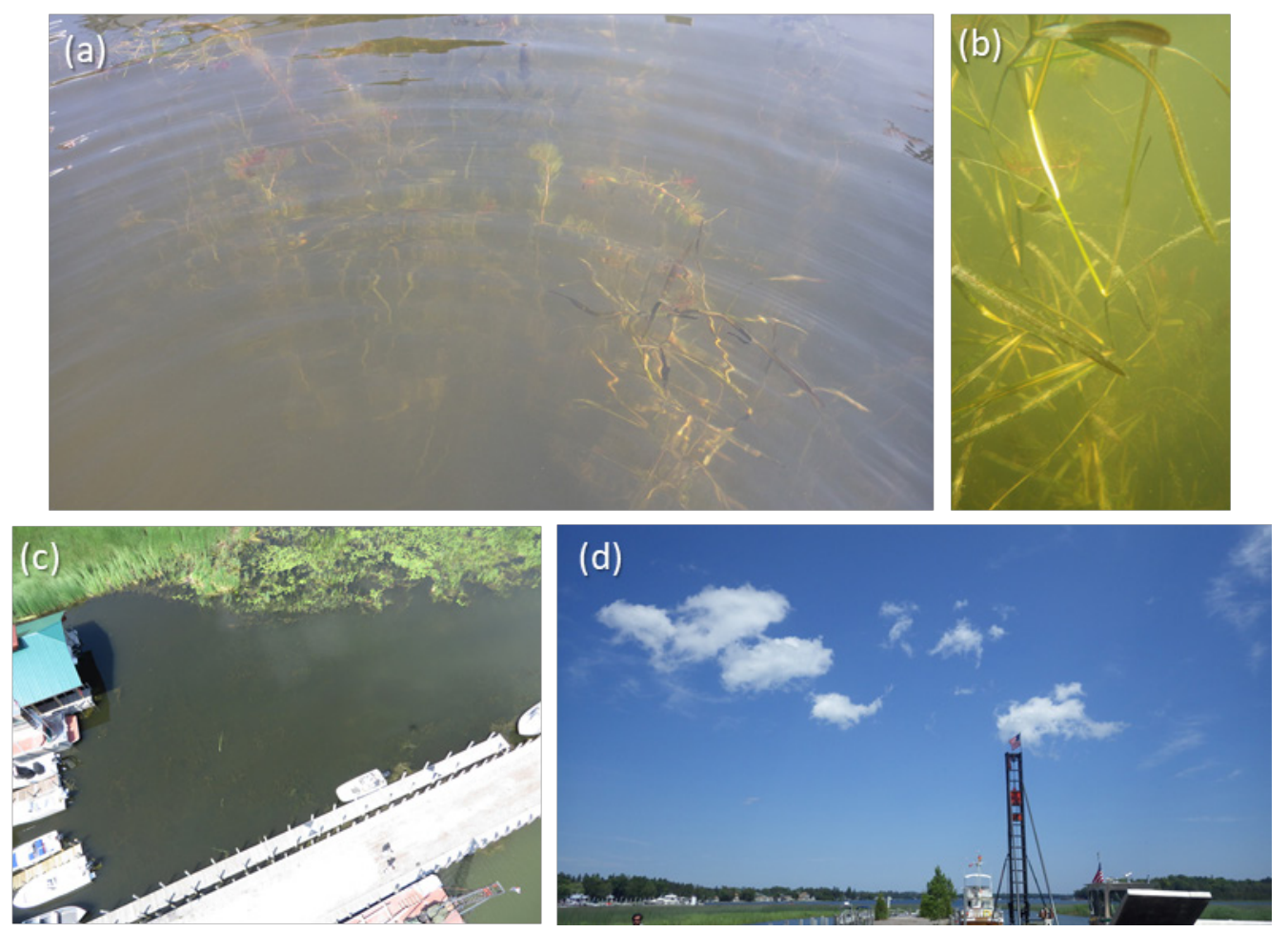

Figure 3.10. Field photos helping to document conditions at Breezeswept North on the day of data collection in July 2017, including documentation of EWM and flat-stem pondweed near the water's surface (a), flat-stem pondweed as seen underwater (b), an overview RGB image of the site (c), and mostly sunny sky conditions on the day of the data collection $(\mathrm{d})$.

\subsubsection{Court East}

Figure 3.11 shows the analyzed Tetracam imagery for the Court East site in August 2016 (3.11A) and the classification results with scale parameter $=25(11 \mathrm{~B})$, and with scale parameter $=50$ (3.11C); a Nikon D800 RGB image collected via Bergen Hexacopter forms the background. Court East is in the dark water cluster grouping, close to the mouth of Pearson Creek. 


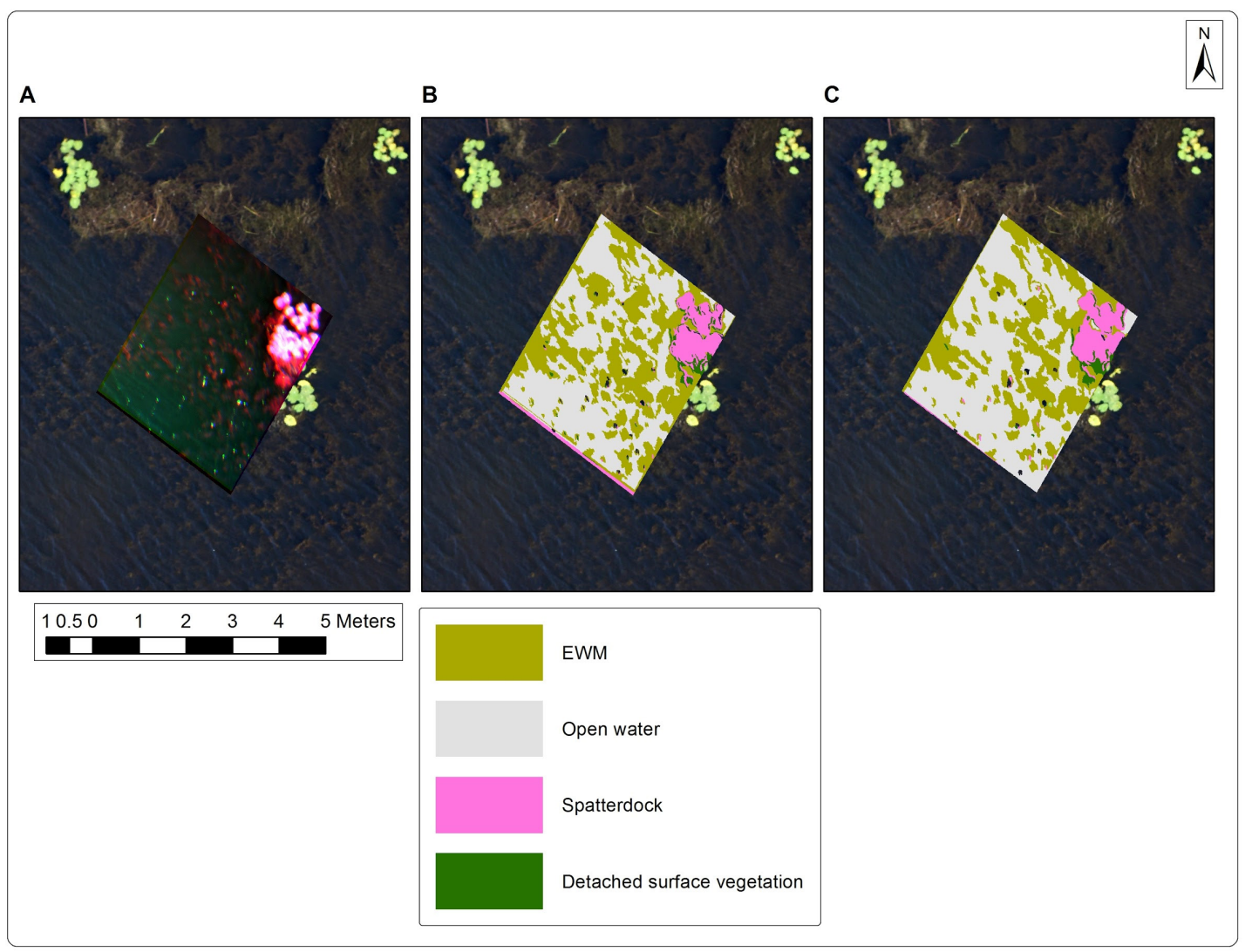

Figure 3.11. Tetracam multispectral image of Court East from August 2016 using colorinfrared bands $(\mathrm{A})$ and classification results with scale parameter $=25(\mathrm{~B})$ and scale parameter $=50(\mathrm{C})$.

With 2016 flights mostly taking place at lower elevations than in later years, the August 2016 Court East classifications in Figure 3.11 cover a relatively small area of approximately $3 \times 3 \mathrm{~m}$ (in contrast, the single Breezeswept North image in 3.9A from a higher flight elevation covers an area of approximately $15 \times 15 \mathrm{~m}$ ). Visual surveys indicated that the surface vegetation showing as the brightest red towards the top right in the NIR view (3.11A) was Nuphar variegata (spatterdock or bullhead pond lily) and the underwater vegetation was EWM. The field photograph taken on the same survey day in 2016 in Figure 3.12A helps verify this, and also the presence of an area of detached surface vegetation with EWM visible underwater that was able to be classified. Figure 3.12B shows an underwater photograph taken at this site, showing EWM with visible periphytic algae. This EWM shows up as dark red areas underwater in the color-infrared display in $3.11 \mathrm{~A}$ due to sufficient penetration by the red edge band $(720 \mathrm{~nm})$ of the Tetracam into the water column. 

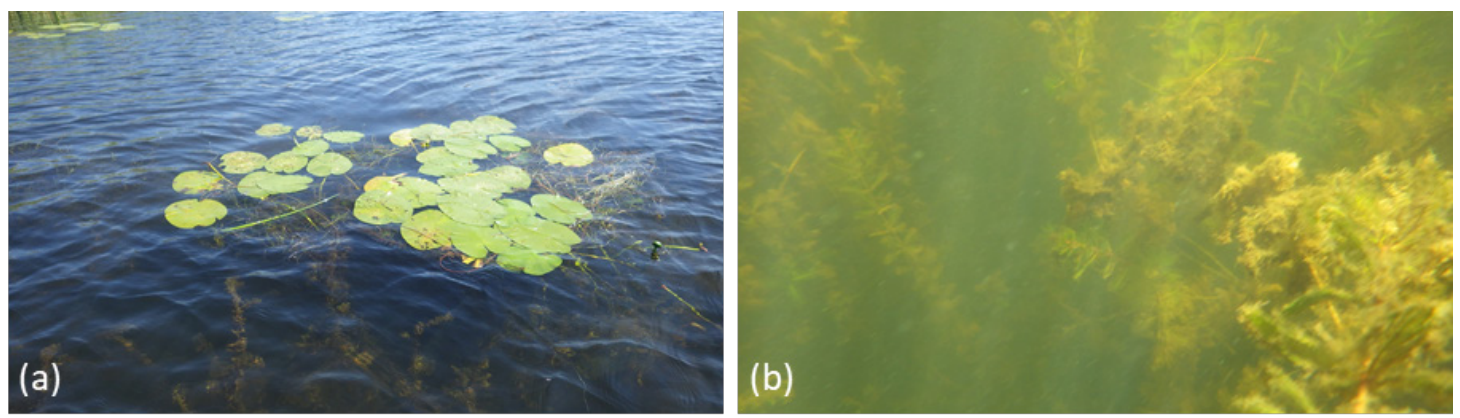

Figure 3.12. Field photographs showing much of the Court East August 2016 classification area on the same day as UAS imagery was collected, including (a) the presence of spatterdock and some loose surface vegetation at the surface near the spatterdock and (b) EWM underwater.

Figure 3.13 shows the analyzed Tetracam imagery for the Court East site in June 2017 $(3.13 \mathrm{~A})$ and the classification results with scale parameter $=25(3.13 \mathrm{~B})$ and scale parameter $=50(3.13 \mathrm{C})$; a Phantom $3 \mathrm{~A}$ RGB composite image forms the background .

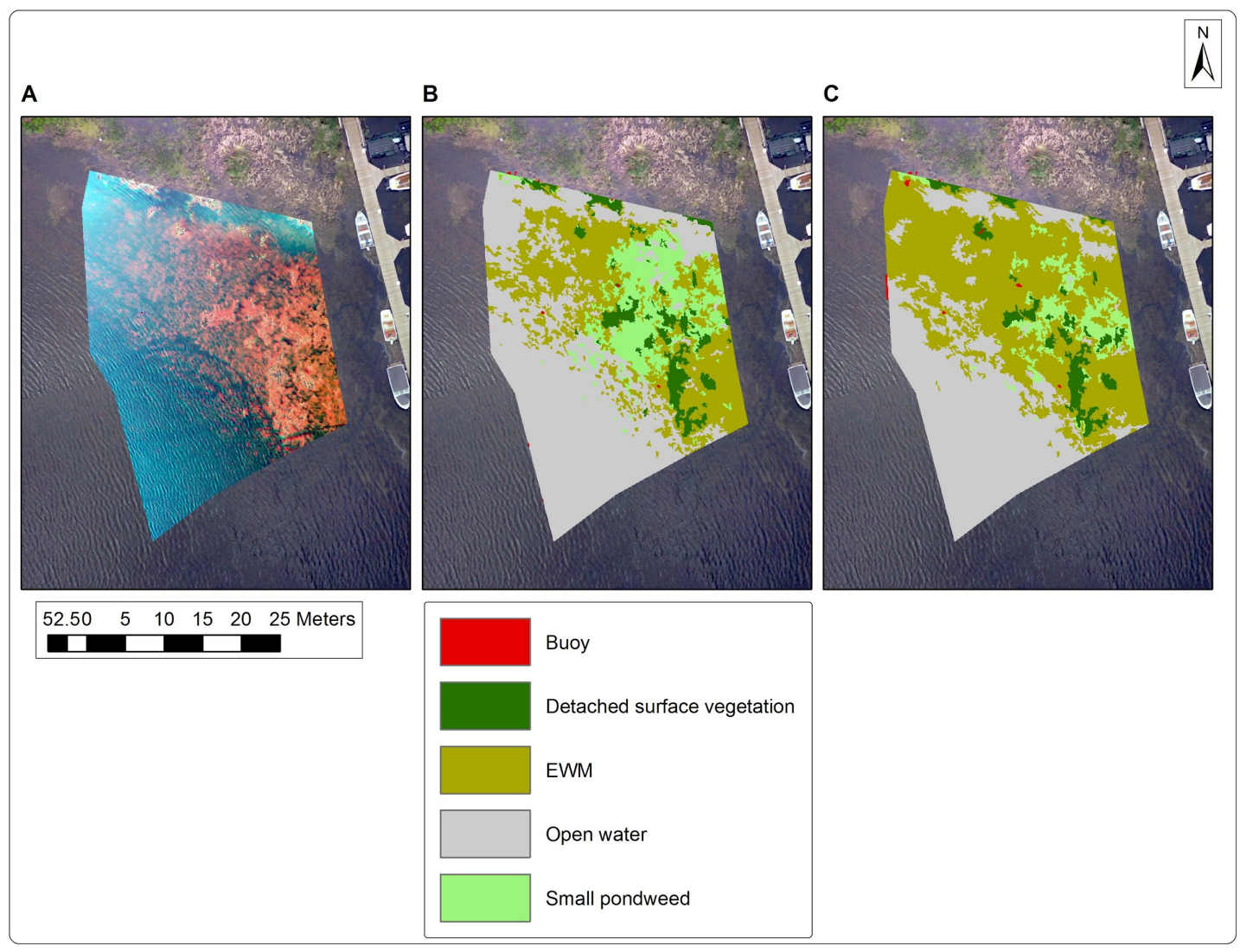

Figure 3.13. VISNIR multispectral image from June 2017 for Court East using colorinfrared bands (A) and classification results with scale parameter $=25(\mathrm{~B})$ and scale parameter $=50(\mathrm{C})$. 
At the Court East site in June of 2017, field surveys showed that visible vegetation was primarily EWM near the sampling buoys, with some areas of Potamogeton pusillus ssp. pusillus (small or small-leaf pondweed), shown out of the water in Figure 3.14D, and Elodea. During this visit, Elodea was mostly beneath the water's surface, while the top of the EWM canopy was at the surface (but not emergent) (Figures 3.14A and 3.14B). Floating spatterdock leaves were distinctly visible, as were areas of detached, floating surface vegetation (3.14C). We thought it could be possible to differentiate the EWM visible at the surface from small pondweed and selected areas for use in classification that were dominated by those two vegetation types based on the visual estimates that took place near the three sampling buoys deployed here. The dense EWM shows up prominently in the near-infrared VISNIR imagery (Figure 3.13A), but training sites for small pondweed were harder to reliably select because the areas were not extensive, and it appeared mostly near the detached surface vegetation in classification results (Figures $3.13 \mathrm{~B}$ and $3.13 \mathrm{C}$ ). The scale parameter $=25$ results (designed for clearer waters) and the scale parameter $=50$ results (designed for the darker waters, such as this site) appear different, with small pondweed more extensive with the smaller scale parameter and EWM more extensive with the larger scale parameter. Detached surface vegetation appears similar in both results.
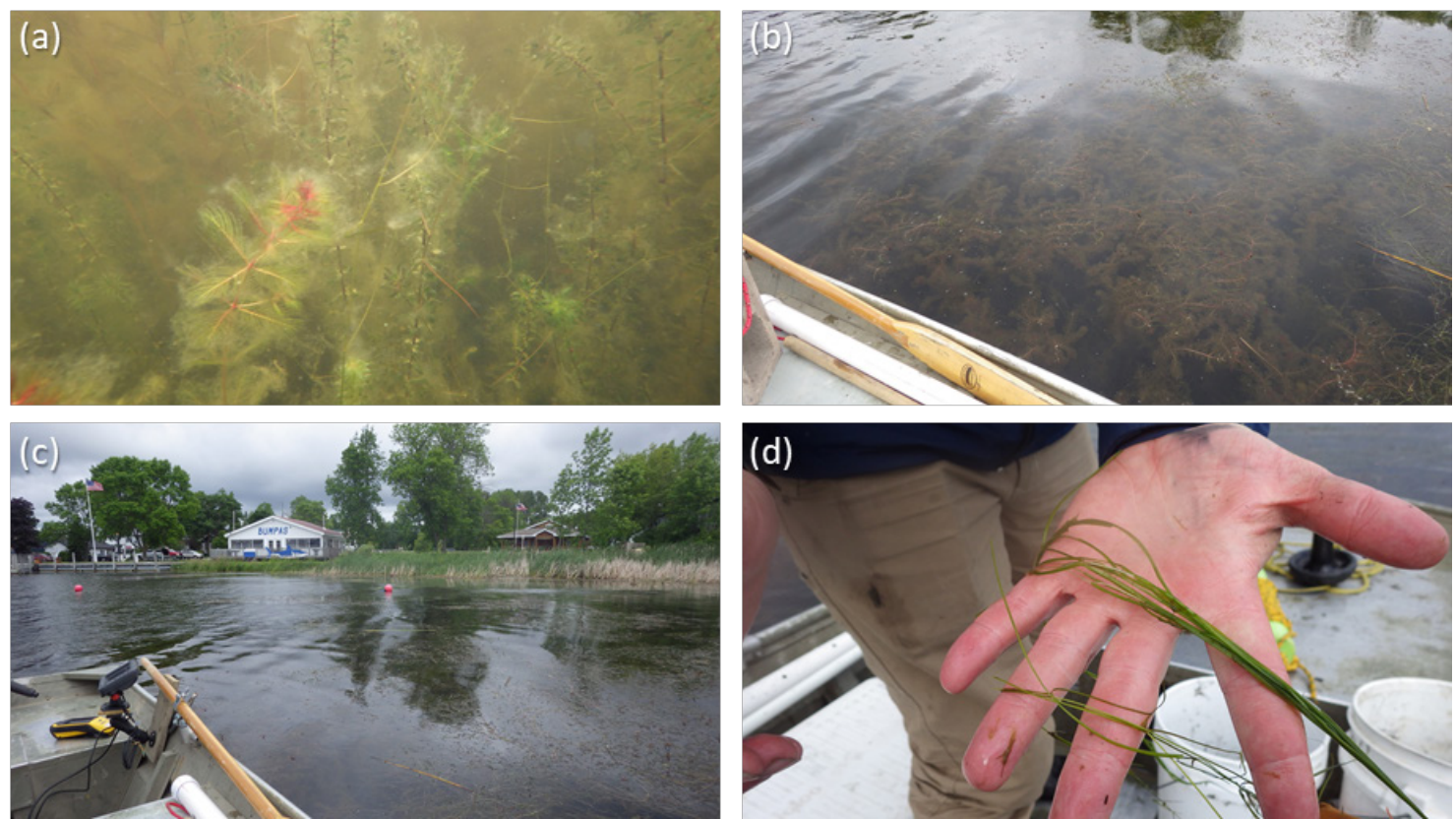

Figure 3.14. Field photos taken at Court East on the July 2017 survey day, showing a mixture of EWM and Elodea beneath the water surface (A), dense EWM at the water surface (B), detached areas of vegetation to the right of the survey vessel with two sampling buoy locations visible in the background (C), and small pondweed removed from the water (D).

Court East in July 2017 was one of the sites we used when initially testing different scale parameters. Figure 3.15 adds a classification result with a very small scale parameter of 5 
(Fig. 3.15A), zoomed in to the northeast corner of the area shown in Figure 13. The three different scale parameters ( 5 vs. 25 vs. 50) create classification results with different appearances. The smallest scale parameter allows for more finely divided vegetation polygons and the ability to include a spatterdock class that we were not able to capture with training areas at the two larger scale parameters. Small pondweed appears less extensive with the smallest scale parameter but more extensive with the scale parameter of 25 .

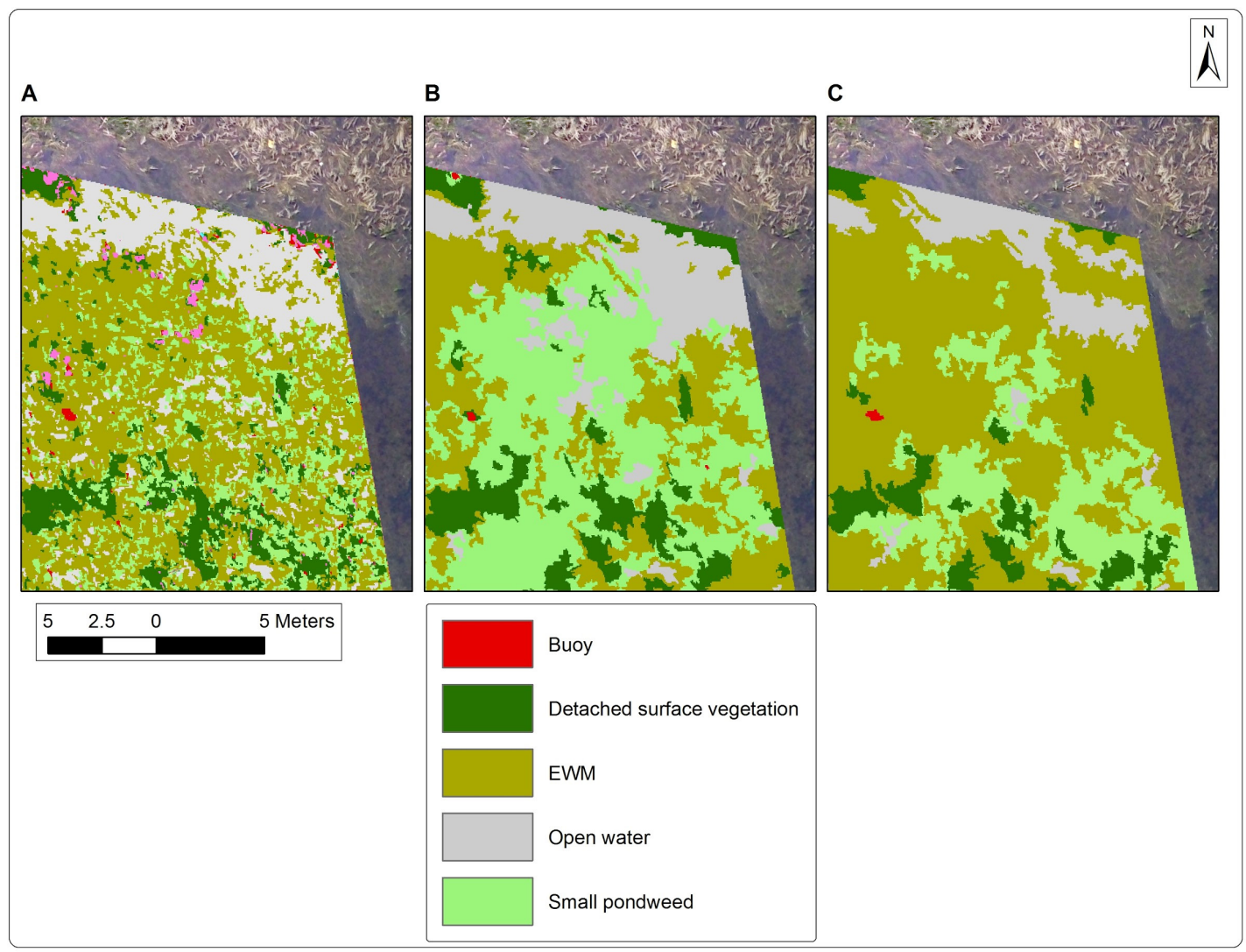

Figure 3.15. Comparison of June 2017 VISNIR classification results for the northeastern corner of the analyzed image, with scale parameter $=5(\mathrm{~A}), 25(\mathrm{~B})$, and $50(\mathrm{C})$. 




Figure 3.16. Tetracam multispectral image from July 2017 for Court East using colorinfrared bands (A) and classification results with scale parameter $=25(\mathrm{~B})$ and scale parameter $=50(\mathrm{C})$.

Our visit to Court East in July 2017 occurred soon after an aquatic vegetation harvester had been deployed by local marinas to control nuisance growth, leaving behind significant areas of detached surface vegetation. These show up as the brighter white areas in the Tetracam CIR image (Fig. 3.16A), so we created a separate vegetation class for this cover type. Visual estimates for the area around a sampling buoy in the southwest corner showed a dominance of Elodea with EWM also being prominent. Underwater photos such as Fig. 3.17 showed EWM and Elodea closely mixed together, and inspection of the Tetracam imagery did not show any obvious difference between the two. The tops of the canopies for both species were approximately $0.75 \mathrm{~m}$ to $1.0 \mathrm{~m}$ below the surface in approximately $1.5 \mathrm{~m}$ of water. Because they were growing so closely together, we created a "mixed EWM/Elodea" class for this classification. 


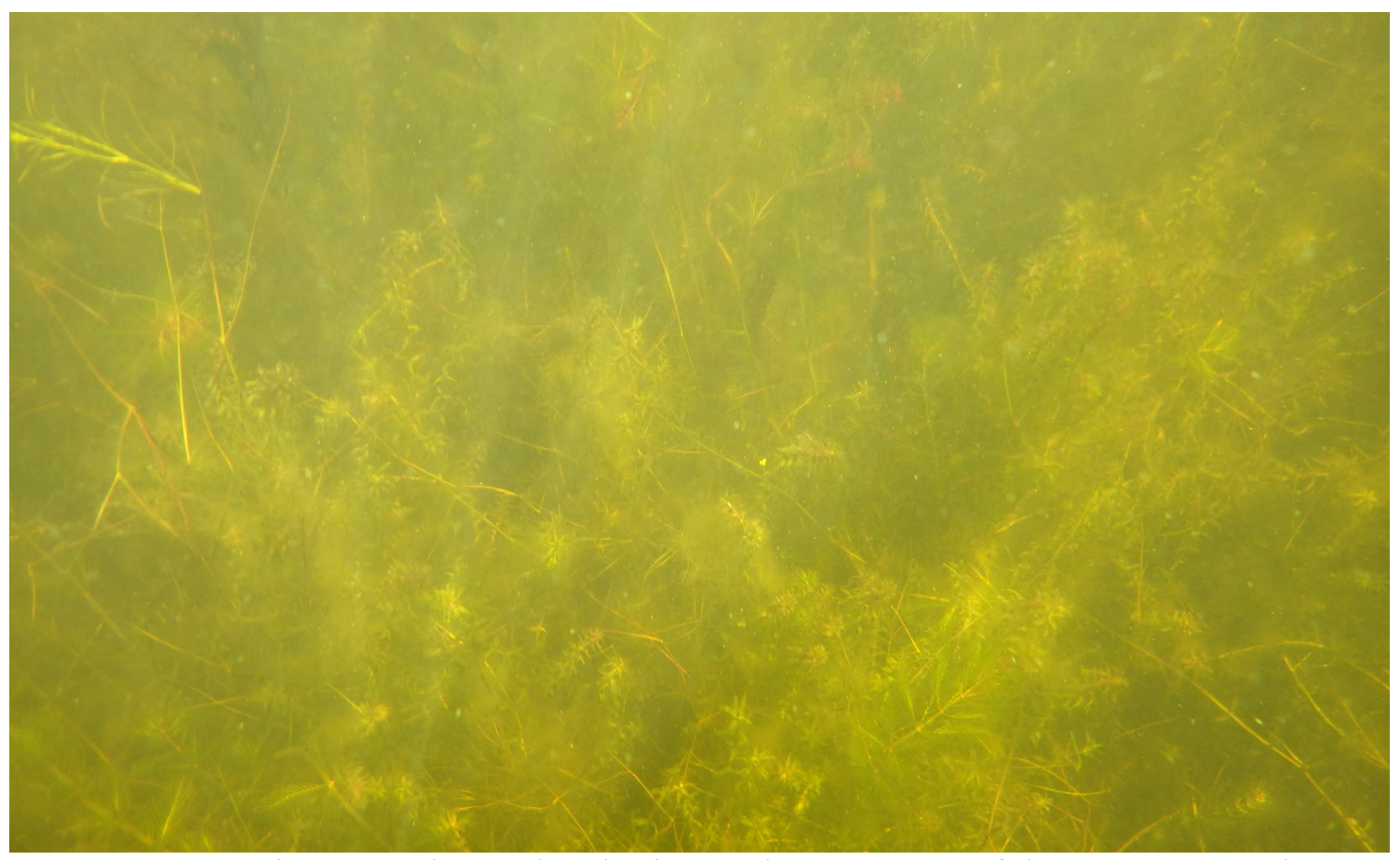

Figure 3.17. Underwater photo taken in the southwest corner of the Court East July 2017 Tetracam image area, showing a matrix of Elodea and EWM. 


\subsubsection{Hessel Marina}

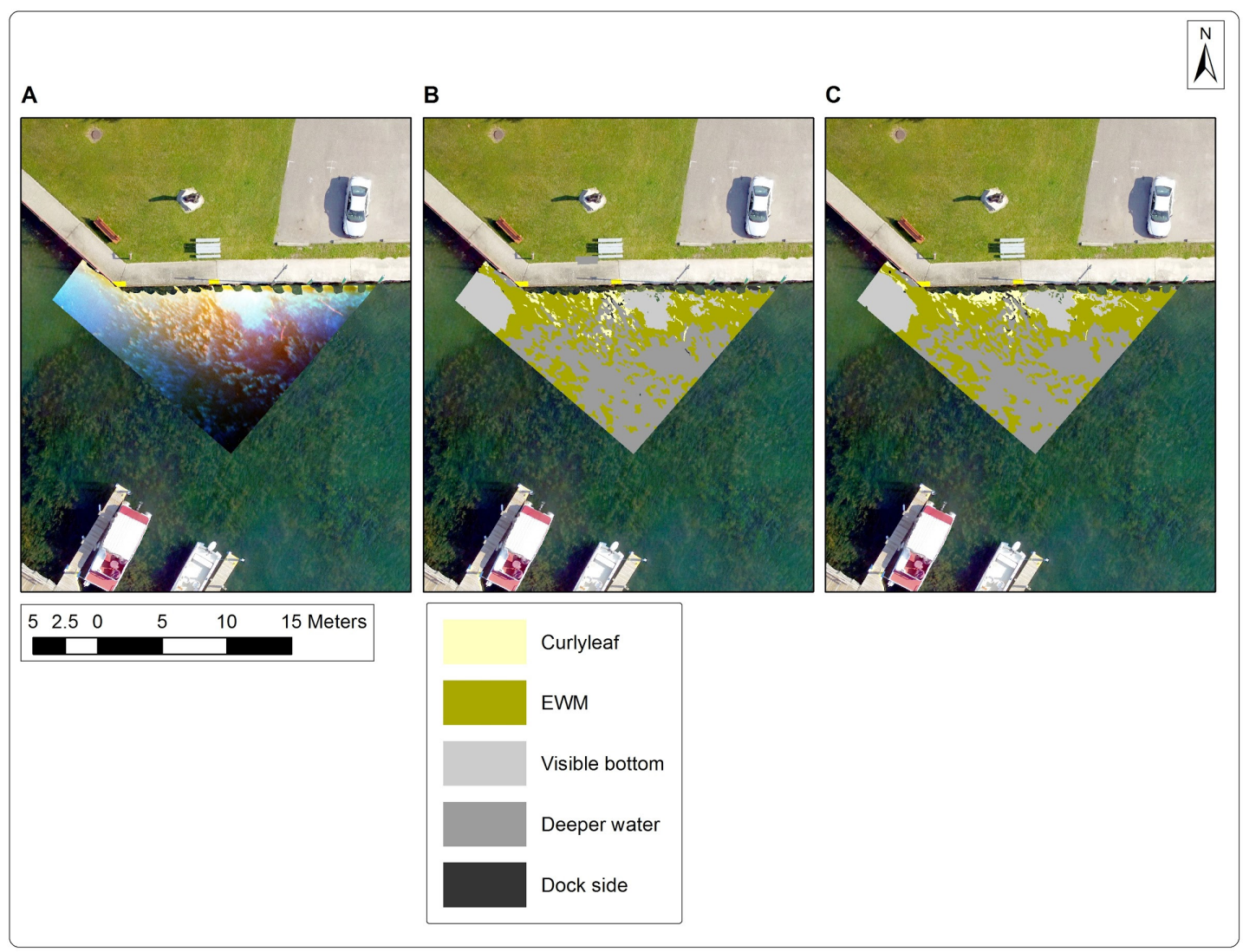

Figure 3.18. Tetracam multispectral image from July 2017 for Hessel Marina using color-infrared bands $(\mathrm{A})$ and classification results with scale parameter $=25(\mathrm{~B})$ and scale parameter $=50(\mathrm{C})$.

Visual estimates recorded for the Hessel Marina site in July 2017 showed that the predominant vegetation was EWM, with Potamogeton crispus (curlyleaf pondweed, another invasive pecies of SAV) also present. Field photos such as Figure 3.19 show both species present, with curlyleaf having similar heights and appearing generally brighter in this instance than EWM. This observation led us to identify the brightest areas of SAV in the imagery as curlyleaf. The extent of EWM in the July 2017 Hessel Marina classification results (Figs. 3.18 B and C) appears similar between the two scale parameters, but curlyleaf covers larger areas in the scale parameter $=50$ results (Fig. 3.18C). 


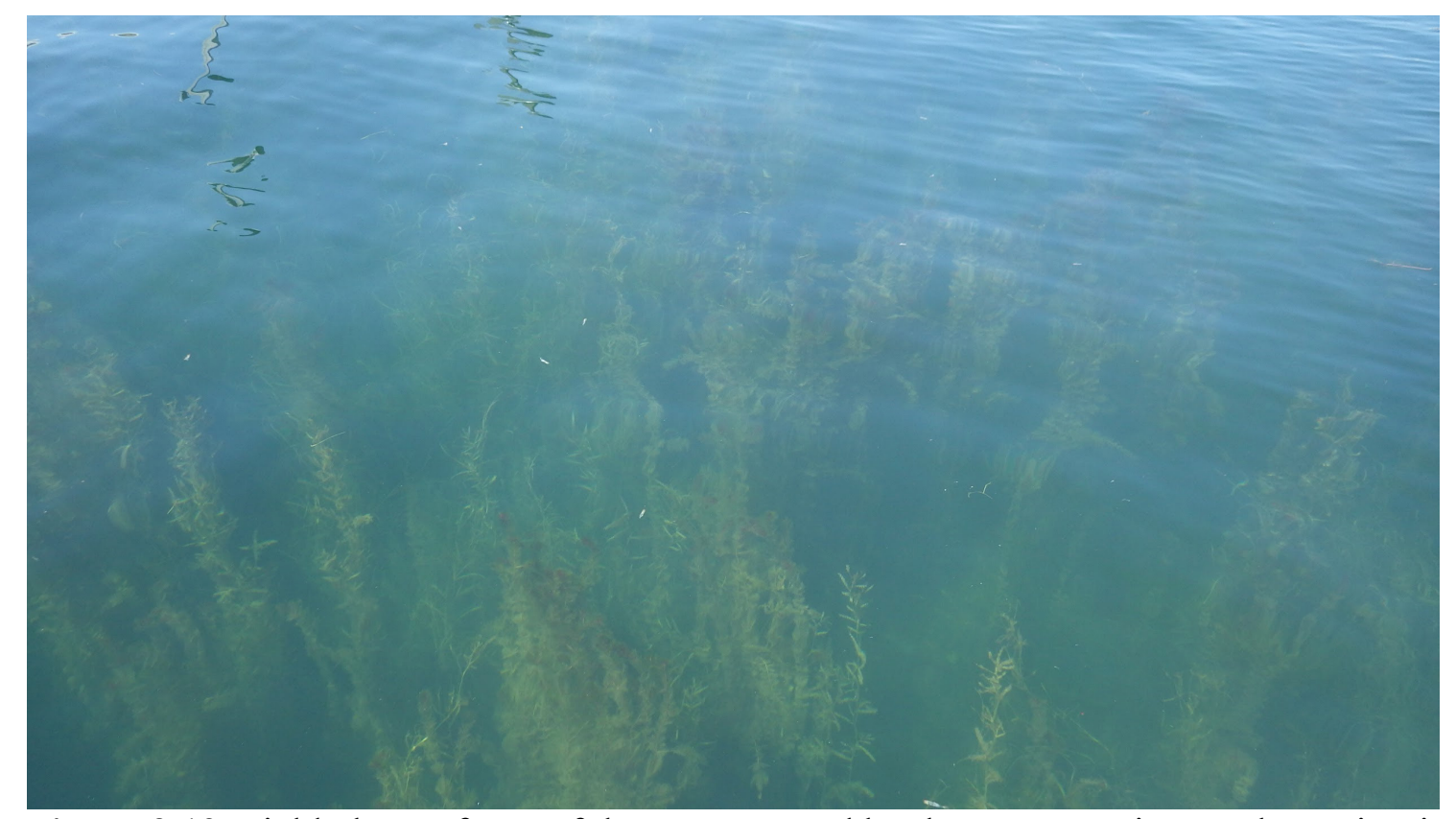

Figure 3.19. Field photo of part of the area covered by the Tetracam image shown in Fig. 3.18, with both EWM and curlyleaf pondweed present.

\subsubsection{Howells Dock}

Three Howells Dock classifications were completed using the six Tetracam bands plus mNDVI, including one for August 2016, two image scenes for August 2017, and one for August 2018. Howells Dock has locally extensive EWM that appears to be growing on the underwater remnants of an old crib dock and has not undergone treatment for EWM removal or reduction since at least 2015. Figure 3.20 shows the input image and classification results for August 2016; Figure 3.21 shows the August 2017 result for Tetracam image number 910, Figure 3.22 shows the August 2017 result for image number 916, and Figure 3.23 shows the August 2018 image and results. For August 2017, we found that there was sufficient color variation between neighboring Tetracam images that we analyzed images separately. 


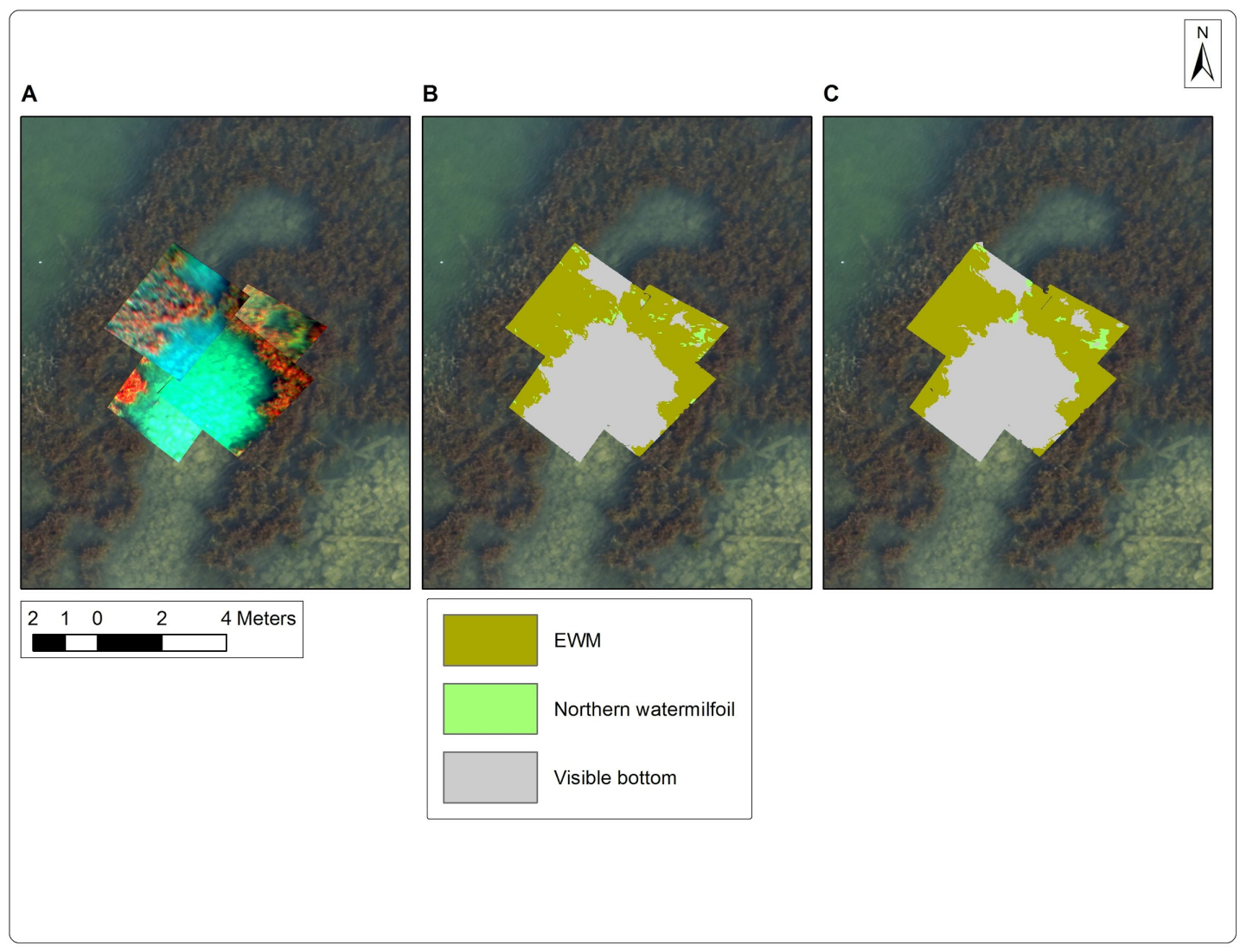

Figure 3.20. Tetracam multispectral imagery from August 2016 for Howells Dock (A) using color-infrared bands (A) and classification results with scale parameter $=25$ (B) and scale parameter $=50(\mathrm{C})$. 


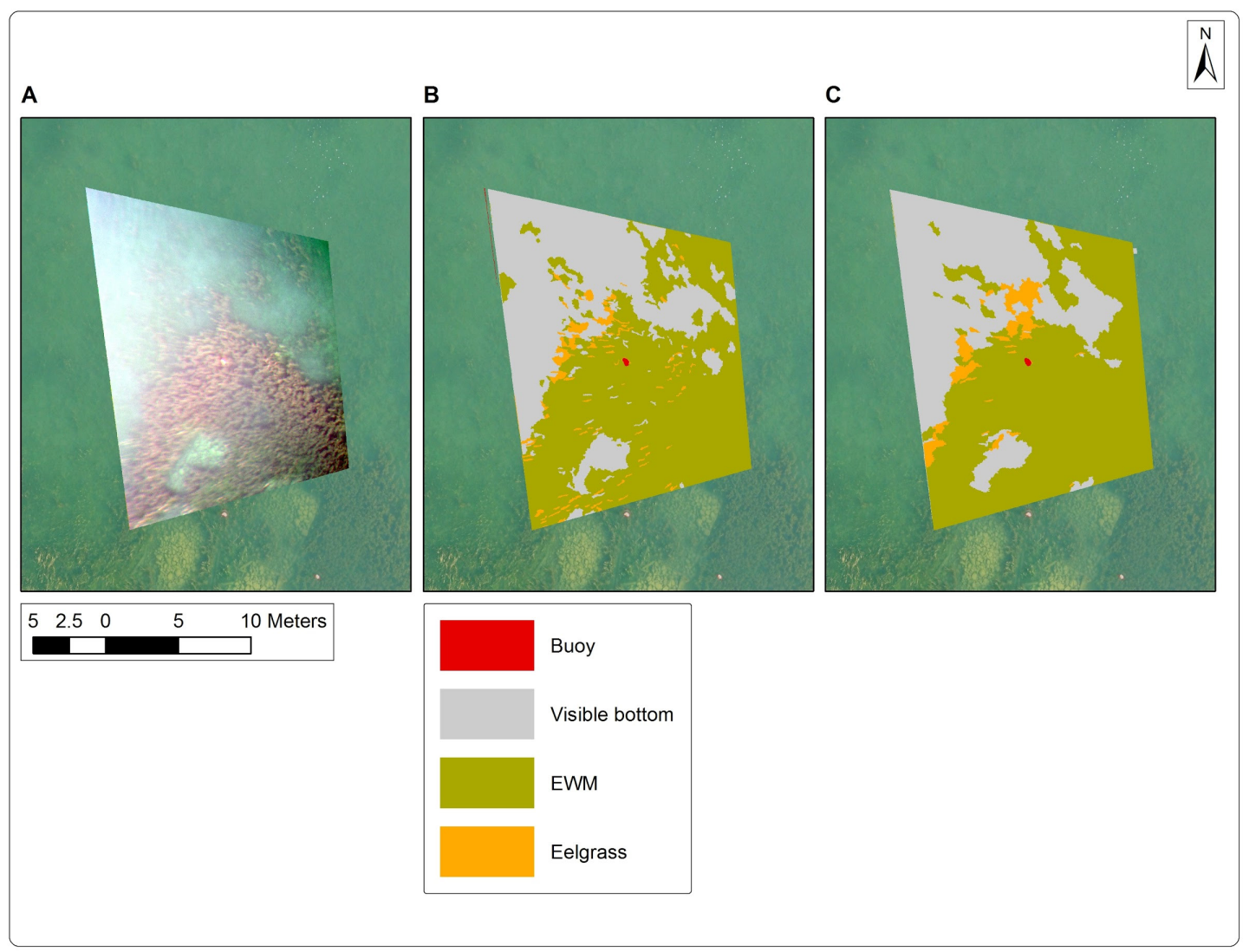

Figure 3.21. Tetracam multispectral image number 910 from August 2017 for the northern part of Howells Dock (A) using color-infrared bands (A), classification results with scale parameter $=25(B)$, and with scale parameter $=50(\mathrm{C})$. 


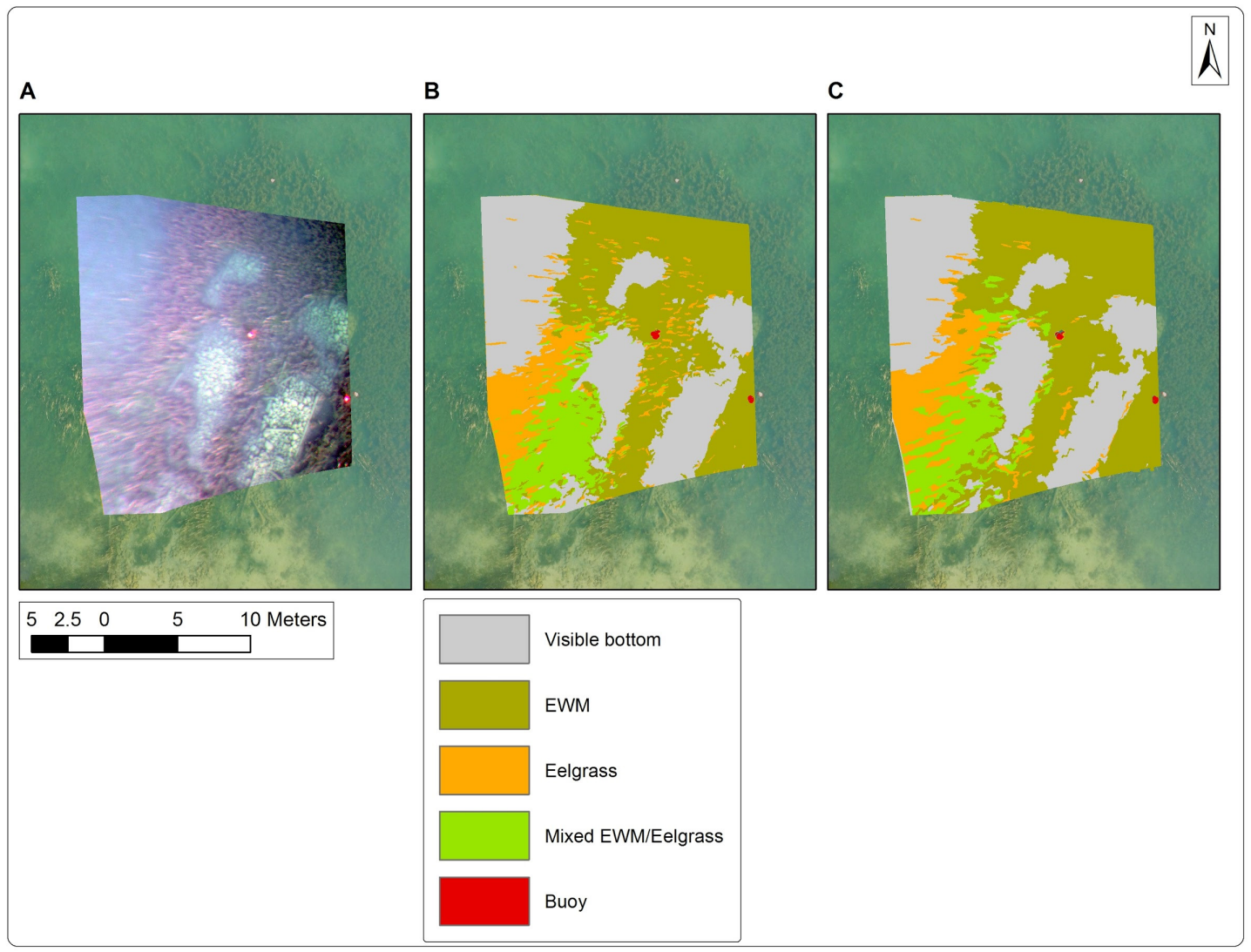

Figure 3.22. Tetracam multispectral image number 916 from August 2017 for the centre part of Howells Dock using color-infrared bands (A), classification results with scale parameter $=25(\mathrm{~B})$, and with scale parameter $=50(\mathrm{C})$. 


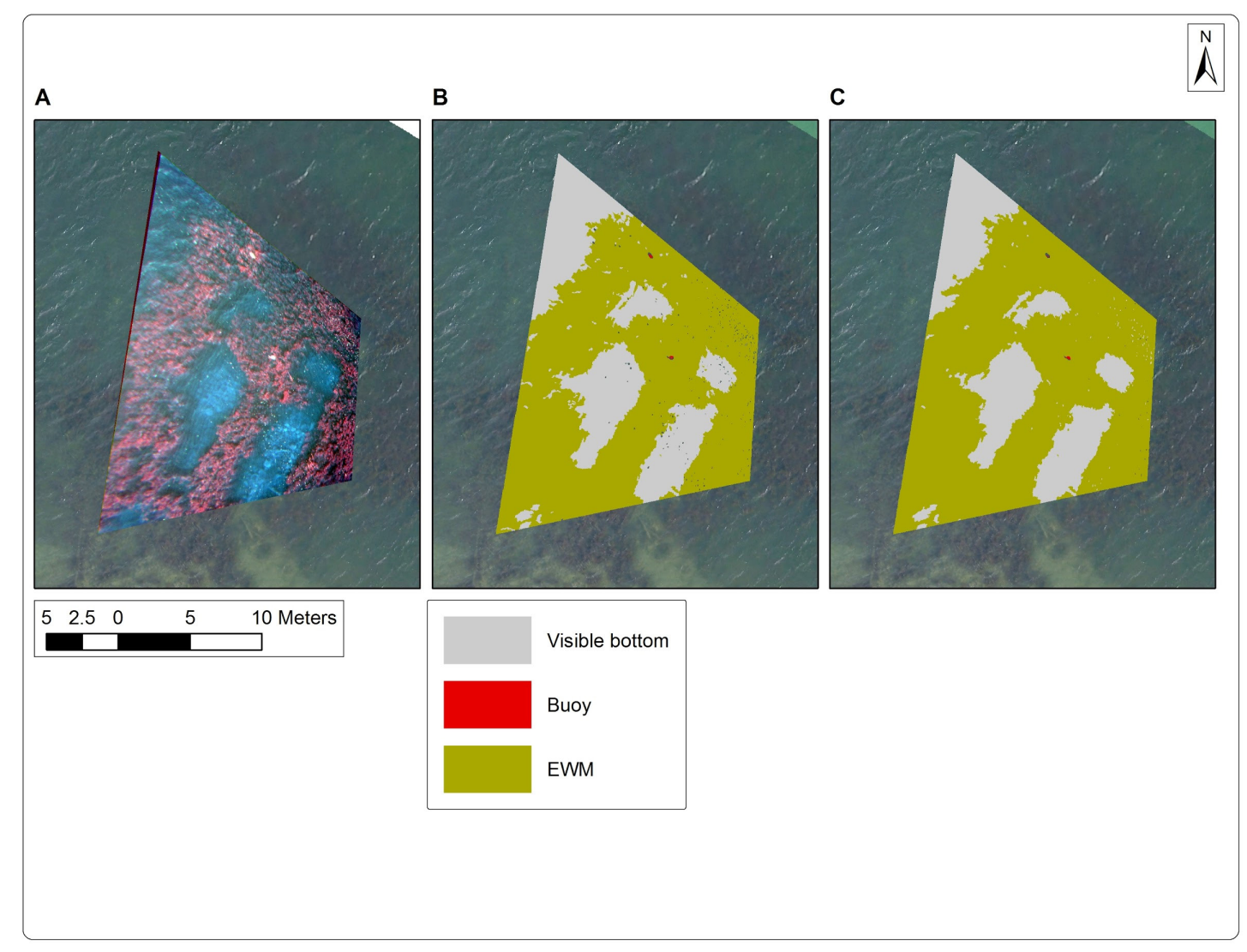

Figure 3.23. Tetracam multispectral image from August 2018 for Howells Dock using color-infrared bands (A), classification results with scale parameter $=25(\mathrm{~B})$, and with scale parameter $=50(\mathrm{C})$.

The August 2016 Howells Dock classification (Fig. 3.20) used four Tetracam images that were combined into a single image for classification purposes, with each covering approximately at $3 \times 3 \mathrm{~m}$ area. The visual estimates for this site showed that vegetation was primarily EWM, with nearby areas of eelgrass (Vallisneria americana, also known as water celery or tapegrass) not visible in the Tetracam images. While northern watermilfoil (Myriophyllum sibiricum), a native species, was not recorded in the visual estimates, it was present in the rake twist data for this site, and it could be seen in field photographs that were inspected more closely after field work was completed (Fig. 3.24). 


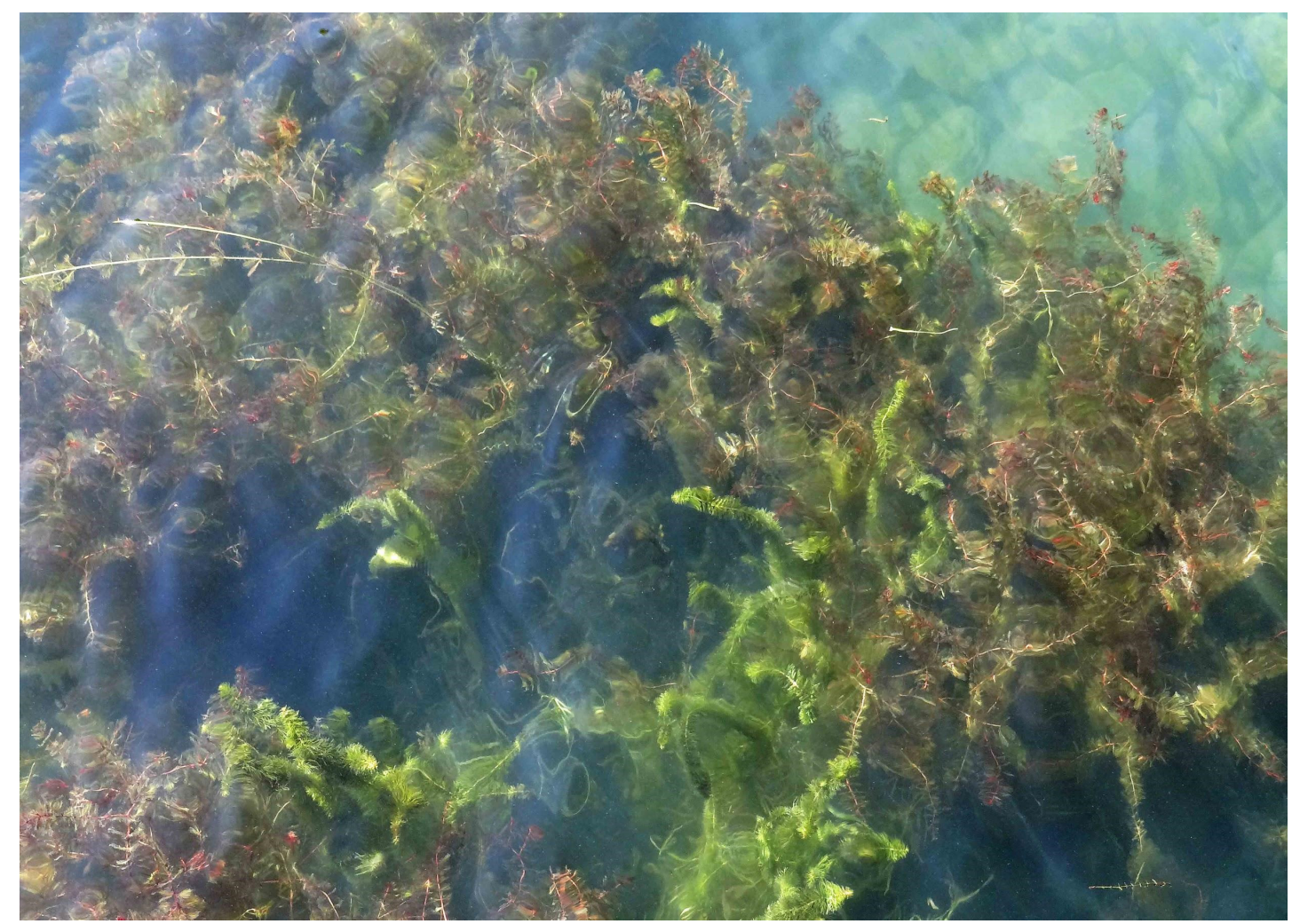

Figure 3.24. The bright green vegetation is northern watermilfoil that was visible in the August 2016 Tetracam imagery for Howells Dock, while the darker green/brown vegetation is Eurasian watermilfoil.

The areas visible in image 910 (Fig. 3.21) were predominantly EWM that were one to two meters below the surface, with small areas of eelgrass based on our visual estimates, and the classification results reflect this. The areas in image 916 (Fig. 3.22) were a mix of eelgrass and EWM based on visual estimates. The peduncles (long, coiled flower stalk) of eelgrass were quite distinct in the field (Fig. 3.25) and could be seen in the Tetracam imagery as well, serving to help define training sites for classification. There did not appear to be distinct visually identifiable differences in the Tetracam imagery between EWM and eelgrass for the main stems of the plants when reviewing the aerial imagery that had been collected. 


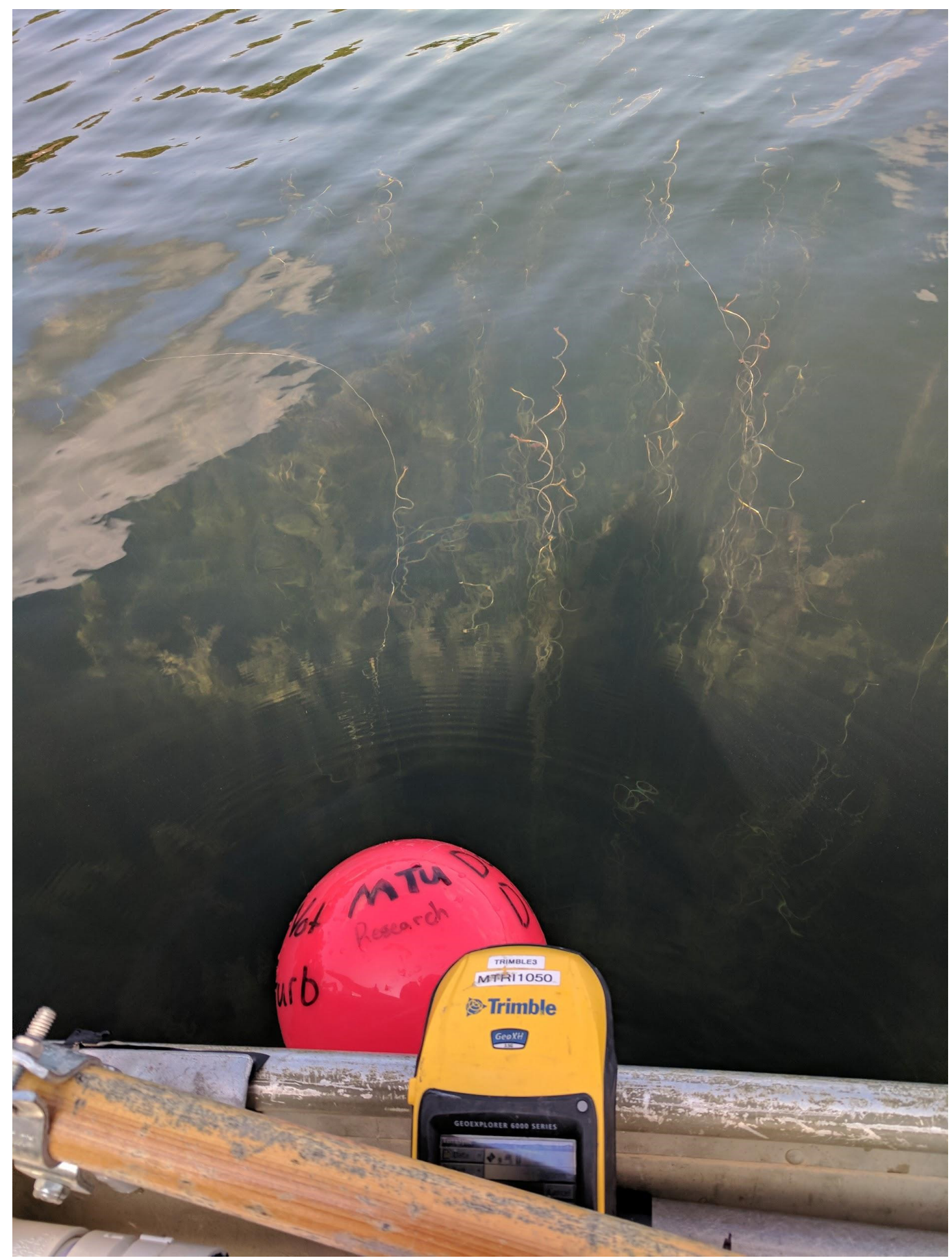

Figure 3.25. Example of eelgrass peduncles visible at the water's surface near one of the sampling buoys in August 2017 at Howells Dock, with a Trimble GPS unit recording the location in the foreground. 
Fieldwork in August 2018 showed that there was almost no eelgrass present at Howells Dock and only EWM could be identified visually, at depths of 0.5 to $1.5 \mathrm{~m}$ below the water's surface (Fig. 3.26). This informed our selection of training polygons and the results shown in Fig. 3.23, where only EWM and visible bottom are identified, along with a distinct class for the buoys (one of which can be seen in Figure 3.25). Areas of EWM vs. the visible lake bottom are distinct in the input imagery and in the classification results.

Figure 3.26. Example underwater field photo taken on the same day as the August 2018 Tetracam flight showing EWM. 


\subsubsection{Neil}

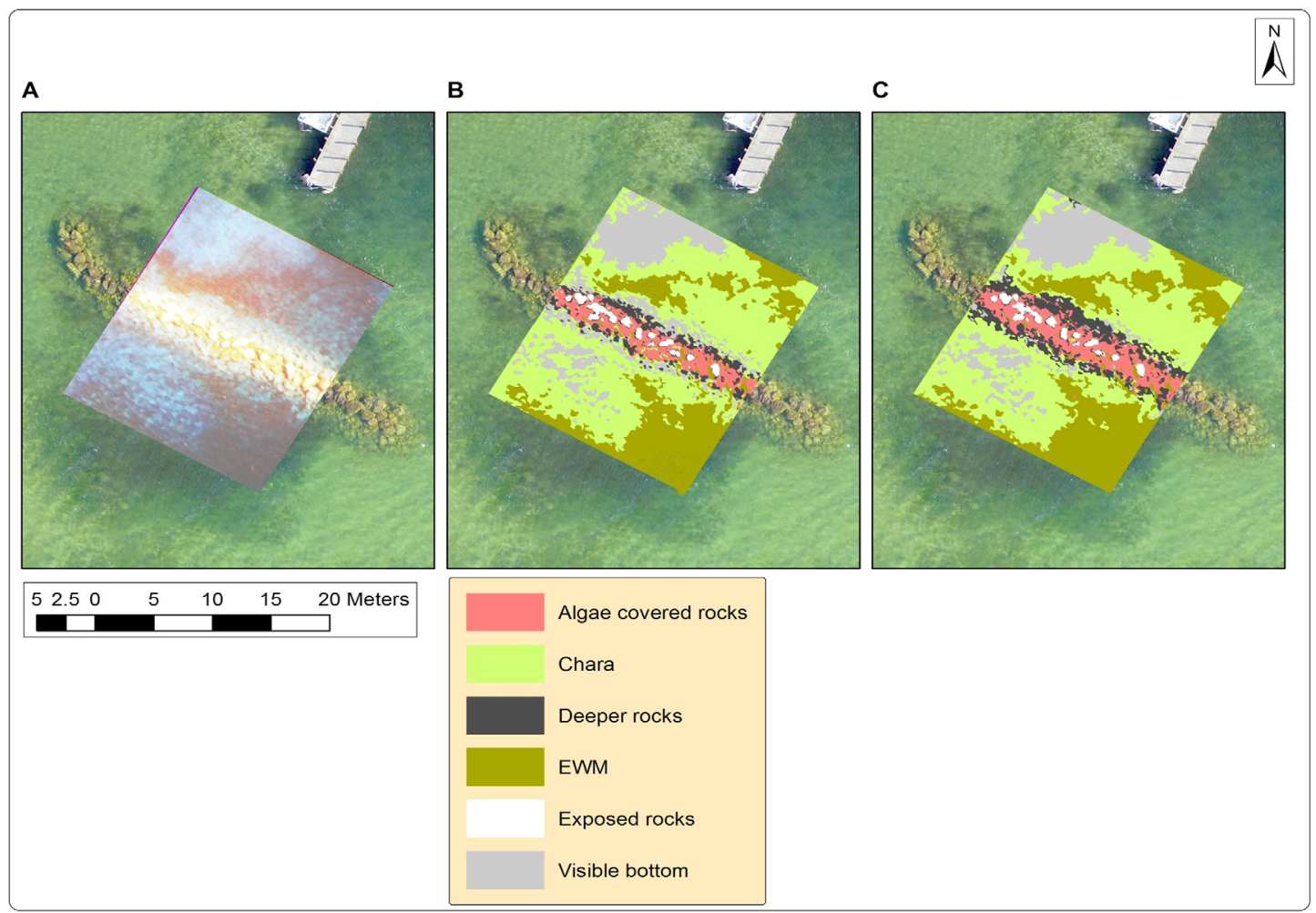

Figure 3.27. Tetracam multispectral image from August 2018 for Neil using colorinfrared bands (A), classification results with scale parameter $=25(\mathrm{~B})$, and with scale parameter $=50(\mathrm{C})$.

Visual estimates showed that the taller vegetation showing up as darker areas in Fig. 3.27A was EWM, especially on the southwest side of the breakwater in the middle of the image. EWM was $1.75 \mathrm{~m}$ beneath the surface in approximately $2.4 \mathrm{~m}$ of water. There was also a vegetation class we initially called "low vegetation" from visual estimates because it appeared to be at the bottom of the site (in approximately $2.4 \mathrm{~m}$ of water). Rake tosses showed this to be Chara (both EWM and Chara can be seen in Fig. 3.28). The breakwater had three distinct-appearing areas in the Tetracam image of exposed rocks, deeper rocks, and algae covered rocks in between these, so these were all used as training and mapping classes for the classification results, but they could also be combined into a single "rocks" class. 


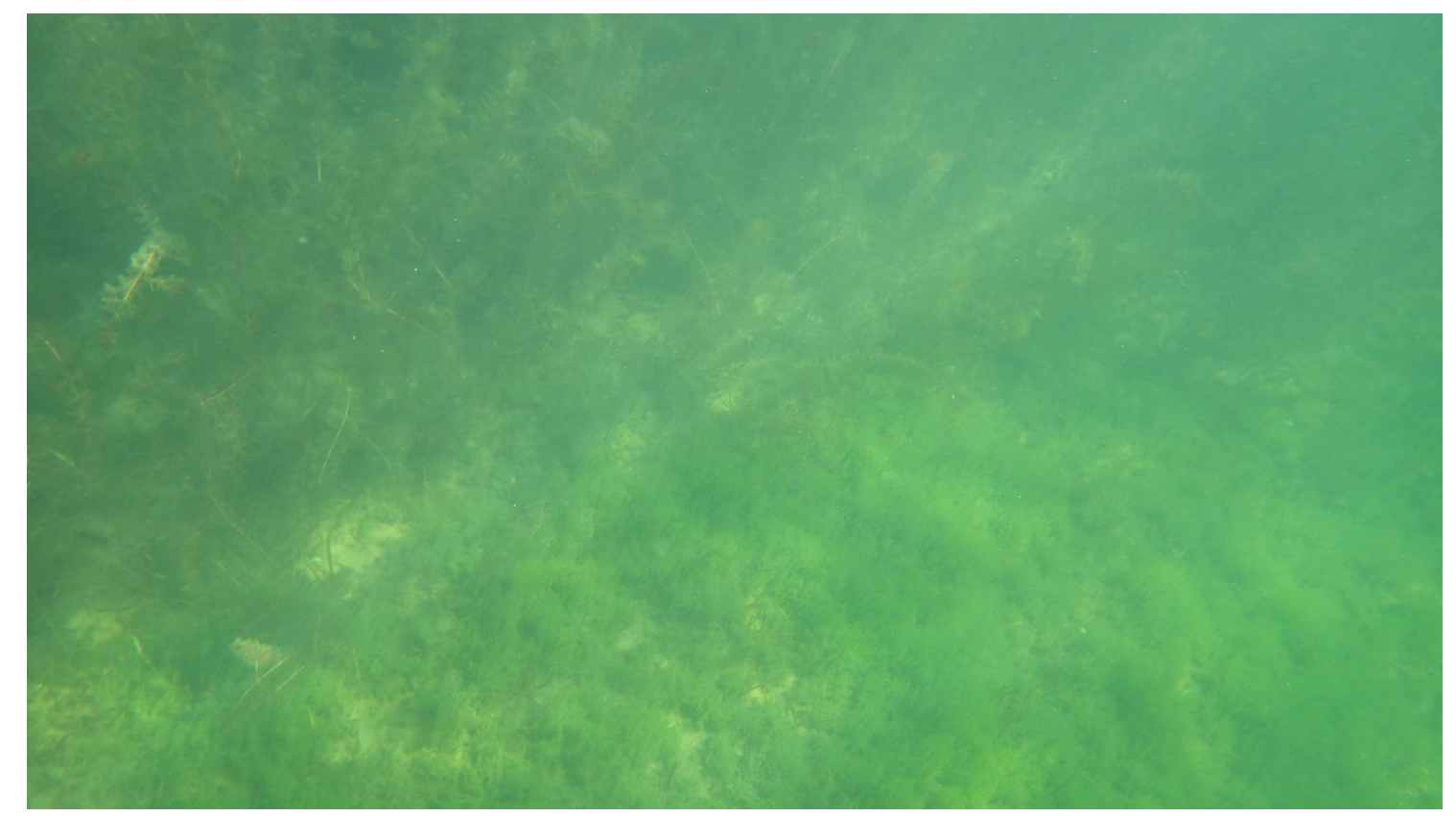

Figure 3.28. Example underwater photo of Neil area taken at a transition zone between EWM (top left, taller and darker vegetation) and Chara (bottom right, shorter and lighter colored vegetation).

\subsubsection{Error Analysis}

The error matrices for each classification are summarized in Table 3.4, and the full error matrices are available as supplementary material in Appendix 2-A. 
Table 3.4. Summary of error analysis results for 2016-2018 classifications

\begin{tabular}{|c|c|c|c|c|c|c|c|c|}
\hline Site & Date & $\begin{array}{l}\text { Image } \\
\text { type } \\
\text { (and } \\
\text { no.) }\end{array}$ & $\begin{array}{l}\text { Overall } \\
\text { accuracy }\end{array}$ & $\begin{array}{l}\text { EWM } \\
\text { producer's } \\
\text { accuracy }\end{array}$ & $\begin{array}{l}\text { EWM } \\
\text { user's } \\
\text { accuracy }\end{array}$ & $\begin{array}{l}\text { Water } \\
\text { type }\end{array}$ & $\begin{array}{l}\text { Scale } \\
\text { parameter }\end{array}$ & $\begin{array}{l}\text { No. of } \\
\text { SAV } \\
\text { classes }\end{array}$ \\
\hline $\begin{array}{l}\text { Breezeswept } \\
\text { N. }\end{array}$ & $\begin{array}{l}\text { July } \\
2017\end{array}$ & $\mathrm{TC}$ & $\begin{array}{l}74.5 \% \\
(38 / 51)\end{array}$ & $\begin{array}{l}0.0 \% \\
(0 / 2)\end{array}$ & $\begin{array}{l}0.0 \% \\
(0 / 1)\end{array}$ & Dark & 25 & 3 \\
\hline $\begin{array}{l}\text { Breezeswept } \\
\text { N. }\end{array}$ & $\begin{array}{l}\text { July } \\
2017\end{array}$ & $\mathrm{TC}$ & $\begin{array}{l}71.7 \% \\
(33 / 46)\end{array}$ & $\begin{array}{l}25.0 \% \\
(1 / 4)\end{array}$ & $\begin{array}{l}100 \% \\
(1 / 1)\end{array}$ & Dark & 50 & 3 \\
\hline Court East & $\begin{array}{l}\text { Aug. } \\
2016\end{array}$ & $\mathrm{TC}$ & $\begin{array}{l}83.3 \% \\
(40 / 48)\end{array}$ & $\begin{array}{l}93.3 \% \\
(14 / 15)\end{array}$ & $\begin{array}{l}73.7 \% \\
(14 / 19)\end{array}$ & Dark & 25 & 1 \\
\hline Court East & $\begin{array}{l}\text { Aug. } \\
2016\end{array}$ & $\mathrm{TC}$ & $\begin{array}{l}80.9 \% \\
(38 / 47)\end{array}$ & $\begin{array}{l}90.0 \% \\
(9 / 10)\end{array}$ & $\begin{array}{l}56.2 \% \\
(9 / 16)\end{array}$ & Dark & 50 & 1 \\
\hline Court East & $\begin{array}{l}\text { June } \\
2017\end{array}$ & VN & $\begin{array}{l}67.9 \% \\
(38 / 56)\end{array}$ & $\begin{array}{l}56.0 \% \\
(14 / 25)\end{array}$ & $\begin{array}{l}66.7 \% \\
(14 / 21)\end{array}$ & Dark & 25 & 2 \\
\hline Court East & $\begin{array}{l}\text { June } \\
2017\end{array}$ & VN & $\begin{array}{l}67.9 \% \\
(38 / 56)\end{array}$ & $\begin{array}{l}73.7 \% \\
(14 / 19)\end{array}$ & $\begin{array}{l}51.9 \% \\
(14 / 27)\end{array}$ & Dark & 50 & 2 \\
\hline Court East & $\begin{array}{l}\text { July } \\
2017\end{array}$ & $\mathrm{TC}$ & $\begin{array}{l}97.7 \% \\
(43 / 44)\end{array}$ & $\begin{array}{l}100 \% 1 \\
(14 / 14)\end{array}$ & $\begin{array}{l}93.3 \%^{1} \\
(14 / 15)\end{array}$ & Dark & 25 & $1^{1}$ \\
\hline Court East & $\begin{array}{l}\text { July } \\
2017\end{array}$ & $\mathrm{TC}$ & $\begin{array}{l}88.9 \% \\
(40 / 45)\end{array}$ & $\begin{array}{l}80.0 \%^{1} \\
(12 / 15)\end{array}$ & $\begin{array}{l}85.7 \%^{1} \\
(12 / 14)\end{array}$ & Dark & 50 & $1^{1}$ \\
\hline $\begin{array}{l}\text { Hessel } \\
\text { Marina }\end{array}$ & $\begin{array}{l}\text { July } \\
2017\end{array}$ & $\mathrm{TC}$ & $\begin{array}{l}60.4 \% \\
(32 / 53)\end{array}$ & $\begin{array}{l}73.3 \% \\
(11 / 15)\end{array}$ & $\begin{array}{l}57.9 \% \\
(11 / 19)\end{array}$ & Clear & 25 & 2 \\
\hline $\begin{array}{l}\text { Hessel } \\
\text { Marina }\end{array}$ & $\begin{array}{l}\text { July } \\
2017\end{array}$ & $\mathrm{TC}$ & $\begin{array}{l}60.0 \% \\
(30 / 50)\end{array}$ & $\begin{array}{l}60.0 \% \\
(12 / 20)\end{array}$ & $\begin{array}{l}60.0 \% \\
(12 / 20)\end{array}$ & Clear & 50 & 2 \\
\hline $\begin{array}{l}\text { Howells } \\
\text { Dock }\end{array}$ & $\begin{array}{l}\text { Aug. } \\
2016\end{array}$ & $\mathrm{TC}$ & $\begin{array}{l}93.0 \% \\
(40 / 43)\end{array}$ & $\begin{array}{l}100 \% \\
(19 / 19)\end{array}$ & $\begin{array}{l}95.0 \% \\
(19 / 20)\end{array}$ & Clear & 25 & 2 \\
\hline $\begin{array}{l}\text { Howells } \\
\text { Dock }\end{array}$ & $\begin{array}{l}\text { Aug. } \\
2016\end{array}$ & $\mathrm{TC}$ & $\begin{array}{l}88.4 \% \\
(38 / 43)\end{array}$ & $\begin{array}{l}89.5 \% \\
(17 / 19)\end{array}$ & $\begin{array}{l}85.0 \% \\
(17 / 20)\end{array}$ & Clear & 50 & 2 \\
\hline $\begin{array}{l}\text { Howells } \\
\text { Dock }\end{array}$ & $\begin{array}{l}\text { Aug. } \\
2017\end{array}$ & $\begin{array}{l}\text { TC - } \\
910\end{array}$ & $\begin{array}{l}74.5 \% \\
(35 / 47)\end{array}$ & $\begin{array}{l}80.8 \% \\
(21 / 26)\end{array}$ & $\begin{array}{l}77.8 \% \\
(21 / 27)\end{array}$ & Clear & 25 & 2 \\
\hline $\begin{array}{l}\text { Howells } \\
\text { Dock }\end{array}$ & $\begin{array}{l}\text { Aug. } \\
2017\end{array}$ & $\begin{array}{l}\text { TC - } \\
910\end{array}$ & $\begin{array}{l}74.5 \% \\
(35 / 47)\end{array}$ & $\begin{array}{l}76.7 \% \\
(23 / 30)\end{array}$ & $\begin{array}{l}85.2 \% \\
(23 / 27)\end{array}$ & Clear & 50 & 2 \\
\hline $\begin{array}{l}\text { Howells } \\
\text { Dock }\end{array}$ & $\begin{array}{l}\text { Aug. } \\
2017\end{array}$ & $\begin{array}{l}\text { TC - } \\
916\end{array}$ & $\begin{array}{l}72.5 \% \\
(37 / 51)\end{array}$ & $\begin{array}{l}65.5 \% \\
(19 / 29)\end{array}$ & $\begin{array}{l}95.0 \% \\
(19 / 20)\end{array}$ & Clear & 25 & 2 \\
\hline $\begin{array}{l}\text { Howells } \\
\text { Dock }\end{array}$ & $\begin{array}{l}\text { Aug. } \\
2017\end{array}$ & $\begin{array}{l}\text { TC - } \\
916\end{array}$ & $\begin{array}{l}84.6 \% \\
(44 / 52)\end{array}$ & $\begin{array}{l}79.2 \% \\
(19 / 24)\end{array}$ & $\begin{array}{l}90.5 \% \\
(19 / 21)\end{array}$ & Clear & 50 & 2 \\
\hline $\begin{array}{l}\text { Howells } \\
\text { Dock }\end{array}$ & $\begin{array}{l}\text { Aug. } \\
2018\end{array}$ & $\mathrm{TC}$ & $\begin{array}{l}86.7 \% \\
(26 / 30)\end{array}$ & $\begin{array}{l}100 \% \\
(17 / 17)\end{array}$ & $\begin{array}{l}81.0 \% \\
(17 / 21)\end{array}$ & Clear & 25 & 1 \\
\hline $\begin{array}{l}\text { Howells } \\
\text { Dock }\end{array}$ & $\begin{array}{l}\text { Aug. } \\
2018\end{array}$ & $\mathrm{TC}$ & $\begin{array}{l}82.4 \% \\
(28 / 34)\end{array}$ & $\begin{array}{l}100 \% \\
(19 / 19)\end{array}$ & $\begin{array}{l}76.0 \% \\
(19 / 25)\end{array}$ & Clear & 50 & 1 \\
\hline Neil & $\begin{array}{l}\text { July } \\
2017\end{array}$ & $\mathrm{TC}$ & $\begin{array}{l}73.2 \% \\
(41 / 56)\end{array}$ & $\begin{array}{l}72.2 \% \\
(13 / 18)\end{array}$ & $\begin{array}{l}92.9 \% \\
(13 / 14)\end{array}$ & Clear & 25 & 2 \\
\hline Neil & $\begin{array}{l}\text { July } \\
2017\end{array}$ & $\mathrm{TC}$ & $\begin{array}{l}79.6 \% \\
(43 / 54)\end{array}$ & $\begin{array}{l}75.0 \% \\
(12 / 16)\end{array}$ & $\begin{array}{l}92.3 \% \\
(12 / 13)\end{array}$ & Clear & 50 & 2 \\
\hline $\begin{array}{l}\text { All sites and } \\
\text { classifications }\end{array}$ & & & $\begin{array}{l}76.7 \% \\
(731 / 953)\end{array}$ & $\begin{array}{l}78.7 \% \\
(280 / 356)\end{array}$ & $\begin{array}{l}77.6 \% \\
(280 / 361)\end{array}$ & & & \\
\hline
\end{tabular}

$T C=$ Tetracam system; $V N=$ VISNIR system ${ }^{I}=$ In July 2017, the Court East site was a matrix of EWM and Elodea that was not visibly separate in imagery or field photos so this was treated as a mixed EWM/Elodea class for accuracy assessment.

Overall accuracies varied from a low of $60.0 \%$ at Hessel Marina in July 2017 with scale parameter $=50(30 / 50$ interpretation points correct $)$ to a high of $97.7 \%$ at Court East in 
July 2017 with scale parameter $=25$ (43/44 correct). The lowest EWM producer's accuracy was $0.0 \%$ at Breezeswept North in July 2017 with scale parameter $=25$, but this was at a site with a limited presence of EWM and 0/2 interpretation points correct; excluding this site, EWM producer's accuracies ranged from a low of $56.0 \%$ at Court East in June 2017 (for the only pair of classifications done from VISNIR imagery) with scale parameter $=25(14 / 25$ correct $)$ to three sites having a high of $100 \%$ : at Court East in July 2017 with scale parameter $=25$, with this site having a mixed EWM/Elodea class (14/14 correct); Howells Dock in August 2016 with scale parameter $=25$ (19/19 correct); and Howells Dock in August 2018 for scale parameters 25 and 50 (17/17 correct for scale parameter $=25$ and 19/19 correct for scale parameter $=50$ ). Excluding Breezeswept North again where EWM was present but scarce, EWM user's accuracies ranged from a low of 51.9\% at Court East in June 2017 with scale parameter $=50(14 / 27$ correct, for the only VISNIR classification pair) to two sites with a high of $95.0 \%$ : Howells Dock in August 2016 with scale parameter $=25(19 / 20$ correct $)$ and Howells Dock image 916 in August 2017 with scale parameter $=25$ (19/20 correct). Average accuracies using all 20 classification results were $76.7 \%$ for overall accuracy, $78.7 \%$ for producer's accuracy, and $77.6 \%$ for user's accuracy.

These results can also be summarized to match the format of Table 3.1, with the averages plus or minus one standard deviation (see Table 3.5). For the "clear water" type of sites with greater light penetration on average, the average accuracy for the "clear" type classification with scale parameter $=25$ was not higher than that for the "dark" type classification with scale parameter $=50$. For the "dark water" sites with lower light penetration on average, accuracy was higher using the "clear" type scale parameter than the "dark" type scale parameter. This was the opposite of our prediction that accuracies would be higher when our selected classification scale parameter and water type matched. All of the average accuracies were within one standard deviation of each other, indicating that it was unlikely that they were significantly different.

Table 3.5. Summary of average accuracy results by site (water) type and classification type $($ small scale parameter $=$ light or large scale parameter $=$ dark $)$.

\begin{tabular}{|c|c|c|c|}
\hline \multirow{3}{*}{ Water type } & \multirow[b]{3}{*}{ Clear } & \\
\hline & & Clear & Dark \\
\hline & & $76.7 \%(+/-10.5 \%)$ & $\underline{78.3 \%(+/-9.2 \%)}$ \\
\hline & Dark & $80.9 \%(+/-11.2 \%)$ & $77.4 \%(+/-8.2 \%)$ \\
\hline
\end{tabular}

(+/- one standard deviation)

The two-way ANOVA mixed model was designed to understand whether the classification accuracies were significantly affected by scale parameter. Table 3.6 shows these mixed model results. 
Table 3.6. Results for the mixed model analysis for each tested accuracy (overall, EWM producer's, and EWM user's) using all sites and years.

\begin{tabular}{llllll}
\hline \multicolumn{5}{c}{ Dependent variable } \\
\hline & Effect & Num DF & Den DF & $\boldsymbol{F}$ value & Pr $>\boldsymbol{F}$ \\
\hline Overall accuracy & Scale & 1 & 8.0 & 0.291 & 0.6042 \\
& Site_type & 1 & 8.0 & 0.055 & 0.8199 \\
& Scale*Site_type & 1 & 8.0 & 1.907 & 0.2047 \\
Producer's accuracy & Scale & 1 & 8.0 & 0.096 & 0.7641 \\
& Site_type & 1 & 8.0 & 1.020 & 0.3421 \\
& Scale*Site_type & 1 & 8.0 & 0.505 & 0.4976 \\
User's accuracy & Scale & 1 & 8.0 & 0.387 & 0.5512 \\
& Site_type & 1 & 8.0 & 2.879 & 0.1282 \\
& Scale*Site_type & 1 & 8.0 & 0.496 & 0.5012 \\
\hline
\end{tabular}

None of the results were significant at the $p=0.05$ level. Neither the scale parameter nor the site type appear to have a significant effect on overall accuracy, and there was not a significant interaction between scale and site type.

As the classification process continued, it seemed possible that accuracy was influenced by the number of SAV species classes that we were attempting to map for each image. Numbers of SAV classes ranged from one (such as at Howells Dock in August 2018 when only EWM was mapped based on vegetation field surveys, Fig. 3.23) to as many as three (at Breezeswept North, with EWM, Elodea, and flatstem pondweed all identified and mapped, Fig. 3.9). To test this, we used the linear regression function in JMP version 14.0.0 to regress accuracy as the response variable against the number of SAV classes. We ran the regression for overall accuracy, producer's accuracy, and user's accuracy.

For overall accuracy, a significant regression equation was found $(\mathrm{F}(1,18)=6.3872, p=$ 0.0211) with the following formula (Fig. 3.29):

$$
\text { Overall accuracy }=0.934-0.085 x \text { (number of } S A V \text { classes), } R^{2}=0.2619 \text {. }
$$




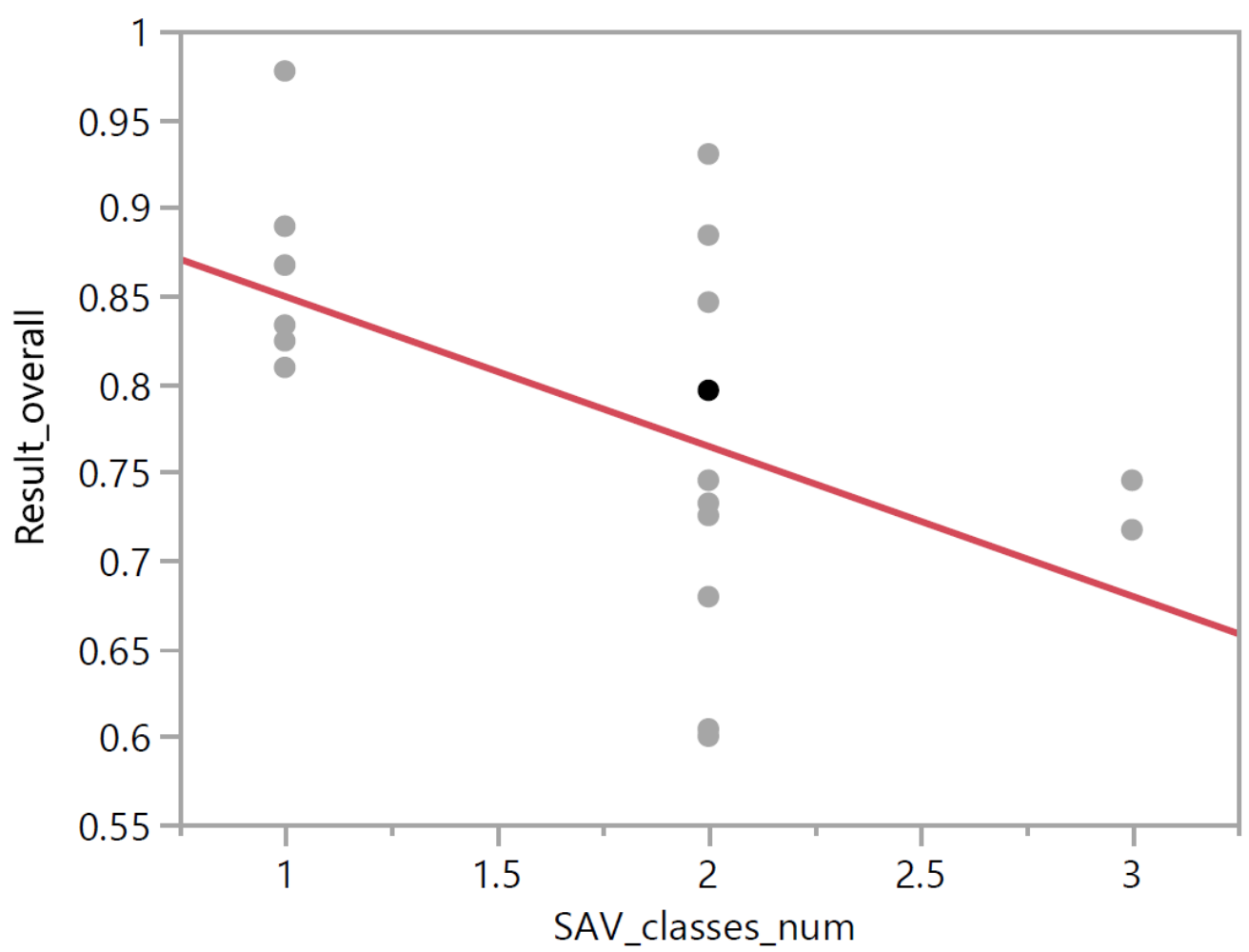

Figure 3.29. Regression equation for overall accuracy vs. number of SAV classes.

For producer's accuracy, a significant regression equation was found $(\mathrm{F}(1,18)=34.8510$, $p<0.0001$ ) with the following formula:

Producer's accuracy $=1.346-0.334 x$ (number of SAV classes), $R^{2}=0.6594$

For user's accuracy, a significant regression equation was not found $(\mathrm{F}(1,18)=1.5128, p$ $=0.2345$ ). 


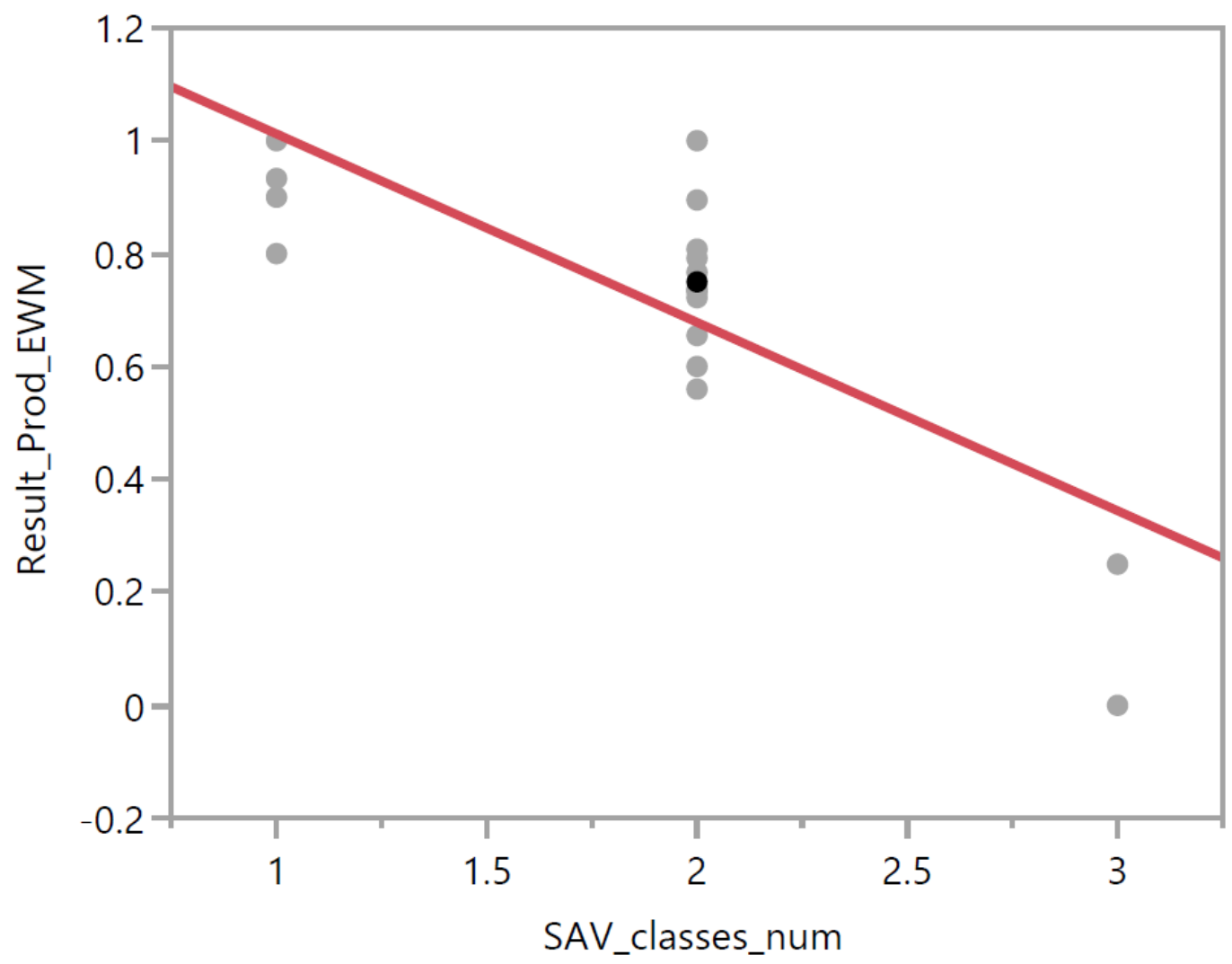

Figure 3.30. Regression equation for producer's accuracy vs. number of SAV classes.

\subsection{Discussion}

The cluster analysis showed that we had two types of sites based on the water chemistry data that were collected: those with relatively clear water and those with relatively darker water. This informed our classification methods, with the idea that a smaller scale parameter was more appropriate for clear water sites and a larger scale parameter was more appropriate for dark water sites. However, classification accuracy did not differ significantly between the light and dark water sites in our analyses, with some local variation. Accuracies varied among the classified images, most often in the range of 50$100 \%$, with an average overall accuracy of $76.7 \%$, producer's accuracy of $78.7 \%$, and user's accuracy of $77.6 \%$ across the 20 classifications. With the Tetracam results, we were able to exceed the $61 \%$ maximum overall accuracy noted in Visser et al. 2018 on a consistent basis across both dark and clear water sites. VISNIR results were only available for one site, as this was a backup sensing system, but were more similar to the Visser levels of accuracy.

All of our sites could be considered to have relatively clear water, though, with average $\mathrm{k}$ values of 0.5010 to 2.1960. While Visser et al. 2013 and 2018 do not report a light extinction coefficient for their river site in Belgium, values for other waters indicate that our nearshore areas of the Les Cheneaux Islands were relatively clear: for a shallow, 
turbid reservoir in Texas, Lee and Rast (1997) report k values of 2.49 to $7.93 \mathrm{~m}^{-1}$ while values up to $8 \mathrm{~m}^{-1}$ were reported in eutrophic Lake Okeechobee, FL, depending on the season and lake location (Philips et al. 1995); our values are more similar to Lake Mendota in Wisconsin which have been reported in the range of 0.35 to $0.85 \mathrm{~m}^{-1}$ (Hansson et al. 1994).

Visser et al. (2018) note that there are many factors that affect overall accuracy for SAV identification, including band alignment problems for multispectral imaging devices and the radiometric impacts of sky factors (sunglint, specular reflection, shading). We did see some alignment issues, particularly in the red edge bands, but these did not appear significant over the scale of the images being analyzed, at least based on the mapping accuracies we obtained. We found that clear sky, sunny days were optimal for obtaining images where SAV was most easily visible, while cloudy days produced a large amount of cloud reflectance on the water surface and limited light penetration that made SAV identification much more difficult. We eliminated all imagery collected on overcast days from our analysis because of these issues; therefore, this issue should not affect the results and analyses we present here.

The quality and quantity of field data also likely impacted our ability to create relatively accurate SAV mapping results. Visser compared their OBIA-derived results to manually delineated class boundaries and types to assess accuracy and noted that this can have limitations, as manual interpretation is not error-free. We found that above-water and below-water photos, taken with a waterproof digital camera with GPS capability, were very important for evaluating multispectral imagery, especially when referenced to standardized recording of visual estimates of percent cover by SAV species. After our first year and initial attempts to classify the collected imagery, we had found it challenging to relate the visual interpretation (and other vegetation estimates) to specific locations in the imagery, despite recording the position of the boat during field visits. We found that deploying numbered buoys, and being able to see those in UAS imagery, made this process much easier, especially when significant time (months or years) could sometimes go by between field visits and final image classification and accuracy assessment. We recommend the adoption of these types of marker buoys when using UAS imagery to identify SAV taxa and other applications with similar scale.

Vis et al. (2003) compared field data of emergent and submerged aquatic vegetation to distribution mapping created using remote sensing and echo sounding techniques. Echo sounding produced the most comparable results to field data, with $71 \%$ producer's accuracy and 73\% user's accuracy for non-canopy-forming SAV species (such as eelgrass and Chara), but they were not able to map canopy-forming SAV such as Myriophyllum spp. They tested an early multispectral airborne sensor with eight bands ranging from 390 to $1100 \mathrm{~nm}$ (ultraviolet edge to near-infrared) but only achieved 18\% overall accuracy with $7 \mathrm{~m}$ pixel resolution, and concluded that image-based remote sensing was "expensive and problematic". While they noted problems with water color including turbidity, we were able to identify EWM in sites such as Court East where it 
was found a meter below the surface, and at two meters below the surface in clear water sites such as Howells Dock.

We had expected that the scale parameter of 25 would produce more accurate results for clear water sites and the scale parameter of 50 would produce more accurate results for dark water sites. This was based largely on a visual impression from the initial classification results that a smaller scale parameter appeared to capture finer details in the extent of SAV more accurately than larger ones. It had seemed that greater detail was visible for the SAV areas in clear water sites and that the smaller scale parameter would help capture this. For the dark water sites, SAV areas appeared to be less distinct in early classifications, with DOC being the primary CPA affecting water clarity here. However, this was not borne out when all classifications were completed and the accuracy assessment was complete, as shown in Table 3.5. Indeed, accuracies were statistically similar, and were slightly higher with the smaller scale parameter for dark water sites and slightly higher with the larger scale paramater for clear water sites. This was confirmed through the ANOVA mixed model results, where scale parameter was not associated with a significant difference in overall, producer's, or user's accuracy. It may be that each SAV type has its own optimal scale parameter for the highest accuracy results; this idea has been investigated for terrestrial land cover types (Huiping et al. 2003). Scale parameters are designed to help reflect the landscape heterogeneity captured by imagery (Gamanya et al. 2007), and further investigation of how this parameter can best be used to help identify specific SAV species of interest may be warranted. It appeared that the smaller scale parameter enabled more precise selection of training areas for classification, but this also could mean that inherent variability within a cover class could be missed. This may be what occurred with the large visible differences in extent between the maps created using the two scale parameters for the flat-stem pondweed at Breezeswept North, small pondweed at Court East in June 2017, and the deeper rocks class at Neil.

The regression analysis results showed a significant effect of the number of SAV classes on overall and producer's accuracy. Sites with two or three species of SAV produced lower accuracy results than sites with just one SAV type to identify for overall and producer's accuracy. With multiple SAV types, there is the potential for them to be spectrally similar, at least with the multispectral sensors tested here (Chapter 2 and Brooks et al. 2019). With only one SAV class, we were generally only trying to differentiate it from open water or uncolonized bottom substrate, which is easier to accomplish due to larger spectral differences. Our methods have the greatest applicability if the purpose of EWM identification is to map its extent in underwater stands where it is predominant. This would be most useful when tracking changes in its extent due to management efforts that focus on EWM-dominated stands.

Wood et al. 2012 noted that percentage cover, percentage volume, and dry weight biomass mass could be strongly correlated $\left(\mathrm{R}^{2}\right.$ range of 54-96\%) for SAV in shallow rivers, with seasonal and site variations in these relationships. We have previously demonstrated that percent cover can reasonably related to biomass for SAV in our Cladophora algae remote sensing work that used Landsat data to map SAV extent with 
83\% overall accuracy across Lakes Michigan, Huron, Erie, and Ontario (Brooks et al. 2015, Shuchman et al. 2013). Relatively accurate mapping of EWM could potentially be used to estimate EWM biomass and how this could change when EWM undergoes management methods.

With SAV, we have been attempting to measure the presence and extent of specific species at sites that have a greater variability in the sensing environment than terrestrial sites. Atmospheric correction of imagery of terrestrial areas is a standard procedure, especially for satellite imagery, but we are dealing with apparent optical properties of water affected by the CPAs and the inherent optical properties affected by the absorption and backscatter of the light signal that gets attenuated. Visser et al. 2018 noted that standard targets of $85 \%$ accuracy are based on terrestrial environments but are more challenging in aquatic environments due to these types of complication factors. In our sites, we have areas with higher DOC values, most likely because of a local creek that drains wetland areas, while sites further away without a local DOC source have clearer water. Even without DOC, absorption, backscatter, and surface glint make aquatic remote sensing more challenging (Bukata et al. 1995, Silva et al. 2008).

\subsection{Conclusions}

While we found that our field sites clustered into two distinct types (relatively dark and relative clear waters), our attempt to use two different scale parameters that could help improve classification accuracy for these types of sites did not result in significant differences. At least as tested, the scale parameter of 25 for clear water sites was not any more useful than a scale parameter of 50, and a scale parameter of 50 for dark water sites was not any more useful than a scale parameter of 25 . However, the overall $76.7 \%$ average accuracy we obtained, with $78.7 \%$ producer's accuracy and $77.6 \%$ user's accuracy for EWM, is higher than previously reported efforts for SAV mapping, and shows promise for multispectral UAS-enabled identification of EWM extent.

We also found that the inclusion of mNDVI appeared useful in identifying EWM, most likely because this index is sensitive to green vegetative biomass. Despite limited penetration of the red, red edge, and near-infrared wavelengths into the water column, we found sufficient penetration that multispectral sensing including a red edge or nearinfrared sensitive camera system could help identify SAV, at least if it was present in the first meter of water at sites with higher DOC concentrations or first two meters at relatively clear water sites. In Brooks et al. 2019, we found that additional spectral bands were more likely to lead to reliable EWM identification, and exploration of the specific wavelengths in the red to near-infrared that help identify shallow-depth SAV species is recommended.

With multispectral sensors now deployable onboard UAS on a practical basis, together they can be a valuable tool for ecologists and aquatic managers wanting to understand the extent of specific species of SAV such as EWM, particularly where the species is dominant in the area of interest. With the dominance of SAV species changing year by 
year, as seen at some of our sites, UAS-based methods can provide information on the variability of these sites. It can also show the changing extent and presence of different species throughout a growing season, such as when we were able to visit sites three times in one summer. The most rapid changes in SAV extent can be due to anthropogenic management of aquatic vegetation, such as the harvesting that occurred in parts of our study area. We expect that our methods will be most applicable to monitoring the effects of these types of management methods.

\subsection{Acknowledgments:}

This project has been funded in part through the United States Environmental Protection Agency (US EPA) under assistance agreements 00E01928 and 00E01291 to Michigan Technological University, as part of the Great Lakes Restoration Initiative. The contents of this document do not necessarily reflect the views and policies of the US EPA nor does the EPA endorse trade names or recommend the use of commercial products mentioned in this document. Support was provided by the Michigan Tech Research Institute and the Biological Sciences Department of Michigan Technological University. The lead author would like to thank everyone that helped collect field data, with particular thanks for Ryan Van Goethem for his expertise on aquatic plant species identification and Dr. Amy Marcarelli for her insights on aquatic ecology and the water characterization field design. Richard Dobson's and Nicholas Marion's collection of most of the UAS imagery is greatly appreciated. Amanda Grimm's collection of spectral data provided the baseline for EWM identification. Dr. Robert Shuchman and Dr. Michael Sayers provided welcome advice on the impacts of color producing agents on aquatic remote sensing. 


\section{Appendix 3.A: Supplementary Data}

Table 3.A.1. Water chemistry and light data by site and by collection date

\begin{tabular}{|c|c|c|c|c|c|c|}
\hline Collection Sites & Date & $\begin{array}{l}\text { TSS } \\
(\mathrm{g} / \mathrm{L}) \\
\end{array}$ & $\begin{array}{l}\text { Chl-a } \\
\left(\mathrm{mg} / \mathrm{m}^{\wedge} 3\right)\end{array}$ & $\begin{array}{l}\mathrm{DOC} \\
\mathrm{mgC} / \mathrm{L}\end{array}$ & $\begin{array}{l}\text { CDOM } \\
\text { (r.u.) }\end{array}$ & $\begin{array}{l}\text { k ext. } \\
\text { coeff. } \\
(m-1)\end{array}$ \\
\hline Breezeswept South & $7 / 19 / 2017$ & 0.0081 & 2.960 & 6.106 & NA & 1.6671 \\
\hline Breezeswept South & $8 / 24 / 2017$ & 0.0030 & 2.072 & 7.885 & NA & 1.4503 \\
\hline Breezeswept North & $7 / 19 / 2017$ & 0.0024 & 1.480 & 7.360 & NA & 1.0286 \\
\hline Breezeswept North & $8 / 23 / 2017$ & 0.0023 & 1.184 & 8.673 & 1.672 & 0.8155 \\
\hline Court Dock & $7 / 14 / 2016$ & 0.0183 & 0.888 & 4.310 & NA & 2.5358 \\
\hline Court Dock & $8 / 26 / 2016$ & NA & NA & 6.407 & 14.497 & 1.8561 \\
\hline Court East & $7 / 14 / 2016$ & NA & NA & NA & NA & 2.1743 \\
\hline Court East & $8 / 26 / 2016$ & NA & 0.592 & NA & NA & NA \\
\hline Court East & $6 / 20 / 2017$ & 0.0076 & 0.888 & 7.630 & 3.012 & 1.4040 \\
\hline Court East & $7 / 19 / 2017$ & 0.0014 & 2.664 & 7.977 & NA & 0.9664 \\
\hline Court East & $8 / 23 / 2017$ & 0.0020 & 0.296 & 15.140 & 3.851 & 1.9298 \\
\hline Court West & $7 / 19 / 2017$ & 0.0006 & 0.592 & 9.960 & NA & 1.5512 \\
\hline Court West & $8 / 23 / 2017$ & 0.0024 & 0.888 & 15.500 & NA & 2.2242 \\
\hline CRAMP & $8 / 20 / 2018$ & 0.0072 & 4.973 & 5.059 & 1.171 & 1.2256 \\
\hline FDS & $7 / 15 / 2016$ & 0.0019 & 0.000 & 3.210 & NA & 0.8675 \\
\hline FDS & $8 / 25 / 2016$ & NA & 0.592 & 4.248 & 6.835 & 2.2194 \\
\hline FDS & $6 / 22 / 2017$ & 0.0044 & 1.776 & 3.634 & 0.967 & 0.8526 \\
\hline FDS & $7 / 18 / 2017$ & -0.0021 & 1.480 & 7.553 & NA & 1.3591 \\
\hline FDS & $8 / 22 / 2017$ & 0.0004 & 3.552 & 7.227 & 1.765 & 1.2589 \\
\hline Chappell & $6 / 21 / 2017$ & 0.0144 & 0.296 & 3.635 & 0.252 & 0.4460 \\
\hline Chappell & $8 / 24 / 2017$ & 0.0006 & 0.000 & 2.176 & 0.848 & 0.5560 \\
\hline Hessel Marina & $7 / 20 / 2017$ & -0.0008 & 1.184 & 2.805 & NA & 0.3103 \\
\hline Hessel Marina & $8 / 24 / 2017$ & 0.0020 & 0.296 & 3.476 & 1.460 & 1.1400 \\
\hline Hessel Marina & $8 / 23 / 2018$ & 0.0003 & 1.430 & 2.344 & 0.393 & 0.4079 \\
\hline Neil & $6 / 23 / 2017$ & 0.0011 & 0.000 & 2.348 & 0.251 & 0.3786 \\
\hline Neil & $7 / 20 / 2017$ & -0.0001 & 0.888 & 2.321 & NA & 0.2198 \\
\hline Neil & $8 / 24 / 2017$ & 0.0015 & 0.888 & 3.096 & 0.612 & 0.2341 \\
\hline Neil & $8 / 23 / 2018$ & 0.0024 & 0.847 & 2.505 & 0.292 & 1.2782 \\
\hline Howells Dock & $8 / 26 / 2016$ & NA & 0.592 & 2.919 & 1.614 & 0.5199 \\
\hline Howells Dock & $6 / 21 / 2017$ & 0.0073 & NA & 2.738 & 0.464 & 0.4836 \\
\hline Howells Dock & $8 / 25 / 2017$ & 0.0007 & 0.592 & 3.690 & 0.435 & 0.5769 \\
\hline Howells Dock & $8 / 22 / 2018$ & 0.0015 & 3.276 & 2.711 & 0.438 & 1.3893 \\
\hline Urie Point & $8 / 22 / 2018$ & 0.0011 & 1.993 & 2.710 & 0.311 & 0.4396 \\
\hline
\end{tabular}


Table 3.A.2 Error matrices for all classifications, with scale parameter $=25$ and $=50$ results.

Breezeswept North July 2017

Tetracam Scale

Parameter 25

Reference Data

\begin{tabular}{|c|c|c|c|c|c|c|c|c|c|}
\hline & & $\begin{array}{l}\text { Open } \\
\text { water }\end{array}$ & $\begin{array}{l}\text { Flatstem } \\
\text { Pondweed }\end{array}$ & EWM & Elodea & Shadow & $\begin{array}{l}\text { Surface } \\
\text { Veg }\end{array}$ & $\begin{array}{l}\text { Row } \\
\text { Total } \\
\end{array}$ & $\begin{array}{l}\text { User's } \\
\text { Accuracy }\end{array}$ \\
\hline \multirow{8}{*}{$\begin{array}{l}\text { Classified } \\
\text { Data }\end{array}$} & \multirow{2}{*}{$\begin{array}{l}\text { Open } \\
\text { water } \\
\text { Flatstem } \\
\text { Pondweed }\end{array}$} & 25 & 1 & 0 & 7 & 0 & 0 & 33 & $75.8 \%$ \\
\hline & & 0 & 0 & 0 & 0 & 0 & 1 & 1 & $0.0 \%$ \\
\hline & \multirow{4}{*}{$\begin{array}{l}\text { EWM } \\
\text { Elodea } \\
\text { Shadow } \\
\text { Detached } \\
\text { Surface }\end{array}$} & 0 & 0 & 0 & 0 & 1 & 0 & 1 & $0.0 \%$ \\
\hline & & 1 & 0 & 2 & 12 & 0 & 0 & 15 & $80.0 \%$ \\
\hline & & 0 & 0 & 0 & 0 & 1 & 0 & 1 & $100.0 \%$ \\
\hline & & 0 & 0 & 0 & 0 & 0 & 0 & 0 & $\mathrm{n} / \mathrm{a}$ \\
\hline & \multirow{2}{*}{$\begin{array}{l}\text { Veg } \\
\text { Column } \\
\text { Total } \\
\text { Producer's } \\
\text { Accuracy }\end{array}$} & 26 & 1 & 2 & 19 & 2 & 1 & 51 & \\
\hline & & $96.2 \%$ & $0.0 \%$ & $0.0 \%$ & $63.2 \%$ & $50.0 \%$ & $0.0 \%$ & $\begin{array}{r}\text { OVERALL } \\
\text { ACCURACY = } \\
38 / 51=74.5 \%\end{array}$ & \\
\hline
\end{tabular}

Breezeswept North July 2017

Tetracam Scale

Parameter 50

\begin{tabular}{|c|c|c|c|c|c|c|c|c|}
\hline 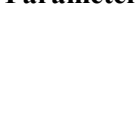 & & $\begin{array}{l}\text { Open } \\
\text { water }\end{array}$ & $\begin{array}{l}\text { Flatstem } \\
\text { Pondweed }\end{array}$ & EWM & Elodea & $\begin{array}{l}\text { Detached } \\
\text { Surface } \\
\text { Veg }\end{array}$ & $\begin{array}{l}\text { Row } \\
\text { Total }\end{array}$ & $\begin{array}{l}\text { User's } \\
\text { Accuracy }\end{array}$ \\
\hline \multirow{7}{*}{$\begin{array}{l}\text { Classified } \\
\text { Data }\end{array}$} & \multirow{2}{*}{$\begin{array}{l}\text { Open } \\
\text { water } \\
\text { Flatstem }\end{array}$} & 21 & 0 & 2 & 8 & 0 & 31 & $67.7 \%$ \\
\hline & & 0 & 1 & 0 & 0 & 0 & 1 & $100.0 \%$ \\
\hline & EWM & 0 & 0 & 1 & 0 & 0 & 1 & $100.0 \%$ \\
\hline & Elodea & 1 & 0 & 1 & 10 & 0 & 12 & $83.3 \%$ \\
\hline & $\begin{array}{l}\text { Detached } \\
\text { Surface } \\
\text { Veg }\end{array}$ & 1 & 0 & 0 & 0 & 0 & 1 & $0.0 \%$ \\
\hline & $\begin{array}{l}\text { Column } \\
\text { Total }\end{array}$ & 23 & 1 & 4 & 18 & 0 & 46 & \\
\hline & $\begin{array}{l}\text { Producer's } \\
\text { Accuracy }\end{array}$ & $91.3 \%$ & $100.0 \%$ & $25.0 \%$ & $55.6 \%$ & $\mathrm{n} / \mathrm{a}$ & $\mathrm{AC}$ & $\begin{array}{l}\text { OVERALL } \\
\text { CURACY= }\end{array}$ \\
\hline
\end{tabular}


Court East August 2016

Tetracam Scale Parameter 25

\begin{tabular}{|c|c|c|c|c|c|}
\hline \multicolumn{4}{|c|}{ Reference Data } & & \\
\hline EWM & Open Water & Spatterdock & Surface Veg & $\begin{array}{l}\text { Row } \\
\text { Total }\end{array}$ & $\begin{array}{l}\text { User's } \\
\text { Accuracy }\end{array}$ \\
\hline 14 & 5 & 0 & 0 & 19 & $73.7 \%$ \\
\hline$\overline{1}$ & 24 & 0 & 0 & 25 & $96.0 \%$ \\
\hline 0 & 0 & 1 & 0 & 1 & $100.0 \%$ \\
\hline 0 & 0 & 2 & 1 & 3 & $33.3 \%$ \\
\hline 15 & 29 & 3 & 1 & 48 & \\
\hline $93.3 \%$ & $82.8 \%$ & $33.3 \%$ & $100.0 \%$ & & $\begin{array}{r}\text { OVERALL } \\
\text { ACCURACY= }\end{array}$ \\
\hline
\end{tabular}

Court East August 2016

Tetracam Scale Parameter 50

$\begin{array}{cl} & \\ \text { Classified } & \text { EWM } \\ \text { Data } & \text { Open Water } \\ & \text { Spatterdock } \\ & \text { Surface Veg } \\ & \text { Column Total } \\ & \text { Producer's } \\ & \text { Accuracy }\end{array}$

Court East June 2017

VISNIR Scale Parameter 25

\begin{tabular}{|c|c|c|c|c|c|}
\hline \multicolumn{4}{|c|}{ Reference Data } & \multirow[b]{2}{*}{$\begin{array}{l}\text { Row } \\
\text { Total }\end{array}$} & \multirow[b]{2}{*}{$\begin{array}{l}\text { User's } \\
\text { Accuracy }\end{array}$} \\
\hline EWM & Open Water & Spatterdock & Surface Veg & & \\
\hline 9 & 7 & 0 & 0 & 16 & $56.3 \%$ \\
\hline 1 & 25 & 0 & 0 & 26 & $96.2 \%$ \\
\hline 0 & 0 & 4 & 0 & 4 & $100.0 \%$ \\
\hline 0 & 0 & 1 & 0 & 1 & $0.0 \%$ \\
\hline 10 & 32 & 5 & 0 & 47 & \\
\hline $90.0 \%$ & $78.1 \%$ & $80.0 \%$ & $\mathrm{n} / \mathrm{a}$ & & $\begin{array}{l}\text { OVERALL } \\
\text { ACCURACY }=\end{array}$ \\
\hline
\end{tabular}

Court East June 2017

VISNIR Scale Parameter 50

$\begin{array}{cl} & \text { Open Water } \\ \text { Classified } & \text { Detached Surface } \\ \text { Data } & \text { Veg } \\ & \text { EWM } \\ & \text { Small Leaf } \\ & \text { Pondweed } \\ & \text { Column Total } \\ & \text { Producer's } \\ & \text { Accuracy }\end{array}$

\begin{tabular}{|c|c|c|c|c|c|}
\hline Open Water & $\begin{array}{l}\quad \text { Referenc } \\
\text { Detached } \\
\text { Surface Veg }\end{array}$ & $\begin{array}{l}\text { Data } \\
\text { EWM }\end{array}$ & $\begin{array}{l}\text { Small Leaf } \\
\text { Pondweed }\end{array}$ & $\begin{array}{l}\text { Row } \\
\text { Total } \\
\end{array}$ & $\begin{array}{l}\text { User's } \\
\text { Accuracy }\end{array}$ \\
\hline 19 & 0 & 10 & 0 & 29 & $65.52 \%$ \\
\hline 0 & 3 & 0 & 0 & 3 & $100.00 \%$ \\
\hline 6 & 0 & 14 & 1 & 21 & $66.67 \%$ \\
\hline 0 & 0 & 1 & 2 & 3 & $66.67 \%$ \\
\hline 25 & 3 & 25 & 3 & 56 & \\
\hline $76.00 \%$ & $100.00 \%$ & $56.00 \%$ & $66.67 \%$ & & $\begin{array}{l}\text { OVERALL } \\
\text { ACCURACY= }\end{array}$ \\
\hline Open Water & $\begin{array}{l}\quad \text { Referenc } \\
\text { Detached } \\
\text { Surface Veg }\end{array}$ & EWM & $\begin{array}{l}\text { Small Leaf } \\
\text { Pondweed }\end{array}$ & $\begin{array}{l}\text { Row } \\
\text { Total }\end{array}$ & $\begin{array}{l}\text { User's } \\
\text { Accuracy }\end{array}$ \\
\hline 20 & 0 & 3 & 0 & 23 & $87.0 \%$ \\
\hline 0 & 4 & 0 & 0 & 4 & $100.0 \%$ \\
\hline 10 & 3 & 14 & 0 & 27 & $51.9 \%$ \\
\hline 0 & 0 & 2 & 0 & 2 & $0.0 \%$ \\
\hline 30 & 7 & 19 & 0 & 56 & \\
\hline $66.7 \%$ & $57.1 \%$ & $73.7 \%$ & $\mathrm{n} / \mathrm{a}$ & & $\begin{array}{r}\text { OVERALL } \\
\text { ACCURACY= } \\
38 / 56=67.9 \%\end{array}$ \\
\hline
\end{tabular}


Court East July 2017

Tetracam Scale Parameter 25

Open Water

Classified EWM/Elodea Mix

Data Detached Surface Veg

Column Total

Producer's Accuracy

Court East July 2017

Tetracam Scale Parameter 50

Open Water

Classified EWM/Elodea Mix

Data Detached Surface Veg

Column Total

Producer's Accuracy

Hessel Tetracam July 2017

Tetracam Scale Parameter 25

Curlyleaf Pondweed

EWM

Classified Deeper Water

Data Dock

Visible Bottom

Column Total

Producer's Accuracy

Hessel Tetracam July 2017

Tetracam Scale Parameter 50

$\begin{array}{cl} & \text { Curlyleaf Pondweed } \\ \text { Classified } & \text { EWM } \\ \text { Data } & \text { Deeper Water } \\ & \text { Dock } \\ & \text { Visible Bottom } \\ & \text { Column Total } \\ & \text { Producer's Accuracy }\end{array}$

\begin{tabular}{r|r|r|r|r|}
\multicolumn{1}{l}{$\begin{array}{l}\text { Reference Data } \\
\text { Open } \\
\text { Water }\end{array}$} & \multicolumn{2}{l}{$\begin{array}{l}\text { EWM/Elodea } \\
\text { Mix }\end{array}$} & \multicolumn{2}{l}{$\begin{array}{l}\text { Detached Surface } \\
\text { Veg }\end{array}$} \\
\hline 13 & 0 & 0 & 13 & $100.0 \%$ \\
\hline 0 & 14 & 1 & 15 & $93.3 \%$ \\
\hline 0 & 0 & 16 & 16 & $100.0 \%$ \\
\hline 13 & 14 & 17 & 44 & \\
& $100.0 \%$ & $94.1 \%$ & OVERALL ACCURACY \\
\hline $100.0 \%$ & &
\end{tabular}

$43 / 44=97.7 \%$

\begin{tabular}{|c|c|c|c|c|}
\hline \multicolumn{5}{|c|}{ Reference Data } \\
\hline Open & EWM/Elodea & Detached Surface & & User's \\
\hline Water & Mix & Veg & Row Total & Accuracy \\
\hline 11 & 3 & 0 & 14 & $78.6 \%$ \\
\hline 1 & 12 & 1 & 14 & $85.7 \%$ \\
\hline 0 & 0 & 17 & 17 & $100.0 \%$ \\
\hline 12 & 15 & 18 & 45 & \\
\hline $91.7 \%$ & $80.0 \%$ & $94.4 \%$ & OVERAI & L ACCURACY= \\
\hline
\end{tabular}

\begin{tabular}{|c|c|c|c|c|c|c|}
\hline $\begin{array}{l}\text { Curlyleaf } \\
\text { Pondweed }\end{array}$ & EWM & $\begin{array}{l}\text { rence Dat } \\
\text { Deeper } \\
\text { Water }\end{array}$ & Dock & $\begin{array}{l}\text { Visible } \\
\text { Bottom }\end{array}$ & $\begin{array}{l}\text { Row } \\
\text { Total }\end{array}$ & $\begin{array}{l}\text { User's } \\
\text { Accuracy }\end{array}$ \\
\hline 2 & 0 & 0 & 0 & 0 & 2 & $100.0 \%$ \\
\hline 4 & 11 & 0 & 1 & 3 & 19 & $57.9 \%$ \\
\hline 7 & 4 & 11 & 1 & 1 & 24 & $45.8 \%$ \\
\hline 0 & 0 & 0 & 1 & 0 & 1 & $100.0 \%$ \\
\hline 0 & 0 & 0 & 0 & 7 & 7 & $100.0 \%$ \\
\hline 13 & 15 & 11 & 3 & 11 & 53 & \\
\hline $15.38 \%$ & $73.33 \%$ & $100.0 \%$ & $33.3 \%$ & $63.6 \%$ & & $\begin{array}{l}\text { OVERALL } \\
\text { ACCURACY= } \\
32 / 53=60.4 \\
\%\end{array}$ \\
\hline
\end{tabular}

\begin{tabular}{|c|c|c|c|c|c|c|}
\hline $\begin{array}{l}\text { Curlyleaf } \\
\text { Pondweed }\end{array}$ & EWM & $\begin{array}{l}\text { rence Data } \\
\text { Deeper } \\
\text { Water }\end{array}$ & Dock & $\begin{array}{l}\text { Visible } \\
\text { Bottom }\end{array}$ & $\begin{array}{l}\text { Row } \\
\text { Total }\end{array}$ & $\begin{array}{l}\text { User's } \\
\text { Accuracy }\end{array}$ \\
\hline 1 & 1 & 0 & 0 & 0 & 2 & $50.0 \%$ \\
\hline 3 & 12 & 1 & 0 & 4 & 20 & $60.0 \%$ \\
\hline 2 & 6 & 12 & 0 & 2 & 22 & $54.5 \%$ \\
\hline 0 & 0 & 0 & 0 & 0 & 0 & $\mathrm{n} / \mathrm{a}$ \\
\hline 0 & 1 & 0 & 0 & 5 & 6 & $83.3 \%$ \\
\hline 6 & 20 & 13 & 0 & 11 & 50 & \\
\hline $16.67 \%$ & $60.00 \%$ & $92.3 \%$ & $\mathrm{n} / \mathrm{a}$ & $45.5 \%$ & & $\begin{array}{l}\text { OVERALL } \\
\text { ACCURACY }=\end{array}$ \\
\hline
\end{tabular}


Howells Dock August 2016

Tetracam Scale Parameter 25

$$
\begin{array}{cl} 
& \text { Northern Watermilfoil } \\
\text { Classified } & \text { EWM } \\
\text { Data } & \text { Open } \\
& \text { Column Total } \\
& \text { Producer's Accuracy }
\end{array}
$$

Howells Dock August 2016

Tetracam Scale Parameter 50

$\begin{array}{cl} & \text { Northern Watermilfoil } \\ \text { Classified } & \text { EWM } \\ \text { Data } & \text { Open } \\ & \text { Column Total } \\ & \text { Producer's Accuracy }\end{array}$

Howells Dock August 2017

\begin{tabular}{|c|c|c|c|c|}
\hline \multicolumn{4}{|c|}{ Reference Data } & \multirow[b]{2}{*}{$\begin{array}{l}\text { User's } \\
\text { Accuracy }\end{array}$} \\
\hline Bottom & EWM & Eelgrass & Row Total & \\
\hline 14 & 5 & 0 & 19 & $73.68 \%$ \\
\hline 2 & 21 & 4 & 27 & $77.78 \%$ \\
\hline 1 & 0 & 0 & 1 & $0.00 \%$ \\
\hline 17 & 26 & 4 & 47 & \\
\hline $82.35 \%$ & $80.77 \%$ & $0.00 \%$ & & $\begin{array}{l}\text { OVERALL } \\
\text { ACCURACY= }\end{array}$ \\
\hline
\end{tabular}

Tetracam Scale Parameter 25 Image 910

\begin{tabular}{|c|c|c|c|c|}
\hline \multicolumn{4}{|c|}{ Reference Data } & \multirow[b]{2}{*}{$\begin{array}{l}\text { User's } \\
\text { Accuracy }\end{array}$} \\
\hline Bottom & EWM & Eelgrass & Row Total & \\
\hline 11 & 7 & 0 & 18 & $61.11 \%$ \\
\hline 2 & 23 & 2 & 27 & $85.19 \%$ \\
\hline 1 & 0 & 1 & 2 & $50.00 \%$ \\
\hline 14 & 30 & 3 & 47 & \\
\hline $78.57 \%$ & $76.67 \%$ & $33.33 \%$ & & $\begin{array}{l}\text { OVERALL } \\
\text { ACCURACY= }\end{array}$ \\
\hline
\end{tabular}

$\begin{array}{cl}\text { Classified } & \text { Bottom } \\ \text { Data } & \text { EWM } \\ & \text { Eelgrass } \\ & \text { Column Total } \\ & \text { Producer's Accuracy }\end{array}$

Howells Dock August 2017

Tetracam Scale Parameter 50 Image 910

$\begin{array}{cl} & \text { Bottom } \\ \text { Classified } & \text { EWM } \\ \text { Data } & \text { Eelgrass } \\ & \text { Column Total } \\ & \\ & \text { Producer's Accuracy }\end{array}$

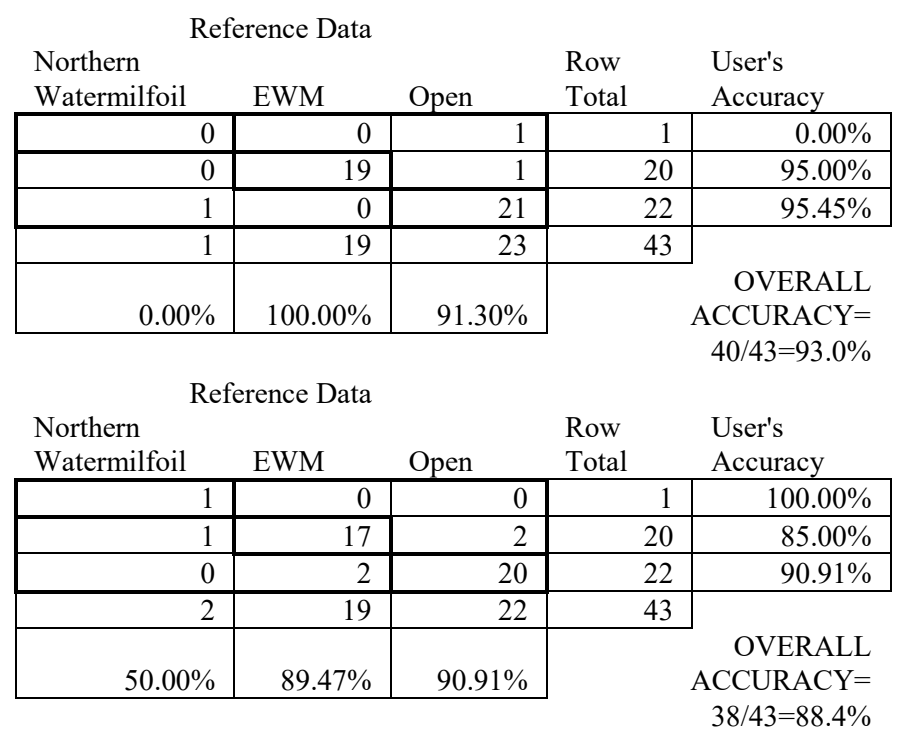


Howells Dock August 2017

Tetracam Scale Parameter 25 Image 916

Visible Bottom

Classified

Data

EWM

Eelgrass
Mixed Vegetation

Column Total

Producer's Accuracy

Howells Dock August 2017

Tetracam Scale Parameter 50 Image 916

Visible Bottom

Classified

EWM

Data

\begin{tabular}{|c|c|c|c|c|c|}
\hline \multicolumn{6}{|c|}{ Reference Data } \\
\hline Visible & & & Mixed & & User's \\
\hline Bottom & EWM & Eelgrass & Vegetation & Row Total & Accuracy \\
\hline 11 & 8 & 0 & 0 & 19 & $57.9 \%$ \\
\hline 1 & 19 & 0 & 0 & 20 & $95.0 \%$ \\
\hline 0 & 2 & 2 & 2 & 6 & $33.3 \%$ \\
\hline 1 & 0 & 0 & 5 & 6 & $83.3 \%$ \\
\hline 13 & 29 & 2 & 7 & 51 & \\
\hline $84.6 \%$ & $65.5 \%$ & $100.0 \%$ & $71.4 \%$ & & $\begin{array}{r}\text { OVERALL } \\
\text { ACCURACY= } \\
37 / 51=72.5 \%\end{array}$ \\
\hline
\end{tabular}

\begin{tabular}{|c|c|c|c|c|c|}
\hline \multicolumn{6}{|c|}{ Reference Data } \\
\hline Visible & & & Mixed & & User's \\
\hline Bottom & EWM & Eelgrass & Vegetation & Row Total & Accuracy \\
\hline 16 & 2 & 0 & 1 & 19 & $84.2 \%$ \\
\hline 2 & 19 & 0 & 0 & 21 & $90.5 \%$ \\
\hline 0 & 2 & 4 & 0 & 6 & $66.7 \%$ \\
\hline 0 & 1 & 0 & 5 & 6 & $83.3 \%$ \\
\hline 18 & 24 & 4 & 6 & 52 & \\
\hline $88.9 \%$ & $79.2 \%$ & $100.0 \%$ & $83.3 \%$ & & $\begin{array}{l}\text { OVERALL } \\
\text { ACCURACY }\end{array}$ \\
\hline
\end{tabular}

Howells Dock August 2018

Tetracam Scale Parameter 25

Classified EWM

Data

Bottom

Column Total

Producer's Accuracy

Howells Dock August 2018

Tetracam Scale Parameter 50

Classified EWM

Data

Bottom

Column Total

Producer's Accuracy

Reference Data
\begin{tabular}{|r|r|r|r|} 
EWM & Bottom & Row Total & User's Accuracy \\
\hline 17 & 4 & 21 & $100.95 \%$ \\
\hline 0 & 9 & 9 & $100 \%$ \\
\hline 17 & 13 & 30 & \\
\hline $100.00 \%$ & $69.23 \%$ & \multicolumn{3}{c}{ OVERALL ACCURACY= } \\
$26 / 30=86.7 \%$
\end{tabular}

Reference Data

\begin{tabular}{|r|r|r|r|}
\multicolumn{1}{l|}{ EWM } & Bottom & Row Total & User's Accuracy \\
\hline 19 & 6 & 25 & $76.00 \%$ \\
\hline 0 & 9 & 9 & $100.00 \%$ \\
\hline 19 & 15 & 34 & \\
$100.00 \%$ & $60.00 \%$ & \multicolumn{3}{|c|}{ OVERALL ACCURACY= } \\
$28 / 34=82.4 \%$
\end{tabular}


Neil July

2017

Tetracam Scale Parameter

25

$\begin{array}{cl} & \text { Algae covered } \\ & \text { rocks } \\ & \text { Chara } \\ \text { Classified } & \text { Deeper rocks } \\ \text { Data } & \text { EWM } \\ & \text { Exposed rocks } \\ & \text { Visible Bottom } \\ & \text { Column Total } \\ & \text { Producer's } \\ & \text { Accuracy }\end{array}$

Neil July 2017

Tetracam Scale Parameter

50

$\begin{array}{cl} & \text { Algae covered } \\ & \text { rocks } \\ & \text { Chara } \\ \text { Classified } & \text { Deeper rocks } \\ \text { Data } & \text { EWM } \\ & \text { Exposed rocks } \\ & \text { Visible Bottom } \\ & \text { Column Total } \\ & \text { Producer's } \\ & \text { Accuracy }\end{array}$

\begin{tabular}{|c|c|c|c|c|c|c|c|}
\hline $\begin{array}{l}\text { Algae } \\
\text { covered } \\
\text { rocks }\end{array}$ & Chara & $\begin{array}{l}\text { Deeper } \\
\text { rocks }\end{array}$ & ce Data & $\begin{array}{l}\text { Exposed } \\
\text { rocks }\end{array}$ & $\begin{array}{l}\text { Visible } \\
\text { Bottom }\end{array}$ & $\begin{array}{l}\text { Row } \\
\text { Total }\end{array}$ & $\begin{array}{l}\text { User's } \\
\text { Accuracy }\end{array}$ \\
\hline 3 & 0 & 0 & 0 & 0 & 0 & 3 & $100.0 \%$ \\
\hline 0 & 18 & 2 & 5 & 0 & 1 & 26 & $69.2 \%$ \\
\hline 1 & 0 & 1 & 0 & 0 & 0 & 2 & $50.0 \%$ \\
\hline 0 & 1 & 0 & 13 & 0 & 0 & 14 & $92.9 \%$ \\
\hline 0 & 0 & 0 & 0 & 1 & 0 & 1 & $100.0 \%$ \\
\hline 0 & 4 & 1 & 0 & 0 & 5 & 10 & $50.0 \%$ \\
\hline 4 & 23 & 4 & 18 & 1 & 6 & 56 & \\
\hline $75.0 \%$ & $78.3 \%$ & $25.0 \%$ & $72.2 \%$ & $100.0 \%$ & $83.3 \%$ & & $\begin{array}{l}\text { OVERALL } \\
\text { CCURACY= }\end{array}$ \\
\hline
\end{tabular}

Reference Data

\begin{tabular}{|c|c|c|c|c|c|c|c|}
\hline $\begin{array}{l}\text { Algae } \\
\text { covered } \\
\text { rocks }\end{array}$ & Chara & $\begin{array}{l}\text { Deeper } \\
\text { rocks }\end{array}$ & EWM & $\begin{array}{l}\text { Exposed } \\
\text { rocks }\end{array}$ & $\begin{array}{l}\text { Visible } \\
\text { Bottom }\end{array}$ & $\begin{array}{l}\text { Row } \\
\text { Total }\end{array}$ & $\begin{array}{l}\text { User's } \\
\text { Accuracy }\end{array}$ \\
\hline 3 & 0 & 1 & 0 & 0 & 0 & 4 & $75.0 \%$ \\
\hline 0 & 20 & 0 & 4 & 0 & 0 & 24 & $83.3 \%$ \\
\hline 1 & 0 & 4 & 0 & 0 & 0 & 5 & $80.0 \%$ \\
\hline 0 & 1 & 0 & 12 & 0 & 0 & 13 & $92.3 \%$ \\
\hline 0 & 0 & 0 & 0 & 0 & 0 & 0 & $\mathrm{n} / \mathrm{a}$ \\
\hline 0 & 3 & 1 & 0 & 0 & 4 & 8 & $50.0 \%$ \\
\hline 4 & 24 & 6 & 16 & 0 & 4 & 54 & \\
\hline $75.00 \%$ & $83.33 \%$ & $66.7 \%$ & $75.0 \%$ & $\mathrm{n} / \mathrm{a}$ & $100.0 \%$ & & $\begin{array}{l}\text { OVERALL } \\
\text { ACCURACY }=\end{array}$ \\
\hline
\end{tabular}




\section{References}

ALOO, P. et al. 2013. A review of the impacts of invasive aquatic weeds on the biodiversity of some tropical water bodies with special reference to Lake Victoria (Kenya). Biodiversity Journal, 4(4), 471-482.

AMERICAN PUBLIC HEALTH ASSOCIATION (APHA). 2005. Standard methods for the examination of water and wastewater, 21st edition. American Public Health Association, American Water Works Association, and Water Environment Federation, Washington, DC. 1,368 pgs.

BANKO, G. 1998. A review of assessing the accuracy of classifications of remotely sensed data and of methods including remote sensing data in forest inventory, Interim Report IR-98-081, International Institute for Applied Systems Analysis. 42 pgs.

BOYLEN, C. W., EICHLER, L. W. \& J. D. MADSEN. 1999. Loss of native aquatic plant species in a community dominated by Eurasian watermilfoil. Hydrobiologia, 415, 207-211.

BREZONIK, P. L. et al. 2015. Factors affecting the measurement of CDOM by remote sensing of optically complex inland waters. Remote Sensing of Environment, 157, 199-215.

BROOKS, C. N., GRIMM, A. G., MARCARELLI, A. M. \& DOBSON, R. J. 2019. Multiscale collection and analysis of submerged aquatic vegetation spectral profiles for Eurasian watermilfoil detection. Journal of Applied Remote Sensing, 13(3): 037501.

BUKATA, R. P. et al. 1995. Optical properties and remote sensing of inland and coastal waters, CRC press. 384 pgs.

CONGALTON, R. G. 1991. A review of assessing the accuracy of classifications of remotely sensed data. Remote Sensing of Environment 37(1), 35-46.

CONGALTON, R. G. \& GREEN, K. 2019. Assessing the accuracy of remotely sensed data: principles and practices, third edition, CRC press. 328 pgs.

GALLARDO, B. et al., 2016. Global ecological impacts of invasive species in aquatic ecosystems. Global Change Biology, 22(1), 151-163.

GAMANYA, R., DE MAEYER, P. \& DE DAPPER, M. 2007. An automated satellite image classification design using object-oriented segmentation algorithms: A move towards standardization. Expert Systems with Applications, 32(2), 616-624. 
HANSSON, L. et al. 1994. Patterns in algal recruitment from sediment to water in a dimictic, eutrophic lake. Canadian Journal of Fisheries and Aquatic Sciences, 51(12), 2825-2833.

HERSHNER, C. \& HAVENS, K. J. 2008. Managing invasive aquatic plants in a changing system: strategic consideration of ecosystem services. Conservation Biology, 22(3), 544-550.

HUIPING, H., BINGFANG, W. \& JINLONG, F. 2003. Analysis to the relationship of classification accuracy, segmentation scale, image resolution. IGARSS 2003. 2003 IEEE International Geoscience and Remote Sensing Symposium. Proceedings (IEEE Cat. No. 03CH37477) 3671-3673.

ISTVÁNOVICS, V. 2010. Eutrophication of lakes and reservoirs. Lake Systems Ecology, pgs. 47-55 Elsevier, San Diego, CA.

JOHNSON J. A., \& NEWMAN, R. M. 2011. A comparison of two methods for sampling biomass of aquatic plants. Journal of Aquatic Plant Management, 49, 1-8.

KASSAMBARA, A. \& MUNDT, F. 2017. factoextra: Extract and Visualize the Results of Multivariate Data Analyses. R package version 1.0.5. https://CRAN.Rproject.org/package $=$ factoextra

KUEHNE, L.M., OLDEN, J. D. \& RUBENSON, E. S. 2016. Multi-trophic impacts of an invasive aquatic plant. Freshwater Biology, 61(11), 1846-1861.

MADSEN, J.D. , SUTHERLAND, J. W., BLOOMFIELD, J. A., EICHLER, L. W. \& BOYLEN, C. W. 1991. The decline of native vegetation under dense Eurasian watermilfoil canopies. Journal of Aquatic Plant Management, 29, 94-99.

MADSEN, J. D. 2005. Eurasian watermilfoil invasions and management across the United States. Current, 21(2), 21-26.

MAECHLER, M., ROUSSEEUW, P., STRUYF, A., HUBERT, M. \& HORNIK, K. 2019. cluster: Cluster Analysis Basics and Extensions. R package version 2.0.8.

MICHIGAN DEPARTMENT OF ENVIRONMENTAL QUALITY (MDEQ). 2005. Procedures for aquatic vegetation surveys. https://www.michigan.gov/documents/deq/wrd-illmsurveyprocedure 445615 7.pdf

MILLS, E. L., LEACH, J. H., CARLTON, J. T. \& SECOR, C. L. 1994. Exotic species and the integrity of the Great Lakes. BioScience, 44(10), 666-676.

NICHOLS, D. S. \& KEENEY, D. R. 1973. Nitrogen and phosphorus release from decaying water milfoil. Hydrobiologia, 42(4), 509-525. 
NUSCH, E. A. 1980. Comparison of different methods for chlorophyll and phaeopigment determination. Archiv für Hydrobiologie-BeiheftErgebnisse der Limnologie 14, 14-36.

LEE, R. W. \& RAST, W. 1997. Light attenuation in a shallow, turbid reservoir, Lake Houston, Texas, US Geological Survey Water-Resources Investigations Report, 97-4064, Austin, TX.

PALMER, S. C., KUTSER, T. \& HUNTER. P. D. 2015. Remote sensing of inland waters: Challenges, progress and future directions. Elsevier.

PARKINSON, H., MANGOLD, J., JACOBS, J., MADSEN, J. \& HALPOP, J. 2011. Ecology and Management of Eurasian Watermilfoil (Myriophyllum spicatum L.), 2nd ed., Montana State University Extension: Bozeman, MT, USA. 6 pgs.

PHLIPS, E. et al.1995. Relationships between light availability, chlorophyll a, and tripton in a large, shallow subtropical lake. Limnology and Oceanography, 40(2), 416421.

TREBITZ, A. S. \& TAYLOR, D. L. 2007. Exotic and invasive aquatic plants in Great Lakes coastal wetlands: distribution and relation to watershed land use and plant richness and cover. Journal of Great Lakes Research 33(4), 705-721.

SHUCHMAN, R. A., LESHKEVICH, G., SAYERS, M. J., JOHENGEN, T. H., BROOKS, C. N. \& POZDNYAKOV, D. 2013. An algorithm to retrieve chlorophyll, dissolved organic carbon, and suspended minerals from Great Lakes satellite data. Journal of Great Lakes Research, 39, 14-33.

SILVA, T. S., COSTA, M. P., MELACK, J. M. \& NOVO, E. M. 2008. Remote sensing of aquatic vegetation: theory and applications. Environmental Monitoring and Assessment 140(1-3), 131-145.

SMITH, C. S. \& BARKO, J., 1990. Ecology of Eurasian watermilfoil. Journal of Aquatic Plant Management, 28(2), 55-64.

VAN GOETHEM, R. R., HUCKINS, C. J. \& MARCARELLI, A. M. 2020. Effects of Invasive Watermilfoil on Primary Production in Littoral Zones of NorthTemperate Lakes, Diversity, 12(2), 82.

VIS, C., HUDON, C. \& CARIGNAN, R. 2003. An evaluation of approaches used to determine the distribution and biomass of emergent and submerged aquatic macrophytes over large spatial scales, Aquatic Botany, 77(3), 187-201.

VISSER, F., WALLIS, C. \& SINNOTT, A. M. 2013. Optical remote sensing of submerged aquatic vegetation: Opportunities for shallow clearwater streams. Limnologica-Ecology and Management of Inland Waters, 43(5), 388-398. 
VISSER, F., KERST, B., VERSCHOREN, V. \& SCHOELYNCK, J. 2018. Mapping of submerged aquatic vegetation in rivers from very high-resolution image data, using object-based image analysis combined with expert knowledge.

Hydrobiologia, 812(1), 157-175.

WOOD, K. A., STILLMAN, R. A., CLARKE, R. T., DAUNT, F. \& O'HARE, M. T. 2012. Measuring submerged macrophyte standing crop in shallow rivers: a test of methodology. Aquatic botany, 102, 28-33. 


\section{Measuring Change in EWM Extent Due to Treatment Using Multispectral UAS Imagery}

\subsection{Abstract}

Remote sensing of aquatic ecosystems can enable measuring and monitoring of ecological characteristics of littoral zones. This study used multispectral and natural color cameras mounted on small unmanned aerial systems (UAS) to image areas that underwent management to reduce the extent of the invasive submerged aquatic plant Eurasian watermilfoil (Myriophyllum spicatum or EWM). The three study sites, located in the Upper Peninsula of Michigan, USA, each underwent different treatments: one had EWM removed via mechanical harvesting, another had a native fungus applied as a method of biological control, and a third underwent EWM removal via diver-assisted suction harvesting. We collected imagery from each site before and after treatment and conducted image classifications to quantify reductions in EWM extent for all three treatments. Extent reductions of $63-89 \%$ were measured with analyzed UAS imagery. These results demonstrate that UAS-enabled remote sensing can be used to monitor change in aquatic ecosystems such as removal of invasive aquatic plants, and could be applied to other monitoring needs.

\subsection{Introduction}

Remote sensing data such as aerial and satellite imagery can be a useful field survey and assessment tool for quantitative assessment of aquatic plant species and communities, but it has mainly been applied for floating and emergent plants, with limited successful use for submerged aquatic vegetation (SAV) (Ackleson and Klemas 1987, Birk and Ecke 2014, Madsen and Wersal 2018, Silva et al. 2008, Visser et al. 2018). These papers have shown at least some ability to identify the extent and type of aquatic vegetation. Ackleson and Klemas (1987) using low-resolution Landsat MSS and TM imagery found relative success with one of four classes of SAV based on density (but not species), and found that masking out optically deep waters $>1.9 \mathrm{~m}$ improved accuracy. Birk and Ecke (2014) focused on emerging and floating-leaved taxa for Swedish lakes, because high DOC concentrations make submergent vegetation difficult to identify. They note that UAS remote sensing missions cost $75 \%$ less than macrophyte field samping. They conclude that remote sensing is useful for high DOC lakes that have depths less than two meters, which is where most littoral productivity takes place. Madsen and Wersal (2018) also note that remote sensing of aquatic vegetation has been focused on emergent and floating vegetation because of light absorption in water issues. Visser et al. 2018 obtained 53-61\% accuracy for SAV identification in clear-water streams, and also noted that light absorption in aquatic environments is a complicating factor. All of studies support the idea that SAV identification has the challenge of being subject to the effects of the colorproducing agents (CPAs) of chlorophyll, dissolved organic carbon (DOC, specifically 
color dissolved organic matter, CDOM), and suspended minerals that attenuate the backscattered light signal that reaches remote sensors (Shuchman et al. 2013).

There are many different species of invasive SAV present in the midwest; the Midwest Invasive Plant Network lists 16 species in need of monitoring to help reduce their spread (2008) and there are 18 aquatic plants species that are prohibited from sale in Michigan (https://www.canr.msu.edu/news/aquatic-plant-species-prohibited-from-sale-inmichigan). In Michigan and elsewhere, considerable funding is spent on the treatment and control of many species of invasive aquatic plants, especially Eurasian watermilfoil (Myriophyllum spicatum L., hereafter EWM) (Czarapata 2005). These efforts often provide only short-term relief (Johnson and Blossey 2002). EWM is now present in many North American lakes, often growing at nuisance levels, particularly in waters one to four meters deep (Smith and Barko 1990). Negative effects of dense EWM growth include restricting recreation such as boating, swimming, and sport fishing; reducing lakeside property values, clogging water intakes, lowering dissolved oxygen concentrations, and reducing numbers of native plant species (Madsen et al. 1991, Smith and Barko 1990, Unmuth et al. 2000, Zhang and Boyle 2010).

Treatment methods known to be deployed for EWM control include mechanical harvesting (Painter 1988), diver-assisted suction harvesting or DASH (Tucker 2017), herbicide (Nelson and Shearer 2006), and biological control methods such as weevils (Roley and Newman 2006) and application of at least two species of native fungus (Nelson and Shearer 2006, Sorsa et al. 1988). Evaluating the ecological impacts and efficacy of different treatment methods would be enhanced by having a repeatable, practical method of measuring reductions in the extent and density of invasive SAV species through these types of treatment methods.

Our recent work (Brooks et al. 2019) has shown that specific species of SAV can be identified using remote sensing data. Our analysis included multispectral and hyperspectral profile data, with the results showing that a modified version of the normalized difference vegetation index (mNDVI) was useful for identifying different vegetation types. We further demonstrated that multispectral imagery collected with an unmanned aerial system (UAS) platform is able to map the extent of EWM in multiple shallow water $(<2 \mathrm{~m})$ sites with reasonable accuracy of $78.7 \%$ producer's accuracy and $77.6 \%$ user's accuracy, and overall average accuracy of $76.7 \%$ (Chapter 2 of this dissertation). These accuracies were generally higher than other remote sensing mapping results and helped demonstrate that multispectral UAV-enabled mapping could be a practical tool for invasive SAV identification. This level of accuracy also provides the potential to quantify changes in extent of SAV, which would be helpful in understanding the impacts and efficacy of different methods of aquatic plant management.

In this study, we demonstrate how using the methods developed and demonstrated in Brooks et al. 2019 and Chapter 3 are able to produce quantitative information on the change in EWM extent for three types of treatment: mechanical harvesting, DASH, and fungal treatment. Our goal was to understand if and how quantitative results could be 
created using UAS-enabled sensing that would reflect the visible effects of different treatment methods. Our hypothesis was that analysis of UAS-collected imagery would show a difference in amounts of visible EWM present comparing imagery collected before and after treatment.

\subsection{Materials and Methods}

We collected multispectral imagery from a hexacopter UAS platform in the Les Cheneaux Islands area of Michigan, USA, in northwestern Lake Huron and in the Sturgeon River Sloughs area of the Keweenaw Waterway, which bisects the Keweenaw Peninsula and connects to Lake Superior (Figure 4.1). Three sites and time periods from our EWM studies coincided with three treatment methods designed to reduce the extent of EWM (Table 4.1).

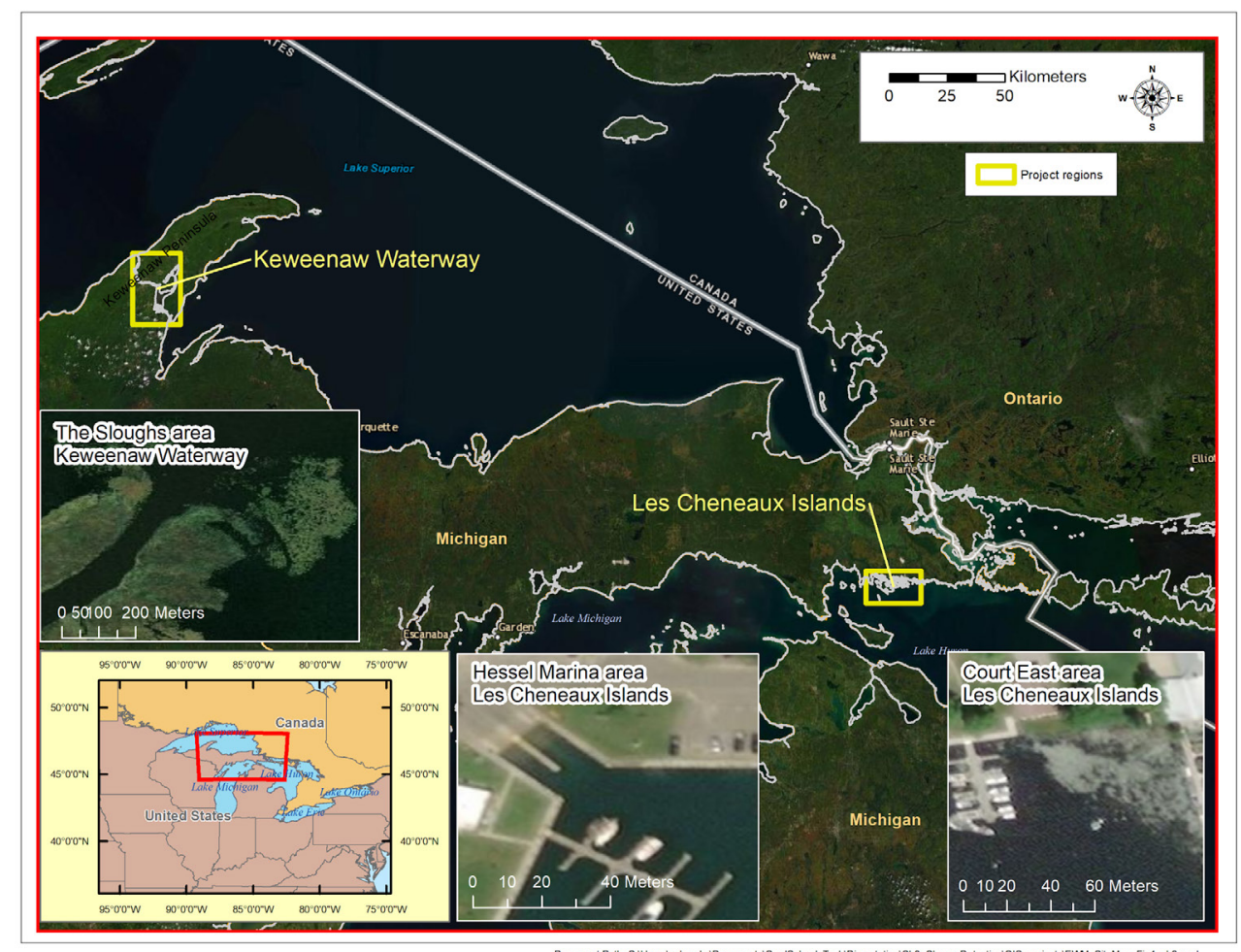

Figure 4.1. Les Cheneaux Islands and Keweenaw Waterway areas in northern Michigan, USA. 
Table 4.1. Treatment locations with geospatial analysis of change in EWM extent

\begin{tabular}{lllll}
\hline \multicolumn{1}{c}{$\begin{array}{c}\text { Site and } \\
\text { location }\end{array}$} & \multicolumn{1}{c}{$\begin{array}{c}\text { Treatment } \\
\text { type }\end{array}$} & $\begin{array}{c}\text { Pre-treatment } \\
\text { UAS assessment } \\
\text { time period }\end{array}$ & $\begin{array}{c}\text { Time period } \\
\text { of treatment }\end{array}$ & $\begin{array}{c}\text { Post-treatment } \\
\text { UAS assessment } \\
\text { time period }\end{array}$ \\
\hline $\begin{array}{l}\text { Court East, Les } \\
\text { Cheneaux Islands }\end{array}$ & $\begin{array}{l}\text { Mechanical } \\
\text { harvesting }\end{array}$ & June 2017 & July 2017 & August 2017 \\
$\begin{array}{l}\text { Hessel Marina, Les } \\
\text { Cheneaux Islands }\end{array}$ & $\begin{array}{l}\text { Biological } \\
\text { control (Mt } \\
\text { fungus) }\end{array}$ & $\begin{array}{l}\text { July 2017 }(1 \text { week } \\
\text { before treatment })\end{array}$ & July 2017 & August 2018 \\
$\begin{array}{l}\text { Sturgeon River } \\
\begin{array}{l}\text { Sloughs, } \\
\text { Keweenaw } \\
\text { Waterway }\end{array}\end{array}$ & DASH & $\begin{array}{l}\text { July 2017 (1 day } \\
\text { before treatment) }\end{array}$ & July 2017 & $\begin{array}{l}\text { July 2017 (3 days } \\
\text { after treatment) }\end{array}$ \\
\hline
\end{tabular}

In the Les Cheneaux Islands, mechanical harvesting by an aquatic weed harvesting boat operated by a local marina, apparently focused on EWM removal and independent of our project, took place in the Court East study location near Cedarville, MI, in between a field visit in June of 2017 and shortly before field work at the same location in July 2017, with a repeat visit in August of 2017. VISNIR imagery was analyzed to show the extent of EWM before treatment in June of 2017 and Tetracam imagery was collected in July and August of 2017. In the Hessel Marina location of the Les Cheneaux Islands, a biological control agent, the native fungal pathogen Mycoleptodiscus terrestris (Gerd.) or "Mt" was deployed in July 2017. Mt fungus has been investigated and tested for many decades as a biocontrol agent for EWM (Smith and Winfield 1991). It has to be fermented and then is applied as part of a solution in areas infested with EWM, where it causes necrotic legions on the plant and its eventual disintegration (Verma and Charudattan 1993). The Hessel Marina site was imaged with RGB and Tetracam imagery one week before treatment in July 2017, and revisited in August 2018 one year later for post-treatment sampling. We could only deploy RGB cameras for the post-treatment sampling due to hexacopter malfunction that prevented aerial deployment of the Tetracam at Hessel Marina, so the comparisons are based on two dates of RGB imagery covering the same treated area. At the Sturgeon River Sloughs in the Keweenaw Waterway near Houghton, MI, the VISNIR system was deployed before and after a DASH aquatic plant management treatment experiment. Pre-treatment imagery was collected on a Monday in July 2017, after which treatment occurred; post-treatment images were collected on the Friday of the same week. These three different types of treatment provided an opportunity to test and potentially demonstrate if multispectral UAS-enabled sensing could provide quantitative information on the changes in EWM extent due to the treatment methods.

The UAS deployed to collect multispectral data was a Bergen Hexacopter manufactured by Bergen RC Helicopters of Vandalia, MI. This system was used to deploy a multispectral imaging camera, the Tetracam six-band Micro-MCA6 multispectral imager, as described in Brooks et al. 2019 / Chapter 2. This sensor is capable of being sensitive to six narrow bands of light in the visible to near-infrared range. These bands are 10- 
nanometer (nm) wide ranging from approximately 400 to $1000 \mathrm{~nm}$, with the actual bands set by installed filters. The version deployed for these surveys was sensitive to $490 \mathrm{~nm}$ (blue), $530 \mathrm{~nm}$ (green band version 1), $550 \mathrm{~nm}$ (green band version 2), $600 \mathrm{~nm}$ (yellow/orange), $680 \mathrm{~nm}$ (red), and $720 \mathrm{~nm}$ (red edge). We also often used the hexacopter platform to collect 36-megapixel (mp) natural color (red/green/blue or RGB) images of field sites. We also often deployed a DJI Phantom 3 Advanced (P3A) and DJI Mavic to collect 12-mp RGB aerial images that could form basemaps of field sites useful for georeferencing multispectral images. We stitched together the RGB images into orthophotographs (orthophotos) using on-board global positioning system (GPS) data for each image and Agisoft Metashape (Agisoft, St. Petersburg, Russia, 2019) as the closerange photogrammetry software solution. Because the Tetracam sensor was rented until the last year of data collection and therefore was not always available for field use, we developed a backup low-cost "VISNIR" system (described in Chapter 3) that deployed two Canon "point and shoot" RGB cameras from the Bergen UAS; one of these of which was modified to make it sensitive only to the near-infrared in the approximate range of 830-1100 nm. This type of consumer-grade camera conversion has been shown to be useful for terrestrial vegetation mapping applications such as crop evaluation and invasive plant identification using the converted near-infrared capability on other Canon cameras (Yang et al. 2014).

Our work in analyzing spectral profiles described in Brooks et al. 2019 demonstrated that it was possible to identify EWM from other SAV species, although this required a hyperspectral set of bands to accomplish reliably. The work also showed that a modified version of the Normalized Difference Vegetation Index (NDVI) that used the $720 \mathrm{~nm}$ red edge band in place of a true infrared band was significant in differentiating EWM from other SAV species. The modified NDVI (mNDVI) was calculated for all analyzed Tetracam image sets and used to map the extent of EWM for ten sets of multispectral images at five sites in the Les Cheneaux Islands, including the Hessel Marina and Court East sites. The use of the VISNIR system was demonstrated as a lower-cost alternative to the Tettracam sensor for mapping at one site (Court East) to identify EWM and map its extent. We completed image classifications presented in this chapter with object-based image analysis (OBIA) software eCognition Developer, version 9 (Trimble Germany 2017) using methods described in Chapter 2.

With classifications available before and after treatment at the three sites, we calculated the visible extent of EWM vs. other SAV for each pair of before and after images using ESRI Desktop ArcMap version 10.6 and 10.7. Imagery classification results were maintained in a locally appropriate Universal Transverse Mercator (UTM) project to support accurate area calculations. The before and after areas were placed into summary tables, and total areas and percentage of total areas calculated.

\subsection{Results and Discussion}

Figure 4.2 shows three dates of multispectral UAV imagery for the Court East site in the Les Cheneaux Islands, from June 2017 using VISNIR imagery (before mechanical 
harvesting), July 2017 using Tetracam imagery (within a few days of mechanical harvesting), and August 2017 using Tetracam imagery (one month after harvesting).

Figure 4.3 shows the results of each of the classifications for the input images. To enable direct comparison of change in vegetation types and extent due to harvesting, Figure 4.4 focuses on the June 2017 pre-harvesting imagery with the same extent as the analyzed frame of August 2017 post-harvest Tetracam imagery shown in Figure 4.2C. The classifications show in Figure 4.3A and 4.3B had accuracy assessments completed in Chapter 3; the June 2017 result displayed had an overall accuracy of $67.9 \%$ and the July 2017 result had an overall accuracy of $97.7 \%$. Using the same accuracy assessment methods used in Chapter 3, the August 2017 classification result has an overall accuracy of $92.3 \%$. Figures $4.2,4.3$, and 4.4 show approximately parallel areas of EWM that remained after vegetation removal, with the mostly empty areas in between where the harvester removed vegetation. Figure 4.5 shows another view of this area, taken on the same day as the Tetracam image, with remaining rows of EWM and the harvested visible towards the top right.

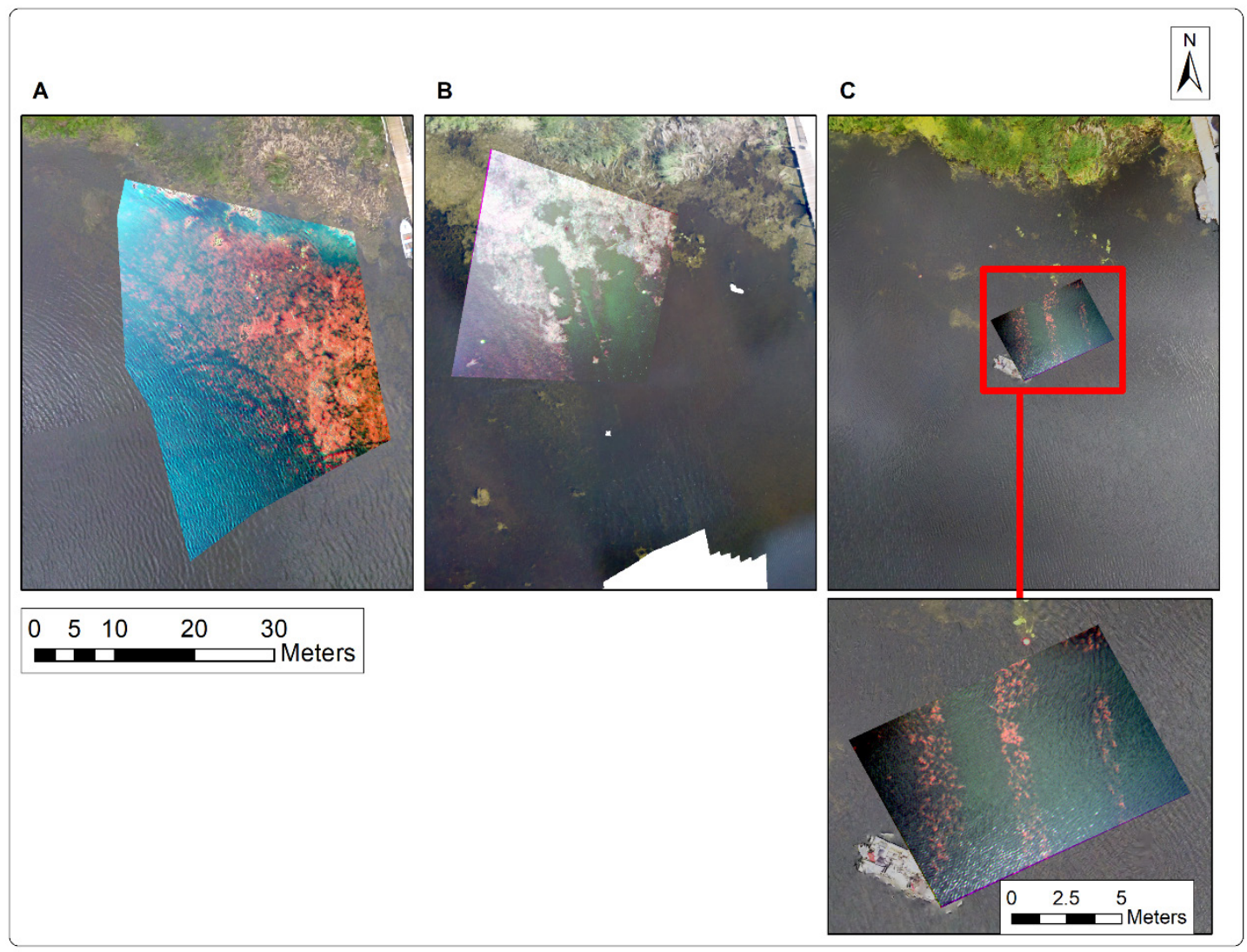

Figure 4.2. Multispectral imagery of the Court East site, A) before mechanical harvesting (June 2017), B) a few days after mechanical harvesting (July 2017), and C) a month after mechanical harvesting. 


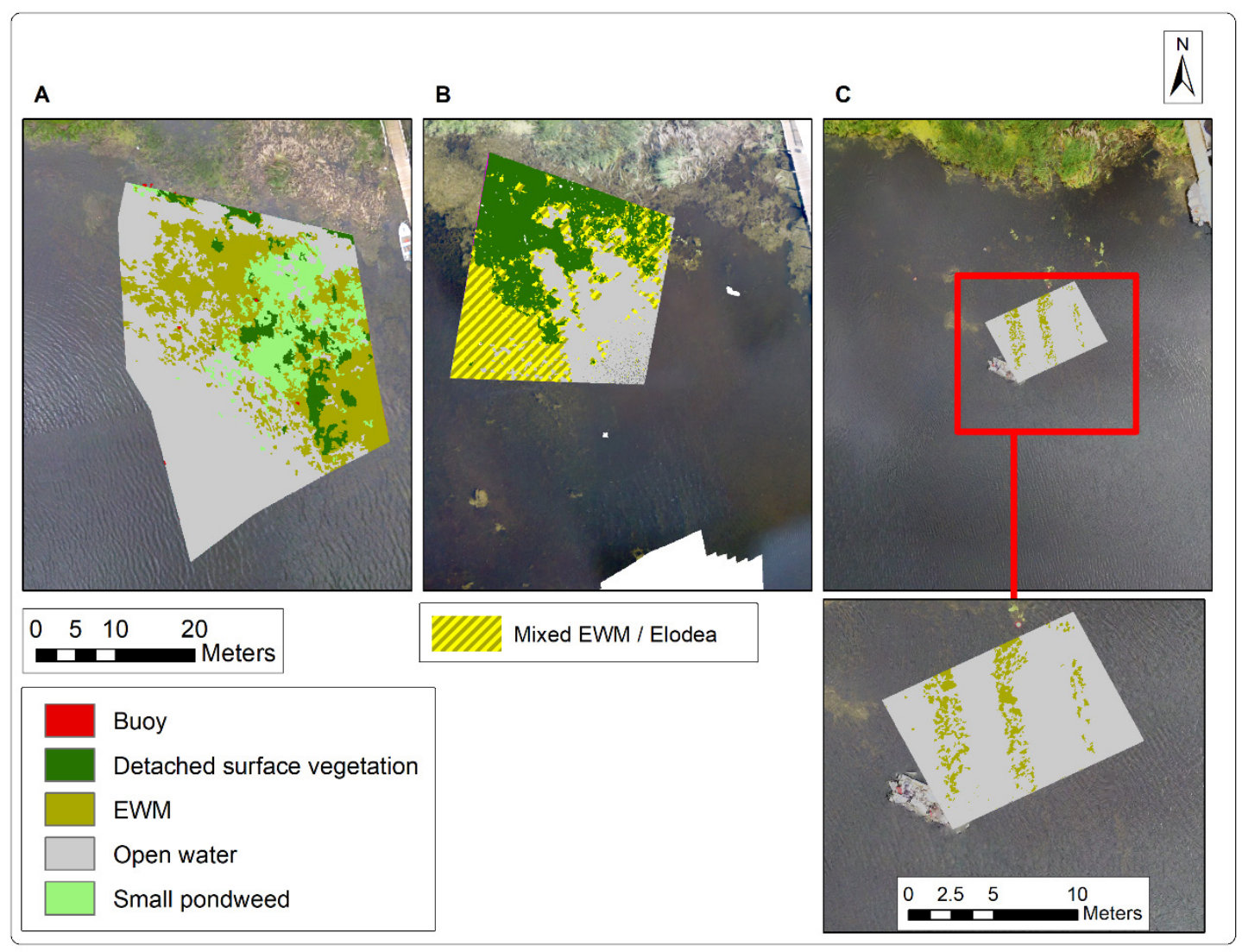

Figure 4.3. Classification results for the Court East showing imagery before (A) and after (B) mechanical harvesting. Results shown in A and B were previously described in Chapter 3. 


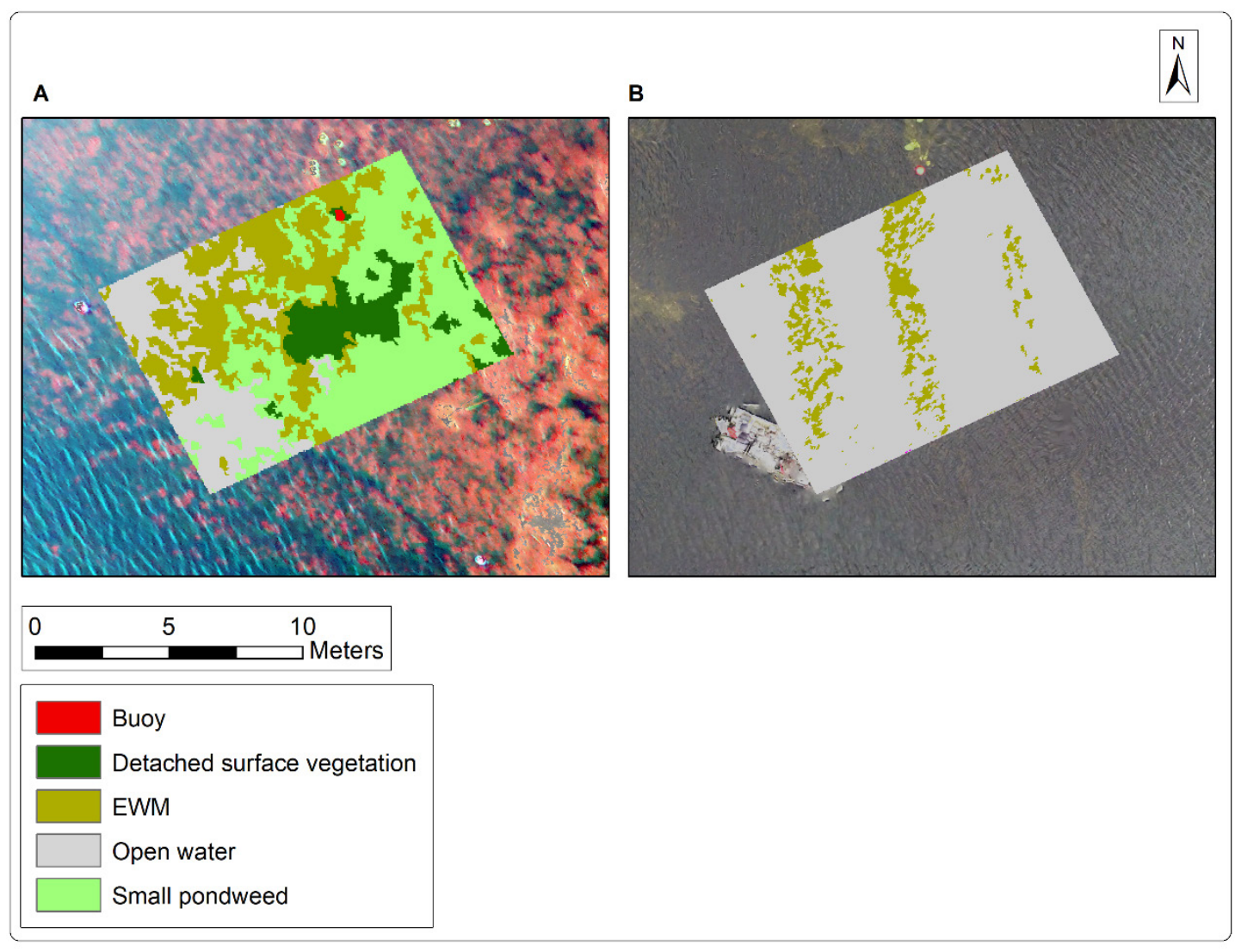

Figure 4.4. Identical extents for the June 2017 pre-harvesting classification and the August 2017 post-harvesting classification to enable change comparison at the Court East site.

Clipping the extent of the June 2017 pre-harvest VISNIR image down to the extent of the analyzed August 2018 Tetracam image resulted in an area of $108.6 \mathrm{~m}^{2}$. In June of 2017 , the classification results showed that the vegetation visible at the surface area was $29.0 \%$ EWM and 40.5\% small pondweed (Potamogeton pusillus ssp. pusillus), for a total of $69.5 \%$ vegetated (Table 4.2). One month after mechanical harvesting, the vegetated area was $10.6 \%$ EWM, with no small pondweed reported from visual estimates recorded on the same day, and the balance of the area as open water. Total visible EWM was reduced from $31.5 \mathrm{~m}^{2}$ to $11.5 \mathrm{~m}^{2}$ for the comparable area (a reduction of $63 \%$ ). 
Table 4.2. Change in class areas from June 2017 to August 2017 at the Court East site, before and after mechanical harvesting treatment.

\begin{tabular}{lrr}
\hline June 2017 & & \\
\hline Class & Area $\left(\mathrm{m}^{2}\right)$ & Percent \\
Buoy & 0.1 & $0.1 \%$ \\
Detached surface vegetation & 11.0 & $10.1 \%$ \\
EWM & 31.5 & $29.0 \%$ \\
Open water & 21.9 & $20.2 \%$ \\
Small pondweed & 44.0 & $40.5 \%$ \\
& $\mathbf{1 0 8 . 6}$ & \\
\hline August 2017 & & \\
\hline Class & Area $\left(\mathrm{m}^{2}\right)$ & Percent \\
EWM & 11.5 & $10.6 \%$ \\
Open water & 112.6 & $89.4 \%$ \\
& $\mathbf{1 0 8 . 6}$ & \\
\hline & &
\end{tabular}

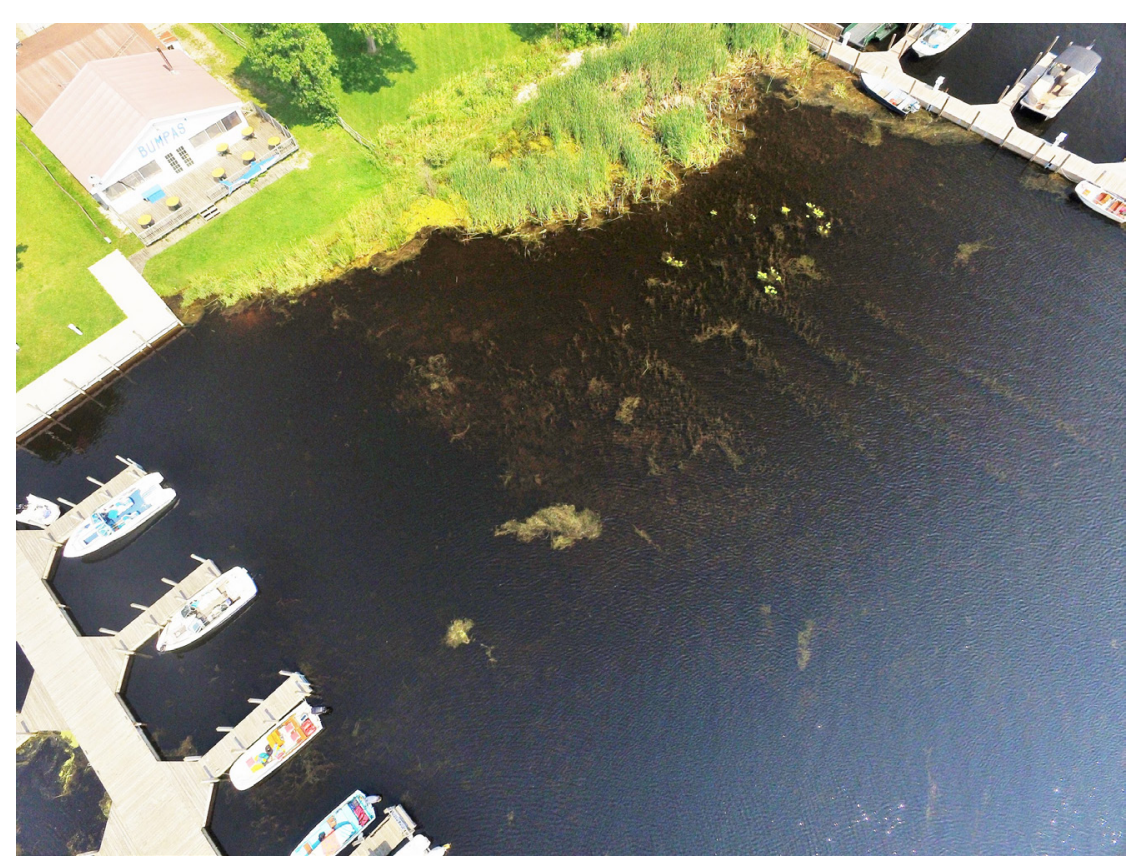

Figure 4.5. Natural color UAV image of the Court East site, with the harvested "rows" and remaining vegetation also captured in the Tetracam image taken on the same day. Additional harvesting took place towards the docks on the bottom left and further to the top right.

Figure 4.6 shows two dates of natural color UAV imagery for the Hessel Marina site in the Les Cheneaux Islands, one from July 2017 (4.6A, left) a few days after Mt fungus was applied to approximately the $652 \mathrm{~m}^{2}$ area outlined in yellow, and one from August 2018 (4.6B, right), a year after this application. 


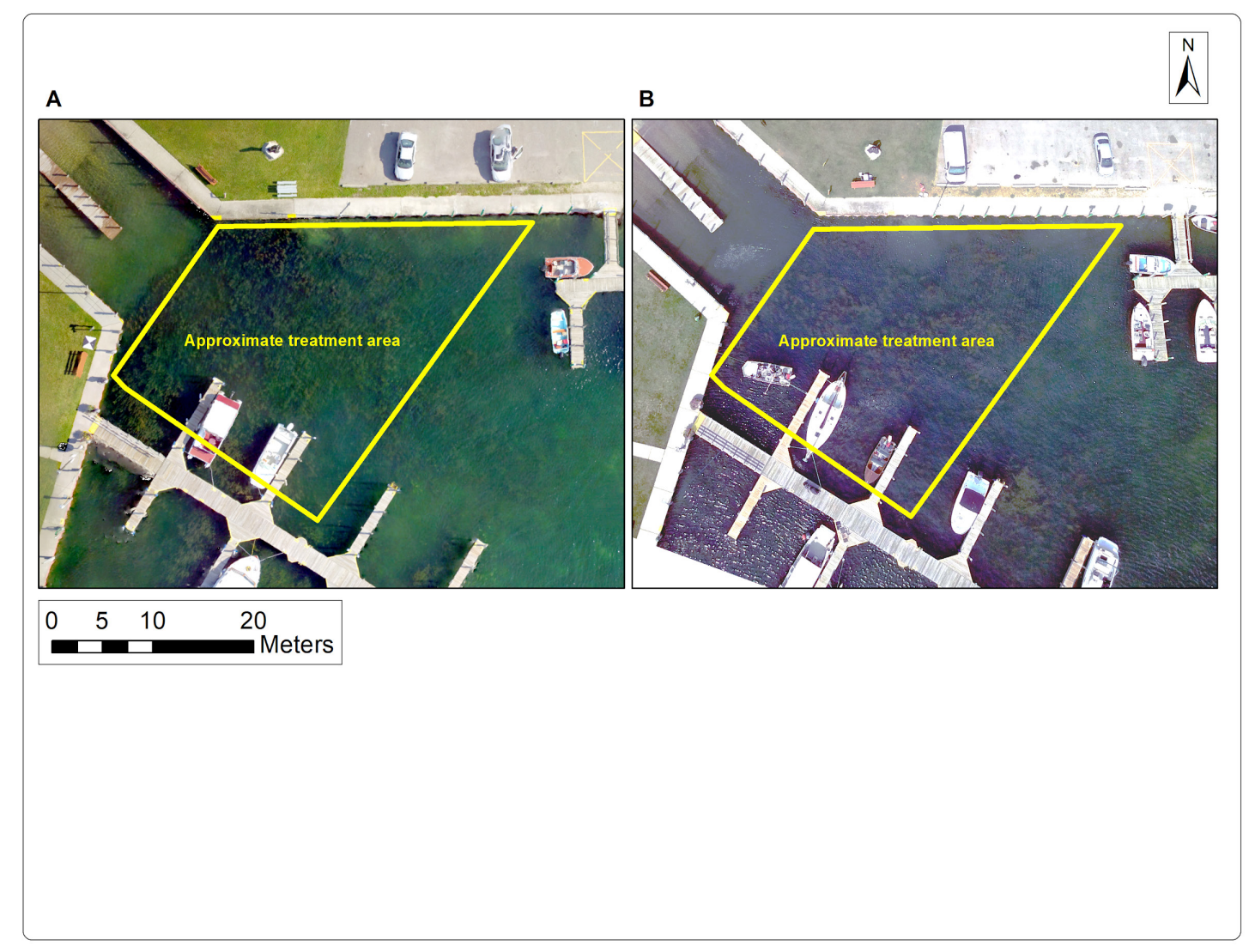

Figure 4.6. Hessel Marina natural color imagery from A) July 2017 at the start of Mt treatment and from B) August 2018 one year after treatment.

Figure 4.7 shows the classification results using RGB imagery, with a large change in extent of EWM a year after application. The group performing the application, the Les Cheneaux Watershed Council, reported that EWM biomass at the Hessel Marina site was "minimal" one year after treatment, and that non-EWM macrophyte biomass was six times greater than EWM at this point (Smith et al. 2018). However, our visual estimates showed EWM was still predominant, although rake tosses produced levels of 2 ("sparse") and no higher for EWM, Elodea sp., and clasping-leaf pondweed (Potamogeton richardsonii). Classification results indicate that $59.8 \%$ of the treatment area was EWM in July 2017 (and 1.7\% other SAV for total SAV cover of 61.5\%), but by August 2018, this same area was $16.0 \%$ EWM and $63.4 \%$ other SAV (for total SAV cover of $79.4 \%$; Table 3.3). This equates to a reduction in EWM extent from $390.0 \mathrm{~m}^{2}$ to $104.7 \mathrm{~m} 2$ of the $652.4 \mathrm{~m}^{2}$ treatment area (a $73 \%$ reduction). Smith et al. report similar total SAV biomass in 2017 vs. 2018. However, the contrast in SAV types reported by the Michigan Tech and Watershed Council field surveys could indicate that these results, which use only RGB imagery, are resulting in an overestimate of EWM reduction one year after treatment if using the Watershed Council data. 


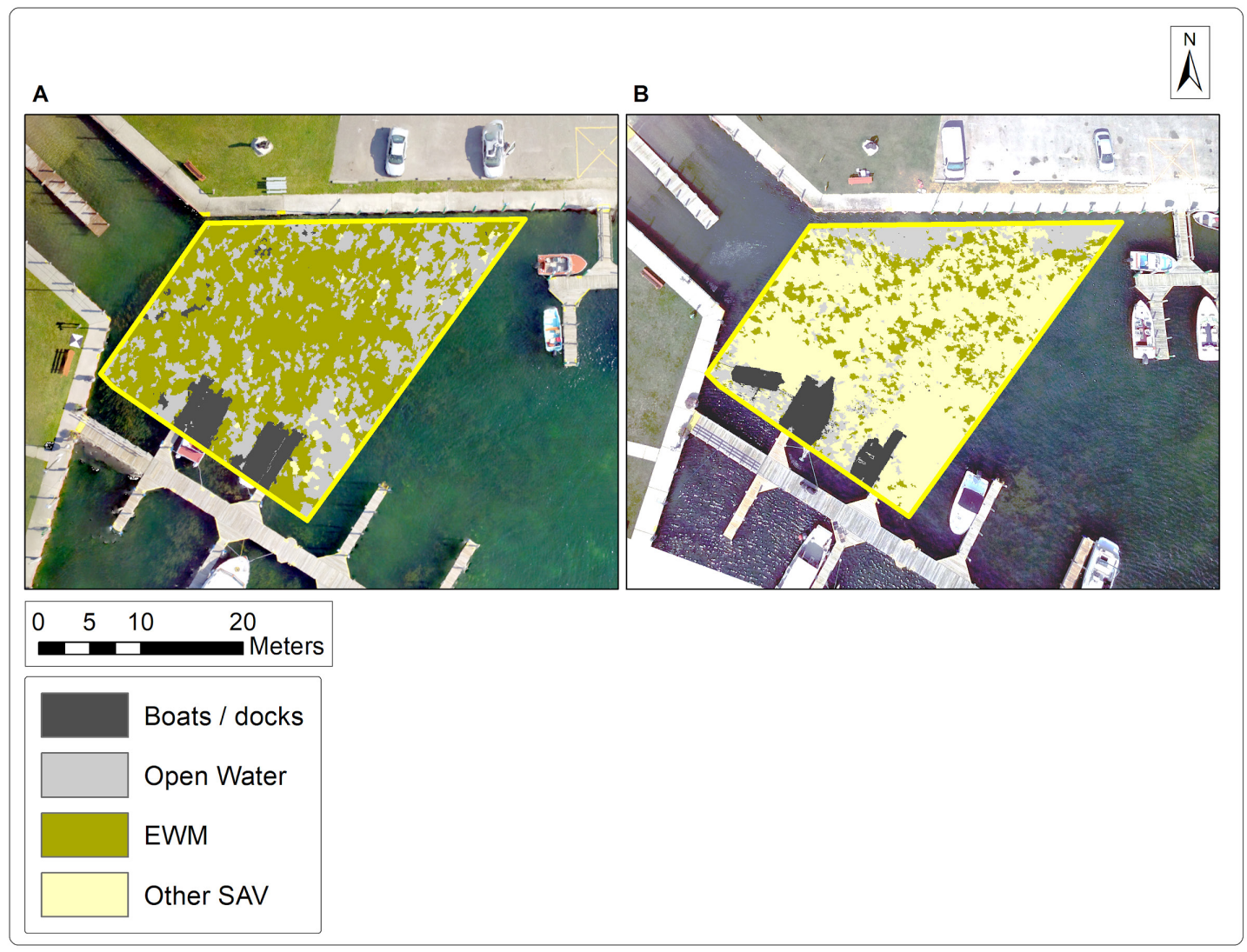

Figure 4.7. Hessel Marina classification results from A) July 2017 of the week before Mt treatment and from B) August 2018 one year after treatment.

Table 4.3. Change in class areas from July 2017 to August 2018 at the Hessel Marina site, from the start of $\mathrm{Mt}$ treatment to one year later.

\begin{tabular}{l|rr|rr}
\hline \multicolumn{1}{c|}{ Class } & July $\mathbf{2 0 1 7}$ area $\left.\mathbf{( m}^{\mathbf{2}}\right)$ & $\mathbf{\%}$ of area & August $\mathbf{2 0 1 8}$ area $\left.\mathbf{( m}^{\mathbf{2}}\right)$ & \% of area \\
\hline Open water & 200.8 & $30.8 \%$ & 86.2 & $13.2 \%$ \\
EWM & 390.0 & $59.8 \%$ & 104.7 & $16.0 \%$ \\
Other SAV & 11.0 & $1.7 \%$ & 413.6 & $63.4 \%$ \\
Boats/Docks & 50.6 & $7.8 \%$ & 47.9 & $7.3 \%$ \\
& $\mathbf{6 5 2 . 4}$ & & $\mathbf{6 5 2 . 4}$ & \\
\hline
\end{tabular}

Figure 4.8 shows the four DASH plots in the Sloughs area of the Keweenaw Waterway with near-infrared VISNIR UAS imagery collected on July 17th (immediately before treatment) and July 21st (immediately after treatment) in 2017. Surface vegetation (such as lily pads) and near-surface vegetation, such as EWM, show up as a brighter pink color in the near-infrared imagery due to stronger reflectance of green, healthy vegetation in this spectral band. The southernmost plot has some glint in the pre-treatment image, but the reduction in SAV presence can be more easily seen in the other three DASH plots in the post-treatment image. 


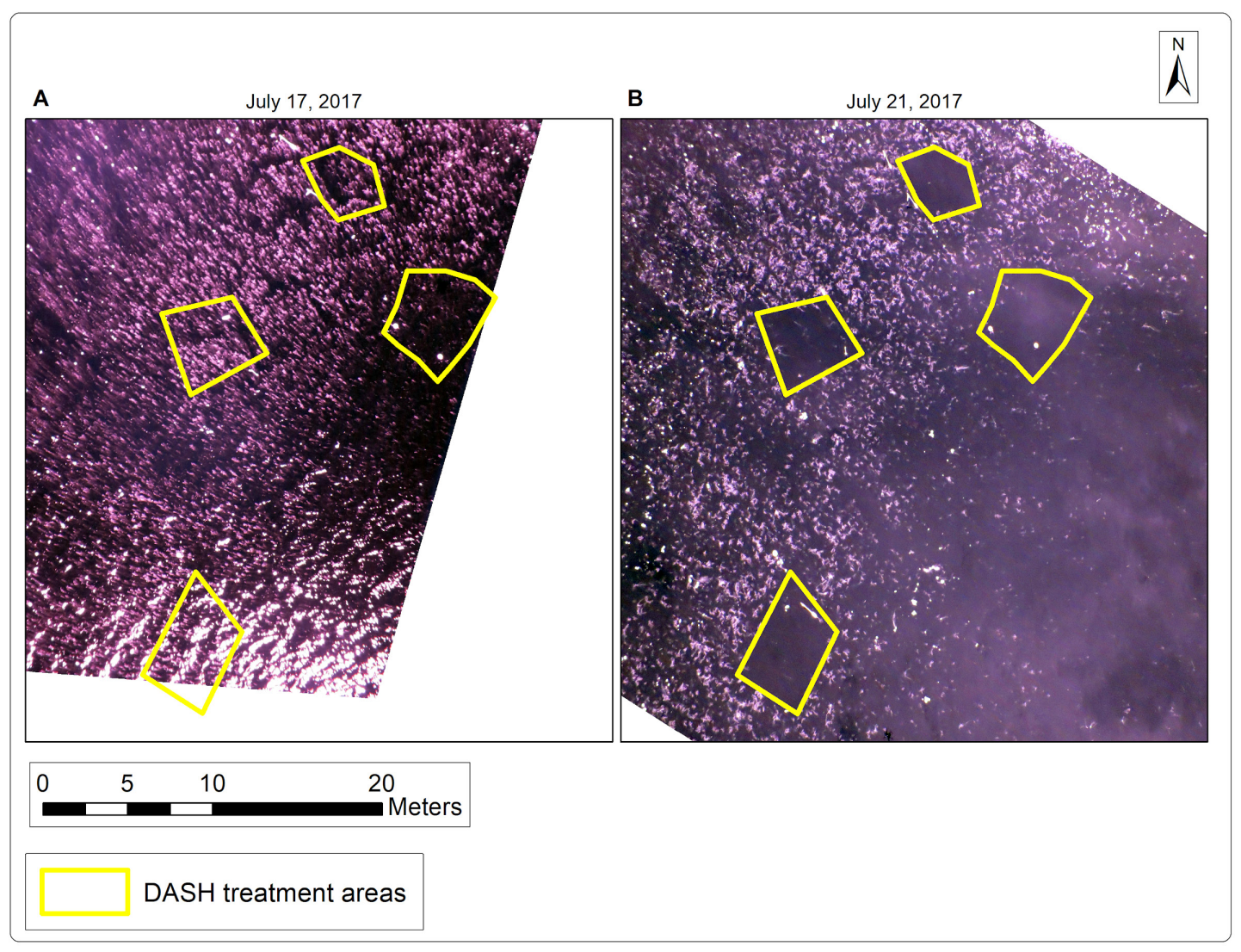

Figure 4.8. Near-infrared UAV imagery for the same locations at four DASH treatment plots immediately pre- and post-treatment in July, 2017 at the Sloughs site.

The Sloughs classification results are shown in Figure 4.9, with all four plots appearing to have little remaining EWM areas immediately after DASH treatment. On July 17, 2017, visible EWM forms $25.1 \%$ of the surface area of the four plots (with $1.6 \%$ other aquatic vegetation), while on July $21 \mathrm{st}$, this has been reduced to $2.7 \%$ of the surface area (with $0.2 \%$ other aquatic vegetation), a reduction from $44 \mathrm{~m}^{2}$ to $4.7 \mathrm{~m}^{2}(89 \%)$ of the $175 \mathrm{~m}^{2}$ combined plot areas. 


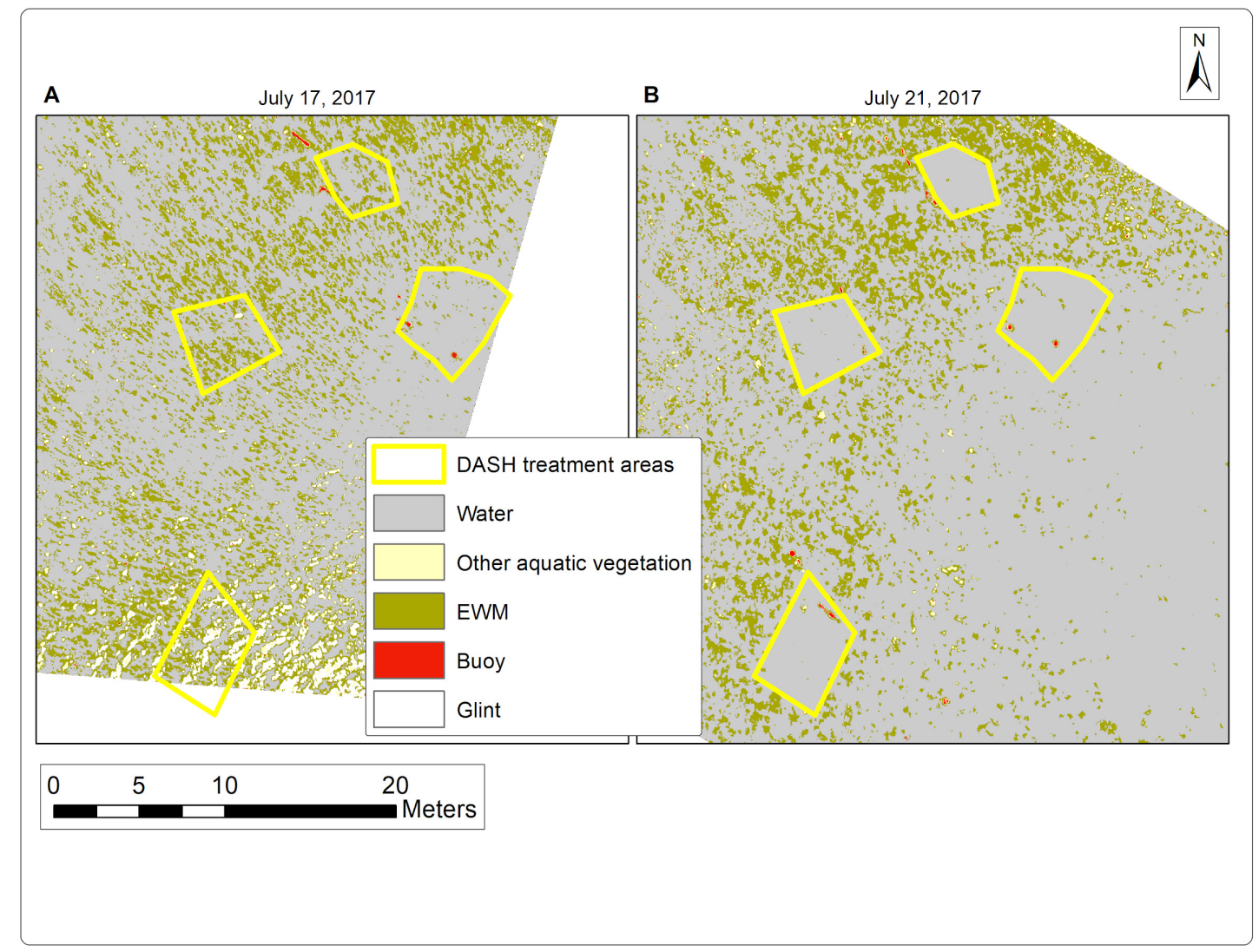

Figure 4.9. Classification results for pre- and post-DASH treatment color-infrared imagery

Table 4.4. Change in class areas from July 17, 2017 to July 21, 2017 at the Sloughs site, before and after DASH treatment

\begin{tabular}{l|rr|rr}
\hline \multicolumn{1}{c|}{ Class } & \multicolumn{2}{|c|}{ Pre-DASH } & \multicolumn{2}{c}{ Post-DASH } \\
area (m2) & \% of area & area (m2) & \% of area \\
\hline Open water & 119.4 & $68.2 \%$ & 169.3 & $96.8 \%$ \\
EWM & 44.0 & $25.1 \%$ & 4.7 & $2.7 \%$ \\
Other aquatic vegetation & 2.8 & $1.6 \%$ & 0.4 & $0.2 \%$ \\
Other (buoy or glint) & 8.9 & $5.1 \%$ & 0.5 & $0.3 \%$ \\
& $\mathbf{1 7 5 . 0}$ & & $\mathbf{1 7 5 . 0}$ & \\
\hline
\end{tabular}

These three examples indicate that it is possible to quantify the impacts of three types of EWM treatment. In all three cases, we were able to measure a reduction in EWM extent after treatment using UAS-enabled methods developed for Brooks et al. 2019 (Chapter 2) and Chapter 3 that have approximately 78\% mapping accuracy for EWM. For the mechanical harvesting and DASH treatment, this represents detection of immediate change. For Mt fungus, we appear to be quantifying a change in balance of EWM vs. other macrophytes one year after this treatment. 
Our study was focused on detecting change in EWM following treatment using a novel remote sensing approach, not to evaluate the appropriateness or efficacy of various treatment techniques. The entity choosing to treat EWM must consider what treatment methods make the most sense for location conditions, including available funding, willingness to deploy different treatment methods, and tolerance for effects of treatment such as EWM fragmentation, as discussed below.

It must be noted that mechanical harvesting comes with significant problems as a management tool. EWM reproduces primarily by vegetative fragments (Grace and Wetzel 1978). EWM management guides note that there is a high risk of spread due to stem fragments created by mechanical harvesting (Jacobs and Mangold 2009), and repeated harvesting efforts may actually increase EWM extent (Smith and Barko 1990). It is likely that the $63 \%$ reduction in EWM extent we saw in imagery covering the same area resulted in significant fragmentation of EWM and its potential re-establishment in existing areas and spread to nearby areas.

The DASH technique was developed in part to help address the negative effects of mechanical harvesting. Eichler et al. (1993) describe an early application of suction harvesting on Lake George, New York, USA where herbicides and mechanical cutting were considered unacceptable due to water quality and fragmentation concerns. Their DASH technique used a vacuum pump mounted on a pontoon boat, with a diver pulling the EWM (including the roots) and feeding it into two vacuum hoses. A $2,828 \mathrm{~m}^{2}$ area was suction harvested with 28 person-days of effort. A year after DASH, only $7 \%$ of the pre-harvest biomass was present during a revisit. Tucker (2017) reported on application of DASH for another invasive milfoil, Myriophyllum heterophyllum (variable milfoil) in New Hampshire, USA, that also spreads primarily by fragmentation. DASH is described as efficient, and providing significant advantages over just hand-pulling and useful for management of dense milfoil stands. Our results showing an 89\% decrease in EWM extent appear to support that DASH treatment is effective at rapid reductions in EWM presence, at least within the depth that our imagery could penetrate.

The Mt fungus treatment technique has been reported on for a number of decades as a method of biological control for EWM (Smith and Winfield 1991) based on promising results from greenhouse cylinders. More recently, Nelson and Shearer (2005) reported up to $79 \%$ reduction in EWM biomass with Mt alone and up to $90 \%$ when combined with herbicide. It has been deployed twice in the open nearshore waters of the Les Cheneaux Islands in 2014 and 2017 by the Les Cheneaux Watershed Council (Smith et al. 2018). The fungus must be grown in a fermenter and transported to the field site, and then applied from a boat, such as the gravity fed mix tank setup used at the Les Cheneaux Islands, (Figure 4.10), making practical deployment currently expensive. In the 2017 demonstration at the Les Cheneaux Islands, a 70\% reduction in EWM biomass was reported at 70 days after treatment while a nearby control site had an increase in its EWM biomass (Smith et al. 2018). 


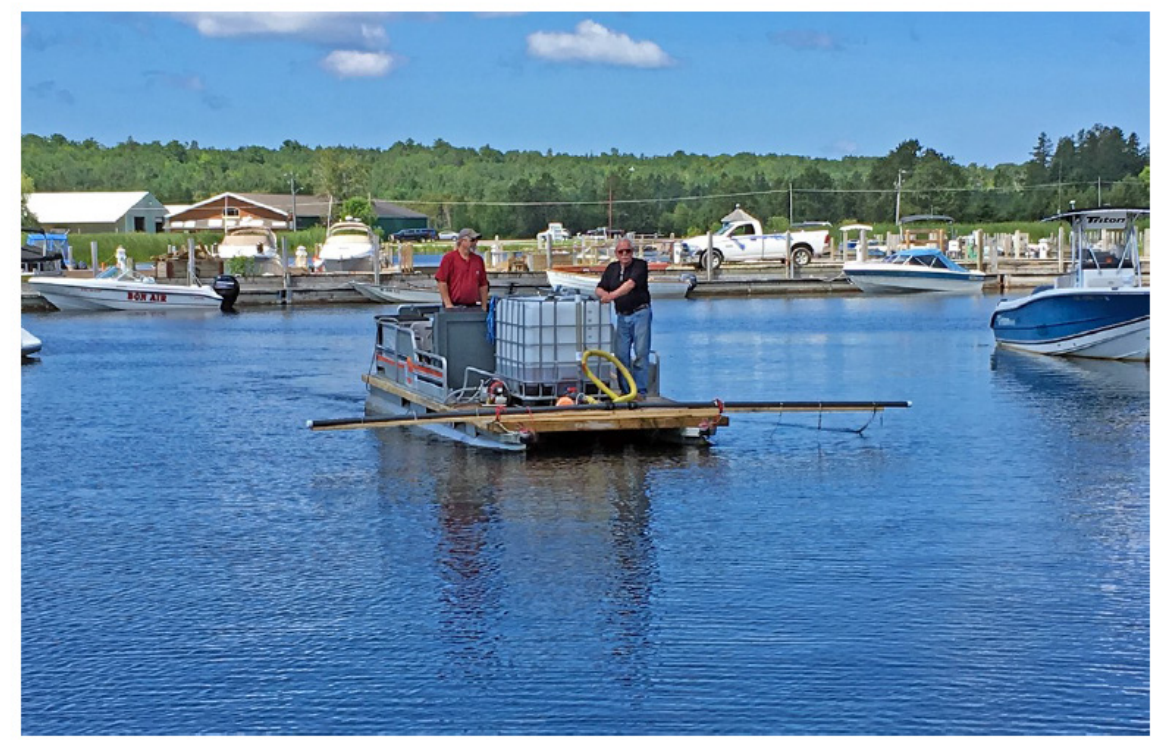

Figure 4.10. Deployment of the Mt fungus from a customized treatment vessel in the Les Cheneaux Islands in 2017 by the Les Cheneaux Watershed Council.

\subsection{Conclusions}

We have demonstrated that UAS-enabled sensing can provide quantitative data documenting changes in visible extent of EWM most obviously due to three types of treatment. For three areas in the Upper Peninsula of Michigan each undergoing different types of treatment (mechanical harvesting, biological treatment, and DASH), we measured the reduction in EWM extent in area and percentage terms. At a mechanical harvesting site, we measured a $63 \%$ reduction in the extent of EWM one month after treatment, using multispectral UAS imagery. At a Mt fungus biological treatment site, we measured a $73 \%$ reduction in EWM extent one year after treatment using natural color imagery, although differing field results may indicate this reduction was not as large as measured. At a DASH treatment site, we measured an $89 \%$ reduction in EWM extent using multispectral UAS imagery within three days of the treatment being completed. UAS-enabled sensing also has the potential to scale to mapping larger areas while still providing high-resolution data that could help track site-specific effects. If entities engaging in treatment efforts want a method to quantify the effects of different management methods, then UAS-enabled remote sensing is an important tool to consider.

\subsection{Acknowledgements}

This project has been funded in part through the United States Environmental Protection Agency (US EPA) under assistance agreement 00E01928 and 00E01291to Michigan Technological University, as part of the Great Lakes Restoration Initiative, and in part through Michigan Department of Natural Resources (MDNR) under project number IS14-2005. The contents of this document do not necessarily reflect the views and 
policies of the US EPA or MDNR nor does the EPA and MDNR endorse trade names or recommend the use of commercial products mentioned in this document. Support was provided by the Michigan Tech Research Institute and the Biological Sciences Department of Michigan Technological University. We also thank Robert Smith and Mark Clymer of the Les Cheneaux Watershed Council for providing their research vessel for accessing field sites on multiple occasions, for sharing their knowledge of the islands, and for taking the lead on Mt deployment.

\subsection{Literature Cited}

ACKLESON, S. \& KLEMAS, V. 1987. Remote sensing of submerged aquatic vegetation in lower Chesapeake Bay: A comparison of Landsat MSS to TM imagery, Remote Sensing of Environment, 22(2), 235-248.

BIRK, S. \& ECKE, F. 2014. The potential of remote sensing in ecological status assessment of coloured lakes using aquatic plants. Ecological indicators, 46, 398406.

BROOKS, C. N., GRIMM, A. G., MARCARELLI, A. M. \& DOBSON, R. J., 2019. Multiscale collection and analysis of submerged aquatic vegetation spectral profiles for Eurasian watermilfoil detection. Journal of Applied Remote Sensing, 13(3):037501.

CZARAPATA, E. J. 2005. Invasive plants of the upper Midwest: an illustrated guide to their identification and control, Univ of Wisconsin Press. 209 pgs.

EICHLER, L. W., BOMBARD, R. T., SUTHERLAND, J. W. \& BOYLEN, C. W. 1993. Suction harvesting of Eurasian watermilfoil and its effect on native plant communities. Journal of Aquatic Plant Management, 31, pp.144-144.

GRACE, J. B. \& WETZEL, R. G. 1978. The production biology of Eurasian watermilfoil (Myriophyllum spicatum L.): a review. J. Aquat. Plant Manage, 16(1), 1-11.

JACOBS, J. \& MANGOLD, J, 2009. Ecology and Management of Eurasian Watermilfoil (Myriophyllum spicatum L.), Invasive Species Technical Note No. MT-23, US Department of Agriculture, Natural Resources Conservation Service - Montana.

JOHNSON, R. L. \& BLOSSEY, B., 2002. Biological control of invasive plants in the eastern United States, Chapter 6: Eurasian watermilfoil. pp.79-90.

MADSEN, J. D., SUTHERLAND, J., BLOOMFIELD, J., EICHLER, L. \& BOYLEN, C. 1991. The decline of native vegetation under dense Eurasian watermilfoil canopies. Journal of Aquatic Plant Management, 29, 94-99. 
MADSEN, J. D. \& WERSAL, R. M. 2017. A review of aquatic plant monitoring and assessment methods. Journal of Aquatic Plant Management, 55(1):1-12.

MADSEN, J. D. \& WERSAL, R. M. 2018. Proper survey methods for research of aquatic plant ecology and management. Journal of Aquatic Plant Management. 56:90-96.

MIDWEST INVASIVE PLANT NETWORK. 2008. Keep a look out for new aquatic invasive plants in the Midwest! 2 pgs.

https://bugwoodcloud.org/mura/mipn/assets/File/Aquatics\%20Early\%20Detection \%20Flyer.pdf

NELSON, L. S. \& SHEARER, J. 2005. 2, 4-D and Mycoleptodiscus terrestris for control of Eurasian watermilfoil, Journal of Aquatic Plant Management, 43(29-34.

PAINTER, D. S. Long-term effects of mechanical harvesting on Eurasian watermilfoil. Journal of Environmental Management, 15(263-271 (1986).

ROLEY, S. \& NEWMAN, R. M. Developmental performance of the milfoil weevil, Euhrychiopsis lecontei (Coleoptera: Curculionidae), on northern watermilfoil, Eurasian watermilfoil, and hybrid (northern×Eurasian) watermilfoil," Environmental Entomology, 35(1), 121-126 (2006).

SHUCHMAN, R. A., LESHKEVICH, G., SAYERS, M. J., JOHENGEN, T. H., BROOKS, C. N. \& POZDNYAKOV, D. 2013. An algorithm to retrieve chlorophyll, dissolved organic carbon, and suspended minerals from Great Lakes satellite data. Journal of Great Lakes Research, 39, 14-33.

SILVA, T. S., COSTA, M. P., MELACK, J. M. \& NOVO, E. M. 2008. Remote sensing of aquatic vegetation: theory and applications. Environmental Monitoring and Assessment, 140, 131-145.

SMITH, C. S. \& BARKO, J. W., 1990. Ecology of Eurasian watermilfoil. Journal of Aquatic Plant Management, 28(2), 55-64.

SMITH, C. S. \& WINFIELD, L. E. 1991. June. Biological control of Eurasian watermilfoil using plant pathogens. In: Proc. 25th Ann. Meeting Aquatic Plant Control Res. Prog., Misc. Paper A-90-3, US Army Engineer Waterways Experiment Station, Vicksburg, MS (pp. 133-137).

SMITH, R., CLYMER, M., DUNN, D. \& MYERS, S. Use of Mycoleptodiscus terrestris as a mycoherbicide for Myriophyllum spicatum (Eurasian watermilfoil) management in the open-water system of the Les Cheneaux Islands, Michigan. http:// lescheneauxwatershed.org/library/nuisance-species/eurasianwatermilfoil/lcwc-ewm-research/310-wc7-mtu-final-report-c-11018/file 
SORSA, K., NORDHEIM, E., \& ANDREWS, J. 1988. Integrated control of Eurasian water milfoil, Myriophyllum spicatum, by a fungal pathogen and a herbicide. Journal of Aquatic Plant Management, 26, 12-17.

TUCKER. 2017. Efficiency of Diver-Assisted Suction Harvesting (DASH) of Invasive Milfoil in New Hampshire Waterbodies. Undergraduate Dissertation, Carthage College. 25 pgs.

UNMUTH, J. M., LILLIE, R. A., DREIKOSEN, D. S. \& MARSHALL, D. W. 2000. Influence of dense growth of Eurasian watermilfoil on lake water temperature and dissolved oxygen. Journal of Freshwater Ecology, 15, 497-503.

VERMA, U. \& CHARUDATTAN, R. 1993. Host range of Mycoleptodiscus terrestris, a microbial herbicide candidate for Eurasian watermilfoil, Myriophyllum spicatum. Biological control, 3, 271-280.

VISSER, F., BUIS, K., VERSCHOREN, V. \& SCHOELYNCK, J. 2018. Mapping of submerged aquatic vegetation in rivers from very high-resolution image data, using object-based image analysis combined with expert knowledge. Hydrobiologia, 812, 157-175.

YANG, C., WESTBROOK, J.K., SUH, C.P.C., MARTIN, D.E., HOFFMANN, W.C., LAN, Y., FRITZ, B.K. and GOOLSBY, J.A., 2014. An airborne multispectral imaging system based on two consumer-grade cameras for agricultural remote sensing. Remote Sensing, 6(6), 5257-5278.

ZHANG, C. \& BOYLE, K.J. 2010. The effect of an aquatic invasive species (Eurasian watermilfoil) on lakefront property values. Ecological Economics, 70(2), 394404. 